\title{
Molecular Vises for Precisely Positioning Ligands near Catalytic Metal Centers in Metal-Organic Frameworks
}

Wei Yan, ${ }^{\dagger}$ Shenhui $\mathrm{Li}^{*},{ }^{\S}$ Tao Yang, ${ }^{*}$ Yucong Xia, ${ }^{\dagger}$ Xinrui Zhang, ${ }^{\dagger}$ Chao Wang, ${ }^{\dagger}$ Zier Yan, ${ }^{\diamond}$ Feng Deng ${ }^{*}{ }^{\S}$ Qianghui Zhou, ${ }^{\dagger, \#, *}$ Hexiang Deng ${ }^{*},+\#$

${ }^{\dagger}$ Key Laboratory of Biomedical Polymers-Ministry of Education, College of Chemistry and Molecular Sciences, Wuhan University, Wuhan 430072, China.

\#The Institute for Advanced Studies, Wuhan University, Wuhan 430072, China.

${ }^{\S}$ State Key Laboratory of Magnetic Resonance and Atomic and Molecular Physics, Wuhan Institute of Physics and Mathematics, Innovation Academy for Precision Measurement Science and Technology, Chinese Academy of Sciences, Wuhan 430071, P. R. China

${ }^{\ddagger}$ Sauvage Center for Molecular Sciences, Engineering Research Center of Organosilicon Compounds \& Materials (Ministry of Education)

${ }^{\diamond}$ Rigaku Beijing Corporation, 2601A, Tengda Plaza, No. 168, Xizhimenwai Avenue, Haidian District, Beijing 100044, P.R. China

Corresponding Author:

*Shenhui Li - lishenhui@wipm.ac.cn

*Feng Deng - dengf@wipm.ac.cn

*Hexiang Deng - hdeng@whu.edu.cn 


\section{Table of Contents}

Section S1 Illustration of MV-PCN-521 S1-S3

Section S2 Synthesis of organic linkers S4-S46

Section S3 Synthesis and activation of MV-MOFs S47-S57

Section S4 Crystal structure characterizations and simulations $\quad$ S58-S62

Section S5 Solid-state NMR experiments S63-S80

$\begin{array}{lll}\text { Section S6 Stability assessment of MV-MOFs } & \text { S81 }\end{array}$

$\begin{array}{lll}\text { Section S7 } & \mathrm{N}_{2} \text { adsorptions analysis of MV-MOFs } & \text { S82-S95 }\end{array}$

Section S8 NMR studies of digested MV-MOFs S96-S105

Section S9 Laser scanning confocal microscopy (LSCM) studies of MV-MOFs

S106-S108

Section S10 Scanning electron microscopy (SEM) studies of MV-MOFs S109-S110

Section S11 ICP and EA results of metal-binded-MV-MOFs

Section S12 Thermogravimetric analysis of MV-MOFs S111-S117

Section S13 XPS analysis of metal-binded-MV-MOFs S118-S119

$\begin{array}{llr}\text { Section S14 Catalytic performance } & \text { S120 }\end{array}$

References 


\section{Section S1 Illustration of MV-PCN-521}

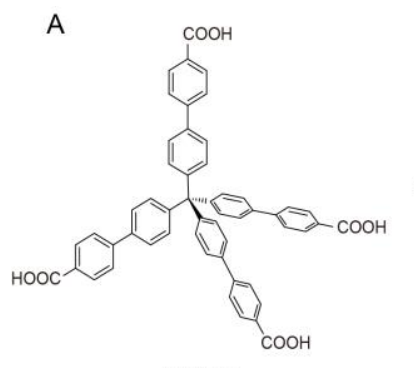

MTBC
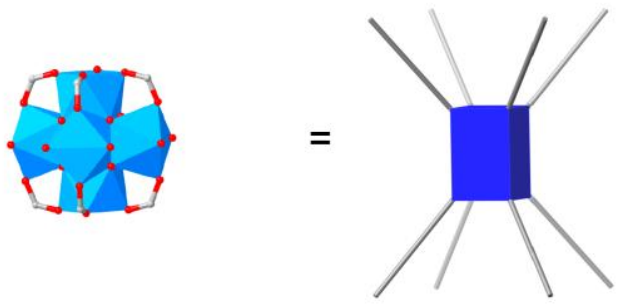

B

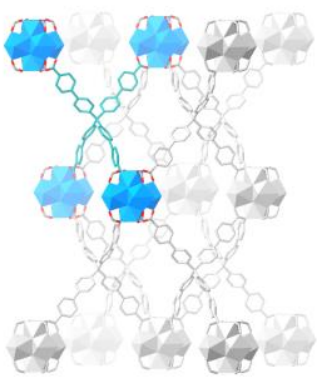

II

C

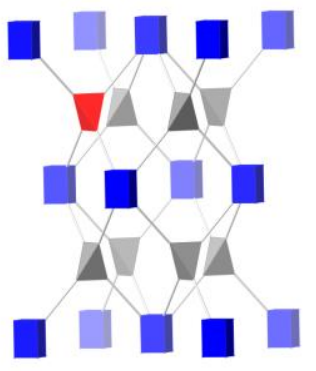

Figure S1. Illustration of parent MOF PCN-521. A) MOF constructed by MTBC linker and Zr-SBUs; B) 3D structure of PCN-521; C) Flu topology of PCN-521.

A

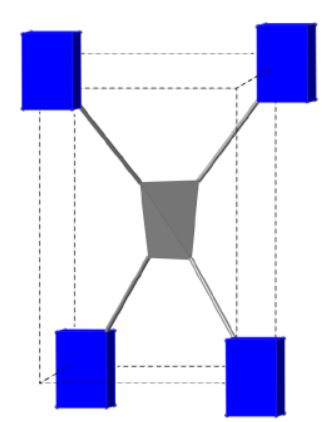

Fixed Geometry

B

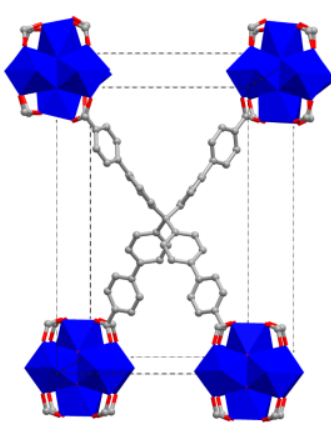

PCN-521
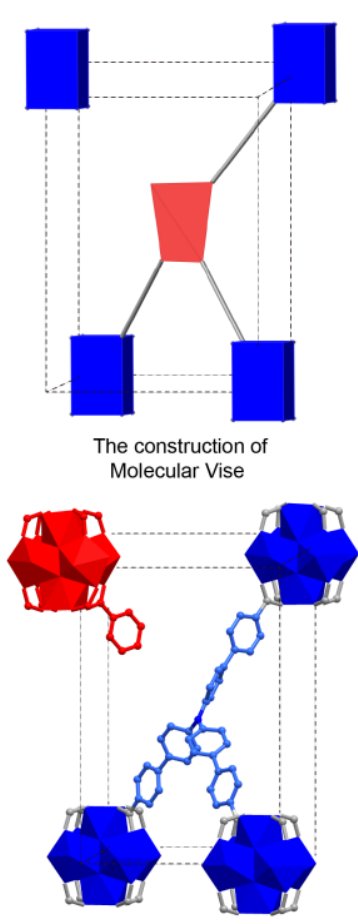

Molecular Vise in PCN-521
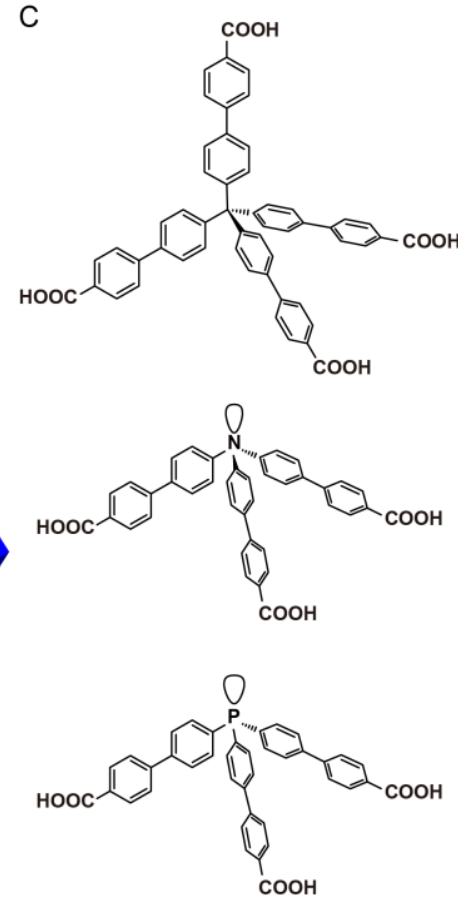

$\mathrm{COOH}$

Figure S2. A) Rigid backbone of PCN-521; B) MV-MOF created by molecular vise approach, one tetratopic linker was replaced by one tritopic linker and one monotopic linker; C) Organic linkers used to construct MV-PCN-521. 

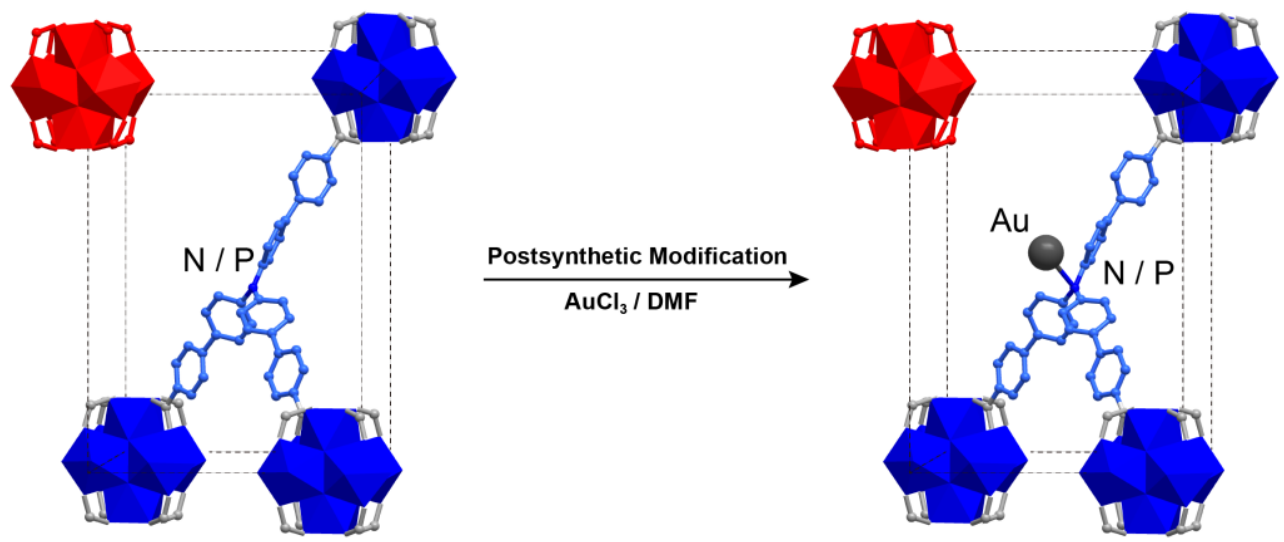

Figure S3. Au metal was deposited to the "vise" . 


\section{Section S2. Synthesis of organic linkers}

\section{S2.1 Chemicals}

All chemicals were purchased from China National Medicines Corporation LTD and were used without further purifications.

Table S1. Chemicals, corresponding CAS numbers and abbreviations

\begin{tabular}{|c|c|c|}
\hline Chemical & Abbreviation & CAS number \\
\hline $\begin{array}{l}\text { 1,4-Diazabicyclo[2.2.2] octane; triethyl } \\
\text { enediamine }\end{array}$ & $\mathrm{DABCO}$ & $280-57-9$ \\
\hline 2-Dicyclohexylphosphino-2',4',6'-triisopropylbiphenyl & Xphos & $564483-18-7$ \\
\hline 4-nitrobenzoic acid & NBA & $62-23-7$ \\
\hline 4-(methoxycarbonyl)-phenylboronic acid & / & $99768-12-4$ \\
\hline Acetone & / & $67-64-1$ \\
\hline Anisole & / & $100-66-3$ \\
\hline Benzoic acid & BA & $65-85-0$ \\
\hline Boron tribromide & $\mathrm{BBr}_{3}$ & $10294-33-4$ \\
\hline Bis(triphenylphosphine)palladium(II) dichloride & $\mathrm{Pd}\left(\mathrm{PPh}_{3}\right) \mathrm{Cl}_{2}$ & $13965-03-2$ \\
\hline Cesium carbonate & $\mathrm{Cs}_{2} \mathrm{CO}_{3}$ & $534-17-8$ \\
\hline Dichloromethane & $\mathrm{CH}_{2} \mathrm{Cl}_{2}$ & $75-09-2$ \\
\hline Dichloroacetic acid & DCA & $79-43-6$ \\
\hline Dimethyl ether & DME & $110-71-4$ \\
\hline Dichloroethane & DCE & $107-06-2$ \\
\hline Ethanol & $\mathrm{EtOH}$ & $64-17-5$ \\
\hline Ethyl acetate & EtOAc & $141-78-6$ \\
\hline Formic acid & FA & $64-18-6$ \\
\hline Gold chloride & $\mathrm{AuCl}_{3}$ & 13453-07-1 \\
\hline Hydrochloric acid & $\mathrm{HCl}$ & $7647-01-0$ \\
\hline$m$-xylene & I & $108-38-3$ \\
\hline Methanol & $\mathrm{MeOH}$ & $67-56-1$ \\
\hline
\end{tabular}




\begin{tabular}{|c|c|c|}
\hline Mesitylene & I & $108-67-8$ \\
\hline $\mathrm{N}, \mathrm{N}$ - diethylformamide & DEF & $617-84-5$ \\
\hline N,N-Dimethylformamide & DMF & $68-12-2$ \\
\hline $\mathrm{N}, \mathrm{N}$ - dimethylacetamide & DMA & $127-19-5$ \\
\hline Naphthalene & / & $91-20-3$ \\
\hline$o$-Xylene & l & $95-47-6$ \\
\hline$p$-Xylene & l & $106-42-3$ \\
\hline p-Toluic acid & PTA & $99-94-5$ \\
\hline Potassium carbonate & $\mathrm{K}_{2} \mathrm{CO}_{3}$ & $584-08-7$ \\
\hline Petroleum ether & $\mathrm{PE}$ & $8032-32-4$ \\
\hline Potassium permanganate & $\mathrm{KMnO}_{4}$ & $7722-64-7$ \\
\hline p-Toluenesulfonyl chloride & $\mathrm{TsCl}$ & $98-59-9$ \\
\hline Palladium(II) acetate & $\mathrm{Pd}(\mathrm{OAc})_{2}$ & $3375-31-3$ \\
\hline Sodium hydroxide & $\mathrm{NaOH}$ & $1310-73-2$ \\
\hline Sodium sulfate & $\mathrm{Na}_{2} \mathrm{SO}_{4}$ & $7757-82-6$ \\
\hline Sodium hydrogen carbonate & $\mathrm{NaHCO}_{3}$ & $144-55-8$ \\
\hline Tetrahydrofuran & $\mathrm{THF}$ & $109-99-9$ \\
\hline Tetrakis- (triphenylphosphine)palladium & $\mathrm{Pd}\left(\mathrm{PPh}_{3}\right)_{4}$ & $14221-01-3$ \\
\hline Tripotassium orthophosphate & $\mathrm{K}_{3} \mathrm{PO}_{4}$ & $7778-53-2$ \\
\hline Triethylamine & $\mathrm{NEt}_{3}$ & $121-44-8$ \\
\hline Trichlorosilane & $\mathrm{HSiCl}_{3}$ & $10025-78-2$ \\
\hline Zirconium tetrachloride & $\mathrm{ZrCl}_{4}$ & $10026-11-6$ \\
\hline
\end{tabular}




\section{S2.2 Synthesis of linkers}

1. Synthesis of MTBC (S1).

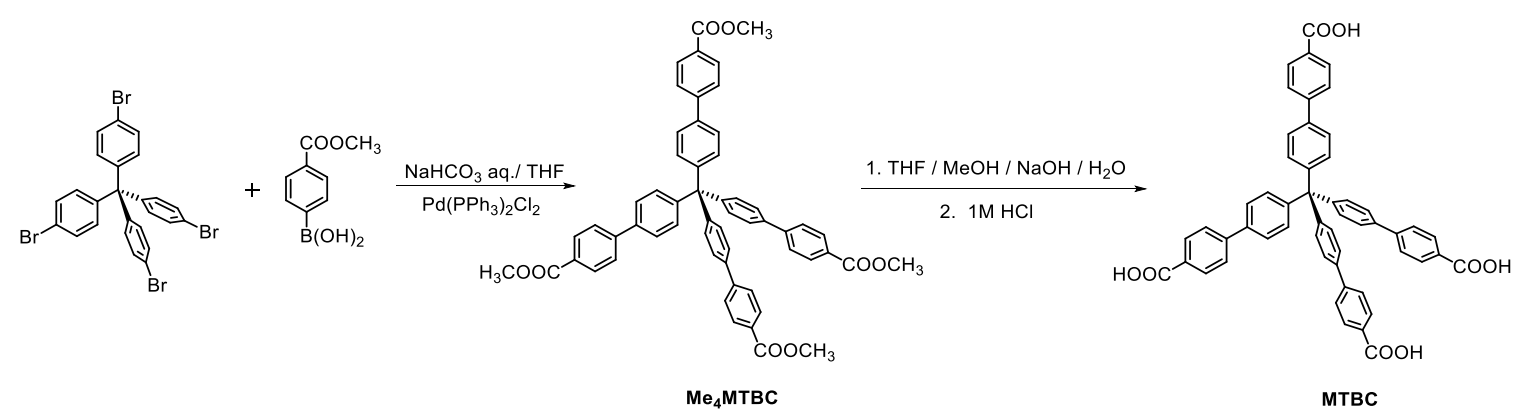

Figure S4. General scheme for the synthesis of MTBC.

Synthesis of tetramethyl 4',4'",4"'",4"'"'"-methanetetrayltetrakis([1,1'-biphenyl] -4-carboxylate) ( $\left.\mathrm{Me}_{4} \mathrm{MTBC}\right)$

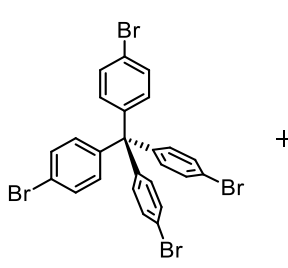

$\mathrm{B}(\mathrm{OH})_{2}$

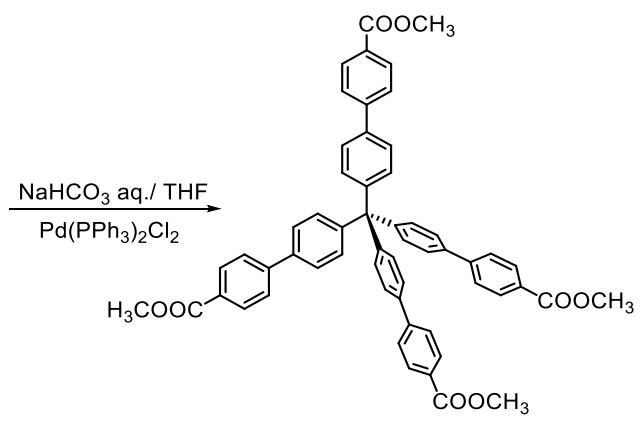

$\mathrm{Me}_{4} \mathrm{MTBC}$

Figure S5. Scheme for the synthesis of $\mathrm{Me}_{4} \mathrm{MTBC}$.

A mixture of tetrakis(4-bromophenyl)methane (1.3 g, $2.0 \mathrm{mmol}, 1.0$ equiv), 4-(methoxycarbonyl)- phenylboronic acid (2.2 g, $12 \mathrm{mmol}, 6.0$ equiv) and $\mathrm{Pd}\left(\mathrm{PPh}_{3}\right) \mathrm{Cl}_{2}(0.14 \mathrm{~g}, 0.20 \mathrm{mmol}, 0.1$ equiv $)$ were added to a Schlenk flask. The flask was then capped with a rubber septum, evacuated and backfilled with argon three times. Under an inert atmosphere, THF $(65 \mathrm{~mL})$ and degassed saturated $\mathrm{NaHCO}_{3}$ were added via syringe. Then, the mixture was heated in $70{ }^{\circ} \mathrm{C}$ for 3 days. After that, the crude product was extracted with dichloromethane $(3 \times 150 \mathrm{~mL})$, the combined organic phases were washed with brine $(300 \mathrm{~mL})$, dried over $\mathrm{Na}_{2} \mathrm{SO}_{4}$ and concentrated in vacuo. Pure product was obtained from column chromatography using PE / dichloromethane as the eluent. The desired product $\mathrm{Me}_{4} \mathrm{MTBC}$ was obtained as a white solid (1.1 g, $1.3 \mathrm{mmol}, 63 \%) .{ }^{1} \mathrm{H} \mathrm{NMR}\left(400 \mathrm{MHz}, \mathrm{CDCl}_{3}\right) \delta 8.10$ (d, J=8.5 Hz, 8H), $7.68(\mathrm{~d}, J=8.4 \mathrm{~Hz}, 8 \mathrm{H}), 7.59(\mathrm{~d}, J=8.5 \mathrm{~Hz}, 8 \mathrm{H}), 7.44(\mathrm{~d}, J=8.5 \mathrm{~Hz}, 8 \mathrm{H}), 3.94$ (s, 12H). $\left.{ }^{13} \mathrm{C} \mathrm{NMR} \mathrm{(101} \mathrm{MHz,} \mathrm{CDCl}_{3}\right) \delta 166.99,146.39,144.84,137.70,131.55$, $130.17,128.97,126.87,126.62,52.16$. 


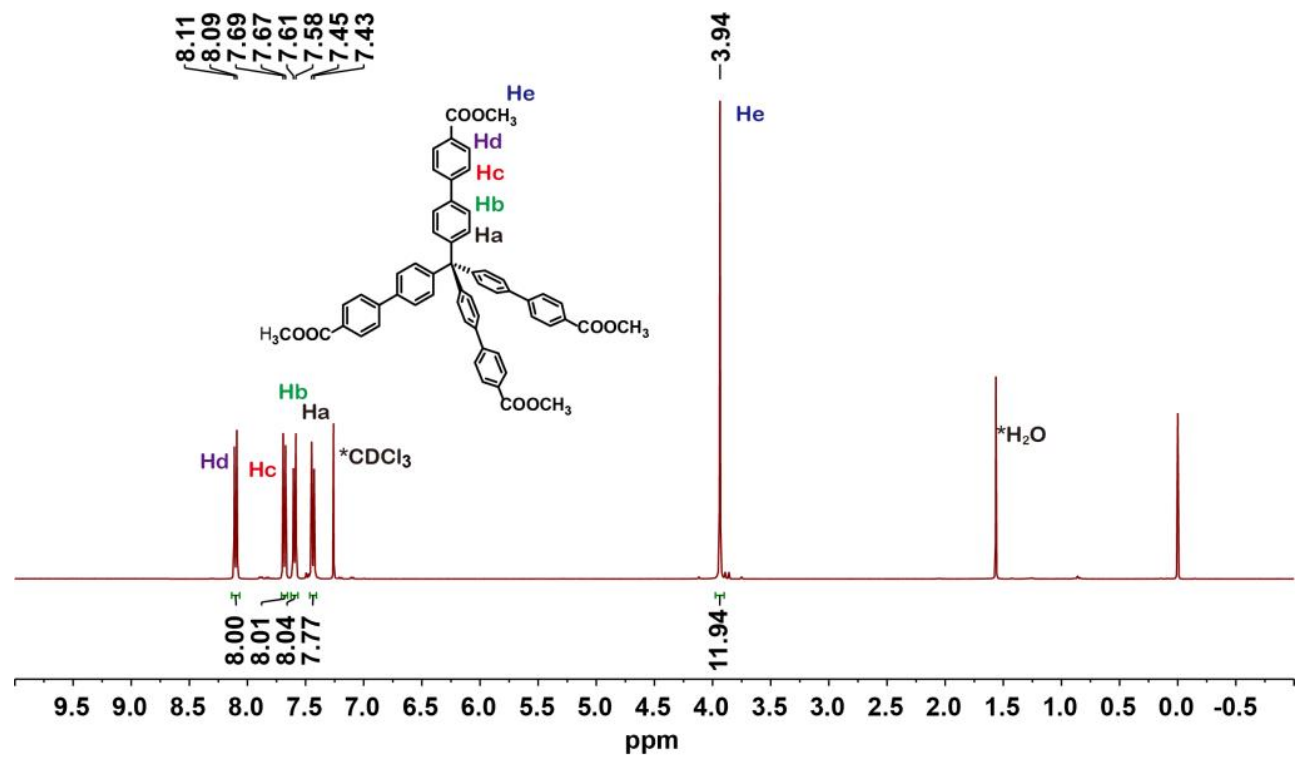

Figure S6. ${ }^{1} \mathrm{H}$ NMR spectrum of compound $\mathrm{Me}_{4} \mathrm{MTBC}$.

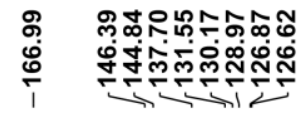

$\stackrel{\circ}{\underset{1}{0}}$
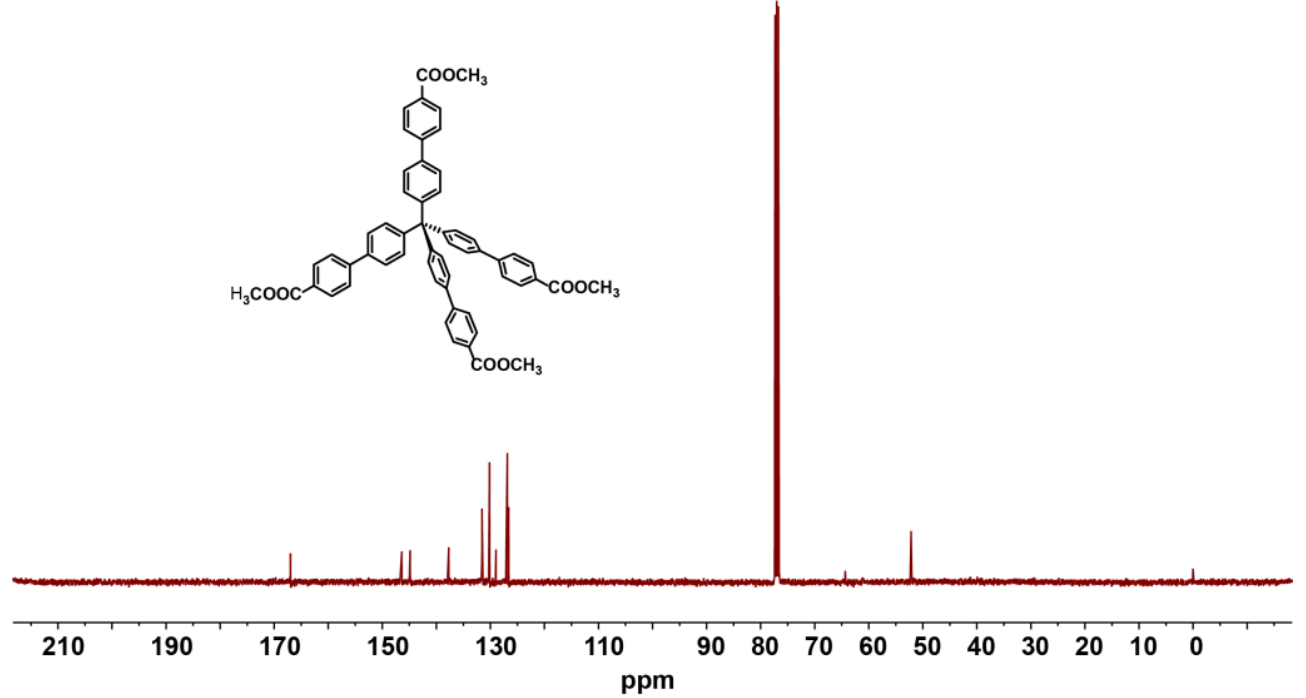

Figure S7. ${ }^{13} \mathrm{C}$ NMR spectrum of compound $\mathrm{Me}_{4} \mathrm{MTBC}$.

Synthesis of 4',4"',4"'",,4"'"'--methanetetrayltetrakis(([1,1'-biphenyl]-4-carboxylic acid)) (MTBC)

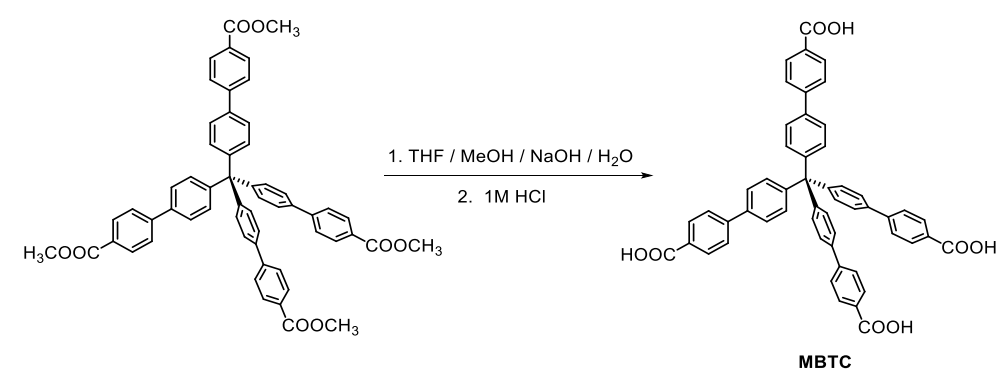

Figure S8. Scheme for the synthesis of $\mathrm{Me}_{4} \mathrm{MTBC}$. 
Tetramethyl 4',4'",4"'",4"'"'--methanetetrayltetrakis([1,1'-biphenyl] -4-carboxylate) (Me $\left.{ }_{4} \mathrm{MTBC}\right)$ (0.86 g, $1.0 \mathrm{mmol}, 1.0$ equiv) was dissolved in a mixture of THF (10 $\mathrm{mL}), \mathrm{MeOH}(15 \mathrm{~mL})$, and $6 \mathrm{M} \mathrm{NaOH}$ (aq.) $(20 \mathrm{~mL})$. After the mixture was stirred at $85{ }^{\circ} \mathrm{C}$ for $24 \mathrm{~h}$, the solvent was removed by rotary evaporation. The white solid was dissolved in water and acidified with $1 \mathrm{M} \mathrm{HCl}$. A white precipitate, which was filtered, washed with water, and dried in an oven at $80{ }^{\circ} \mathrm{C}$ for $10 \mathrm{~h}$. After that, pure product MTBC (0.74 g, $0.93 \mathrm{mmol}, 93 \%)$ was obtained. ${ }^{1} \mathrm{H}$ NMR (400 MHz, DMSO- $\left.d_{6}\right) \delta$ $12.97(\mathrm{~s}, 4 \mathrm{H}), 8.01(\mathrm{~d}, J=8.3 \mathrm{~Hz}, 9 \mathrm{H}), 7.83(\mathrm{~d}, J=8.4 \mathrm{~Hz}, 9 \mathrm{H}), 7.77(\mathrm{~d}, J=8.5 \mathrm{~Hz}$, $5 \mathrm{H}), 7.42(\mathrm{~d}, J=8.4 \mathrm{~Hz}, 6 \mathrm{H}) .{ }^{13} \mathrm{C}$ NMR $\left(101 \mathrm{MHz}, \mathrm{DMSO}-d_{6}\right) \delta 167.58,146.60$, $143.96,137.13,131.55,130.43,130.13,127.14,127.06$.
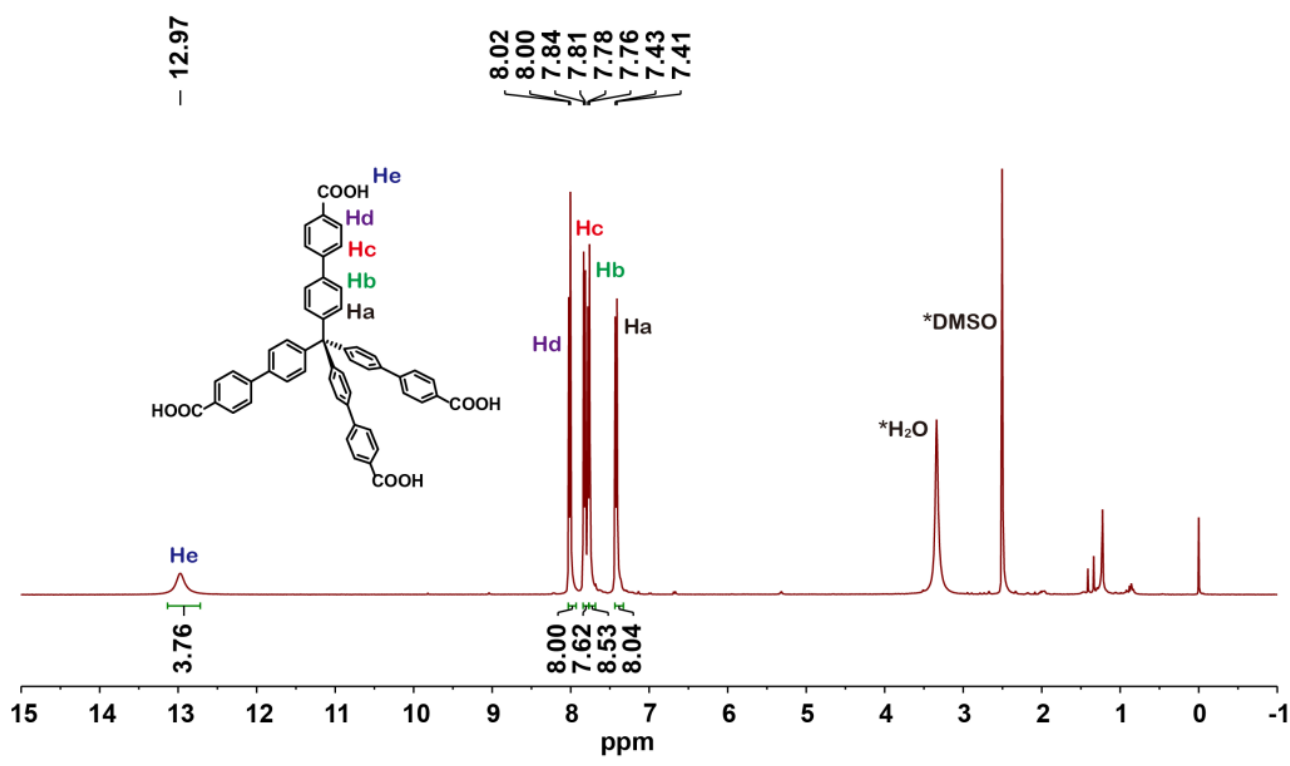

Figure S9. ${ }^{1} \mathrm{H}$ NMR spectrum of compound MTBC.

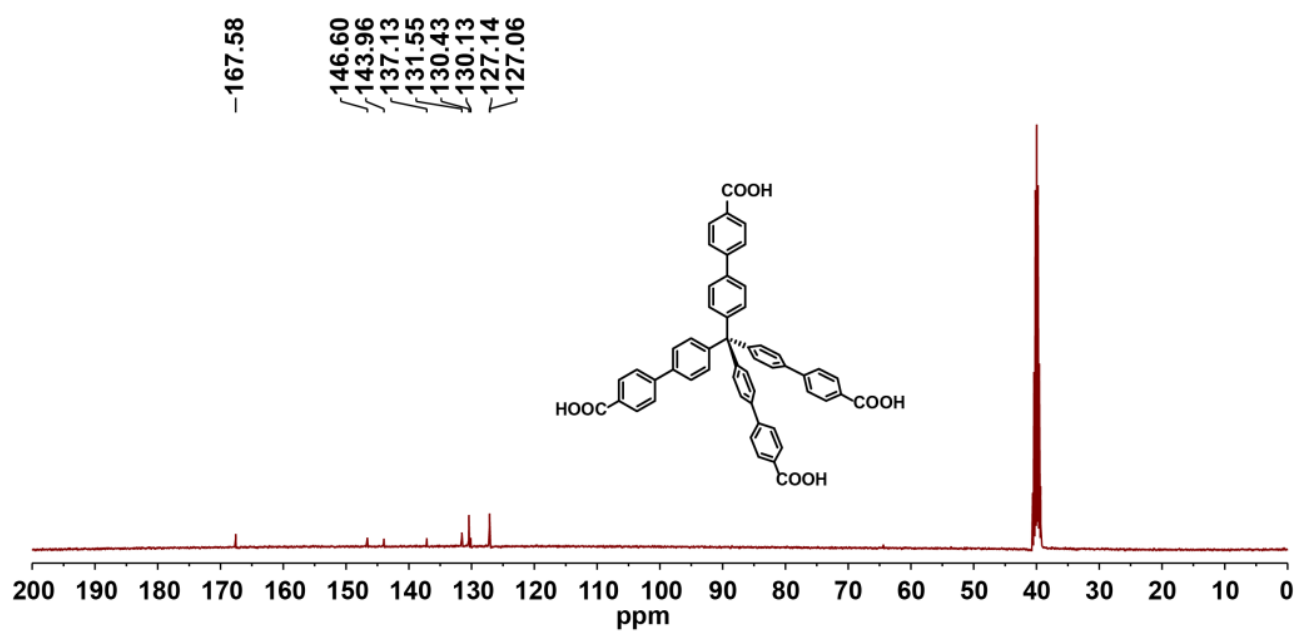

Figure S10. ${ }^{13} \mathrm{C}$ NMR spectrum of compound MTBC. 
2. Synthesis of TBPA
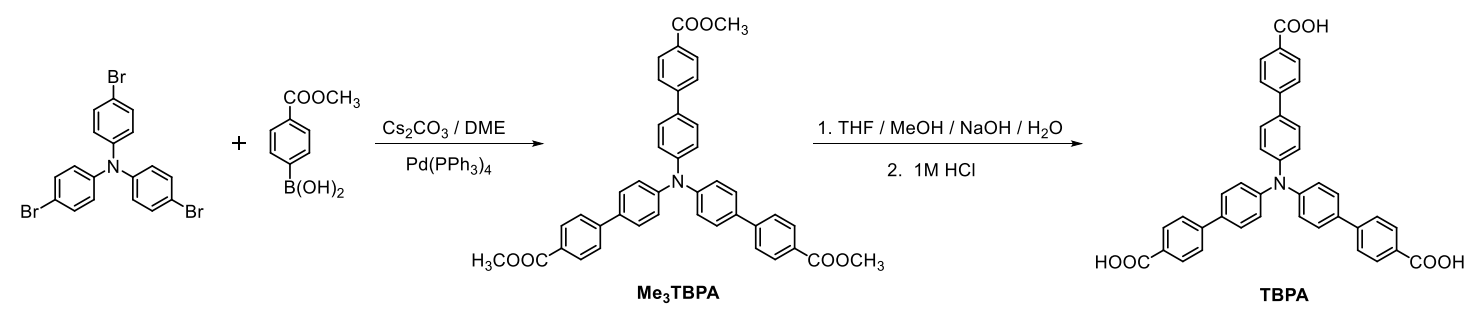

Figure S11. General scheme for the synthesis of TBPA.

\section{Synthesis of trimethyl 4 ',4"',4'"'"-nitrilotris([1,1'-biphenyl]-4-carboxylate) (Me3TBPA)}

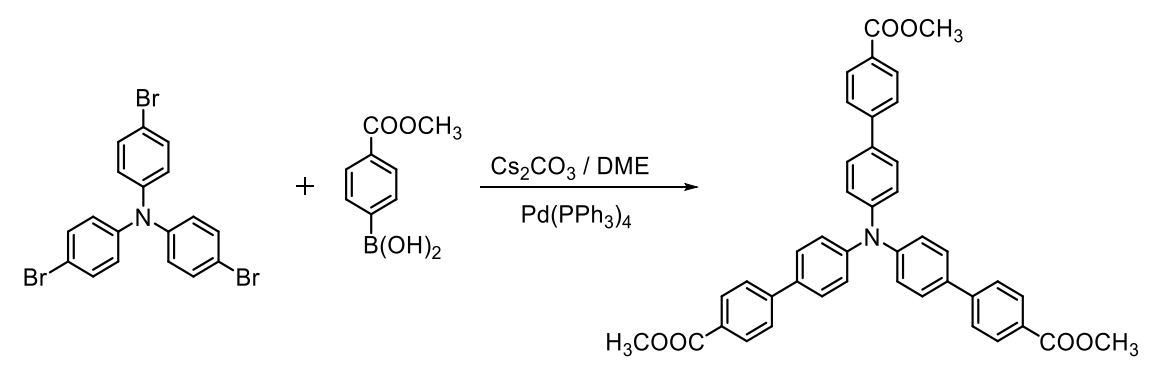

Figure S12. Scheme for the synthesis of $\mathrm{Me}_{3}$ TBPA.

Tris(4-bromophenyl)amine $\quad\left(\begin{array}{llllll}1.4 & \mathrm{~g}, & 3.0 \quad \mathrm{mmol}, & 1.0 & \text { equiv), }\end{array}\right.$ (4-(ethoxycarbonyl)-phenyl)boronic acid (2.7 g, $15 \mathrm{mmol}, 5.0$ equiv), cesium carbonate (4.9 g, $15 \mathrm{mmol}, 5.0$ equiv), and tetrakis- (triphenylphosphine)palladium (0.18 g, $0.15 \mathrm{mmol}, 0.05$ equiv) were added to a Schleck flask. The flask was evacuated and backfilled with argon three times. Under an inert atmosphere, degassed DME (100 mL) was added via syringe. The solution was heated at $100^{\circ} \mathrm{C}$ for $72 \mathrm{~h}$. After the reaction mixture was cooled to room temperature, the organic solvent was evaporated. The aqueous layer was extracted with dichloromethane $(3 \times 50 \mathrm{~mL})$, and then the combined organic layers were dried over $\mathrm{Na}_{2} \mathrm{SO}_{4}$. Then the crude product was purified by column chromatography on silica gel to give compound Me3TBPA (1.67 g, $2.58 \mathrm{mmol}, 86 \%)$. as a yellow solid. ${ }^{1} \mathrm{H}$ NMR (400 MHz, $\left.\mathrm{CDCl}_{3}\right) \delta 8.10(\mathrm{~d}, J$ $=8.5 \mathrm{~Hz}, 6 \mathrm{H}), 7.66(\mathrm{~d}, J=5.0 \mathrm{~Hz}, 6 \mathrm{H}), 7.57(\mathrm{~d}, J=4.9 \mathrm{~Hz}, 6 \mathrm{H}), 7.25(\mathrm{~d}, J=6.7 \mathrm{~Hz}$, 7H), $3.94(\mathrm{~s}, 9 \mathrm{H}) .{ }^{13} \mathrm{C} \mathrm{NMR}\left(101 \mathrm{MHz}, \mathrm{CDCl}_{3}\right) \delta 167.01,147.25,144.78,134.57$, $130.16,128.50,128.20,126.47,124.53,52.15$. 


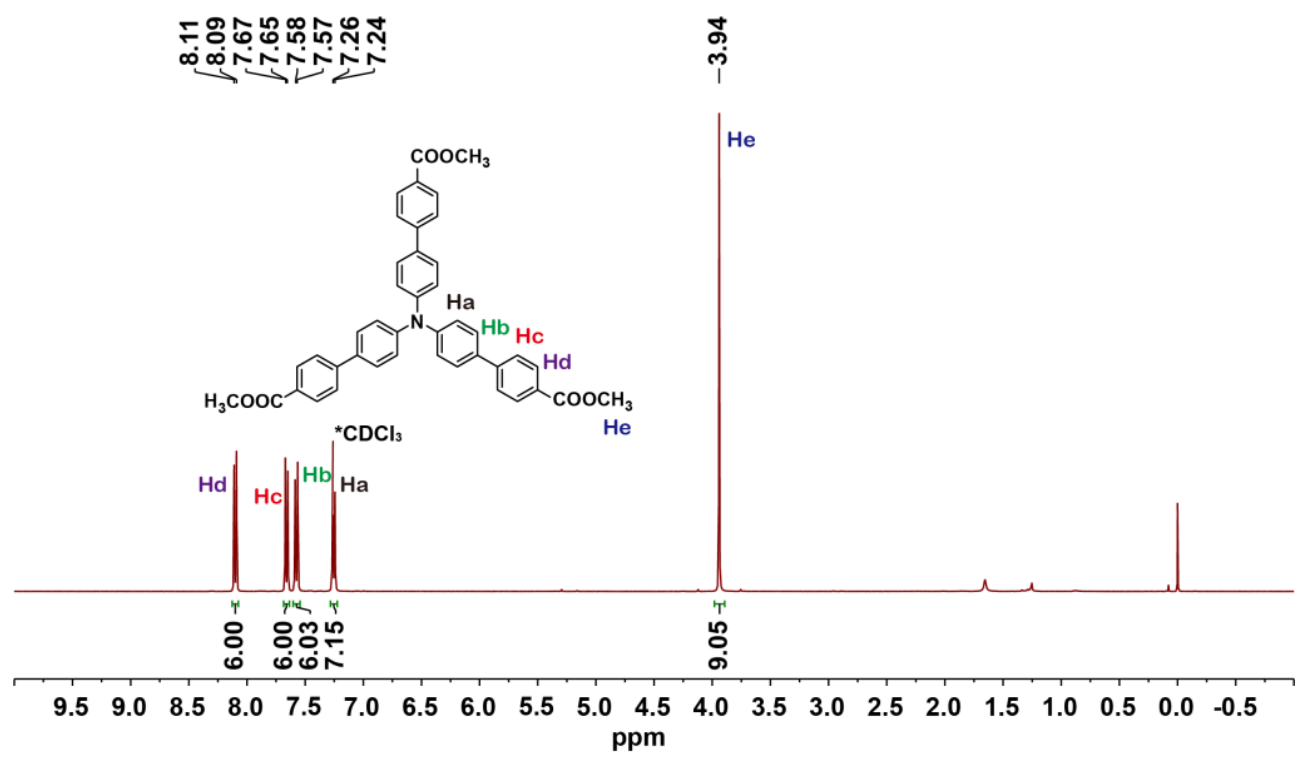

Figure S13. ${ }^{1} \mathrm{H}$ NMR spectrum of compound $\mathrm{Me}_{3}$ TBPA

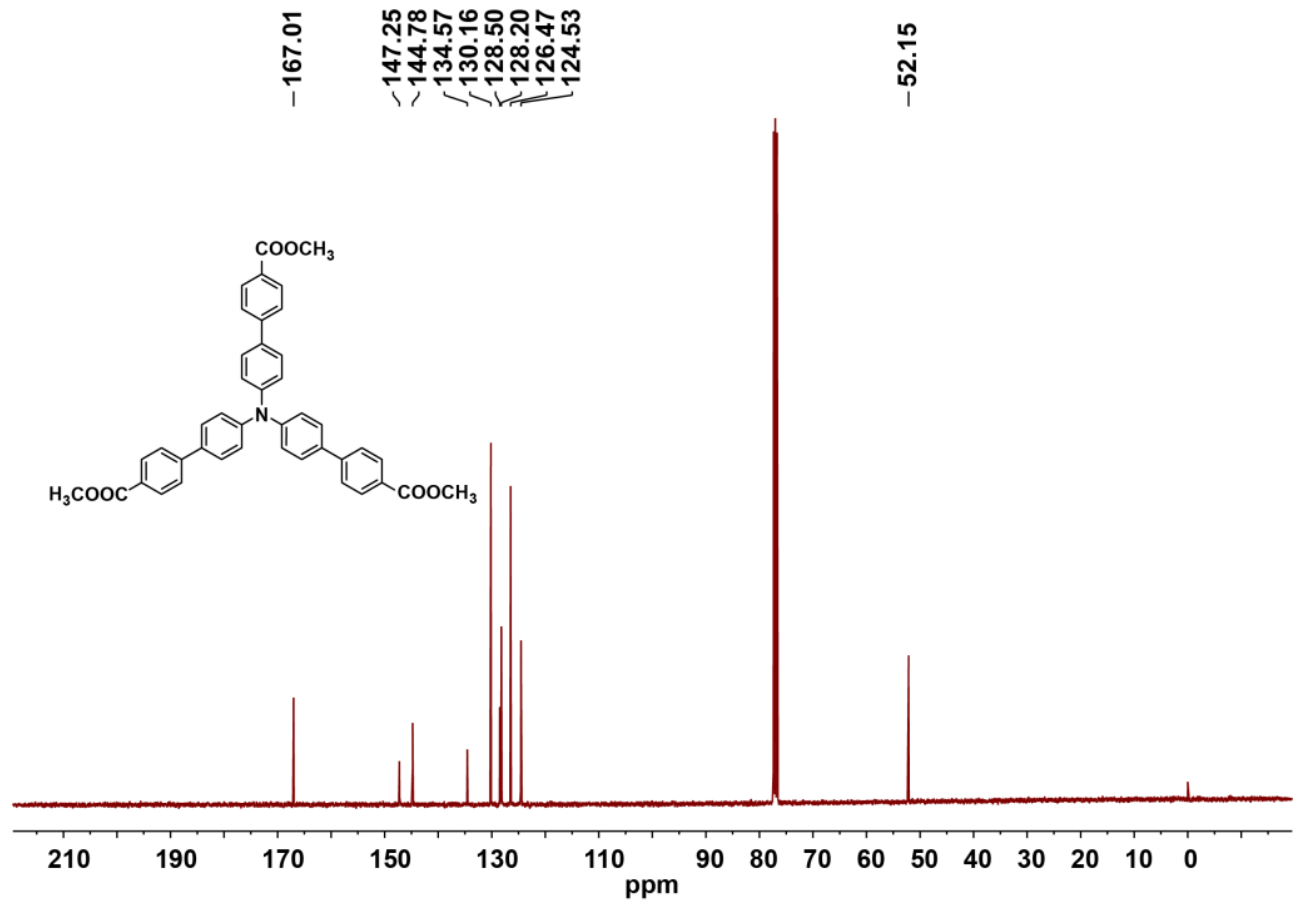

Figure S14. ${ }^{13} \mathrm{C}$ NMR spectrum of compound $\mathrm{Me}_{3} \mathrm{TBPA}$

Synthesis of 4',4'"',4'"'"-nitrilotris(([1,1'-biphenyl]-4-carboxylic acid)) (TBPA)
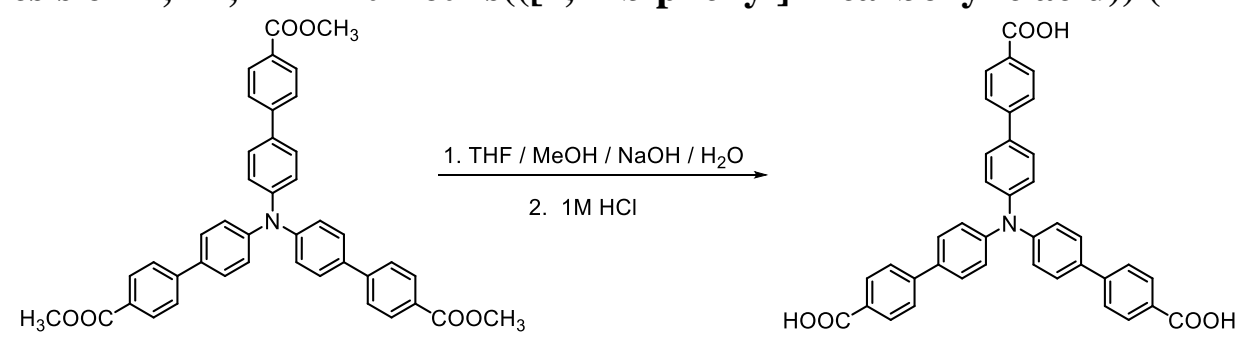

Figure S15. Scheme for the synthesis of TBPA. 
Trimethyl 4',4"',4'"'"-nitrilotris([1,1'-biphenyl]-4-carboxylate) (Me 3 TBPA) (1.3 g, $2.0 \mathrm{mmol}, 1$ equiv) was dissolved in a mixture of THF (25 mL), $\mathrm{MeOH}(40 \mathrm{~mL})$, and $6 \mathrm{M} \mathrm{NaOH}$ (aq.) (40 mL). After the mixture was stirred at $85^{\circ} \mathrm{C}$ for $24 \mathrm{~h}$, solvent was removed by rotary evaporation. The yellow solid was dissolved in water and acidified with $1 \mathrm{M} \mathrm{HCl}$. A yellow precipitate, which was filtered, washed with water, and dried in an oven at $80{ }^{\circ} \mathrm{C}$ for $10 \mathrm{~h}$. After that, pure product TBPA (1.2 g, $\left.1.9 \mathrm{mmol}, 96 \%\right)$ was obtained. ${ }^{1} \mathrm{H}$ NMR (400 MHz, DMSO- $\left.d_{6}\right) \delta 12.96(\mathrm{~s}, 3 \mathrm{H}), 8.01(\mathrm{~d}, J=8.4 \mathrm{~Hz}$, $6 \mathrm{H}), 7.78(\mathrm{~d}, J=8.4 \mathrm{~Hz}, 6 \mathrm{H}), 7.73(\mathrm{~d}, J=8.6 \mathrm{~Hz}, 6 \mathrm{H}), 7.19(\mathrm{~d}, J=8.7 \mathrm{~Hz}, 6 \mathrm{H}) .{ }^{13} \mathrm{C}$ NMR (101 MHz, DMSO-d6) $\delta 167.63,147.23,144.01,134.11,130.47,129.65$, $128.65,126.70,124.78$.

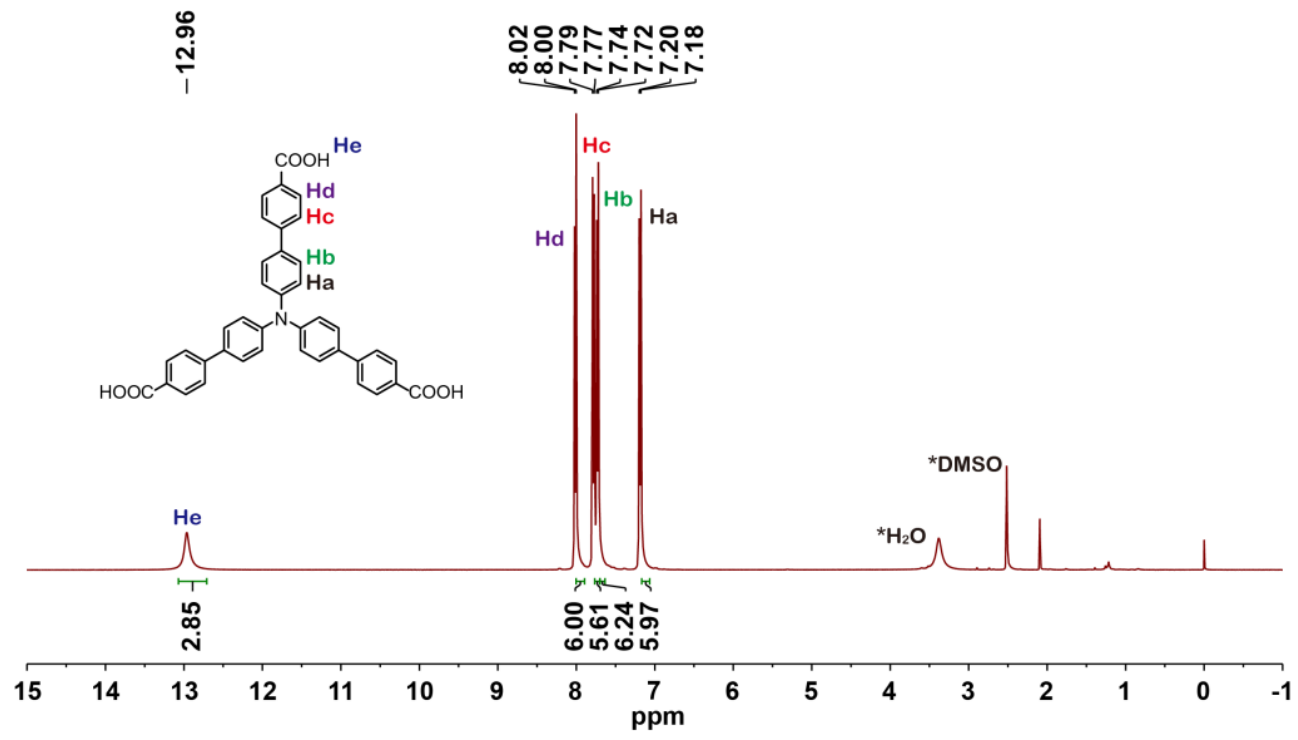

Figure S16. ${ }^{1} \mathrm{H}$ NMR spectrum of compound TBPA

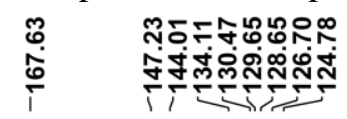

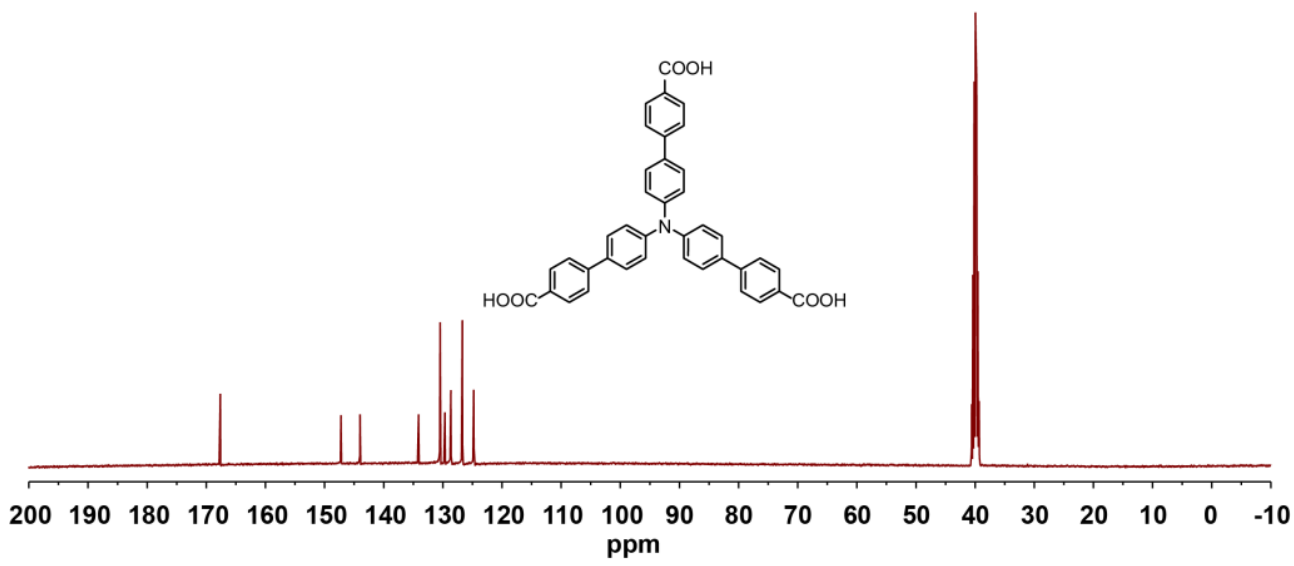

Figure S17. ${ }^{13} \mathrm{C}$ NMR spectrum of compound TBPA 
3. Synthesis of PBCA
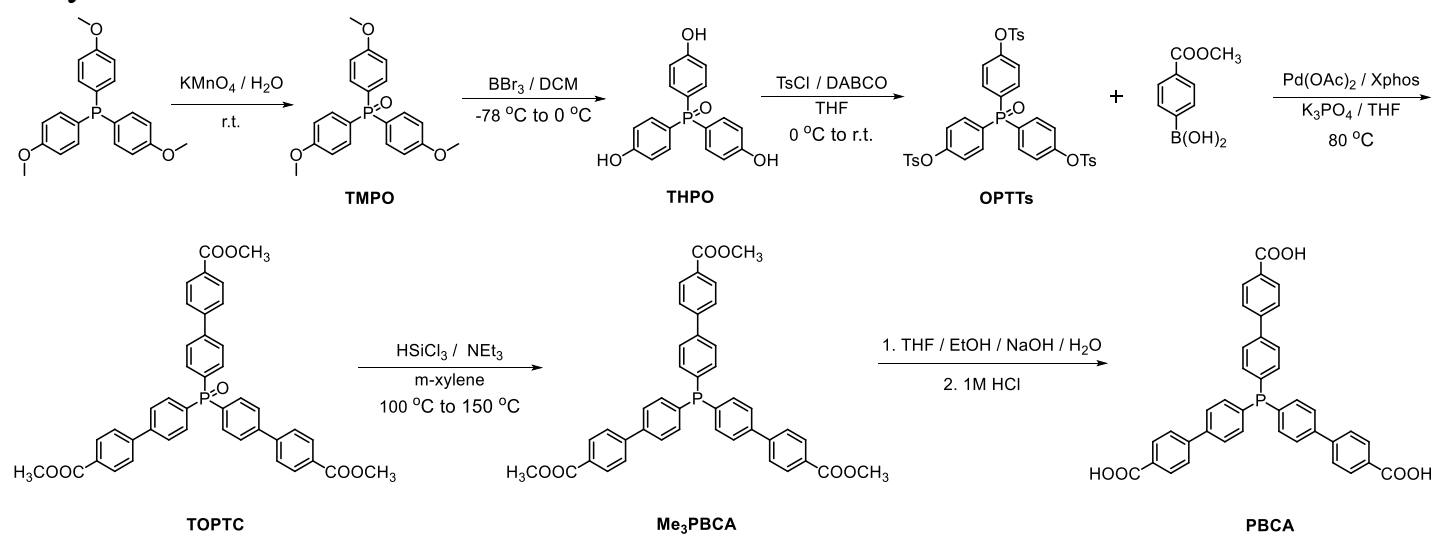

Figure S18. General scheme for the synthesis of PBCA.

Synthesis of tris(4-methoxyphenyl)phosphine oxide (TMPO) (S2).
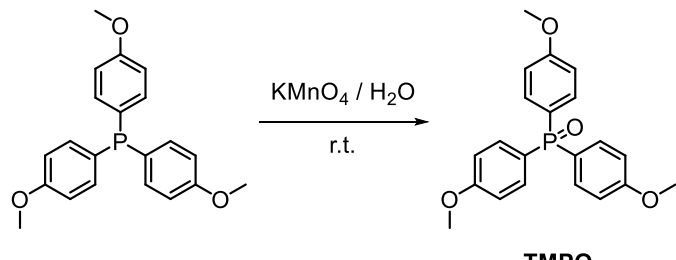

Figure S19. Scheme for the synthesis of TMPO.

To a suspension of tris(4-methoxyphenyl)phosphane (10 g, $28 \mathrm{mmol}, 1.0$ equiv) in deionized water $(250 \mathrm{~mL}), \mathrm{KMnO}_{4}(5.4 \mathrm{~g}, 33 \mathrm{mmol}, 1.2$ equiv) was added. The reaction mixture was stirred at room temperature for $24 \mathrm{~h}$, diluted with deionized water $(300 \mathrm{~mL})$ and extracted with $\mathrm{CH}_{2} \mathrm{Cl}_{2}(5 \times 200 \mathrm{~mL})$. The combined organic phases were washed with brine then dried over $\mathrm{Na}_{2} \mathrm{SO}_{4}$ and concentrated in vacuo. The resulting mixture was concentrated in vacuo, after drying, the desired product $(9.06 \mathrm{~g}, 86 \%)$ was obtained as a white solid. ${ }^{1} \mathrm{H} \mathrm{NMR}\left(400 \mathrm{MHz}, \mathrm{CDCl}_{3}\right) \delta 7.58(\mathrm{dd}, J$ $=11.4,8.7 \mathrm{~Hz}, 6 \mathrm{H}), 6.96(\mathrm{dd}, J=8.5,1.8 \mathrm{~Hz}, 6 \mathrm{H}), 3.85$ (s, 9H). ${ }^{13} \mathrm{C} \mathrm{NMR}(101 \mathrm{MHz}$, $\left.\mathrm{CDCl}_{3}\right) \delta 162.33,162.30,133.95,133.84,124.93,123.83,114.04,113.91,55.35 .{ }^{31} \mathrm{P}$ NMR (162 MHz, CDCl 3 ) $\delta 29.07$. 


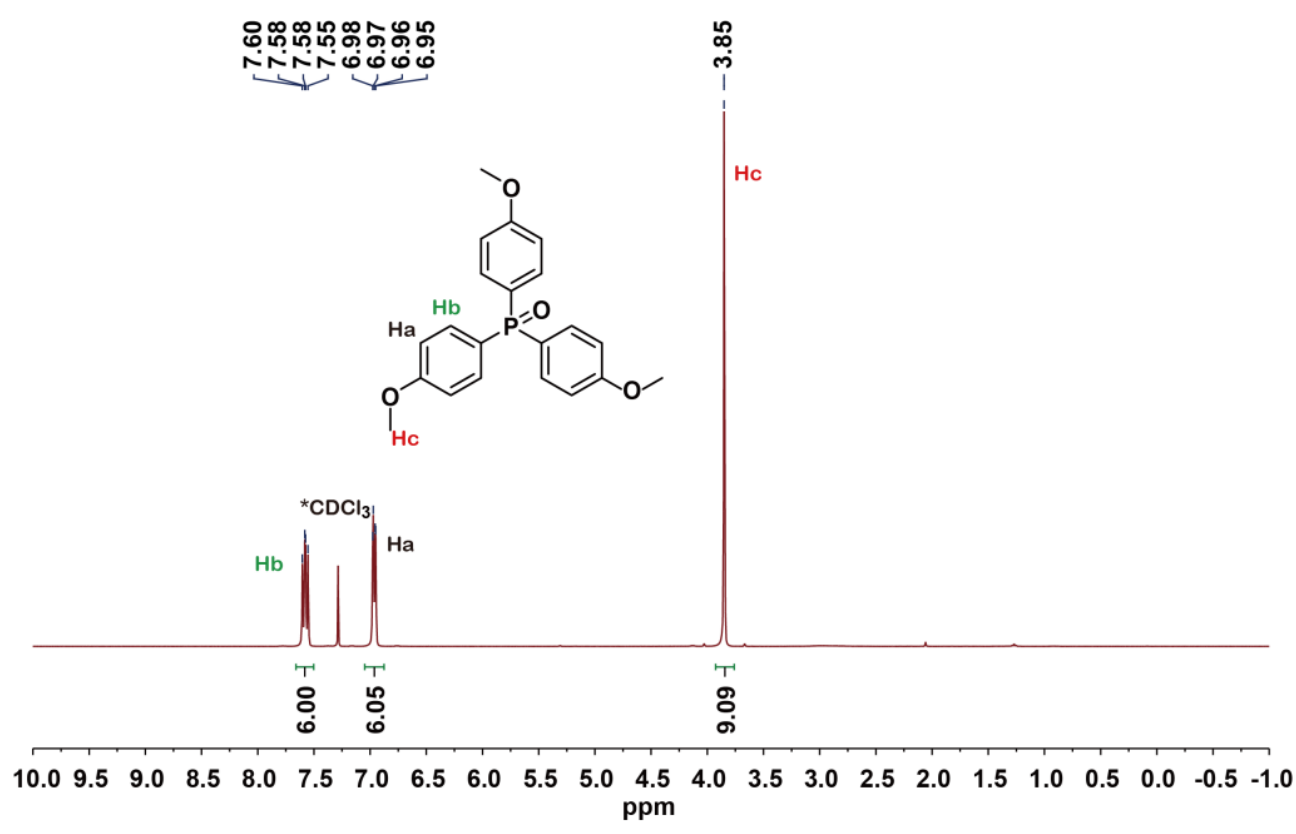

Figure S20. ${ }^{1} \mathrm{H}$ NMR spectrum of compound TMPO.

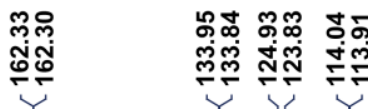

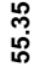

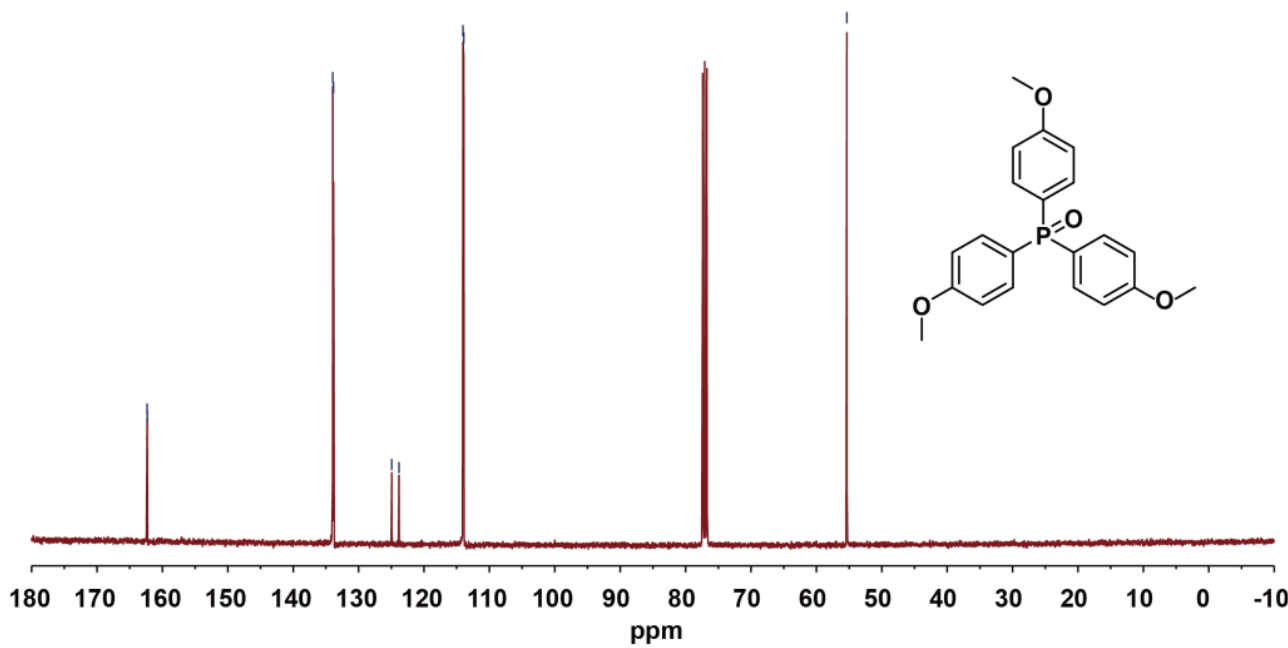

Figure S21. ${ }^{13} \mathrm{C}$ NMR spectrum of compound TMPO. 


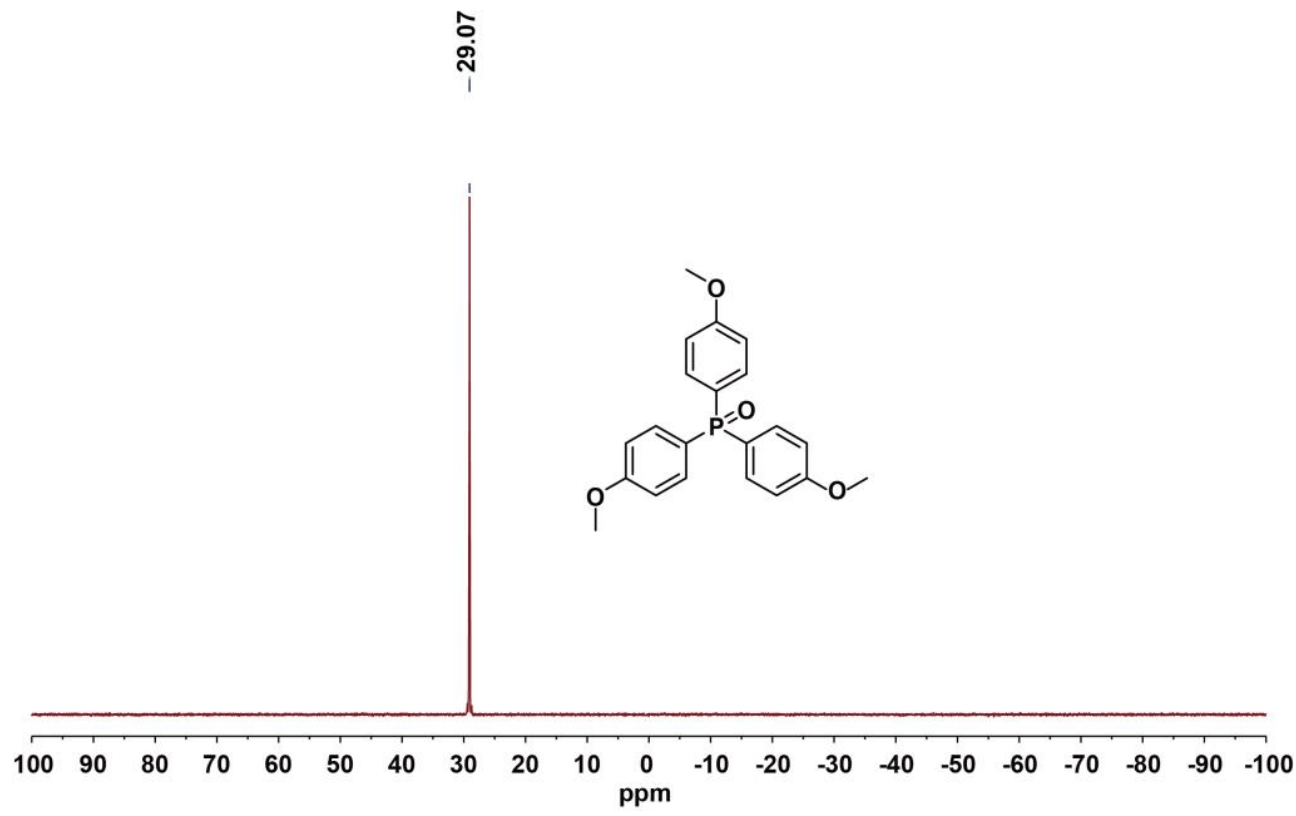

Figure S22. ${ }^{31} \mathrm{P}$ NMR spectrum of compound TMPO.

Synthesis of tris(4-hydroxyphenyl)phosphine oxide (THPO) (S2).

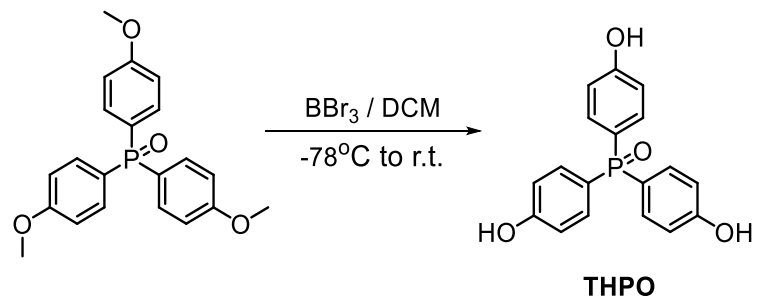

Figure S23. Scheme for the synthesis of THPO.

To a solution of tris(4-hydroxyphenyl)phosphine oxide (TMPO) (5.0g, $13 \mathrm{mmol}$, 1.0 equiv) in dry $\mathrm{CH}_{2} \mathrm{Cl}_{2}(68.0 \mathrm{~mL}), \mathrm{BBr}_{3}\left(1.0 \mathrm{M}\right.$ in $\mathrm{CH}_{2} \mathrm{Cl}_{2}, 68.0 \mathrm{~mL}, 68 \mathrm{mmol}, 5.0$ equiv) was slowly added at $-78{ }^{\circ} \mathrm{C}$ under argon. The reaction mixture was stirred at room temperature for $12 \mathrm{~h}$, quenched by pouring into deionized water $(100 \mathrm{~mL})$ and diluted with EtOAc. The crude was extracted with EtOAc $(3 \times 150 \mathrm{~mL})$, the combined organic phases were washed with brine $(300 \mathrm{~mL})$, dried over $\mathrm{Na}_{2} \mathrm{SO}_{4}$ and concentrated in vacuo. The desired product THPO (4.4 g, $13 \mathrm{mmol}, 99 \%)$ was obtained as a colorless powder. ${ }^{1} \mathrm{H}$ NMR $\left(400 \mathrm{MHz}, \mathrm{CDCl}_{3}\right) \delta 10.13(\mathrm{~s}, 3 \mathrm{H}), 7.34(\mathrm{dd}$, $J=11.1,8.5 \mathrm{~Hz}, 6 \mathrm{H}), 6.86(\mathrm{~d}, J=6.7 \mathrm{~Hz}, 6 \mathrm{H}) .{ }^{13} \mathrm{C} \mathrm{NMR}\left(101 \mathrm{MHz}, \mathrm{CDCl}_{3}\right) \delta 170.41$, $160.31,160.28,133.46,133.34,123.84,122.75,115.48,115.35,59.81 .{ }^{31} \mathrm{P}$ NMR $(162$ $\left.\mathrm{MHz}, \mathrm{CDCl}_{3}\right) \delta 30.42$ 


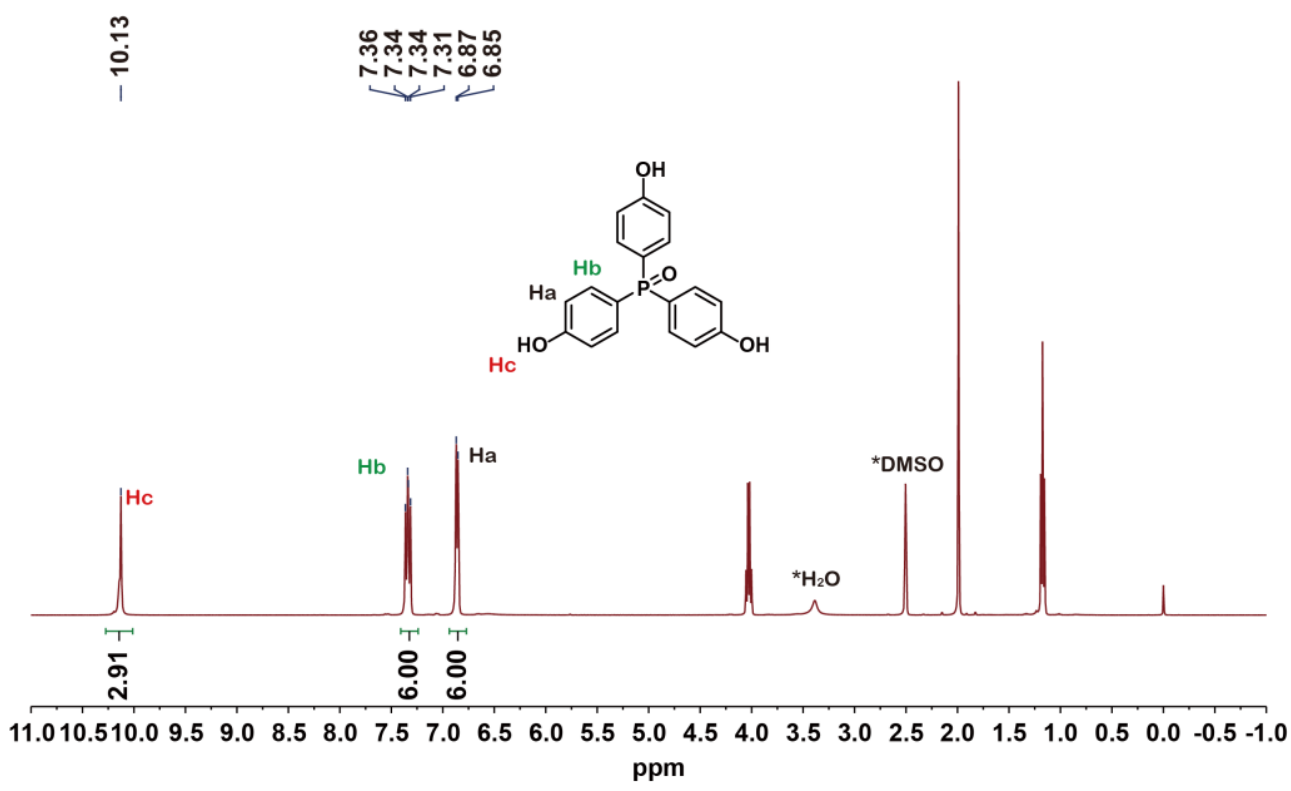

Figure S24. ${ }^{1} \mathrm{H}$ NMR spectrum of compound THPO.

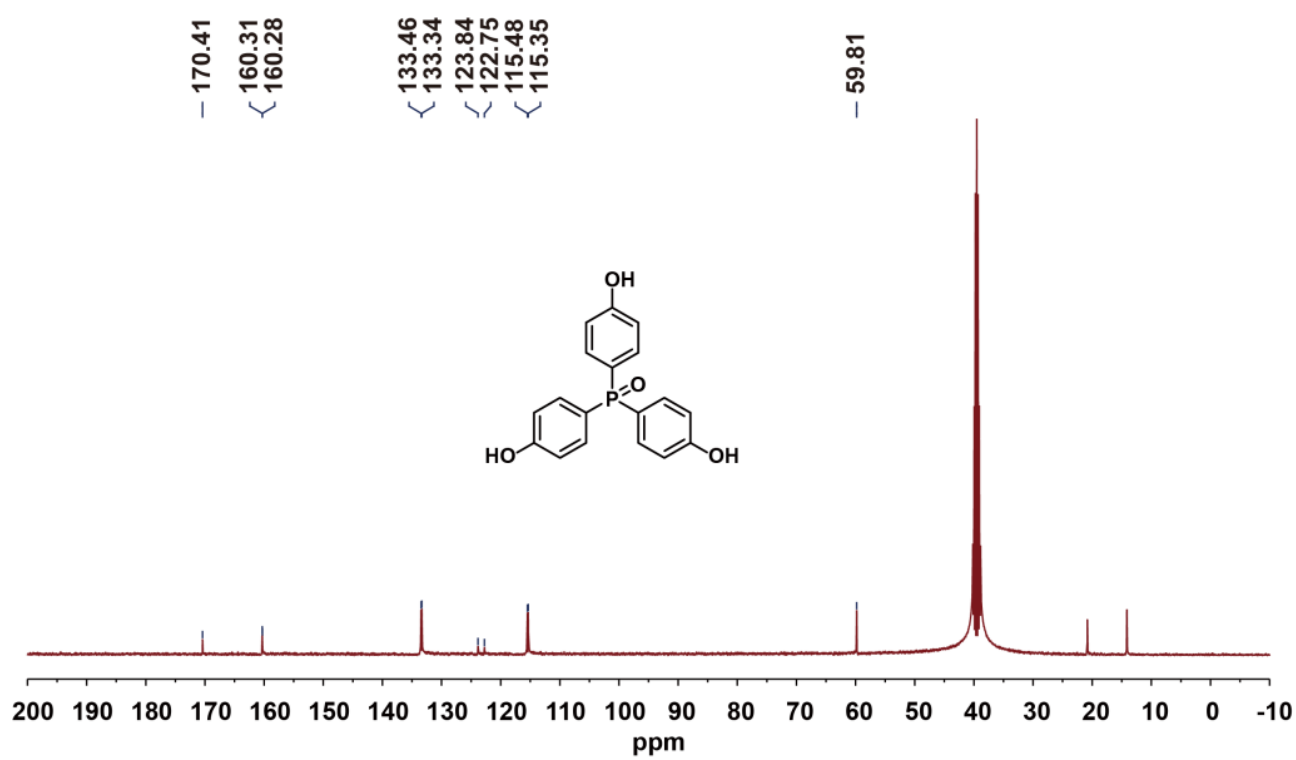

Figure S25. ${ }^{13} \mathrm{C}$ NMR spectrum of compound THPO. 


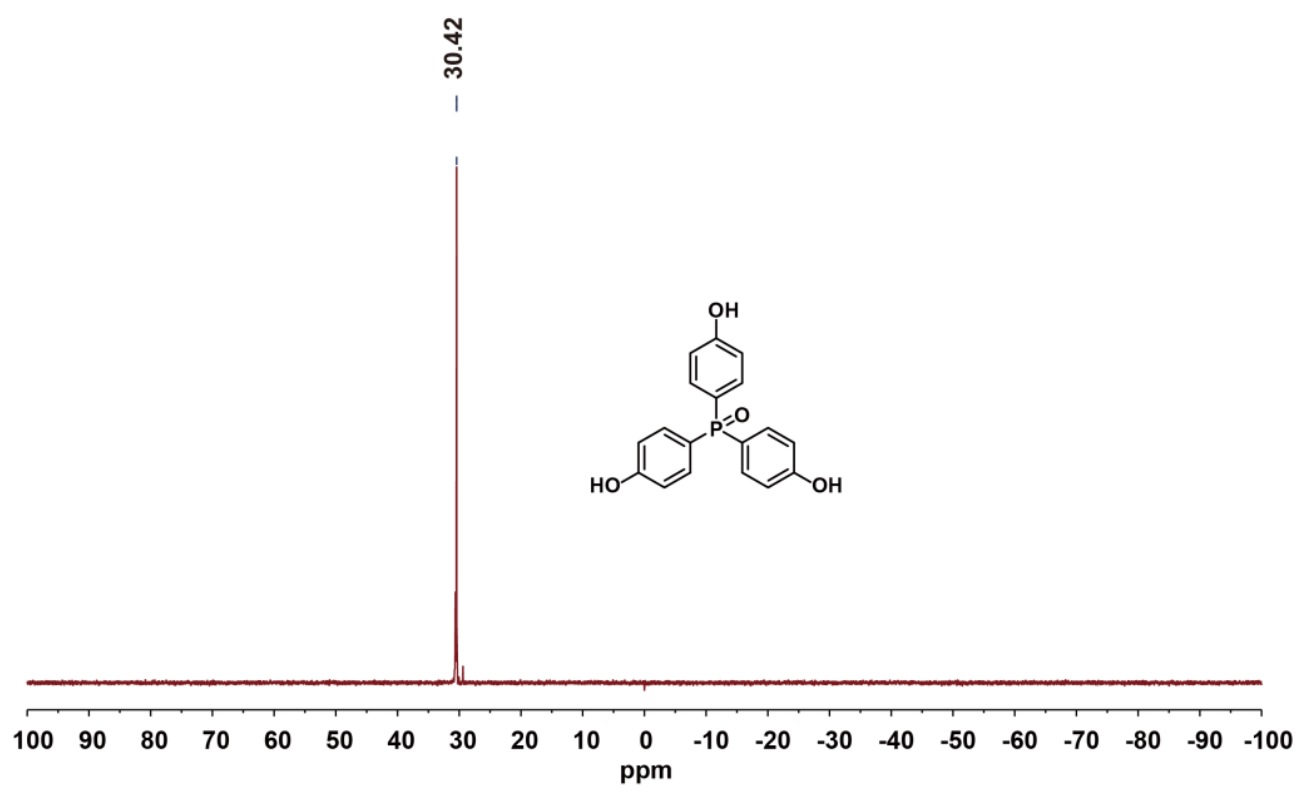

Figure S26. ${ }^{31} \mathrm{P}$ NMR spectrum of compound TMPO.

Synthesis of (oxo- $\lambda^{5}$-phosphanetriyl)tris(benzene-4,1-diyl)

tris(4-methylbenzene-sulfonate) (OPTTs) (S3)

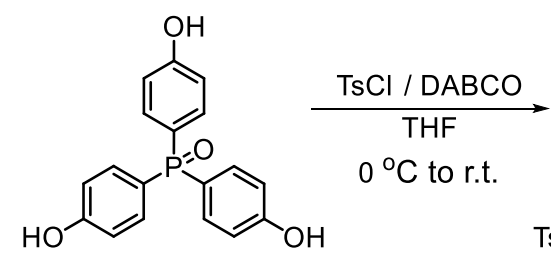

Figure S27. Scheme for the synthesis of OPTTs.

Tris(4-hydroxyphenyl)phosphine oxide (THPO) (4.4g, $13.6 \mathrm{mmol}, 1.0$ equiv) and DABCO (15 g, 135.7 mmol, 10.0 equiv) were dissolved in 50mL THF in a Schlenk flask. Then solution of p-Toluenesulfonyl chloride( $\mathrm{TsCl})(15.5 \mathrm{~g}, 81.4 \mathrm{mmol}, 6.0$ equiv) in THF (50mL) was slowly added at $0{ }^{\circ} \mathrm{C}$ under argon. The reaction mixture was stirred at room temperature for $12 \mathrm{~h}$. The crude was extracted with dichloromethane $(5 \times 150 \mathrm{~mL})$, the combined organic phases were washed with brine $(300 \mathrm{~mL})$, dried over $\mathrm{Na}_{2} \mathrm{SO}_{4}$ and concentrated in vacuo. After that, pure product was obtained from column chromatography using dichloromethane/ methanol as the eluent. The desired product OPTTs (10.3 g, $13.1 \mathrm{mmol}$, 96\%) was obtained as a faint yellow solid. ${ }^{1} \mathrm{H}$ NMR (400 MHz, Chloroform- $d$ ) $\delta 7.74(\mathrm{~d}, J=8.2 \mathrm{~Hz}, 2 \mathrm{H}), 7.55(\mathrm{dd}, J=11.6,8.6 \mathrm{~Hz}$, 2H), $7.36(\mathrm{~d}, J=8.3 \mathrm{~Hz}, 2 \mathrm{H}), 7.14(\mathrm{dd}, J=8.6,2.0 \mathrm{~Hz}, 2 \mathrm{H}), 2.48(\mathrm{~s}, 3 \mathrm{H}) .{ }^{13} \mathrm{C}$ NMR $\left(101 \mathrm{MHz}, \mathrm{CDCl}_{3}\right) \delta 152.64,152.61,146.01,133.79,133.68,132.01,130.87,130.05$, 
129.82, 128.45, 122.91, 122.78, 21.81. ${ }^{31} \mathrm{P}$ NMR $\left(162 \mathrm{MHz}, \mathrm{CDCl}_{3}\right) \delta$ 26.78. HR-MS:

cald for $\mathrm{C}_{39} \mathrm{H}_{33} \mathrm{O}_{10} \mathrm{PS}_{3}[\mathrm{M}+\mathrm{Na}]^{+}$811.0871, found 811.0874.

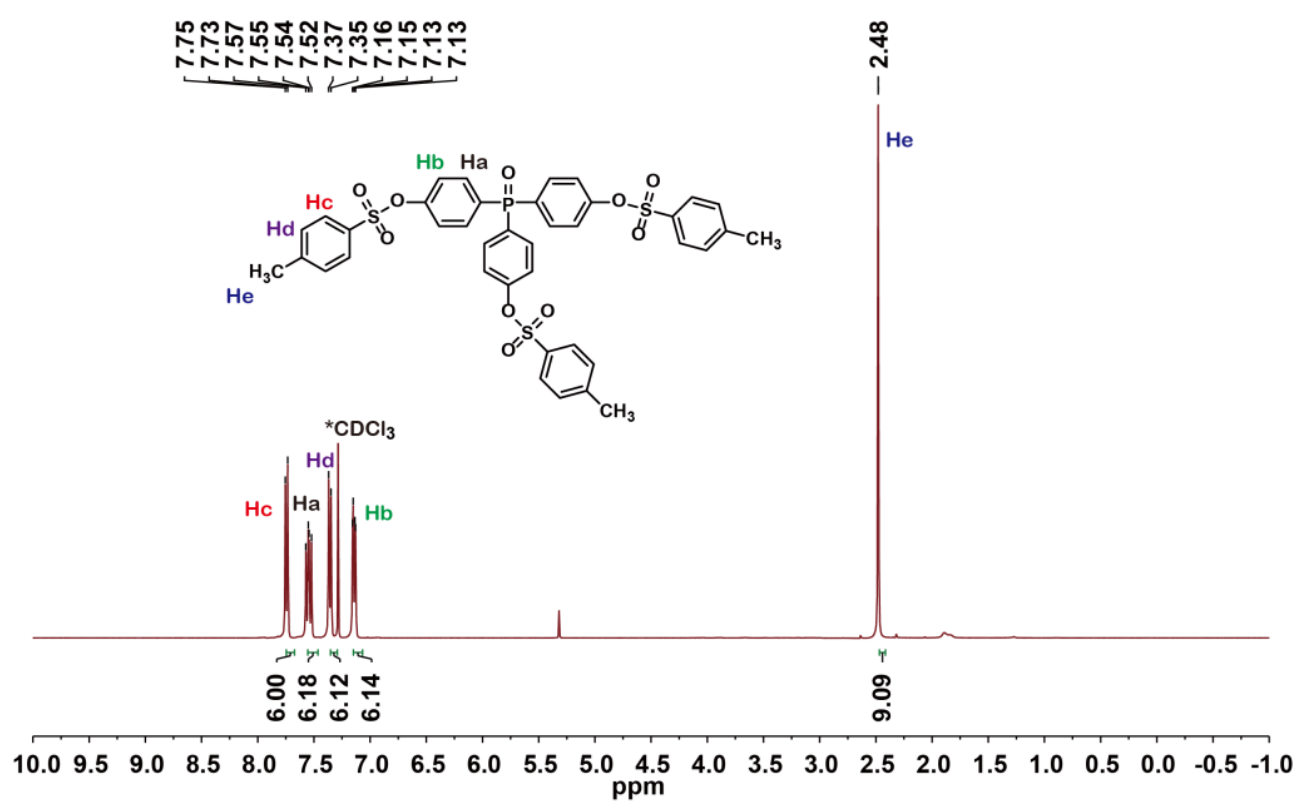

Figure S28. ${ }^{1} \mathrm{H}$ NMR spectrum of compound OPTTs.

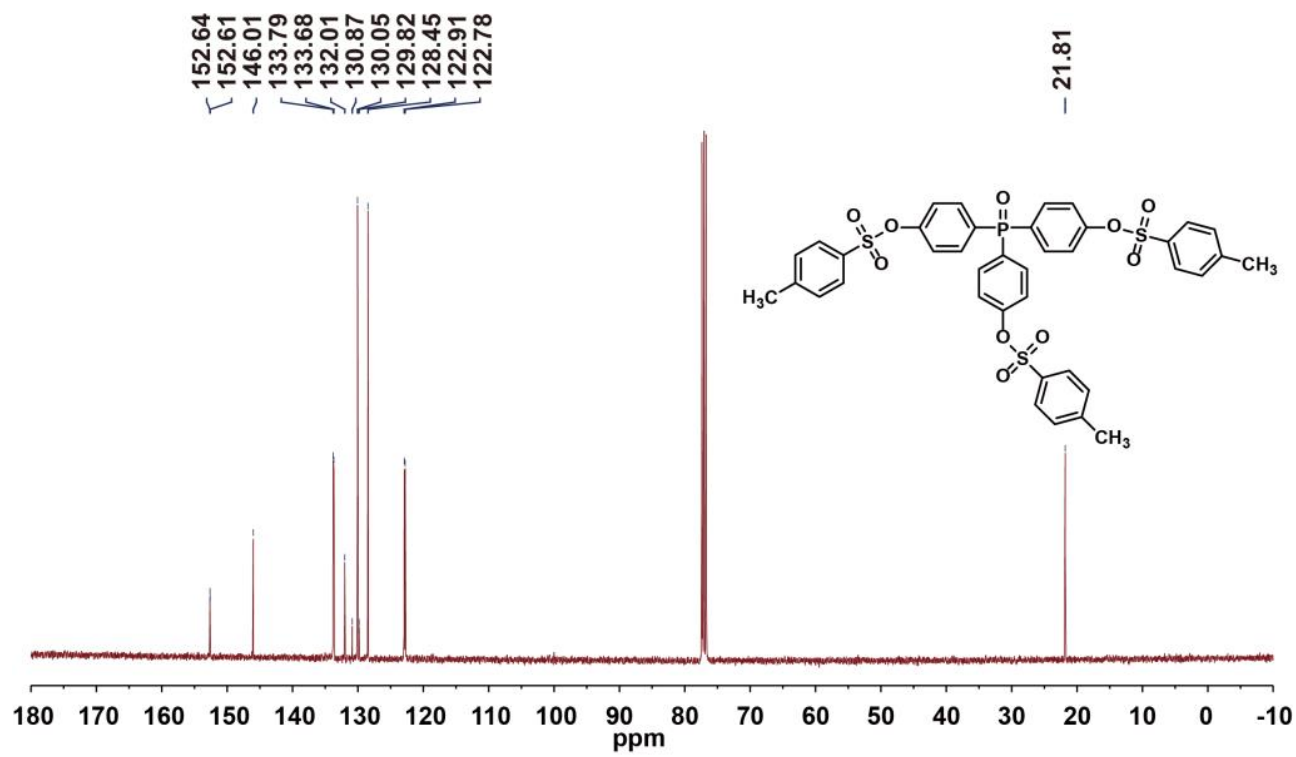

Figure S29. ${ }^{13} \mathrm{C}$ NMR spectrum of compound OPTTs. 


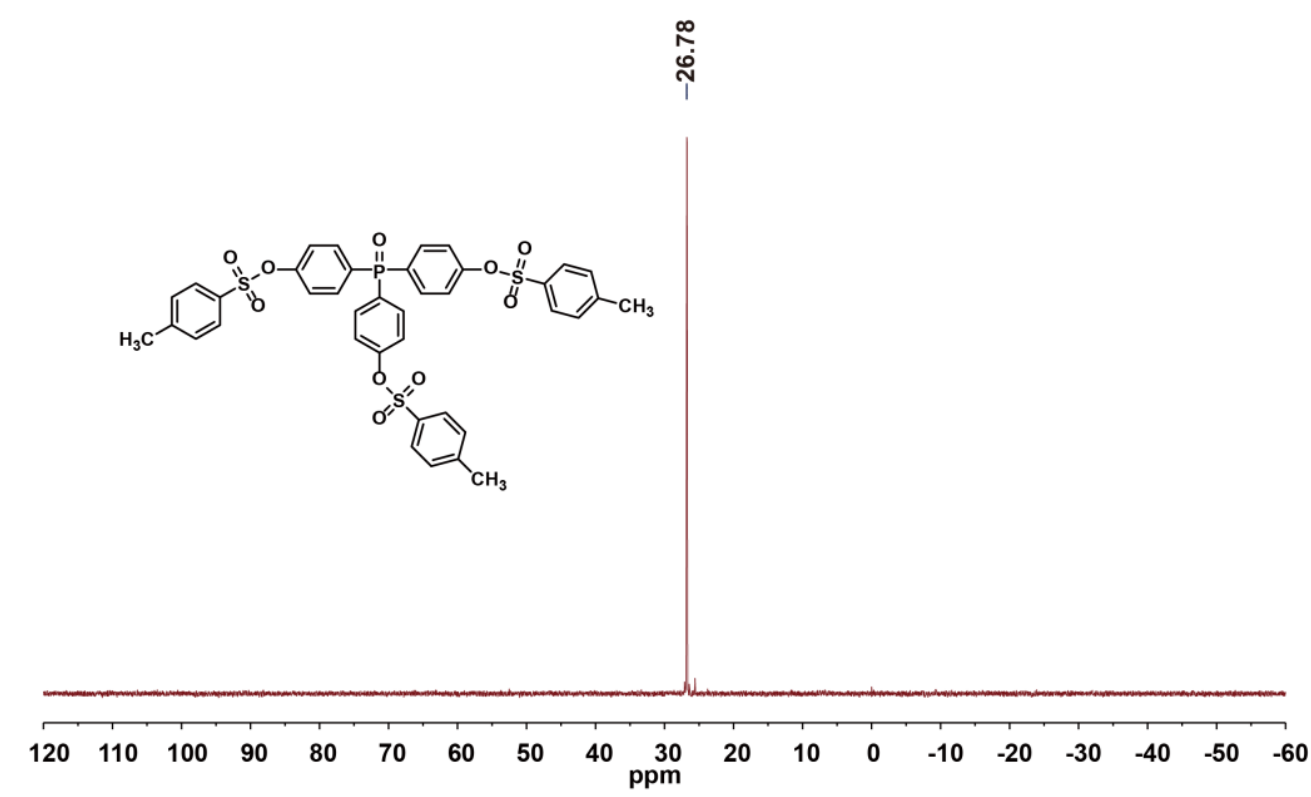

Figure S30. ${ }^{31} \mathrm{P}$ NMR spectrum of compound OPTTs.

\section{Synthesis of trimethyl}

$4^{\prime}, 4^{\prime \prime \prime}, 4^{\prime \prime \prime " '-(o x o-} \lambda^{5}$-phosphanetriyl)tris([1,1'-biphenyl]-4-carboxylate) (TOPTC). (S4)<smiles>CC(=O)c1ccc([Se]O)cc1</smiles>

$\mathrm{H}_{3} \mathrm{COOC}$<smiles>COC(=O)c1ccc(-c2ccc(P(=O)(c3ccc(-c4ccc(C(C)=O)cc4)cc3)c3ccc(-c4ccc(C(=O)OC)cc4)cc3)cc2)cc1</smiles>

TOPTC

Figure S31. Scheme for the synthesis of TOPTC.

(oxo- $\lambda^{5}$-phosphanetriyl)tris(benzene-4,1-diyl) tris(4-methylbenzene-sulfonate)

(OPTTs) (5.0 g, $6.3 \mathrm{mmol}, 1.0$ equiv), 4-methoxycarbonylphenylboronic acid (5.7 g, 31.5mmol, 5.0 equiv), $\mathrm{Pd}(\mathrm{OAc})_{2}(0.28 \mathrm{~g}, 1.3 \mathrm{mmol}, 0.2$ equiv), $\mathrm{Xphos}$ (1.5 g, 3.2 mmol, 0.5 equiv), $\mathrm{K}_{3} \mathrm{PO}_{4}(12.0 \mathrm{~g}, 56.7 \mathrm{mmol}, 9.0$ equiv) were added to a Schlenk flask. The flask was then capped with a rubber septum, evacuated and backfilled with argon three times. Under an inert atmosphere, THF $(65 \mathrm{~mL})$ was added via syringe. The reaction mixture was stirred at $80{ }^{\circ} \mathrm{C}$ for $14 \mathrm{~h}$. When the reaction was completed, the crude was extracted with dichloromethane $(3 \times 150 \mathrm{~mL})$, the combined organic phases were washed with brine $(300 \mathrm{~mL})$, dried over $\mathrm{Na}_{2} \mathrm{SO}_{4}$ and concentrated in vacuo. After that, pure product was obtained from column chromatography using 
dichloromethane/ methanol as the eluent. The desired product TOPTC (4.1 g, 6.1 mmol, 97\%) was obtained as a faint yellow solid. ${ }^{1} \mathrm{H}$ NMR $\left(400 \mathrm{MHz}, \mathrm{CDCl}_{3}\right) \delta 8.19$ $-8.13(\mathrm{~m}, 2 \mathrm{H}), 7.87(\mathrm{dd}, J=11.6,8.1 \mathrm{~Hz}, 2 \mathrm{H}), 7.78(\mathrm{dd}, J=8.3,2.6 \mathrm{~Hz}, 2 \mathrm{H}), 7.71(\mathrm{~d}$, $J=8.3 \mathrm{~Hz}, 2 \mathrm{H}), 3.97(\mathrm{~s}, 3 \mathrm{H}) .{ }^{13} \mathrm{C} \mathrm{NMR}\left(101 \mathrm{MHz}, \mathrm{CDCl}_{3}\right) \delta 166.78,144.16,143.76$, $132.79,132.69,132.42,131.37,130.30,129.82,127.59,127.46,127.29,52.30 .{ }^{31} \mathrm{P}$ $\mathrm{NMR}\left(162 \mathrm{MHz}, \mathrm{CDCl}_{3}\right) \delta 28.25$.

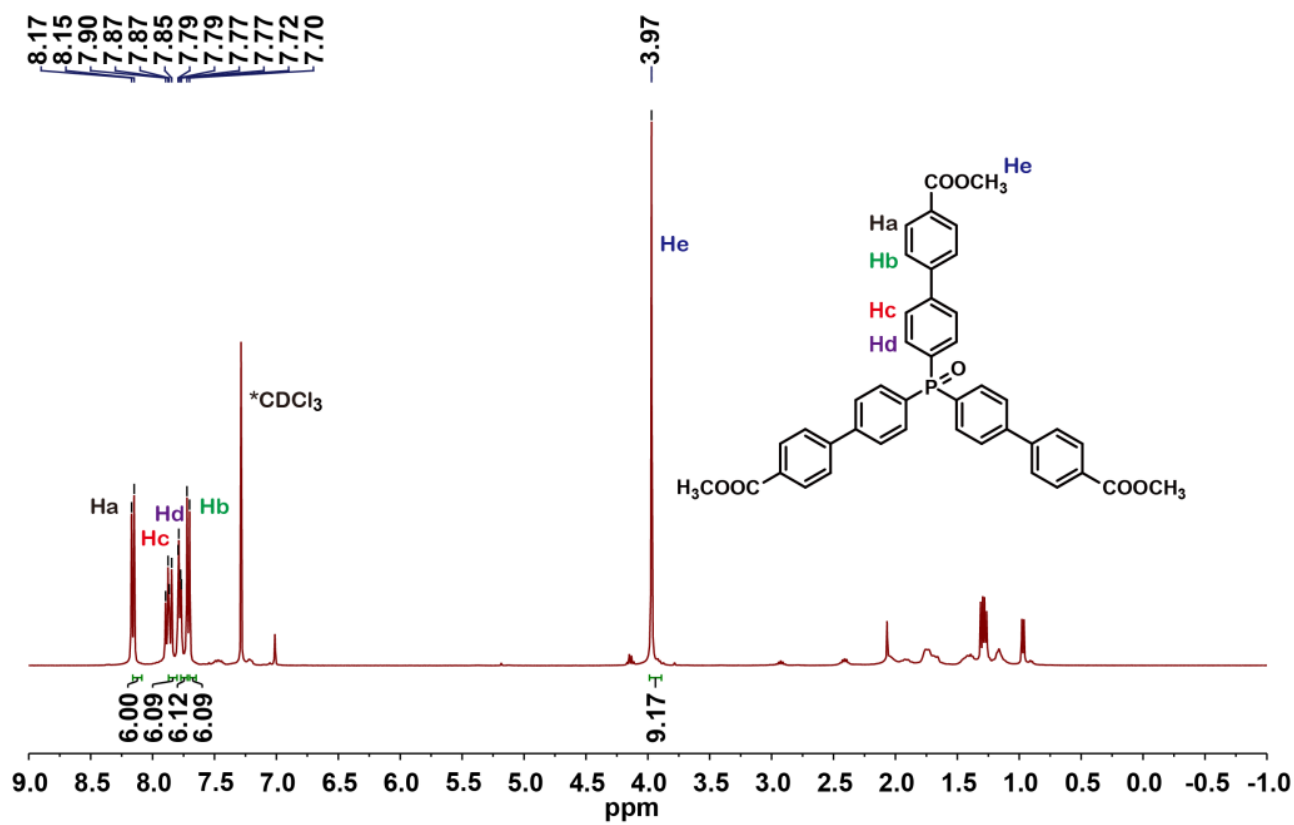

Figure S32. ${ }^{1} \mathrm{H}$ NMR spectrum of compound TOPTC.

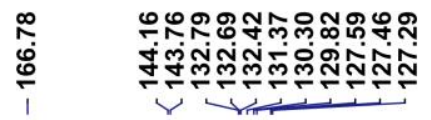

\section{กิ}

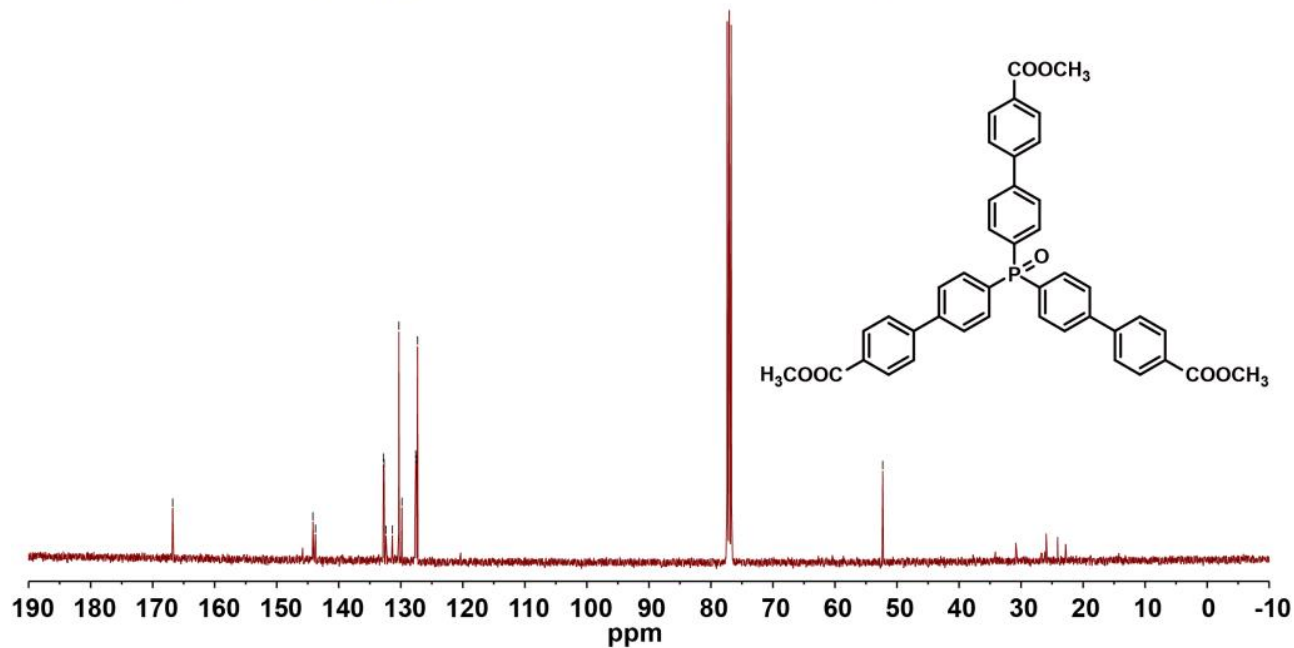

Figure S33. ${ }^{13} \mathrm{C}$ NMR spectrum of compound TOPTC. 


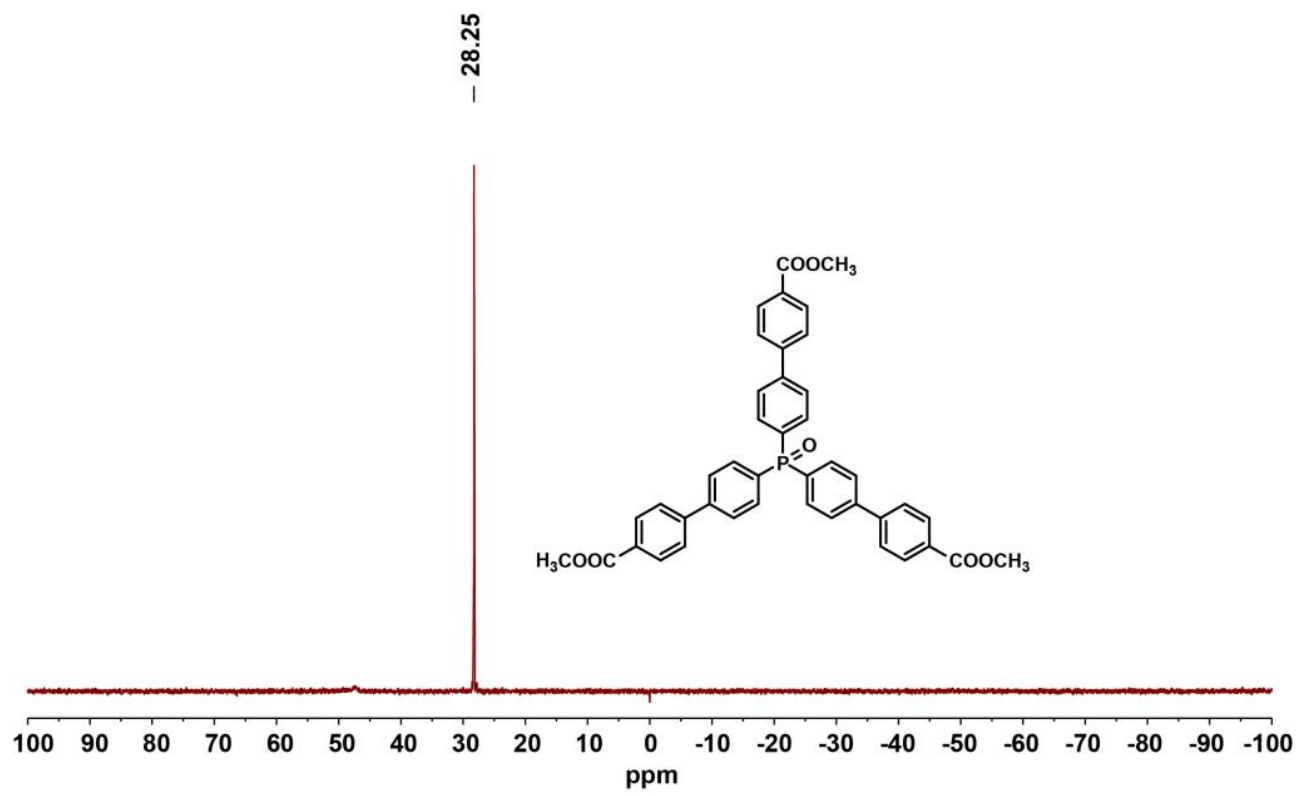

Figure S34. ${ }^{31} \mathrm{P}$ NMR spectrum of compound TOPTC.

Synthesis of trimethyl

4',4'"',4'"'"'-phosphanetriyltris([1,1'-biphenyl]-4-carboxylate) (Me3PBCA). (S5)
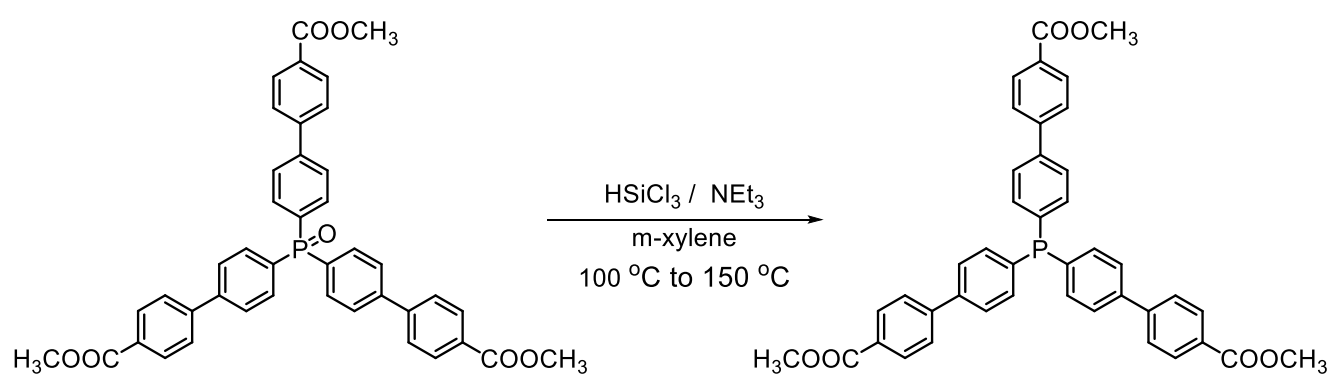

$\mathrm{Me}_{3} \mathrm{PBCA}$

Figure S35. Scheme for the synthesis of $\mathrm{Me}_{3} \mathrm{PBCA}$.

Trimethyl 4',4"',4,',',-(oxo- $\lambda^{5}$-phosphanetriyl)tris([1,1'-biphenyl]-4-carboxylate) (TOPTC) (0.68 g, $1.0 \mathrm{mmol}, 1.0$ equiv) was charged into a reaction vessel and dissolved in anhydrous m-xylene (15 mL). $\mathrm{NEt}_{3}(757 \mu \mathrm{L}, 5.4 \mathrm{mmol}, 5.4$ equiv) and trichlorosilane ( $650 \mu \mathrm{L}, 6.0 \mathrm{mmol}, 6.0$ equiv) were added, and the reaction was sealed and heated at $100^{\circ} \mathrm{C}$ for $3 \mathrm{~h}$, then heated at $150^{\circ} \mathrm{C}$ for $12 \mathrm{~h}$. The mixture was cooled to room temperature, and water and $1 \mathrm{M} \mathrm{NaOH}$ (aq.) were added. The mixture was stirred for $1 \mathrm{~h}$, then the crude was extracted with dichloromethane $(3 \times 150 \mathrm{~mL})$, the combined organic phases were washed with water $(300 \mathrm{~mL})$ and brine $(300 \mathrm{~mL})$, dried over $\mathrm{Na}_{2} \mathrm{SO}_{4}$ and concentrated in vacuo. After that, pure product was obtained from column chromatography using dichloromethane as the eluent. The desired product $\mathrm{Me}_{3}$ PBCA (408.1mg, $0.62 \mathrm{mmol}, 62 \%$ ) was obtained as a white solid. ${ }^{1} \mathrm{H}$ NMR (400 
$\left.\mathrm{MHz}, \mathrm{CDCl}_{3}\right) \delta 8.11(\mathrm{~d}, J=8.4 \mathrm{~Hz}, 6 \mathrm{H}), 7.74-7.60(\mathrm{~m}, 12 \mathrm{H}), 7.48(\mathrm{t}, J=7.8 \mathrm{~Hz}$, 6H), $3.94(\mathrm{~s}, 9 \mathrm{H}) .{ }^{13} \mathrm{C}$ NMR $\left(101 \mathrm{MHz}, \mathrm{CDCl}_{3}\right) \delta 166.94,144.81,140.52,136.93$, $136.82,134.44,134.24,130.22,129.23,127.52,127.45,127.02,52.23 .{ }^{31} \mathrm{P}$ NMR $(162$ $\left.\mathrm{MHz}, \mathrm{CDCl}_{3}\right) \delta-7.36$.

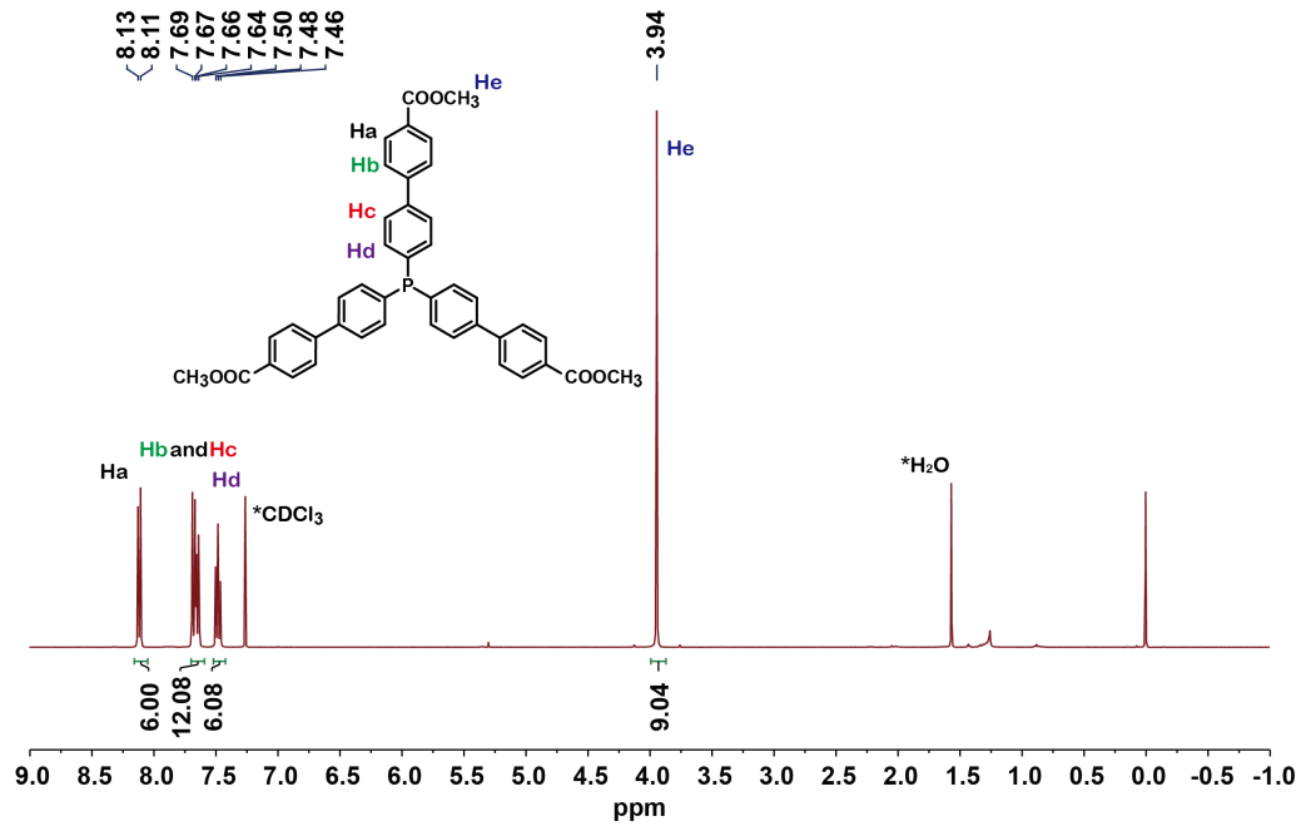

Figure S36. ${ }^{1} \mathrm{H}$ NMR spectrum of compound $\mathrm{Me}_{3}$ PBCA.

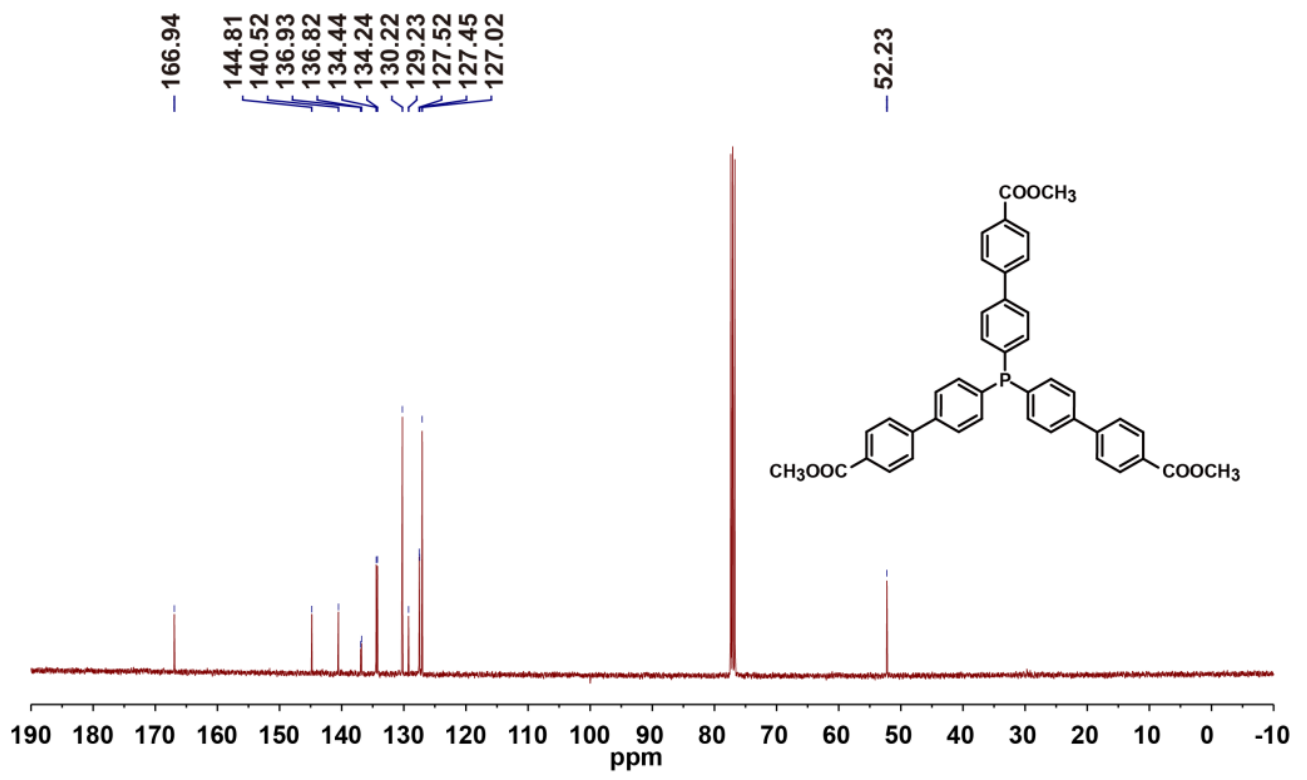

Figure S37. ${ }^{13} \mathrm{C}$ NMR spectrum of compound $\mathrm{Me}_{3}$ PBCA. 


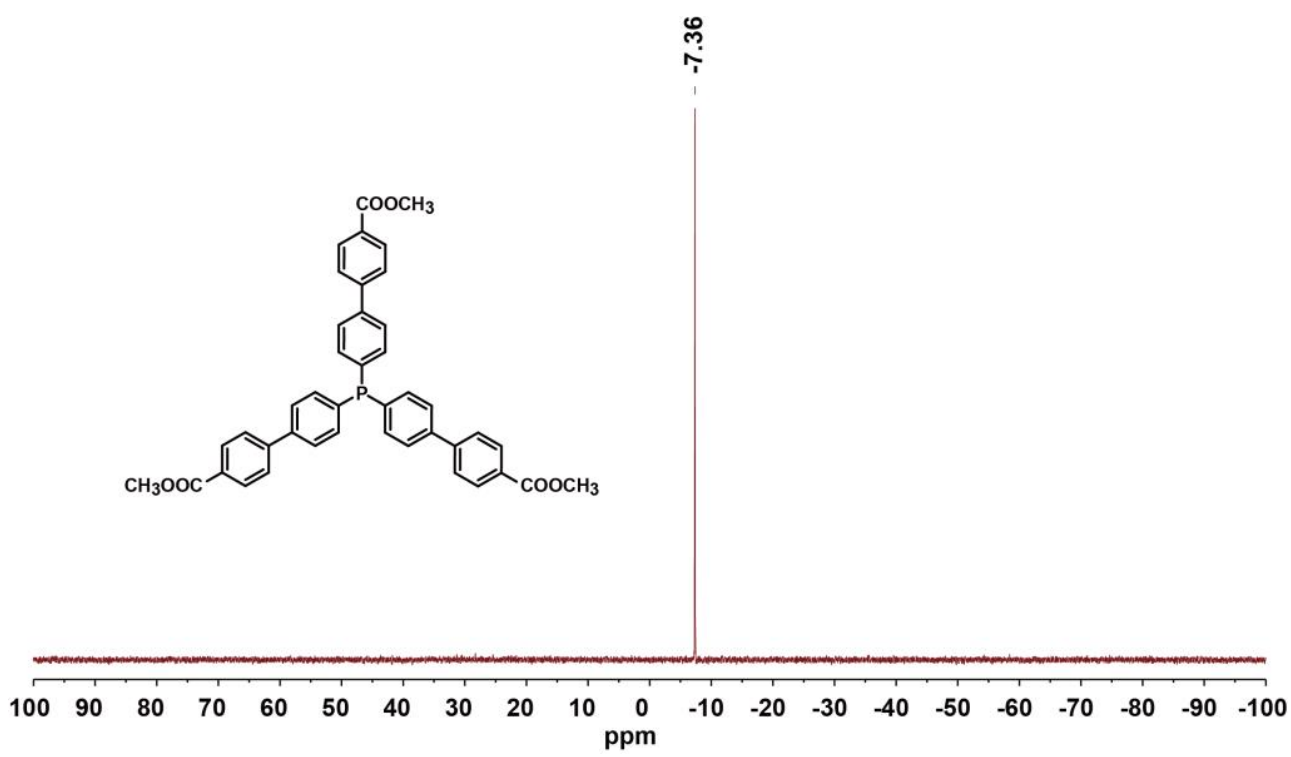

Figure S38. ${ }^{31} \mathrm{P}$ NMR spectrum of compound $\mathrm{Me}_{3}$ PBCA.

Synthesis of 4',4'",4'"'"-phosphanetriyltris(([1,1'-biphenyl]-4-carboxylic acid)) (PBCA).

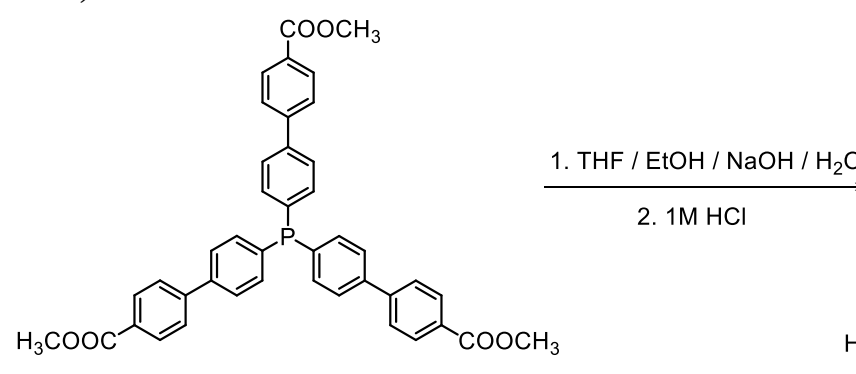

Figure S39. Scheme for the synthesis of OPBCA.

Trimethyl 4',4"',4"''-phosphanetriyltris([1,1'-biphenyl]-4-carboxylate) $\mathrm{mL}), \mathrm{EtOH}(10 \mathrm{~mL})$, and $6 \mathrm{M} \mathrm{NaOH}$ (aq.) $(10 \mathrm{~mL})$. After the mixture was stirred at $50{ }^{\circ} \mathrm{C}$ for $12 \mathrm{~h}, 1 \mathrm{M} \mathrm{HCl}$ (aq.) was slowly added at $0{ }^{\circ} \mathrm{C}$, then the solid was washed with water, $\mathrm{MeOH}$, and hexanes, the desired product PBCA (572 mg, $0.919 \mathrm{mmol}$, 92\%) was obtained as a white solid). ${ }^{1} \mathrm{H}$ NMR (400 MHz, DMSO- $\left.d_{6}\right) \delta 13.05$ (s, 3H), $8.04(\mathrm{~d}, J=8.3 \mathrm{~Hz}, 6 \mathrm{H}), 7.84(\mathrm{~d}, J=8.4 \mathrm{~Hz}, 12 \mathrm{H}), 7.46(\mathrm{t}, J=7.7 \mathrm{~Hz}, 6 \mathrm{H}) .{ }^{13} \mathrm{C} \mathrm{NMR}$ $\left(101 \mathrm{MHz}, \mathrm{DMSO}-d_{6}\right) \delta 167.54,143.92,140.12,136.80,134.61,134.41,130.49$, 130.41, 127.96, 127.88, 127.73, 127.37. ${ }^{31} \mathrm{P}$ NMR (162 MHz, DMSO- $\left.d_{6}\right) \delta-8.52$. 


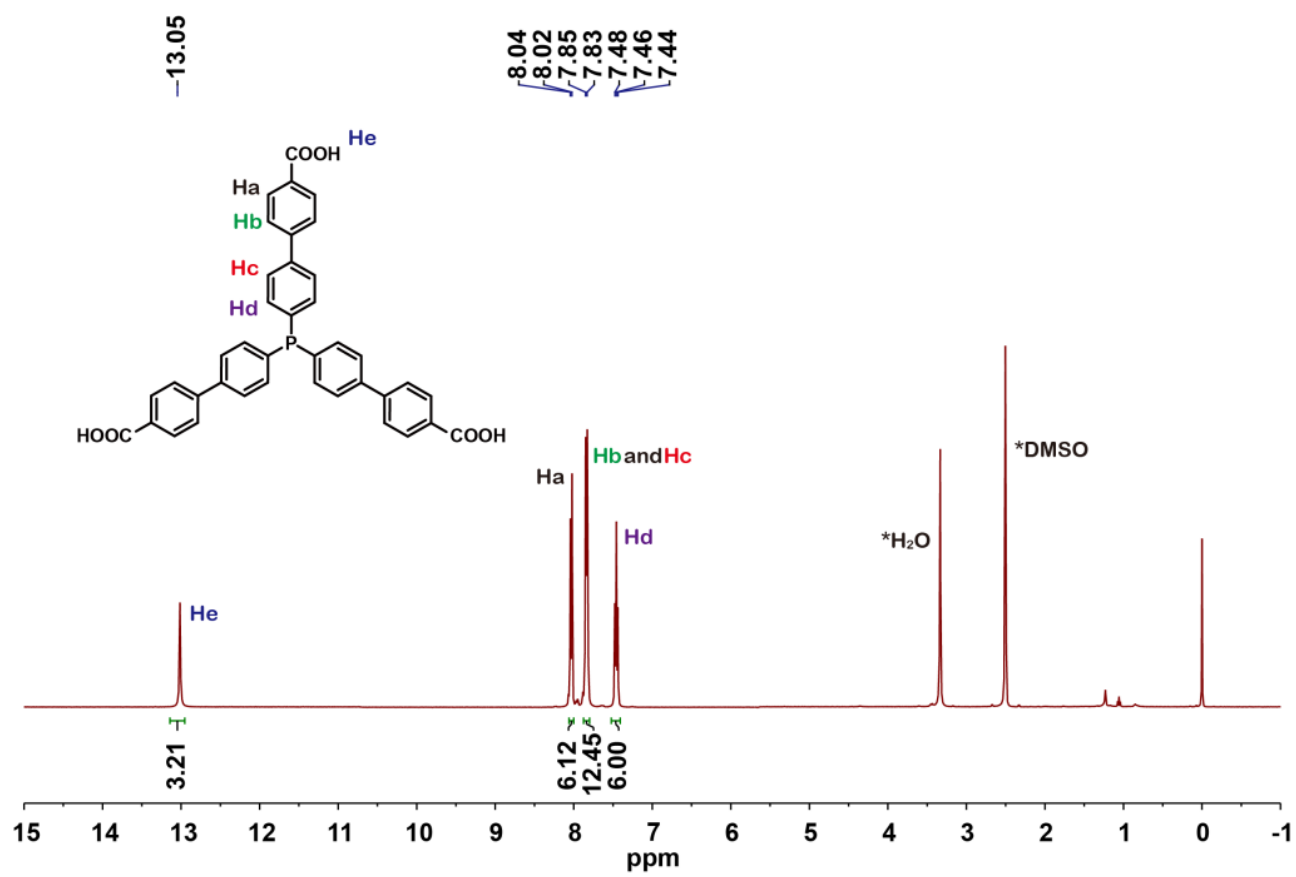

Figure S40. ${ }^{1} \mathrm{H}$ NMR spectrum of compound PBCA.
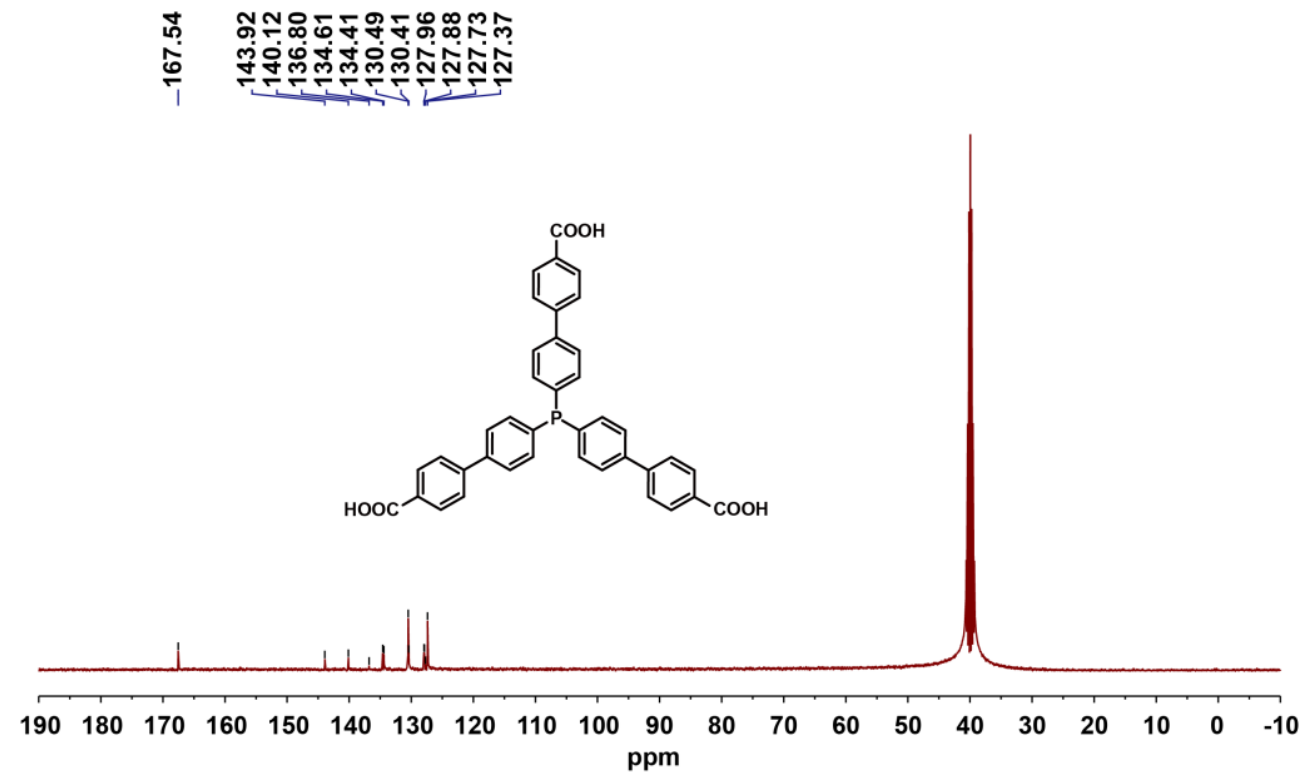

Figure S41. ${ }^{13} \mathrm{C}$ NMR spectrum of compound PBCA. 


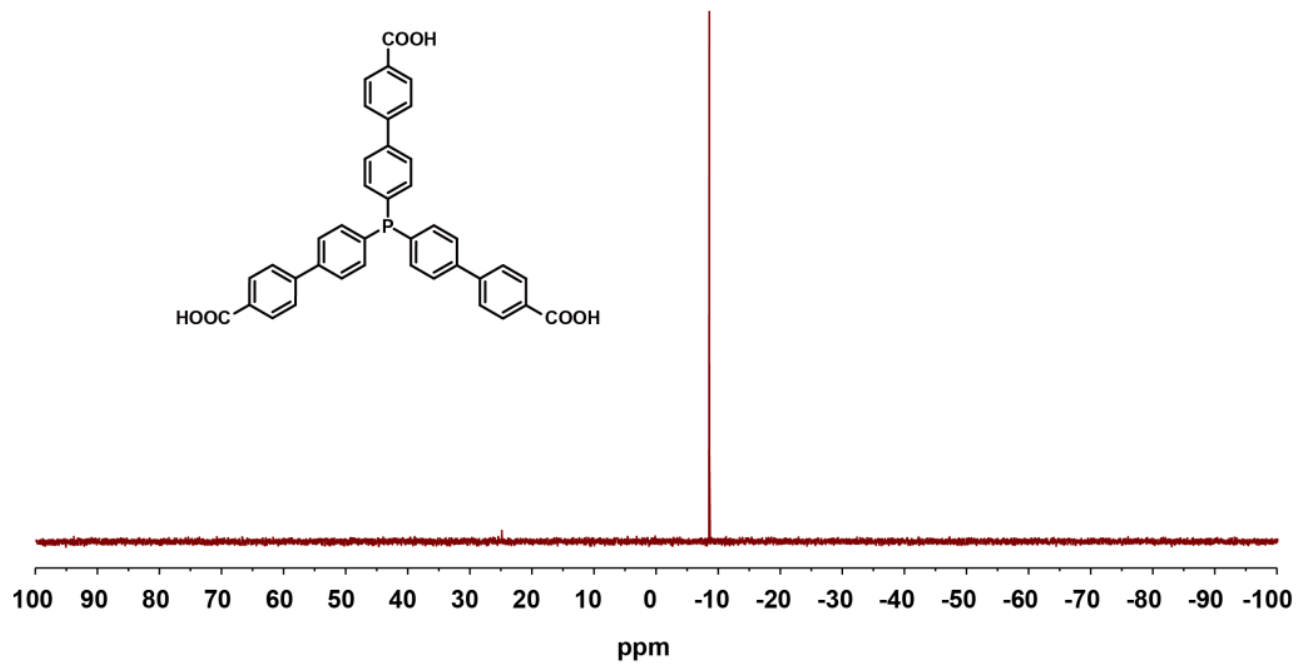

Figure S42. ${ }^{31} \mathrm{P}$ NMR spectrum of compound PBCA.

Synthesis of 4',4'",4'"'"'-(oxo-l5-phosphanetriyl)tris(([1,1'-biphenyl]-4-carboxylic acid)) (OPBCA).

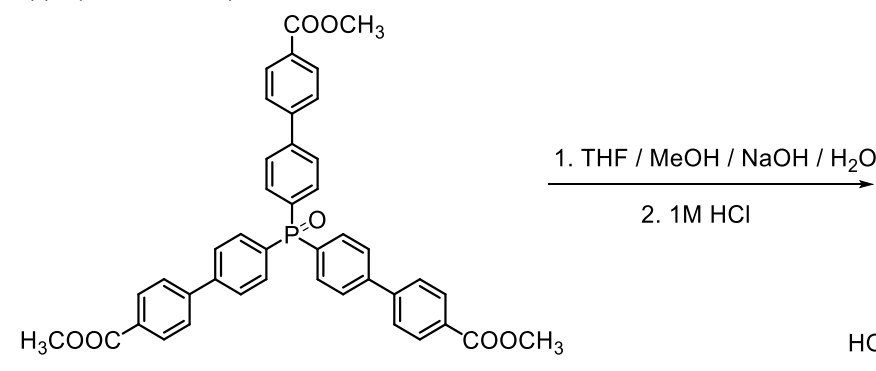

Figure S43. Scheme for the synthesis of OPBCA.

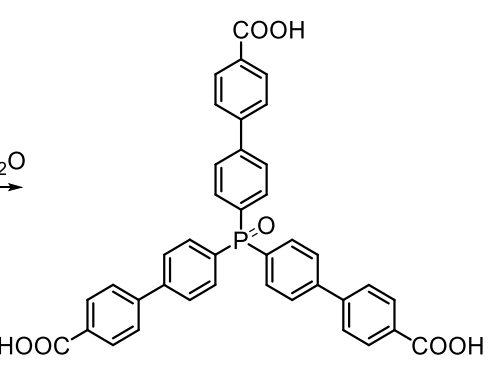

OPBCA

4',4"',4"'"'-(oxo- $\lambda^{5}$-phosphanetriyl)tris([1,1'-biphenyl]-4-carboxylate) (TOPTC) (680.1 mg, $1.0 \mathrm{mmol}, 1.0$ equiv) was dissolved in a mixture of THF (5 mL), $\mathrm{MeOH}$ $(10 \mathrm{~mL})$, and $6 \mathrm{M} \mathrm{NaOH}$ (aq.) $(10 \mathrm{~mL})$. After the mixture was stirred at $85{ }^{\circ} \mathrm{C}$ for 24 $\mathrm{h}$, solvent was removed by rotary evaporation. The white solid was dissolved in water and acidified with $1 \mathrm{M} \mathrm{HCl}$. A white precipitate, which was filtered, washed with water, and dried in an oven at $80{ }^{\circ} \mathrm{C}$ for $10 \mathrm{~h}$. After that, pure product OPBCA $(612.5$ mg, 0.96 mmol, 96\%) was obtained. ${ }^{1} \mathrm{H}$ NMR (400 MHz, DMSO-d6) $\delta 13.08$ (s, 2H), $8.07(\mathrm{~d}, J=8.4 \mathrm{~Hz}, 7 \mathrm{H}), 7.96(\mathrm{dd}, J=8.4,2.4 \mathrm{~Hz}, 6 \mathrm{H}), 7.90-7.79(\mathrm{~m}, 9 \mathrm{H}) .{ }^{13} \mathrm{C} \mathrm{NMR}$ $\left(101 \mathrm{MHz}, \mathrm{DMSO}-d_{6}\right) \delta 167.49,143.47,143.05,143.02,133.11,132.85,132.74$, 
132.08, 130.92, 130.53, 127.98, 127.86, 127.72. ${ }^{31} \mathrm{P}$ NMR (162 MHz, DMSO) $\delta$ 25.15 .
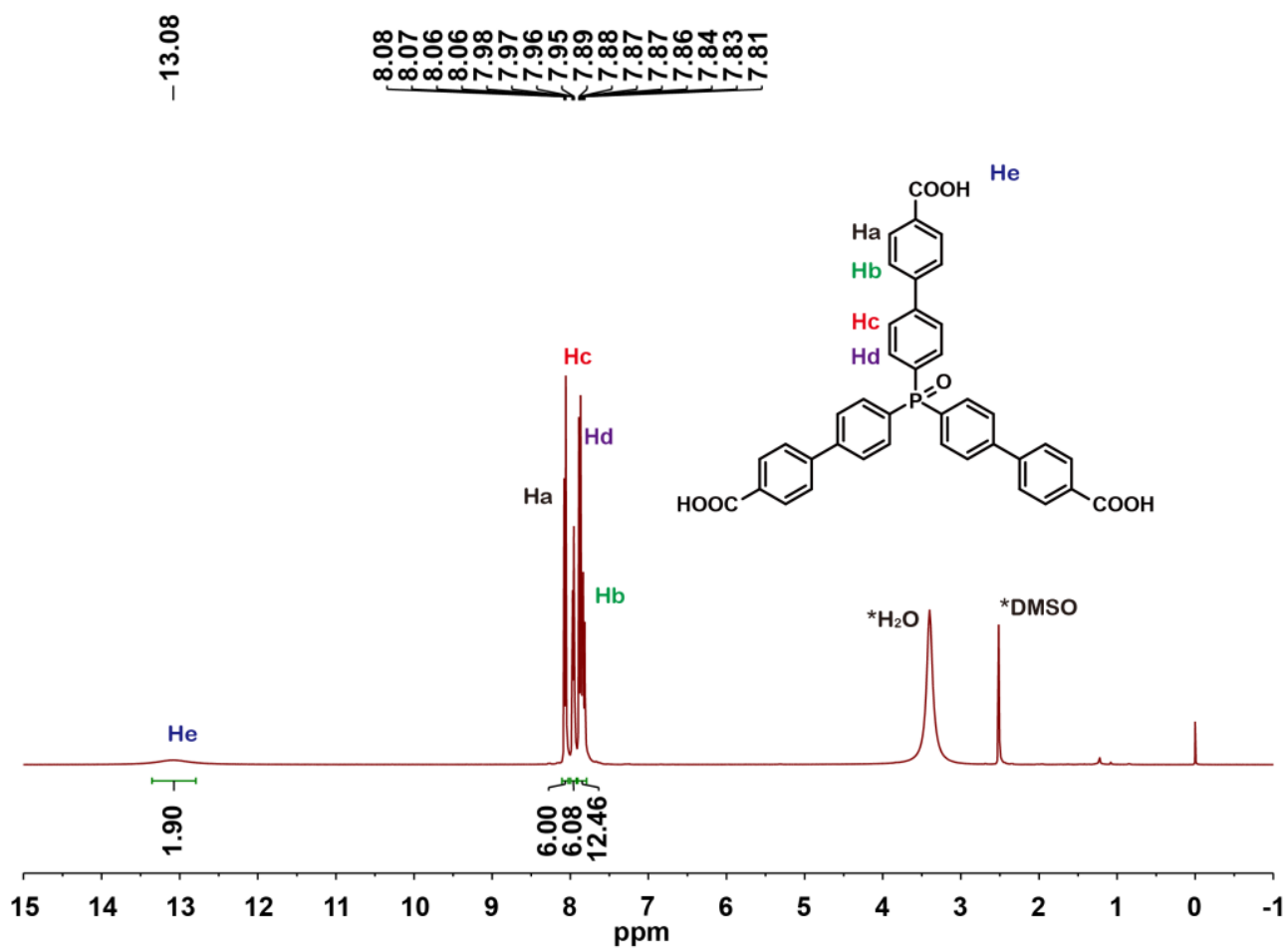

Figure S44. ${ }^{1} \mathrm{H}$ NMR spectrum of compound OPBCA.

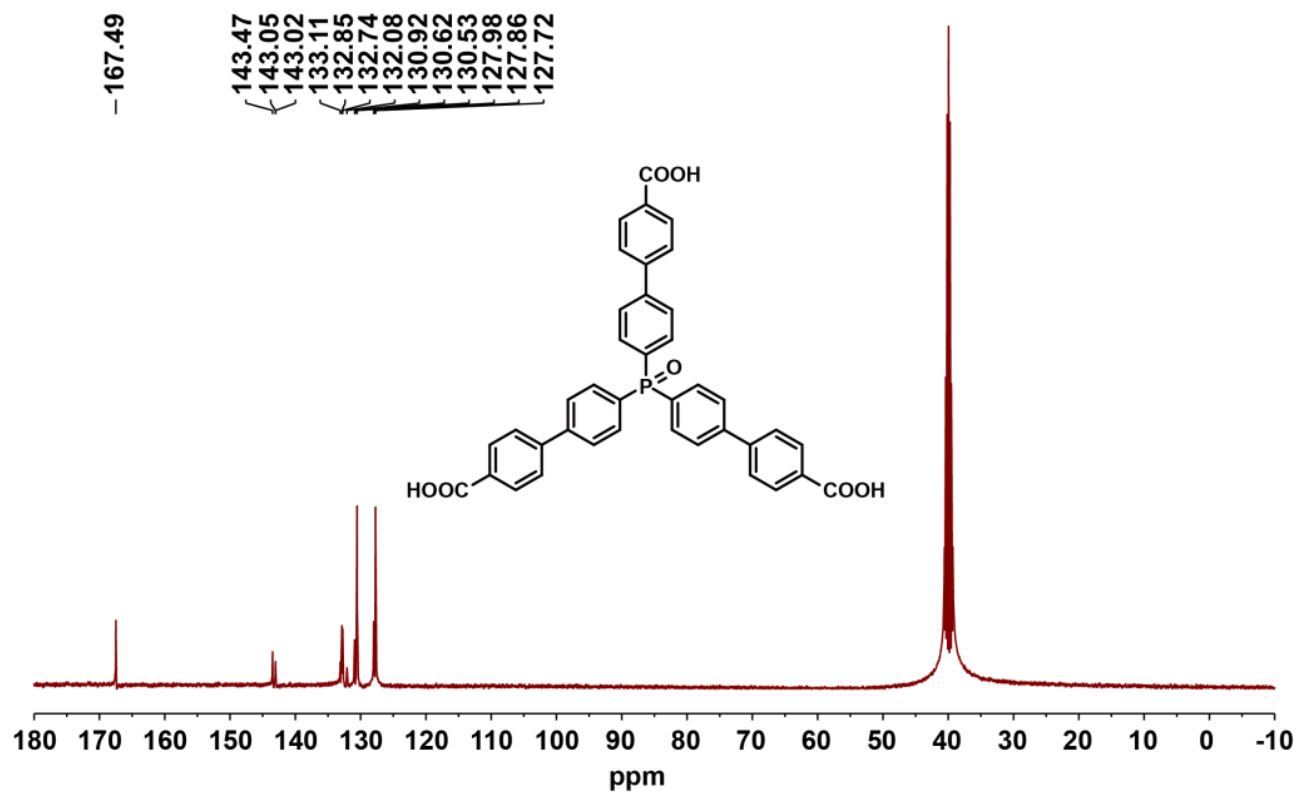

Figure S45. ${ }^{13} \mathrm{C}$ NMR spectrum of compound OPBCA. 


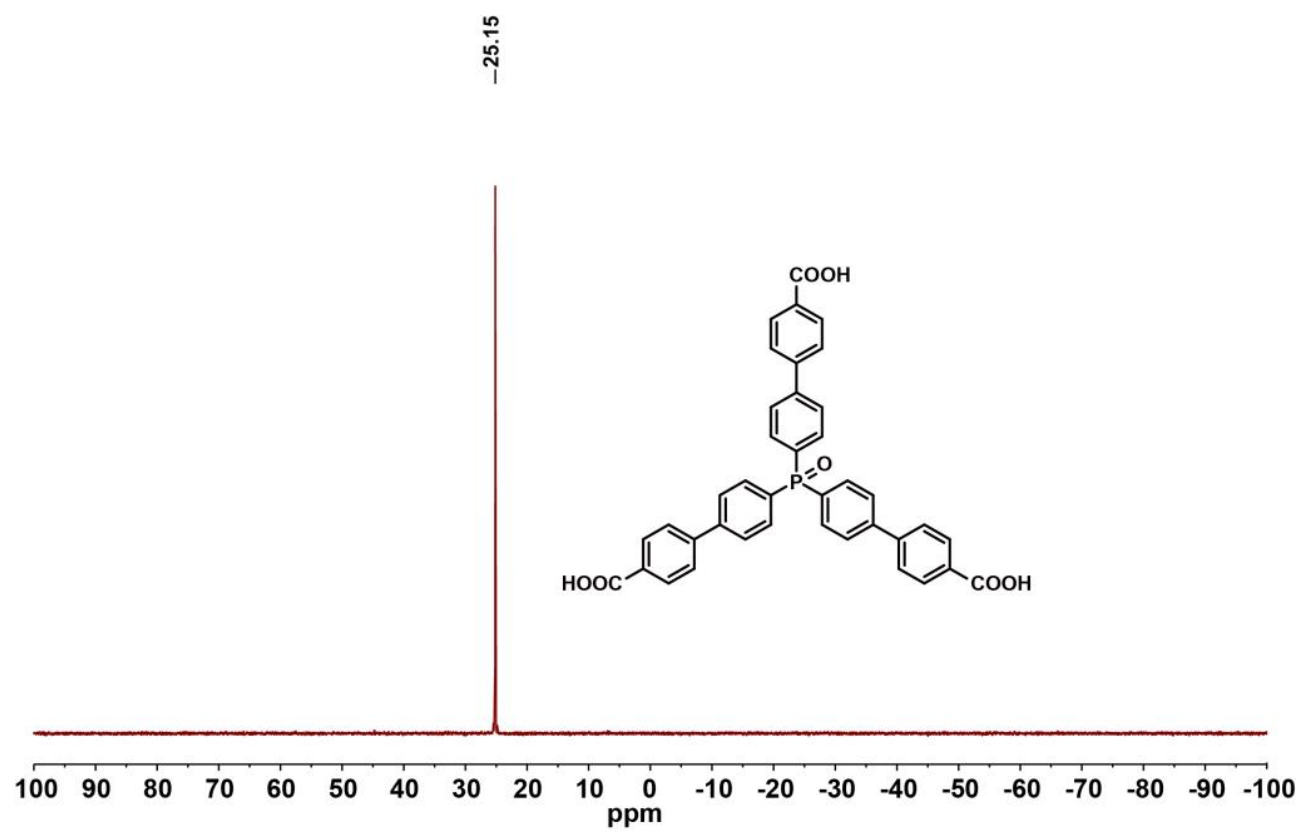

Figure S46. ${ }^{31} \mathrm{P}$ NMR spectrum of compound OPBCA.

\section{Section S3. Synthesis and activation of MV-MOFs}

\section{S2.1 Synthesis of MV-MOFs}

The synthesis of MV-MOFs was achieved by mixing tri-topic linker, TBPA, and tetra-topic linker, MTBC, while different mono-topic linkers were added in to give the corresponding MV-MOFs with specific functional groups. The crystallinity and purity of these MOFs were confirmed by powder X-ray diffraction (PXRD) and single crystal X-ray diffraction (SC-XRD) techniques. PXRD patterns were measured on a Rigaku Smartlab 9KW diffractometer operated at $45 \mathrm{kV}, 200 \mathrm{~mA}$ using $\mathrm{Cu} \mathrm{K} \alpha(\lambda=$ $1.5406 \AA$ ) with a scan speed of $4^{\circ} / \mathrm{min}$ and a step size of $0.01^{\circ}$ in $2 \theta$ at ambient temperature and pressure. Simulated PXRD patterns were calculated using software Material Studio 8.0 using the corresponding single crystal data.

\section{Synthesis of PCN-521}

$\mathrm{ZrCl}_{4}(2.4 \mathrm{mg})$, MTBC $(2.0 \mathrm{mg})$, benzoic acid $(70 \mathrm{mg})$ in $0.34 \mathrm{~mL}$ of DEF were ultrasonically dissolved in a $4 \mathrm{~mL}$ Pyrex vial. The mixture was heated in a $120{ }^{\circ} \mathrm{C}$ oven for $24 \mathrm{~h}$. After cooling down to room temperature, clear rhombic crystals after were yielded (see Figure S51). 


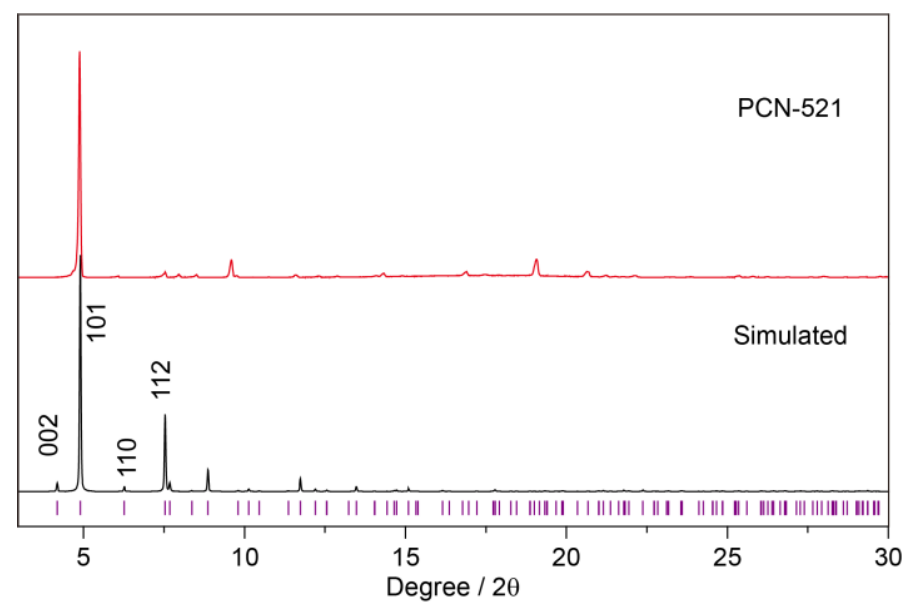

Figure S47. Comparison of the experimental PXRD pattern of as-synthesized PCN-521 with the simulated PCN-521 diffraction pattern based on its single crystal data.

\section{Synthesis of (N)-MV-PCN-521-BA}

$\mathrm{ZrCl}_{4}(2.4 \mathrm{mg}), \mathrm{MTBC}(2.0 \mathrm{mg}), \mathrm{TBPA}(3.0 \mathrm{mg})$ benzoic acid $(70 \mathrm{mg})$ in $0.34 \mathrm{~mL}$ of DEF were ultrasonically dissolved in a $4 \mathrm{~mL}$ Pyrex vial. The mixture was heated in a $120{ }^{\circ} \mathrm{C}$ oven for $24 \mathrm{~h}$. After cooling down to room temperature, clear rhombic crystals after were yielded (see Figure S51). A larger amount of (N)-MV-PCN-521-BA samples were obtained by the same solvothermal condition with benzoic acid in a $20 \mathrm{~mL}$ Pyrex vial.

\section{Synthesis of N-MV-PCN-521-NBA}

$\mathrm{ZrCl}_{4}(24 \mathrm{mg}), \mathrm{MTBC}(20 \mathrm{mg}), \mathrm{TBPA}(30 \mathrm{mg})$ nitrobenzoic acid $(330 \mathrm{mg})$ in 3.4 $\mathrm{mL}$ of DEF were ultrasonically dissolved in a $20 \mathrm{~mL}$ Pyrex vial. The mixture was heated in a $120{ }^{\circ} \mathrm{C}$ oven for $24 \mathrm{~h}$. After cooling down to room temperature, faint yellow powder were yielded.

\section{Synthesis of N-MV-PCN-521-TFA}

$\mathrm{ZrCl}_{4}(24 \mathrm{mg}), \mathrm{MTBC}(20 \mathrm{mg}), \mathrm{TBPA}(30 \mathrm{mg})$ nitrobenzoic acid $(330 \mathrm{mg})$ in 3.4 $\mathrm{mL}$ of DEF were ultrasonically dissolved in a $20 \mathrm{~mL}$ Pyrex vial. The mixture was heated in a $120{ }^{\circ} \mathrm{C}$ oven for $24 \mathrm{~h}$. After cooling down to room temperature, faint yellow powder were yielded. 


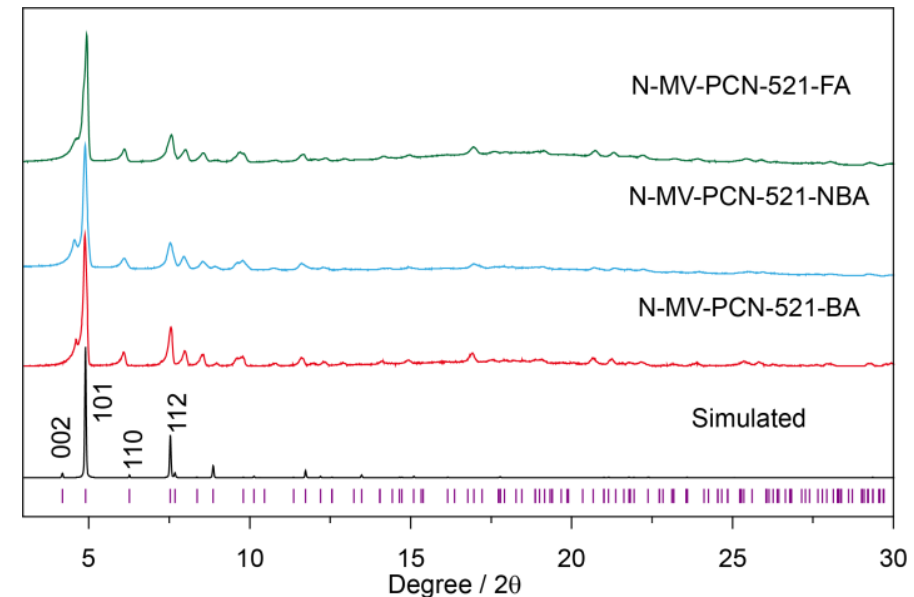

Figure S48. Comparison of the experimental PXRD patterns of as-synthesized N-MV-PCN-521 with the simulated PCN-521 diffraction pattern based on its single crystal data.

\section{Synthesis of P-MV-PCN-521-BA}

$\mathrm{ZrCl}_{4}(2.4 \mathrm{mg}), \mathrm{MTBC}(2.0 \mathrm{mg}), \mathrm{TBPA}(3.0 \mathrm{mg})$ benzoic acid $(70 \mathrm{mg})$ in $0.34 \mathrm{~mL}$ of DEF were ultrasonically dissolved in a $4 \mathrm{~mL}$ Pyrex vial. The vial was evacuated and backfilled with argon three times. Under an inert atmosphere, the mixture was heated in a $120{ }^{\circ} \mathrm{C}$ oven for $24 \mathrm{~h}$. After cooling down to room temperature, clear rhombic crystals after were yielded (see Figure S51). A larger amount of PCN-521 samples were obtained by the same solvothermal condition with benzoic acid

\section{Synthesis of P-MV-PCN-521-NBA}

$\mathrm{ZrCl}_{4}(24 \mathrm{mg})$, MTBC $(20 \mathrm{mg}), \mathrm{TBPA}(30 \mathrm{mg})$ nitrobenzoic acid $(330 \mathrm{mg})$ in 3.4 $\mathrm{mL}$ of DEF were ultrasonically dissolved in a $20 \mathrm{~mL}$ Pyrex vial. The vial was evacuated and backfilled with argon three times. Under an inert atmosphere, the mixture was heated in a $120{ }^{\circ} \mathrm{C}$ oven for $24 \mathrm{~h}$. After cooling down to room temperature, faint yellow powder were yielded.

\section{Synthesis of P-MV-PCN-521-TFA}

$\mathrm{ZrCl}_{4}(24 \mathrm{mg}), \mathrm{MTBC}(20 \mathrm{mg}), \mathrm{TBPA}(30 \mathrm{mg})$ nitrobenzoic acid $(330 \mathrm{mg})$ in 3.4 $\mathrm{mL}$ of DEF were ultrasonically dissolved in a $20 \mathrm{~mL}$ Pyrex vial. The vial was evacuated and backfilled with argon three times. Under an inert atmosphere, the mixture was heated in a $120{ }^{\circ} \mathrm{C}$ oven for $24 \mathrm{~h}$. After cooling down to room temperature, faint yellow powder were yielded. 


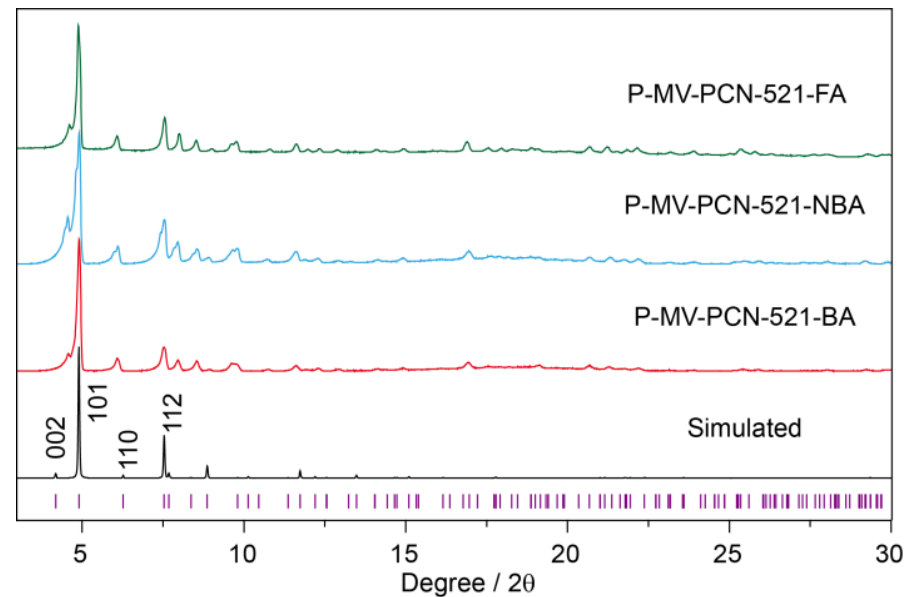

Figure S49. Comparison of the experimental PXRD patterns of as-synthesized P-MV-PCN-521 with the simulated PCN-521 diffraction pattern based on its single crystal data.

\section{Synthesis of P-MV-PCN-521-PTA}

$\mathrm{ZrCl}_{4}(24 \mathrm{mg}), \mathrm{MTBC}(20 \mathrm{mg}), \mathrm{PBCA}(30 \mathrm{mg}), \mathrm{p}$-toluic acid $(770 \mathrm{mg})$ in $3.4 \mathrm{~mL}$ of DEF were ultrasonically dissolved in a $20 \mathrm{~mL}$ Pyrex vial. The vial was evacuated and backfilled with argon three times. Under an inert atmosphere, the mixture was heated in a $120{ }^{\circ} \mathrm{C}$ oven for $24 \mathrm{~h}$. After cooling down to room temperature, faint yellow powder were yielded.

\section{Synthesis of P-MV-PCN-521-DCA}

$\mathrm{ZrCl}_{4}(24 \mathrm{mg}), \mathrm{MTBC}(20 \mathrm{mg}), \operatorname{PBCA}(30 \mathrm{mg})$, diclhloroacetic acid $(70 \mu \mathrm{L})$ in $3.4 \mathrm{~mL}$ of DEF were ultrasonically dissolved in a $20 \mathrm{~mL}$ Pyrex vial. The vial was evacuated and backfilled with argon three times. Under an inert atmosphere, the mixture was heated in a $120{ }^{\circ} \mathrm{C}$ oven for $24 \mathrm{~h}$. After cooling down to room temperature, faint yellow powder were yielded. 


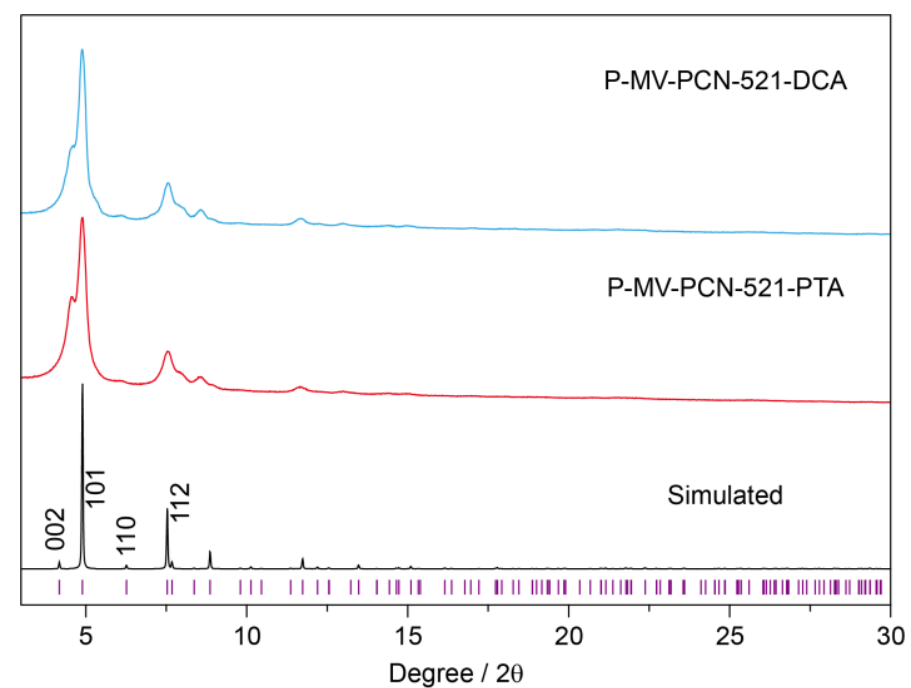

Figure S50. Comparison of the experimental PXRD patterns of as-synthesized P-MV-PCN-521 with the simulated PCN-521 diffraction pattern based on its single crystal data.
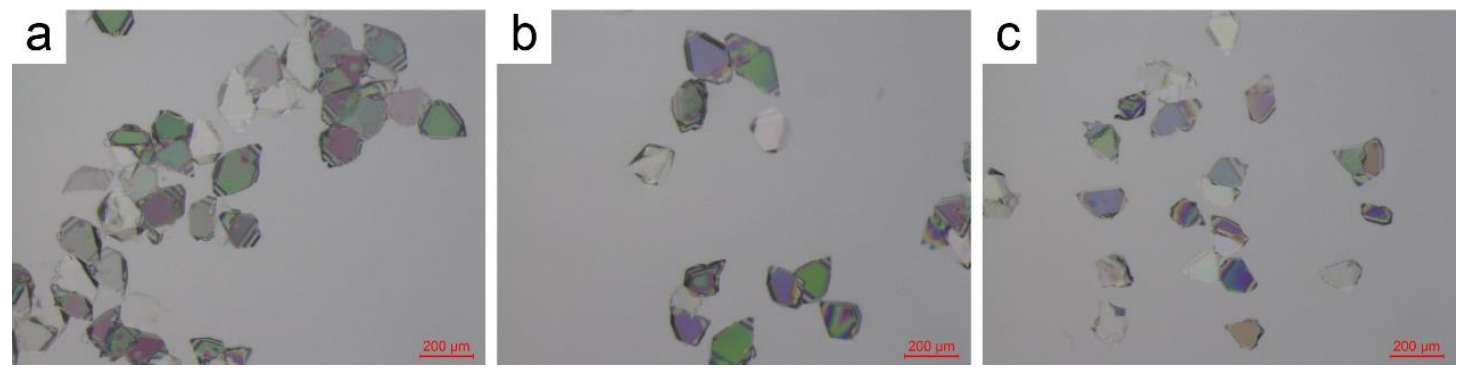

Figure S51. Optical microscope images of (a) PCN-521, (b) N-MV-PCN-521-BA, (c) P-MV-PCN-521-BA.

\section{Synthesis of Au-N-MV-PCN-521-BA}

Au-N-MV-PCN-521-BA was synthesized by adding an equimolar amount of $\mathrm{AuCl}_{3}$ to synthesized MV-N-PCN-521-BA powders. The vials were wrapped in foil and left in the dark under inert atmosphere for $12 \mathrm{~h}$. The samples of Au-N-MV-PCN-521-BA were washed by using fresh degassed 5:2:1 $\mathrm{DMF} / \mathrm{MeOH} / \mathrm{H}_{2} \mathrm{O}$ solvent mixture.

\section{Synthesis of Au-N-MV-PCN-521-NBA}

Au-(N)-MV-PCN-521-NBA was synthesized by adding an equimolar amount of $\mathrm{AuCl}_{3}$ to synthesized MV-N-PCN-521-NBA powders. The vials were wrapped in foil and left in the dark under inert atmosphere for $12 \mathrm{~h}$. The samples of Au-N-MV-PCN-521-NBA were washed by using fresh degassed 5:2:1 $\mathrm{DMF} / \mathrm{MeOH} / \mathrm{H}_{2} \mathrm{O}$ solvent mixture. 


\section{Synthesis of Au-N-MV-PCN-521-FA}

Au-N-MV-PCN-521-FA was synthesized by adding an equimolar amount of $\mathrm{AuCl}_{3}$ to synthesized N-MV-PCN-521-FA powders. The vials were wrapped in foil and left in the dark under inert atmosphere for $12 \mathrm{~h}$. The samples of Au-N-MV-PCN-521-FA were washed by using fresh degassed 5:2:1 $\mathrm{DMF} / \mathrm{MeOH} / \mathrm{H}_{2} \mathrm{O}$ solvent mixture.

\section{Synthesis of Au-P-MV-PCN-521-BA}

Au-P-MV-PCN-521-BA was synthesized by adding an equimolar amount of $\mathrm{AuCl}_{3}$ to synthesized MV-N-PCN-521-BA powders. The vials were wrapped in foil and left in the dark under inert atmosphere for $12 \mathrm{~h}$. The samples of Au-P-MV-PCN-521-BA were washed by using fresh degassed 5:2:1 $\mathrm{DMF} / \mathrm{MeOH} / \mathrm{H}_{2} \mathrm{O}$ solvent mixture.

\section{Synthesis of Au-P-MV-PCN-521-NBA}

Au-(P)-MV-PCN-521-NBA was synthesized by adding an equimolar amount of $\mathrm{AuCl}_{3}$ to synthesized MV-P-PCN-521-NBA powders. The vials were wrapped in foil and left in the dark under inert atmosphere for $12 \mathrm{~h}$. The samples of Au-P-MV-PCN-521-NBA were washed by using fresh degassed 5:2:1 $\mathrm{DMF} / \mathrm{MeOH} / \mathrm{H}_{2} \mathrm{O}$ solvent mixture.

\section{Synthesis of Au-P-MV-PCN-521-FA}

Au-P-MV-PCN-521-FA was synthesized by adding an equimolar amount of $\mathrm{AuCl}_{3}$ to synthesized P-MV-PCN-521-FA powders. The vials were wrapped in foil and left in the dark under inert atmosphere for $12 \mathrm{~h}$. The samples of Au-P-MV-PCN-521-FA were washed by using fresh degassed 5:2:1 $\mathrm{DMF} / \mathrm{MeOH} / \mathrm{H}_{2} \mathrm{O}$ solvent mixture. 


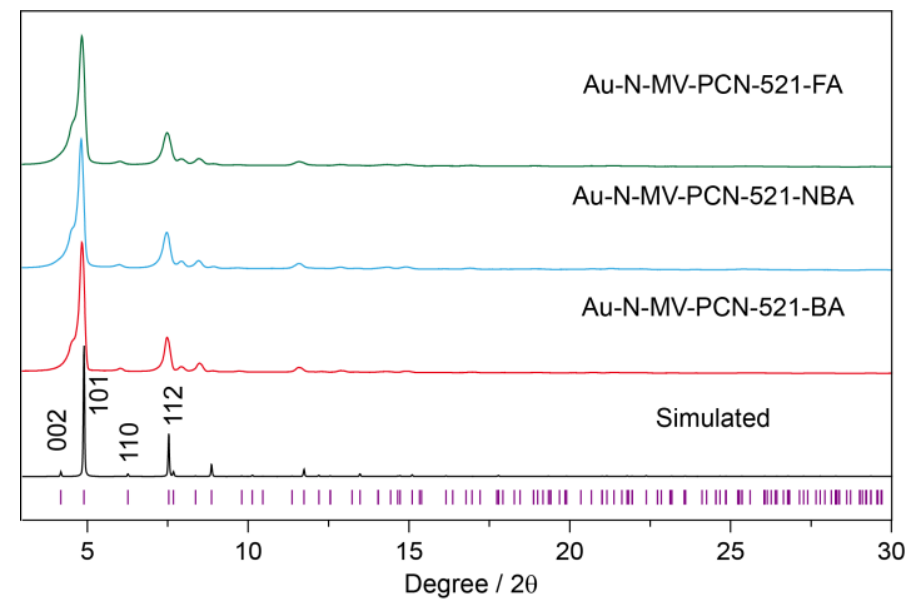

Figure S52. Comparison of the experimental PXRD pattern of as-synthesized Au-N-PCN-521-R with the simulated PCN-521 diffraction pattern based on its single crystal data.

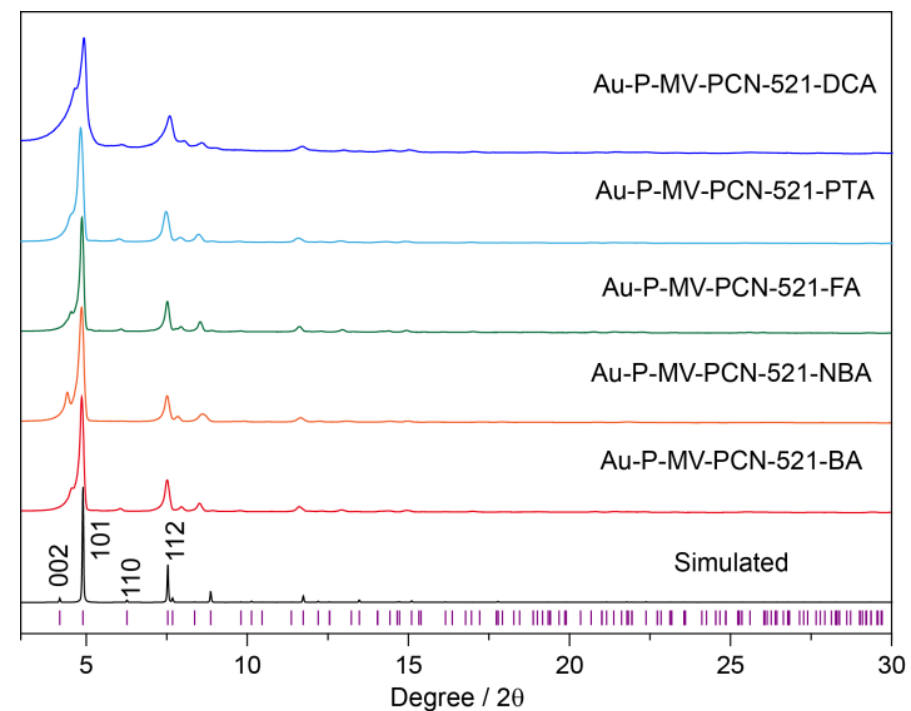

Figure S53. Comparison of the experimental PXRD pattern of as-synthesized Au-P-PCN-521-R with the simulated PCN-521 diffraction pattern based on its single crystal data.

\section{S2.2 Activation of MV-MOFs}

\section{METHODS:}

The fresh PCN-521/MV-PCN-521 samples must be activated prior to any gas sorption measurements. Firstly, the as-synthesized samples were immersed in anhydrous DMA at $100{ }^{\circ} \mathrm{C}, 12 \mathrm{~h}$ later, the solvent was immediately decanted when it was still hot and another fresh DMA was replenished immediately. The sample was subsequently treated with solvent exchange with DMA 6 times. After that, these samples were immersed in acetone for another 3 days at room temperature and exchanged three times each day. Secondly, the remaining acetone in the MOF samples 
was removed by supercritical $\mathrm{CO}_{2}$. For this step, the acetone-containing sample was placed in the chamber and the solvent was completely exchanged with liquid $\mathrm{CO}_{2}$. After this exchange, the chamber was heated up to $40{ }^{\circ} \mathrm{C}$ and held on at the supercritical condition (typically $1300 \mathrm{psi}$ ) for $45 \mathrm{~min}$. The $\mathrm{CO}_{2}$ was slowly vented (ca. $8 \mathrm{~h}$ ) from the chamber at around $38{ }^{\circ} \mathrm{C}$, thus generating the solvent-free porous MOF samples. After the activation, $\mathrm{N}_{2}$ adsorption isotherms of these MOFs were measured to confirm the permanent porosity. PXRD of the activated MOF samples matched well with the simulated pattern based on single crystal structure of PCN-521 (Figure S54-56).

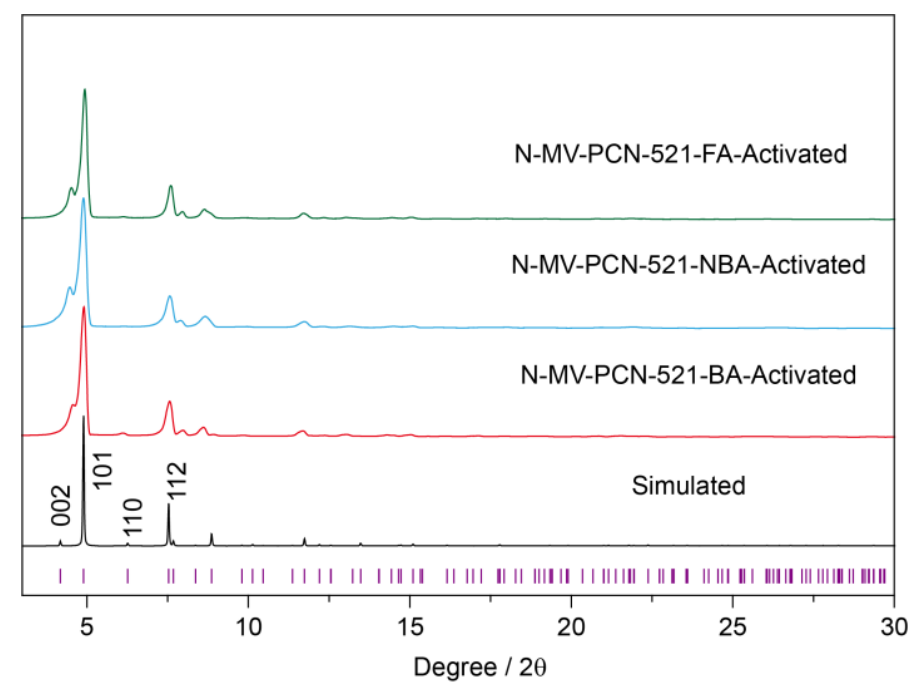

Figure S54. Comparison of the experimental PXRD patterns of activated N-MV-PCN-521 with the simulated diffraction patterns based on PCN-521 single crystal data.

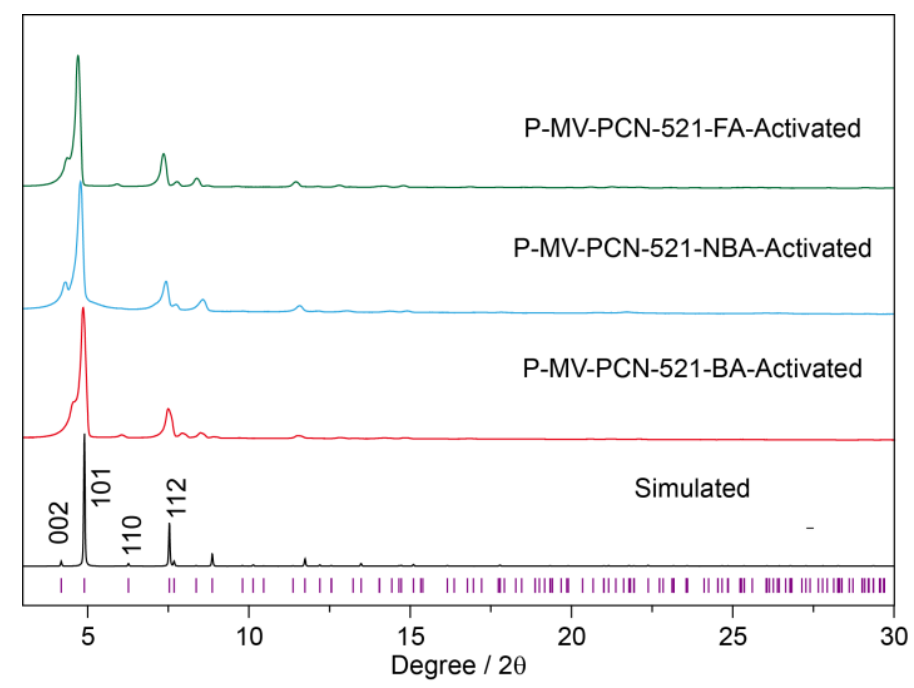

Figure S55. Comparison of the experimental PXRD patterns of activated P-MV-PCN-521 with the simulated diffraction patterns based on PCN-521 single crystal data. 


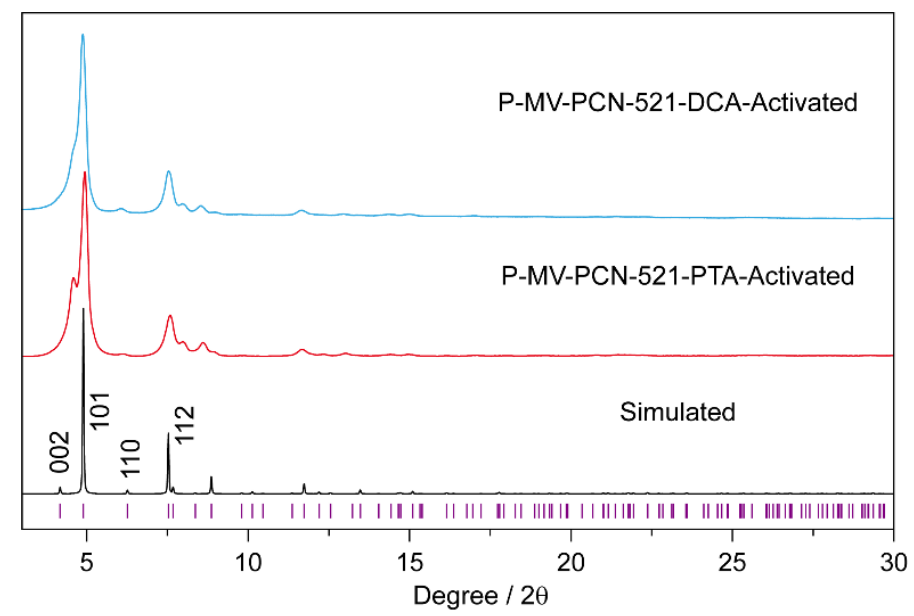

Figure S56. Comparison of the experimental PXRD patterns of as-synthesized P-MV-PCN-521 with the simulated PCN-521 diffraction pattern based on its single crystal data.

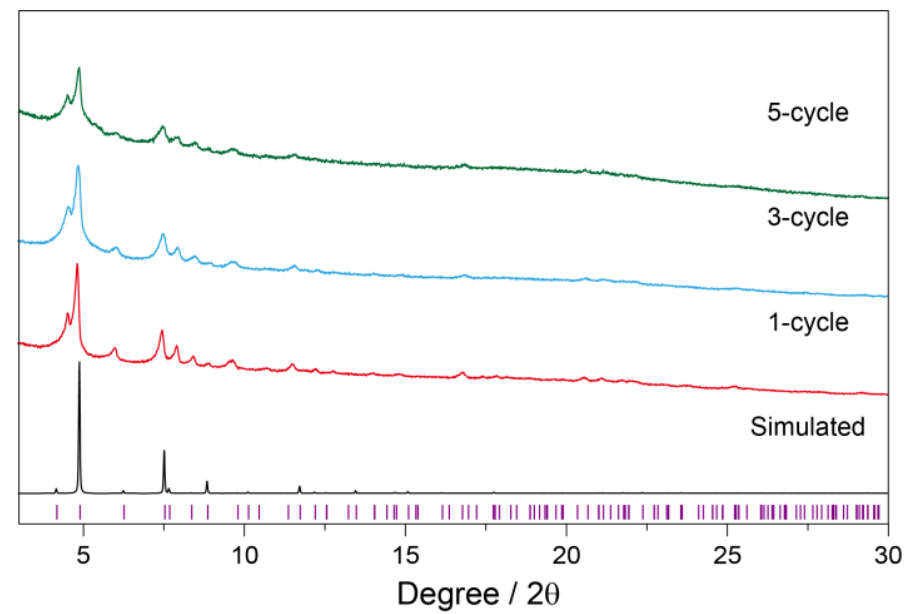

Figure S57. Comparison of the experimental PXRD patterns of as-synthesized P-MV-PCN-521 with the simulated PCN-521 diffraction pattern based on its single crystal data.

\section{Section S4 Crystal structure characterizations and simulations}

\section{S4.1 Single-crystal X-ray crystallography}

The single crystal diffraction data of PCN-521, N-MV-PCN-521-BA and P-MV-PCN-521-BA were collected at $100 \mathrm{~K}$ on a Rigaku XtaLAB diffractometer equipped with a Hypix-6000 detector using $\mathrm{Cu} \mathrm{K} \alpha$ radiation with $\lambda=1.5418 \AA(40 \mathrm{kV}$, 30mA) and kappa goniometer. The incident X-ray beam was focused and monochromated using Rigaku Varimax HF Confocal Max-Flux optics. The quality of SC-XRD data obtained for N-MV-PCN-521-BA, P-MV-PCN-521-BA is similar to that of PCN-521, reflected in low $R$ (int), the occupational disorder of TBPA and 
PBCA linkers in MOF crystals and the displacement disorder of BA linkers result in high goodness of fit (Table S2 to S5). The distribution information of both TBPA (or PBCA) and BA linkers cannot be extracted from the single crystal diffraction data.

Method:

All structures were solved by direct methods and refined using the SHELXTL'2014 (S6) and OLEX2 (S7) software suite. Final structures were refined anisotropically until full convergence was achieved. Hydrogen atoms were placed in calculated positions. To verify the correctness of the atomic position assignments in the framework, SQUEEZE (S8) were applied to remove solvents in the MOF pores. All ellipsoids in ORTEP diagrams are displayed at the 30\% probability level unless noted otherwise (Figure S58 to S60). 
Table S2. Crystal data and structure refinement for PCN-521

\begin{tabular}{|c|c|}
\hline Formula & $\mathrm{C}_{106} \mathrm{H}_{64} \mathrm{O}_{32} \mathrm{Zr}_{6}$ \\
\hline Formula weight & 2396.89 \\
\hline Temperature & $150.15 \mathrm{~K}$ \\
\hline Wavelength & $1.54184 \AA$ \\
\hline Crystal system & tetragonal \\
\hline Space group & $I 4 / m$ \\
\hline$a(\AA)$ & $20.42327(16)$ \\
\hline$b(\AA)$ & $20.42327(16)$ \\
\hline$c(\AA)$ & 41.4623(4) \\
\hline$\alpha\left(^{\circ}\right)$ & 90 \\
\hline$\beta\left(^{\circ}\right)$ & 90 \\
\hline$\gamma\left({ }^{\circ}\right)$ & 90 \\
\hline$V\left(\AA^{3}\right)$ & $17294.3(3)$ \\
\hline $\mathrm{Z}$ & 2 \\
\hline Density (calculated) & $0.460 \mathrm{~g} \mathrm{~cm}^{-3}$ \\
\hline Absorption coefficient & 1.632 \\
\hline Reflns collected/ unique & $27749 / 7375$ \\
\hline Index ranges & $-14 \leq \mathrm{h} \leq 23,-23 \leq \mathrm{k} \leq 12,-48 \leq 1 \leq 48$ \\
\hline $2 \theta \mathrm{range} / \mathrm{deg}$ & 12.258 to 131.162 \\
\hline Completeness to theta $=49.76^{\circ}$ & $97 \%$ \\
\hline R(int) & 0.0289 \\
\hline Refinement method & Full-matrix least-squares on $\mathrm{F}^{2}$ \\
\hline Final $R$ indices $[I>2 \operatorname{sigma}(I)]$ & $R 1=0.0769, w R 2=0.2230$ \\
\hline $\mathrm{R}$ indices (all data) & $R 1=0.0797, w R 2=0.2267$ \\
\hline $\mathrm{F}(000)$ & 2392 \\
\hline GOOF on $\mathrm{F}^{2}$ & 1.109 \\
\hline
\end{tabular}


Table S3. Crystal data and structure refinement for PCN-521 (squeeze)

\begin{tabular}{|c|c|}
\hline Formula & $\mathrm{C}_{106} \mathrm{H}_{64} \mathrm{O}_{32} \mathrm{Zr}_{6}$ \\
\hline Formula weight & 2396.89 \\
\hline Temperature & $150.15 \mathrm{~K}$ \\
\hline Wavelength & $1.54184 \AA$ \\
\hline Crystal system & tetragonal \\
\hline Space group & $I 4 / m$ \\
\hline$a(\AA)$ & $20.42327(16)$ \\
\hline$b(\AA)$ & $20.42327(16)$ \\
\hline$c(\AA)$ & $41.4623(4)$ \\
\hline$\alpha\left(^{\circ}\right)$ & 90 \\
\hline$\beta\left(\left(^{\circ}\right)\right.$ & 90 \\
\hline$\gamma\left({ }^{\circ}\right)$ & 90 \\
\hline$V\left(\AA^{3}\right)$ & $17294.3(3)$ \\
\hline $\mathrm{Z}$ & 2 \\
\hline Density (calculated) & $0.463 \mathrm{~g} \mathrm{~cm}^{-3}$ \\
\hline Absorption coefficient & 1.632 \\
\hline Reflns collected/ unique & $27749 / 7375$ \\
\hline Index ranges & $-14 \leq \mathrm{h} \leq 23,-23 \leq \mathrm{k} \leq 12,-48 \leq 1 \leq 48$ \\
\hline $2 \theta$ range $/ \mathrm{deg}$ & 12.258 to 131.162 \\
\hline Completeness to theta $=49.76^{\circ}$ & $97 \%$ \\
\hline $\mathrm{R}(\mathrm{int})$ & 0.0289 \\
\hline Refinement method & Full-matrix least-squares on $\mathrm{F}^{2}$ \\
\hline Final $\mathrm{R}$ indices [I>2sigma(I)] & $R 1=0.0516, w R 2=0.1545$ \\
\hline $\mathrm{R}$ indices (all data) & $R 1=0.0543, w R 2=0.1573$ \\
\hline $\mathrm{F}(000)$ & 2424 \\
\hline GOOF on $\mathrm{F}^{2}$ & 1.058 \\
\hline CCDC number & 2015142 \\
\hline
\end{tabular}


Table S4. Crystal data and structure refinement for N-MV-PCN-521-BA

\begin{tabular}{|c|c|}
\hline Formula & $\mathrm{C}_{106} \mathrm{H}_{64} \mathrm{O}_{32} \mathrm{Zr}_{6}$ \\
\hline Formula weight & 2396.89 \\
\hline Temperature & $150.15 \mathrm{~K}$ \\
\hline Wavelength & $1.54184 \AA$ \\
\hline Crystal system & tetragonal \\
\hline Space group & $I 4 / m$ \\
\hline$a(\AA)$ & $20.1530(4)$ \\
\hline$b(\AA)$ & $20.1530(4)$ \\
\hline$c(\AA)$ & $41.7914(8)$ \\
\hline$\alpha\left({ }^{\circ}\right)$ & 90 \\
\hline$\beta\left(\left(^{\circ}\right)\right.$ & 90 \\
\hline$\gamma\left({ }^{\circ}\right)$ & 90 \\
\hline $\mathrm{V}\left(\AA^{3}\right)$ & $16973.4(8)$ \\
\hline $\mathrm{Z}$ & 2 \\
\hline Density (calculated) & $0.469 \mathrm{~g} \mathrm{~cm}^{-3}$ \\
\hline Absorption coefficient & 1.663 \\
\hline Reflns collected/ unique & $25951 / 7293$ \\
\hline Index ranges & $-23 \leq \mathrm{h} \leq 22,-21 \leq \mathrm{k} \leq 18,-47 \leq 1 \leq 49$ \\
\hline $2 \theta \mathrm{range} / \mathrm{deg}$ & 9.744 to 131.754 \\
\hline Completeness to theta $=49.76^{\circ}$ & $97 \%$ \\
\hline $\mathrm{R}(\mathrm{int})$ & 0.0233 \\
\hline Refinement method & Full-matrix least-squares on $\mathrm{F}^{2}$ \\
\hline Final $\mathrm{R}$ indices [I>2sigma(I)] & $R 1=0.0907, w R 2=0.2424$ \\
\hline $\mathrm{R}$ indices (all data) & $R 1=0.0968, w R 2=0.2488$ \\
\hline $\mathrm{F}(000)$ & 2392 \\
\hline GOOF on $\mathrm{F}^{2}$ & 1.106 \\
\hline
\end{tabular}


Table S5. Crystal data and structure refinement for N-MV-PCN-521-BA (squeeze)

\begin{tabular}{|c|c|}
\hline Formula & $\mathrm{C}_{106} \mathrm{H}_{64} \mathrm{O}_{32} \mathrm{Zr}_{6}$ \\
\hline Formula weight & 2396.89 \\
\hline Temperature & $150.15 \mathrm{~K}$ \\
\hline Wavelength & $1.54184 \AA$ \\
\hline Crystal system & tetragonal \\
\hline Space group & $I 4 / m$ \\
\hline$a(\AA)$ & $20.1530(4)$ \\
\hline$b(\AA)$ & $20.1530(4)$ \\
\hline$c(\AA)$ & $41.7914(8)$ \\
\hline$\alpha\left(^{\circ}\right)$ & 90 \\
\hline$\beta\left(\left(^{\circ}\right)\right.$ & 90 \\
\hline$\gamma\left({ }^{\circ}\right)$ & 90 \\
\hline$V\left(\AA^{3}\right)$ & $16973.4(8)$ \\
\hline $\mathrm{Z}$ & 2 \\
\hline Density (calculated) & $0.469 \mathrm{~g} \mathrm{~cm}^{-3}$ \\
\hline Absorption coefficient & 1.663 \\
\hline Reflns collected/ unique & $25951 / 7293$ \\
\hline Index ranges & $-23 \leq \mathrm{h} \leq 22,-21 \leq \mathrm{k} \leq 18,-47 \leq 1 \leq 49$ \\
\hline $2 \theta$ range $/$ deg & 9.744 to 131.754 \\
\hline Completeness to theta $=49.76^{\circ}$ & $97 \%$ \\
\hline $\mathrm{R}(\mathrm{int})$ & 0.0233 \\
\hline Refinement method & Full-matrix least-squares on $\mathrm{F}^{2}$ \\
\hline Final $\mathrm{R}$ indices [I>2sigma(I)] & $R 1=0.0563, w R 2=0.1788$ \\
\hline $\mathrm{R}$ indices (all data) & $R 1=0.0624, w R 2=0.1857$ \\
\hline $\mathrm{F}(000)$ & 2392 \\
\hline GOOF on $\mathrm{F}^{2}$ & 1.071 \\
\hline CCDC number & 2015144 \\
\hline
\end{tabular}


Table S6. Crystal data and structure refinement for P-MV-PCN-521-BA

\begin{tabular}{|c|c|}
\hline Formula & $\mathrm{C}_{106} \mathrm{H}_{64} \mathrm{O}_{32} \mathrm{Zr}_{6}$ \\
\hline Formula weight & 2396.89 \\
\hline Temperature & $150.15 \mathrm{~K}$ \\
\hline Wavelength & $1.54184 \AA$ \\
\hline Crystal system & tetragonal \\
\hline Space group & $I 4 / m$ \\
\hline$a(\AA)$ & $19.8155(4)$ \\
\hline$b(\AA)$ & $19.8155(4)$ \\
\hline$c(\AA)$ & $42.1254(4)$ \\
\hline$\alpha\left({ }^{\circ}\right)$ & 90 \\
\hline$\beta\left(\left(^{\circ}\right)\right.$ & 90 \\
\hline$\gamma\left({ }^{\circ}\right)$ & 90 \\
\hline $\mathrm{V}\left(\AA^{3}\right)$ & $16540.7(5)$ \\
\hline $\mathrm{Z}$ & 2 \\
\hline Density (calculated) & $0.481 \mathrm{~g} \mathrm{~cm}^{-3}$ \\
\hline Absorption coefficient & 1.706 \\
\hline Reflns collected/ unique & $24113 / 7091$ \\
\hline Index ranges & $-22 \leq \mathrm{h} \leq 21,-17 \leq \mathrm{k} \leq 23,-30 \leq 1 \leq 48$ \\
\hline $2 \theta \mathrm{range} / \mathrm{deg}$ & 10.2 to 131.434 \\
\hline Completeness to theta $=49.76^{\circ}$ & $97 \%$ \\
\hline $\mathrm{R}(\mathrm{int})$ & 0.0269 \\
\hline Refinement method & Full-matrix least-squares on $\mathrm{F}^{2}$ \\
\hline Final $\mathrm{R}$ indices [I>2sigma(I)] & $R 1=0.0936, w R 2=0.2469$ \\
\hline $\mathrm{R}$ indices (all data) & $R 1=0.1107, w R 2=0.2722$ \\
\hline $\mathrm{F}(000)$ & 2392 \\
\hline GOOF on $\mathrm{F}^{2}$ & 1.052 \\
\hline
\end{tabular}


Table S7. Crystal data and structure refinement for P-MV-PCN-521-BA (squeeze)

\begin{tabular}{|c|c|}
\hline Formula & $\mathrm{C}_{106} \mathrm{H}_{64} \mathrm{O}_{32} \mathrm{Zr}_{6}$ \\
\hline Formula weight & 2396.89 \\
\hline Temperature & $150.15 \mathrm{~K}$ \\
\hline Wavelength & $1.54184 \AA$ \\
\hline Crystal system & tetragonal \\
\hline Space group & $I 4 / m$ \\
\hline$a(\AA)$ & $19.8155(4)$ \\
\hline$b(\AA)$ & $19.8155(4)$ \\
\hline$c(\AA)$ & $42.1254(4)$ \\
\hline$\alpha\left(^{\circ}\right)$ & 90 \\
\hline$\beta\left(\left(^{\circ}\right)\right.$ & 90 \\
\hline$\gamma\left({ }^{\circ}\right)$ & 90 \\
\hline$V\left(\AA^{3}\right)$ & $16540.7(5)$ \\
\hline $\mathrm{Z}$ & 2 \\
\hline Density (calculated) & $0.481 \mathrm{~g} \mathrm{~cm}^{-3}$ \\
\hline Absorption coefficient & 1.706 \\
\hline Reflns collected/ unique & $24113 / 7091$ \\
\hline Index ranges & $-22 \leq \mathrm{h} \leq 21,-17 \leq \mathrm{k} \leq 23,-30 \leq 1 \leq 48$ \\
\hline $2 \theta$ range $/$ deg & 10.2 to 131.434 \\
\hline Completeness to theta $=49.76^{\circ}$ & $97 \%$ \\
\hline $\mathrm{R}(\mathrm{int})$ & 0.0269 \\
\hline Refinement method & Full-matrix least-squares on $\mathrm{F}^{2}$ \\
\hline Final $\mathrm{R}$ indices [I>2sigma(I)] & $R 1=0.0528, w R 2=0.1655$ \\
\hline $\mathrm{R}$ indices (all data) & $R 1=0.0608, w R 2=0.1825$ \\
\hline $\mathrm{F}(000)$ & 2392 \\
\hline GOOF on $\mathrm{F}^{2}$ & 0.978 \\
\hline CCDC number & 2015145 \\
\hline
\end{tabular}


Table S8. Comparison of the crystallographic data for PCN-521, (N)-PCN-521-BA (P)-PCN-521-BA

\begin{tabular}{cccc}
\hline Materials & PCN-521 & N-PCN-521-BA & P-PCN-521-BA \\
\hline Crystal system & tetragonal & tetragonal & tetragonal \\
Space group & $I 4 / m$ & $I 4 / m$ & $I 4 / m$ \\
$a(\AA)$ & $20.42327(16)$ & $20.1530(4)$ & $19.8155(4)$ \\
$b(\AA)$ & $20.42327(16)$ & $20.1530(4)$ & $19.8155(4)$ \\
$c(\AA)$ & $41.4623(4)$ & $41.7914(8)$ & $42.1254(4)$ \\
$\alpha\left(^{\circ}\right)$ & 90 & 90 & 90 \\
$\beta\left({ }^{\circ}\right)$ & 90 & 90 & 90 \\
$\gamma\left({ }^{\circ}\right)$ & 90 & 90 & 90 \\
$\mathrm{~V}\left(\AA^{3}\right)$ & $17294.3(3)$ & $16973.4(8)$ & $16540.7(5)$ \\
\hline
\end{tabular}

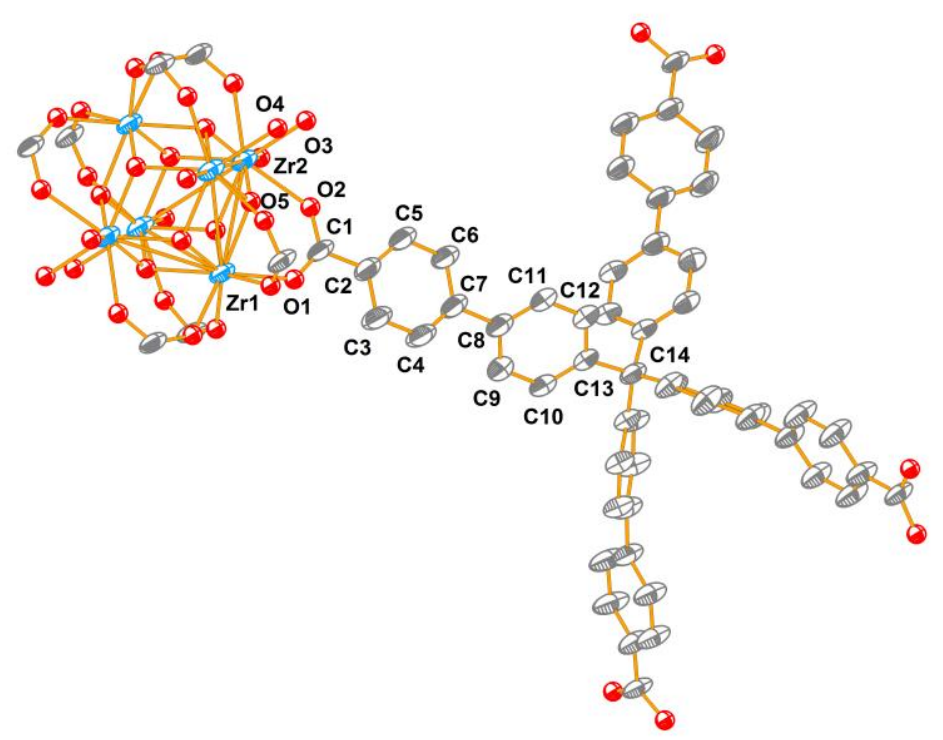

Figure S58. ORTEP representation (30\% probability) of the crystal structures of PCN-521. Atom color, C. grey, O, red, Zr. blue. 


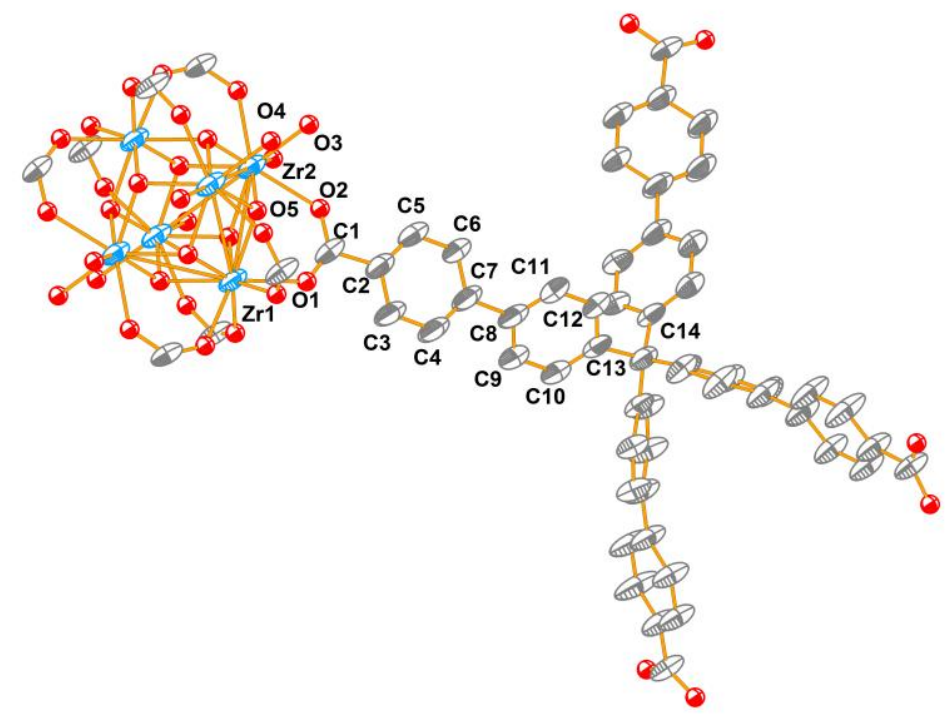

Figure S59. ORTEP representation (30\% probability) of the crystal structures of N-PCN-521-BA. Atom color, C. grey, O, red, Zr. blue.

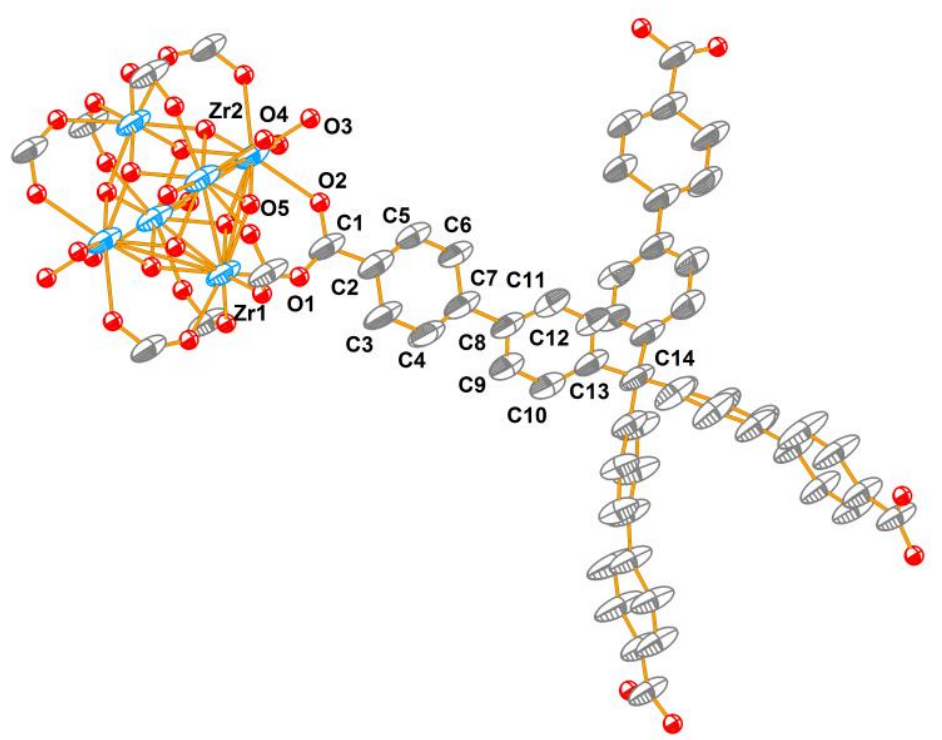

Figure S60. ORTEP representation (30\% probability) of the crystal structures of P-PCN-521-BA. Atom color, C. grey, O, red, Zr. blue. 


\section{S4.2 Structure Simulation}

On the basis of single crystal structure study of MV-MOFs, here, we assume that the arrangement of TBPA (or PBCA) in one unit cell of the framework is random, and the replacement of MTBC linker was in pairs by one TBPA (or PBCA) and one mono-topic linker. Structure simulation was used to build the structural models of all MV-MOFs based on the SXRD data of PCN-521, all unit cells of nano-MV-PCN-521-R were fixed during the simulation.

The homogeneous distribution of TBPA (or PBCA) linkers in the MV-PCN-521 structure was been determined by LSCM (Section S9). We assumed that each unit cell in MV-PCN-521-BA structure contains one TBPA (or PBCA) linker, i.e. close to one eighth of MTBC linkers was replaced by TBPA (or PBCA) in one unit cell (Figure S62). TBPA (or PBCA) and different mono-topic linkers were placed into the lattice of PCN-521 in pairs and refined through geometry optimization. The length of each mono-topic linker can be facilely calculated by Material Studio through accurate molecular simulation (Figure S61). The distance between P of PBCA linker and $\mathrm{H}$ of FA in P-MV-PCN-521-FA was measured to be $10.2 \AA$. In this way, the corresponding distances in other MV-MOFs were calculated, $10.8 \AA, 6.4 \AA 5.4 \AA$ for N-MV-PCN-521-FA, -BA, -NBA while $4.7 \AA, \quad 3.3, \AA 8.5 \AA, 6.6 \AA$ for P-MV-PCN-521-BA, -NBA, -DCA, -PTA (Figure S62).

\section{METHODS:}

All the simulations of MV-PCN-521 were completed using Forcite program in Material Studio 8.0 software suite (S9). And our aim was Geometry Optimization, in which Algorithm set to Smart, and the convergence tolerance of Energy, force, stress and displacement was set to be $1.0 \times 10^{-4} \mathrm{kcal} / \mathrm{mol}, 0.05 \mathrm{kcal} / \mathrm{mol} / \AA \AA 0.005 \mathrm{GPa}$ and $5.0 \times 10^{-4} \AA$, separately. The unit cell was also optimized during the simulation. One out of eight MTBC linkers in the structure of MV-PCN-521-BA was changed to TBPA linker and the corresponding organic ligand molecule, with super cell of $2 a, 2 b$ and $c$ of the original unit cell. In order to reduce the disorder in structure, all simulations were completed in $P 1$ space group. 
Table S9. The simulated unit cell of MV-PCN-521-R

\begin{tabular}{cccccccc}
\hline Materials & $a(\AA)$ & $b(\AA)$ & $c(\AA)$ & $\alpha\left(^{\circ}\right)$ & $\beta\left(^{\circ}\right)$ & $\gamma\left({ }^{\circ}\right)$ & $\mathrm{V}\left(\AA^{3}\right)$ \\
\hline N-PCN-521-BA & 40.8466 & 40.8466 & 40.8466 & 90 & 90 & 90 & 67177.6 \\
N-PCN-521-NBA & 40.8466 & 40.8466 & 40.8466 & 90 & 90 & 90 & 67177.6 \\
N-PCN-521-FA & 40.8466 & 40.8466 & 40.8466 & 90 & 90 & 90 & 67177.6 \\
P-PCN-521-BA & 40.8466 & 40.8466 & 40.8466 & 90 & 90 & 90 & 67177.6 \\
P-PCN-521-NBA & 40.8466 & 40.8466 & 40.8466 & 90 & 90 & 90 & 67177.6 \\
P-PCN-521-FA & 40.8466 & 40.8466 & 40.8466 & 90 & 90 & 90 & 67177.6 \\
\hline
\end{tabular}
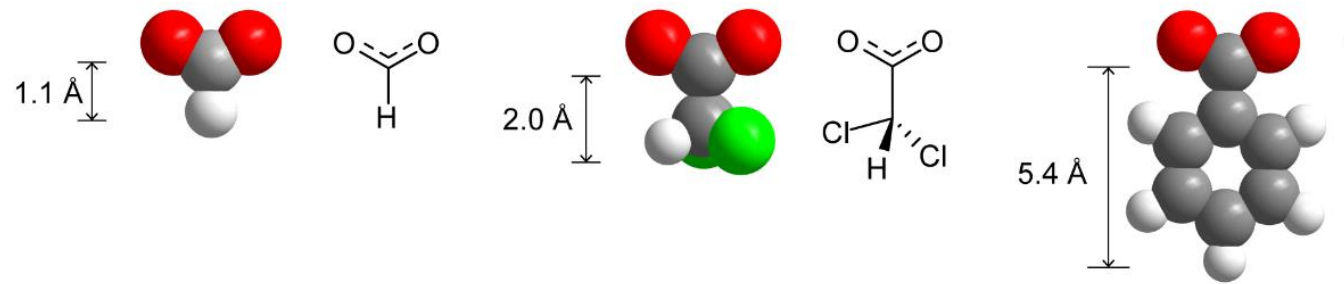<smiles>O=Cc1ccccc1</smiles>
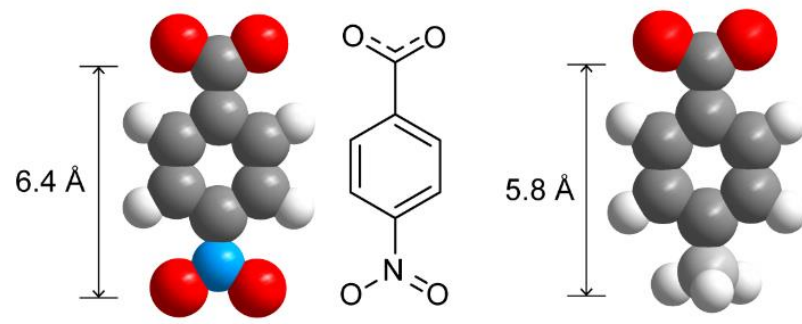

Figure S61. Simulated organic linkers in MV-MOFs 


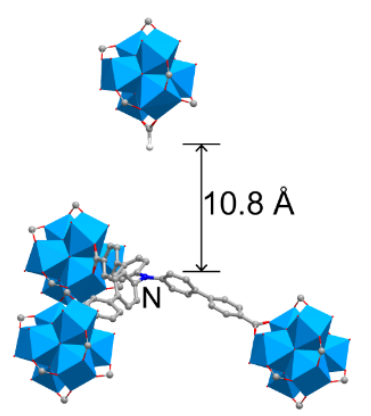

N-MV-PCN-521-FA

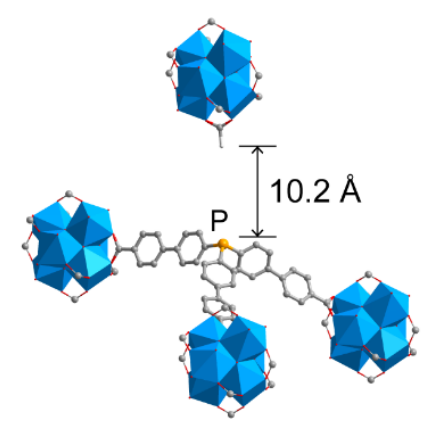

P-MV-PCN-521-FA

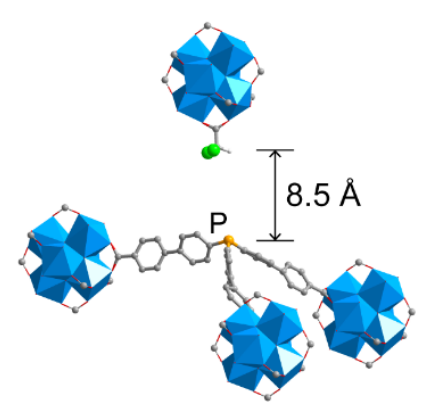

P-MV-PCN-521-DCA

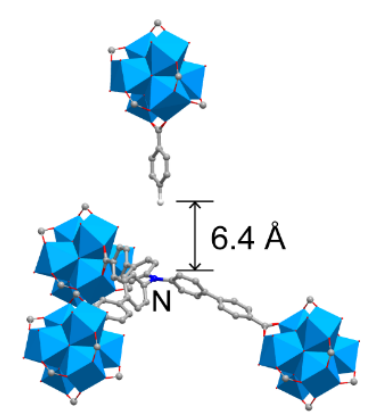

N-MV-PCN-521-BA

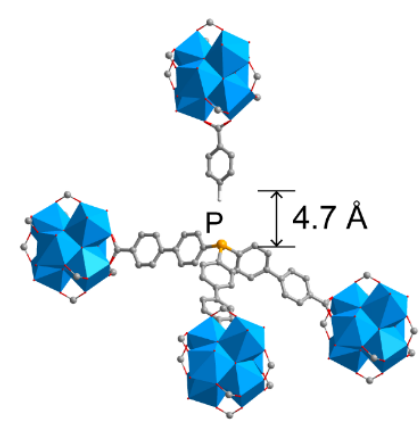

P-MV-PCN-521-BA

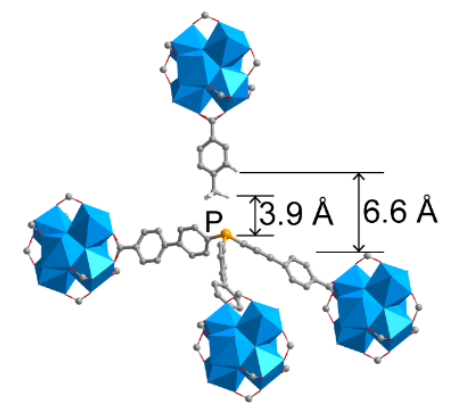

P-MV-PCN-521-PTA

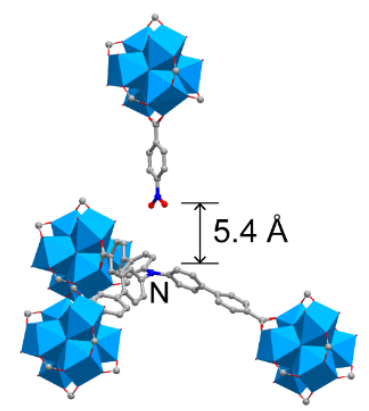

N-MV-PCN-521-NBA

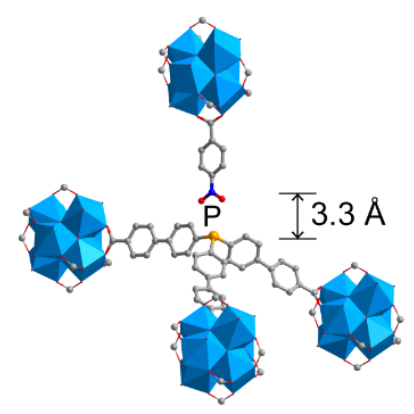

P-MV-PCN-521-NBA

Figure S62. Simulated distances in MV-MOFs. 


\section{Section S5 Solid-state NMR experiments}

\section{Experimental Section}

\section{Solid-State NMR Measurements}

Solid-state NMR experiments were carried out on a Bruker Avance $400 \mathrm{MHz}$ spectrometer with a $4.0 \mathrm{~mm}$ double-resonance MAS probe. The Larmor frequencies are 399.3, 100.4, and $162.7 \mathrm{MHz}$ for ${ }^{1} \mathrm{H},{ }^{13} \mathrm{C}$, and ${ }^{31} \mathrm{P}$ nuclei, respectively. Typical radio frequency field strengths were $42.5-82 \mathrm{kHz}$ for ${ }^{1} \mathrm{H}$, and $42.5-50 \mathrm{kHz}$ for ${ }^{13} \mathrm{C}$ and ${ }^{31} \mathrm{P} .{ }^{1} \mathrm{H}$ MAS NMR spectra were acquired with a $\pi / 2$ pulse length of $5 \mu$ s and a recycle delay of 2 s. 2D ${ }^{1} \mathrm{H}-{ }^{1} \mathrm{H}$ homonuclear correlation (HOMCOR) NMR experiments were carried out under $10 \mathrm{kHz}$ MAS with a spin diffusion mixing time of $1 \mathrm{~ms}$. The increment interval in the indirect dimension was set to $83.3 \mu$ s. Typically, 4 scans were acquired for $320 t_{1}$ increments and $2 \mathrm{D}$ data sets consisted of $512 t_{1} \times 1024 t_{2}$.

${ }^{13} \mathrm{C}$ CP/MAS NMR experiments were performed with a contact time of $1.0 \mathrm{~ms}$, a recycle delay of $2 \mathrm{~s}$, and accumulation of 2048 scans. ${ }^{1} \mathrm{H}-{ }^{13} \mathrm{C}$ HETCOR experiments were conducted with a $\mathrm{CP}$ contact time of $1.0 \mathrm{~ms}$ at a spinning speed of $10 \mathrm{kHz}$. The increment interval in the indirect dimension was set to $83.3 \mu$ s. Typically, 80 scans were acquired for each $\mathrm{t}_{1}$ increment. ${ }^{13} \mathrm{C}-{ }^{1} \mathrm{H}$ dipolar couplings were measured using DIPSHIFT experiments (S10) with a recycle delay of $2 \mathrm{~s}$ and at a spinning speed of $6 \mathrm{kHz}$. The time domain data were fitted to give the apparent dipole coupling strengths in the DIPSHIFT experiments. The true ${ }^{13} \mathrm{C}-{ }^{1} \mathrm{H}$ dipolar couplings were calculated on the basis of apparent dipole coupling strengths and FSLG scaling factor. ${ }^{31} \mathrm{PCP} / \mathrm{MAS} \mathrm{NMR}$ experiments were performed with a contact time of $2.0 \mathrm{~ms}$, a recycle delay of $2 \mathrm{~s}$, and accumulation of 2048 scans. ${ }^{1} \mathrm{H}-{ }^{31} \mathrm{P}$ HETCOR experiments were conducted with a CP contact time of $2.0 \mathrm{~ms}$ at a spinning speed of $10 \mathrm{kHz}$. ${ }^{1} \mathrm{H}-{ }^{31} \mathrm{P}$ dipolar coupling was measured using the pulse sequence as illustrated in Figure S60. A $\pi$ pulse of $6.1 \mu$ s for ${ }^{1} \mathrm{H}$ and a $\pi$ pulse of $10.0 \mu$ s for ${ }^{31} \mathrm{P}$ were applied to recouple the ${ }^{1} \mathrm{H}_{-}^{31} \mathrm{P}$ dipolar interaction. The ${ }^{1} \mathrm{H}-{ }^{1} \mathrm{H}$ decoupling during the dipolar recoupling periods is achieved by using FSLG pulses. The REDOR recoupling periods are ranged from 2.0 to $10.0 \mathrm{~ms}$. The spectra recorded with $(\mathrm{S})$ and without $\left(\mathrm{S}_{0}\right)$ 
${ }^{1} \mathrm{H}_{-}{ }^{31} \mathrm{P}$ dipolar recoupling is deconvoluted separately to yield the integrated intensity of various components. The experimental REDOR fractions $\left(\mathrm{S} / \mathrm{S}_{0}\right)$ are directly calculated from the integrated intensity ratio of each individual component. REDOR dephasing curves were simulated using the SIMPSON program $(\mathrm{S} 11) .{ }^{1} \mathrm{H},{ }^{13} \mathrm{C}$ and ${ }^{31} \mathrm{P}$ chemical shifts were externally referenced with respect to adamantine, and $85 \%$ $\mathrm{H}_{3} \mathrm{PO}_{4}$ respectively.

In the ${ }^{1} \mathrm{H}-{ }^{13} \mathrm{C}$ CP/MAS NMR spectra as shown in Figures S64 and S65, the peaks at 67,19 , and $128 \mathrm{ppm}$ were assigned to dichloromethyl group of coordinated DCA, methyl group and unsubstituted aromatic carbons in PTA, respectively. The absence of ${ }^{1} \mathrm{H}$ signal at $11 \mathrm{ppm}$ and ${ }^{13} \mathrm{C}$ signal at $164 \mathrm{ppm}$ in these spectra further confirmed all carboxylate groups from linkers were in coordinated form. In the ${ }^{1} \mathrm{H}^{3}{ }^{31} \mathrm{P} C \mathrm{P} / \mathrm{MAS}$ NMR spectra, the -5 ppm chemical shift was assigned to phosphine in PBCA (Figures S64-S65). ${ }^{31} \mathrm{P}$ signals were also observed at 19-38 ppm, indicating the presence of oxidized phosphorus (V) in these MVs. The oxidation of P didn't alter its position in MVs, thus both $\mathrm{P}$ (III) and $\mathrm{P}(\mathrm{V})$ signals were used to determine distance in the REDOR experiment.

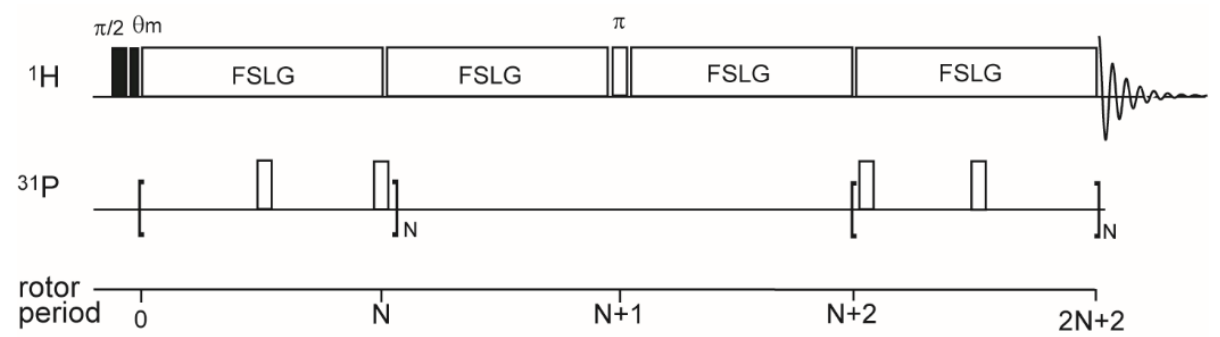

Figure S63. Pulse sequence for collecting ${ }^{1} \mathrm{H}_{-}{ }^{31} \mathrm{P}$ REDOR solid state NMR spectra. 

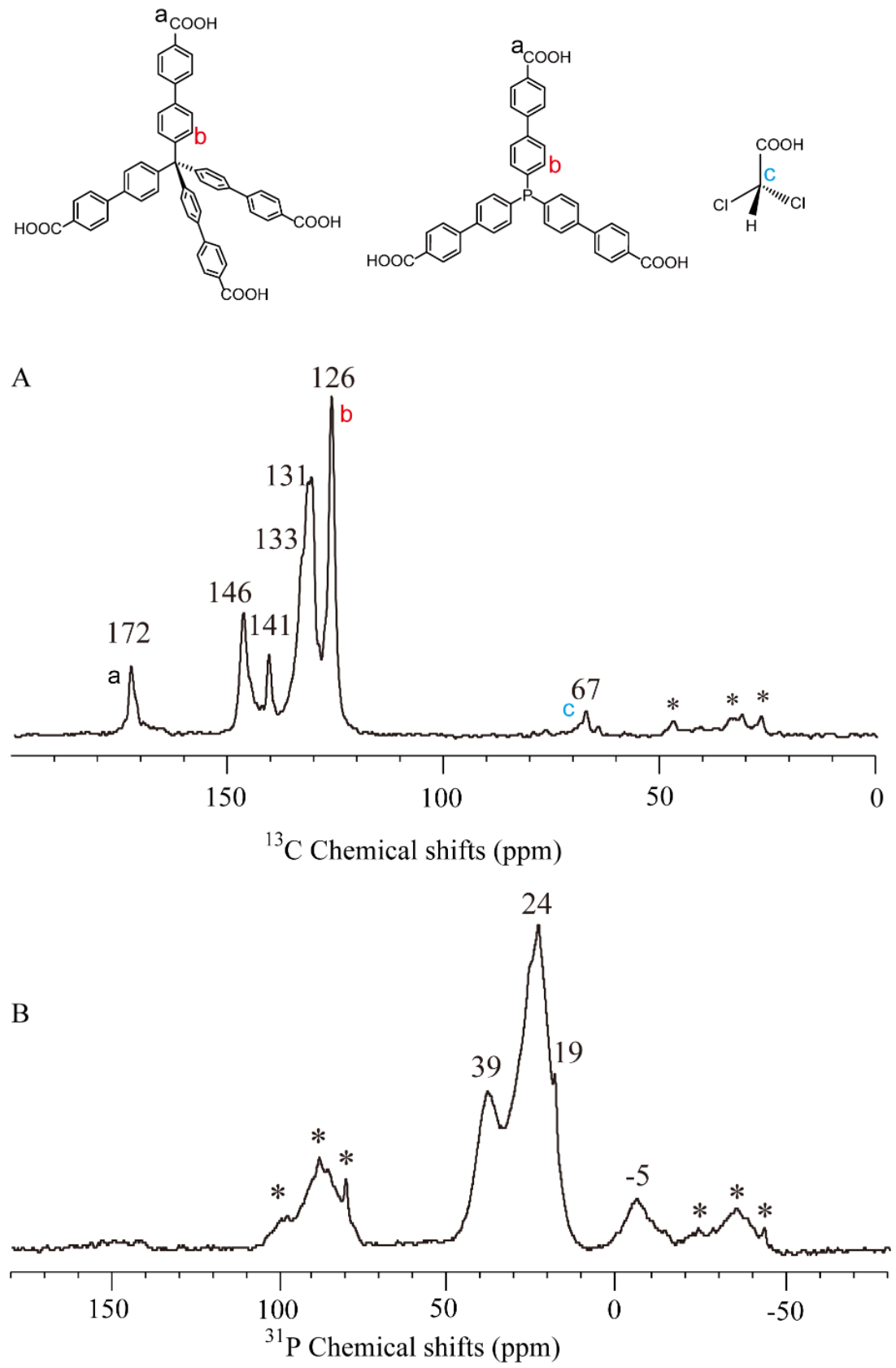

Figure S64. ${ }^{1} \mathrm{H}^{-13} \mathrm{C}$ CP/MAS NMR (A) and ${ }^{1} \mathrm{H}^{-31} \mathrm{P}$ CP/MAS NMR (B) spectrum of P-MV-PCN-521-DCA. Parts of ${ }^{13} \mathrm{C}$ chemical shift assignments are indicated in the molecular structure of MTBC, PBCA linkers, and coordinated DCA. The ${ }^{13} \mathrm{C}$ signal at $172 \mathrm{ppm}$ is assigned to coordinated $\mathrm{C}=\mathrm{O}$ group. The ${ }^{13} \mathrm{C}$ signals in range of $126 \sim 133 \mathrm{ppm}$ are arising from unsubstituted aromatic carbons. The ${ }^{31} \mathrm{P}$ NMR chemical shift at $-5 \mathrm{ppm}$ is assigned to the PBCA. The ${ }^{31} \mathrm{P}$ signal in range of 19 39 ppm indicates the presence of oxidized phosphorus (V) of P-MV-PCN-521-DCA. 

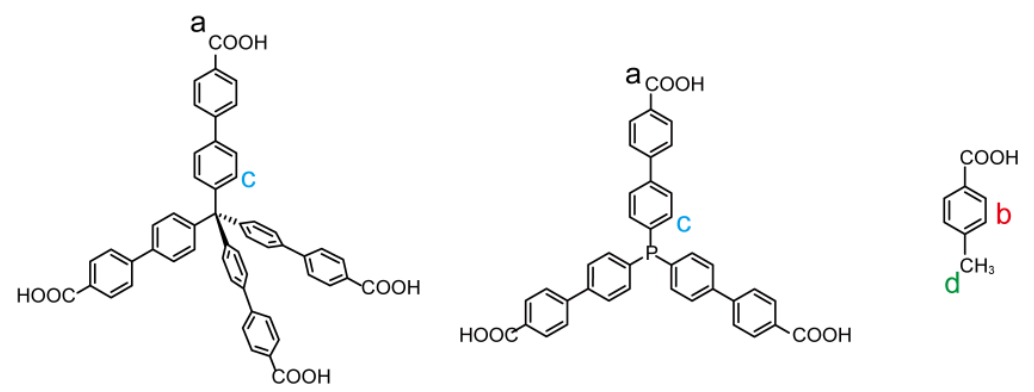

(a)
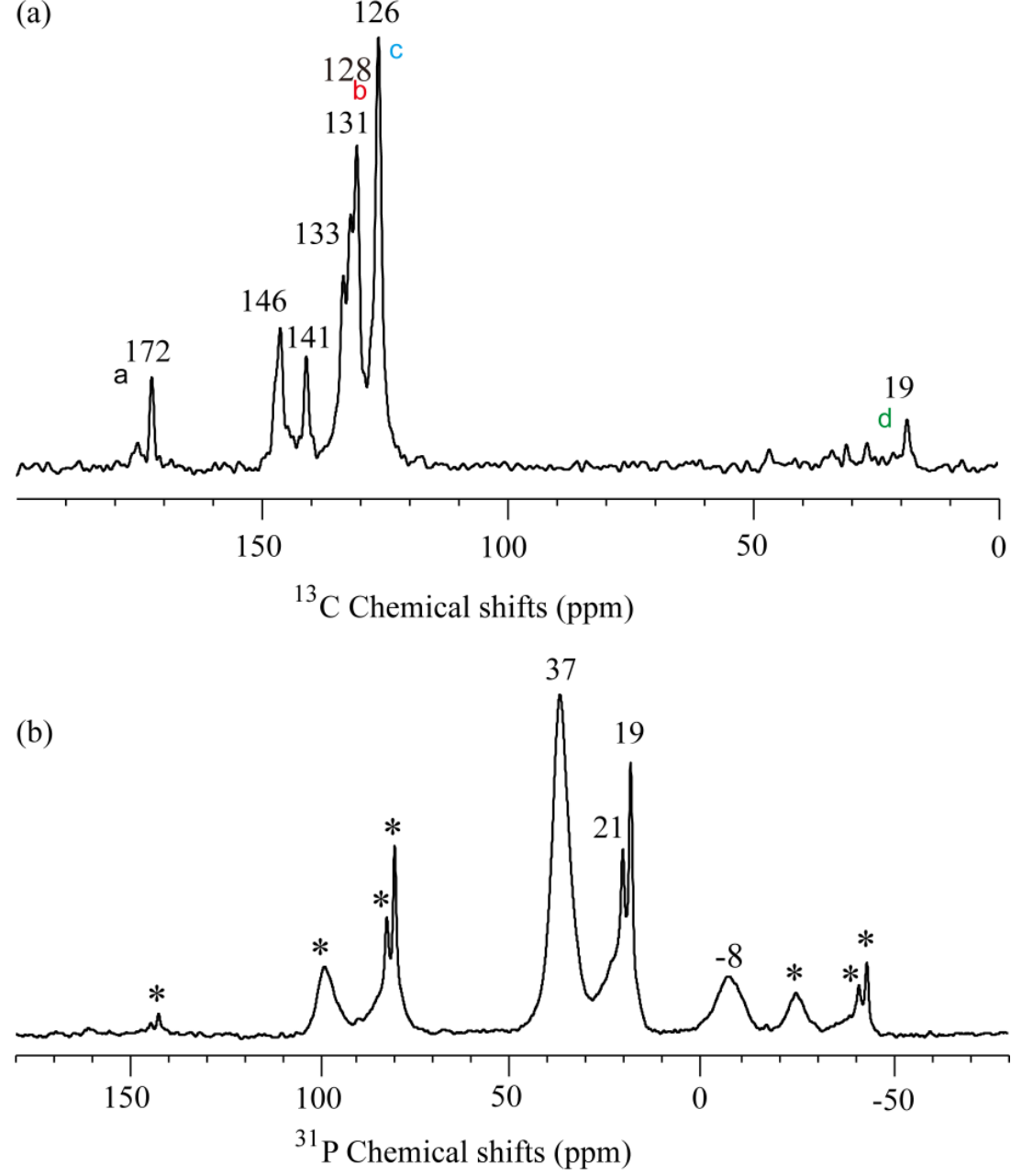

Figure S65. ${ }^{1} \mathrm{H}^{-13} \mathrm{C}$ CP/MAS NMR (A) and ${ }^{1} \mathrm{H}^{-31} \mathrm{P}$ CP/MAS NMR (B) spectra of P-MV-PCN-521PTA. Parts of ${ }^{13} \mathrm{C}$ chemical shift assignments are indicated in the molecular structure of MTBC, PBCA linkers, and coordinated PTA. The ${ }^{13} \mathrm{C}$ signal at $172 \mathrm{ppm}$ is assigned to coordinated $\mathrm{C}=\mathrm{O}$ group. The ${ }^{13} \mathrm{C}$ signals in range of $126 \sim 133 \mathrm{ppm}$ are arising from unsubstituted aromatic carbons. The ${ }^{31} \mathrm{P}$ NMR chemical shift at ca. $-8 \mathrm{ppm}$ is assigned to the PBCA. The ${ }^{31} \mathrm{P}$ signal in range of 19 37 ppm indicates the presence of oxidized phosphorus (V) of P-MV-PCN-521-PTA. 


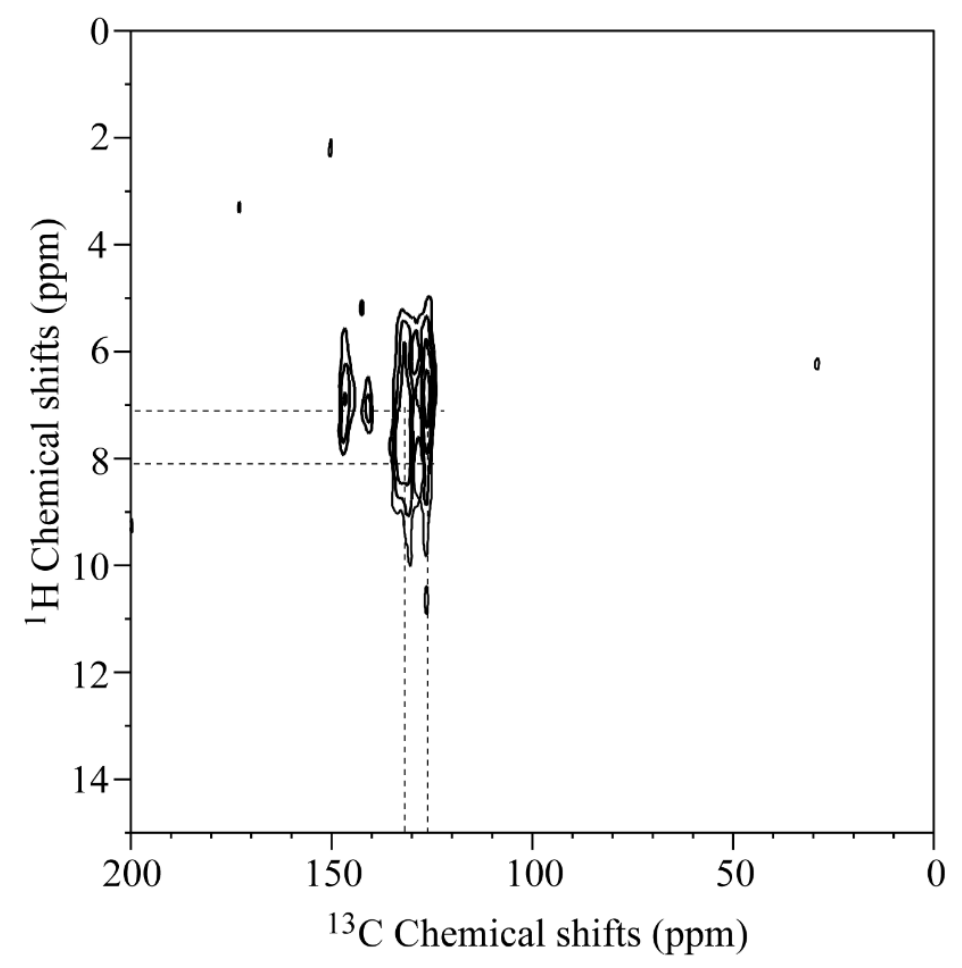

Figure S66. 2D ${ }^{1} \mathrm{H}-{ }^{13} \mathrm{C}$ HETCOR NMR spectrum of P-MV-PCN-521-DCA. The correlations between aromatic protons and aromatic carbons can be clearly resolved.

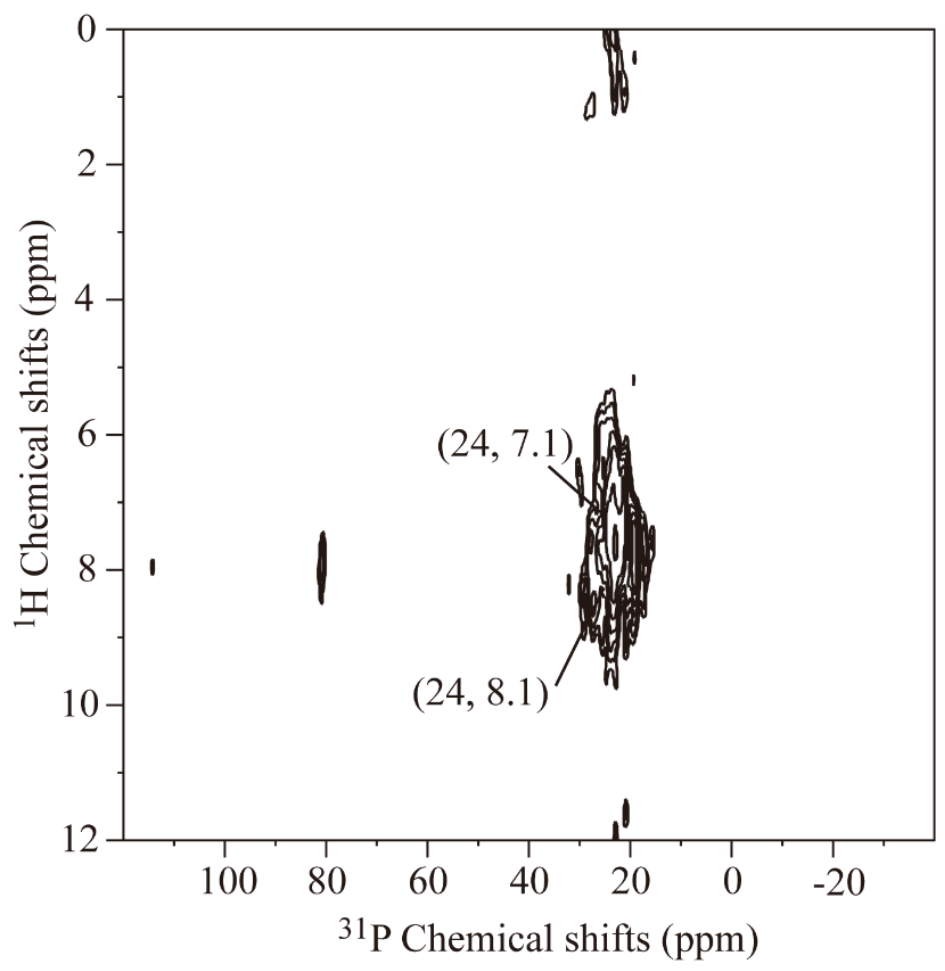

Figure S67. 2D ${ }^{1} \mathrm{H}-{ }^{31} \mathrm{P}$ HETCOR NMR spectrum of P-MV-PCN-521-DCA. The correlations between aromatic protons and PBCA phosphorus sites can be clearly resolved. 


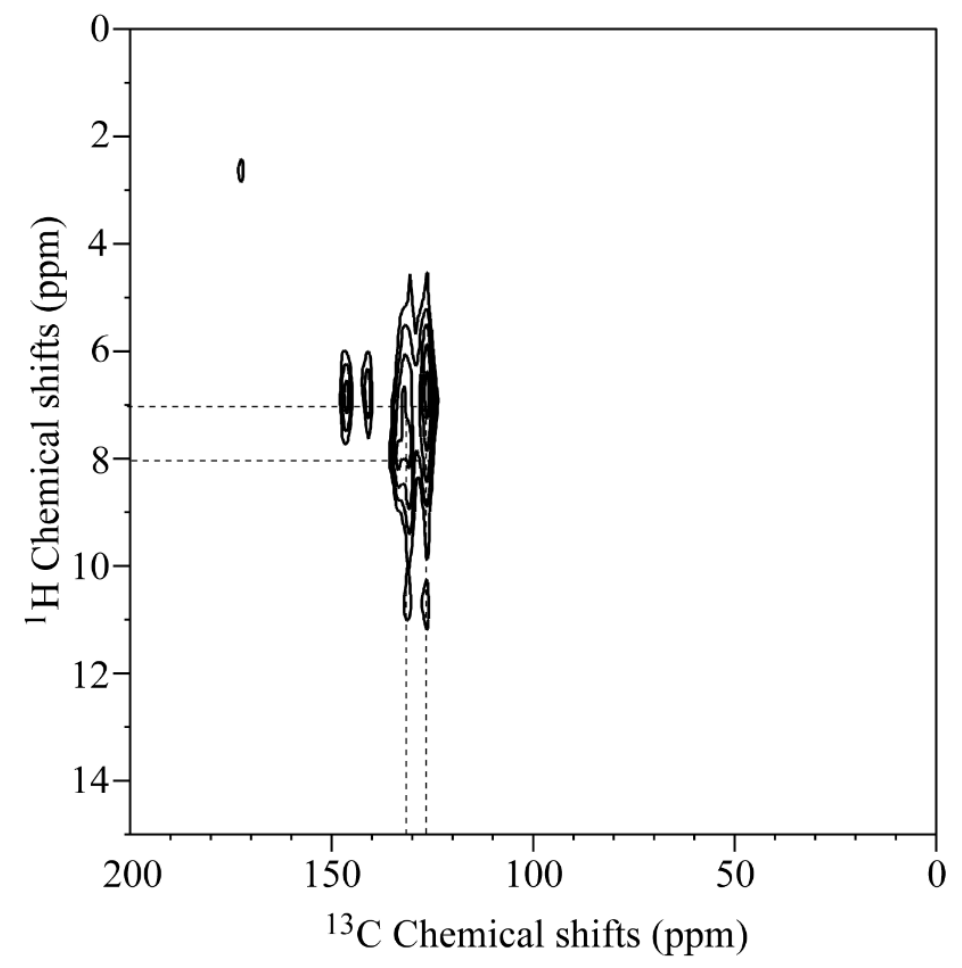

Figure S68. 2D ${ }^{1} \mathrm{H}-{ }^{13} \mathrm{C}$ HETCOR NMR spectrum of P-MV-PCN-521-PTA. The correlations between aromatic protons and aromatic carbons can be clearly resolved.

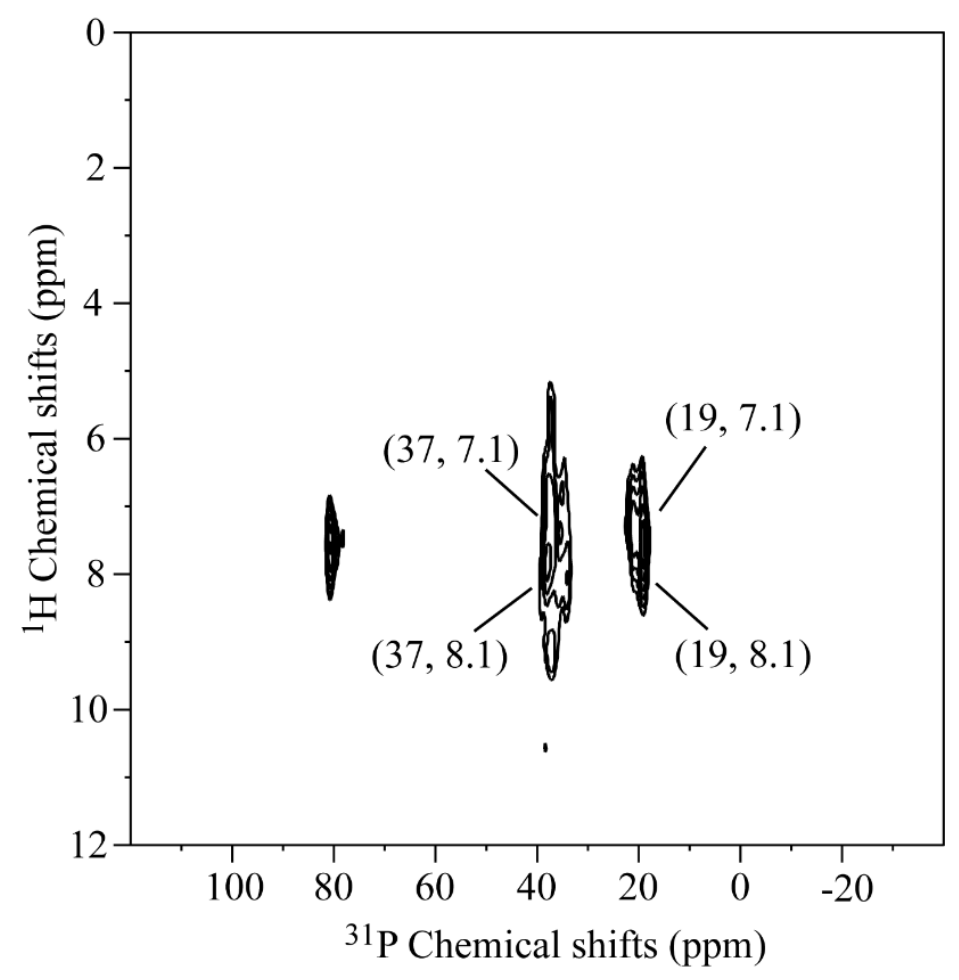

Figure S69. 2D ${ }^{1} \mathrm{H}-{ }^{31} \mathrm{P}$ HETCOR NMR spectrum of P-MV-PCN-521-PTA. The correlations between aromatic protons and PBCA phosphorus sites can be clearly resolved. 

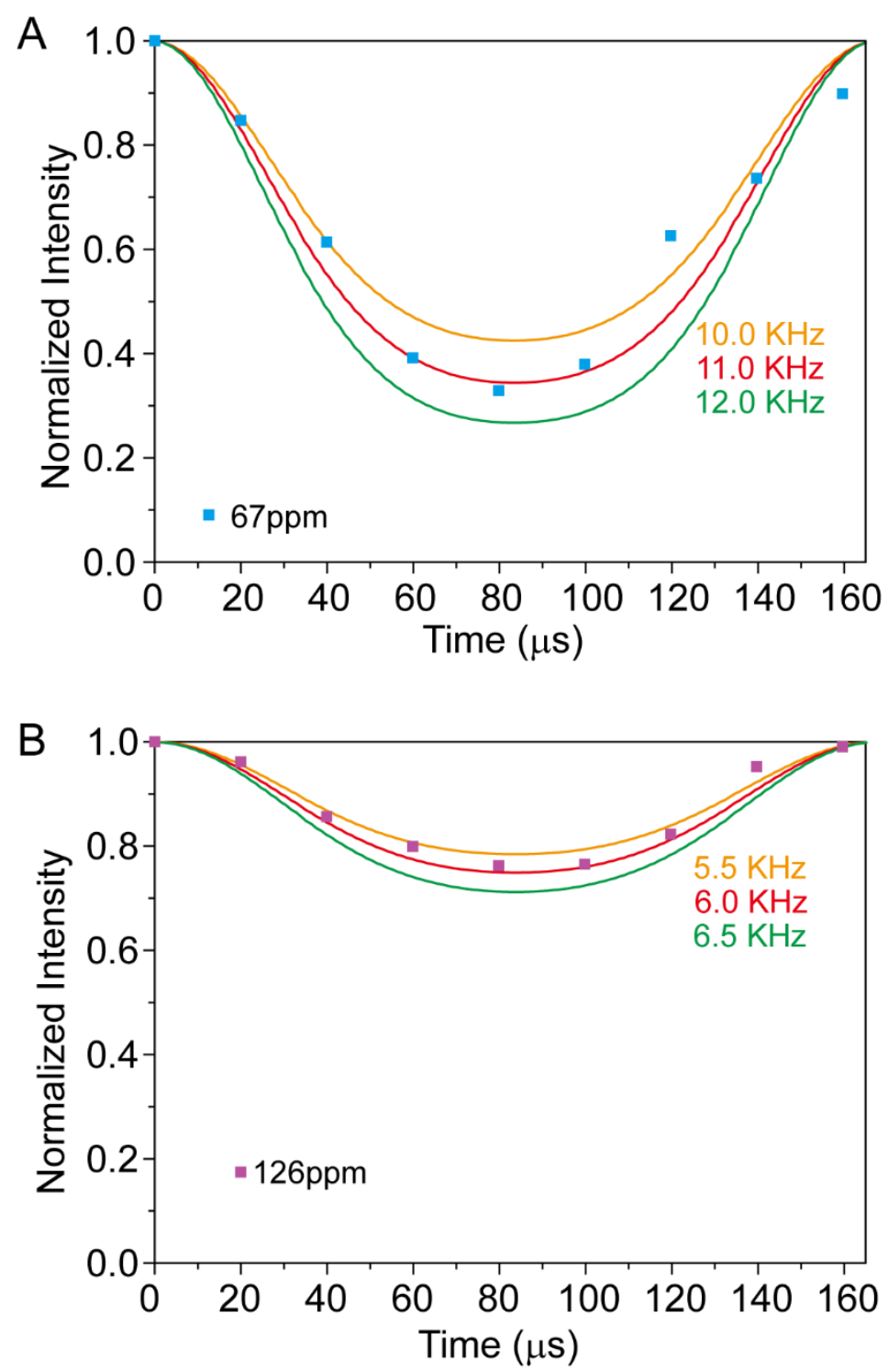

Figure S70. ${ }^{1} \mathrm{H}-{ }^{13} \mathrm{C}$ DIPSHIFT time evolution curves of (A) DCA dichloromethyl group (67 ppm) and (B) unsubstituted aromatic carbon (126 ppm) in the linker of P-MV-PCN-521-DCA. The simulated ${ }^{1} \mathrm{H}-{ }^{13} \mathrm{C}$ one-bond dipole coupling for DCA dichloromethyl group (67 ppm) is $19.1 \mathrm{kHz}$, corresponding to a $S_{\mathrm{CH}}$ order parameter of 0.80 . The simulated ${ }^{1} \mathrm{H}^{-13} \mathrm{C}$ one-bond dipole coupling for unsubstituted aromatic carbon $(126 \mathrm{ppm})$ in the linker is $10.4 \mathrm{kHz}$, corresponding to a $S_{\mathrm{CH}}$ order parameter of 0.44 

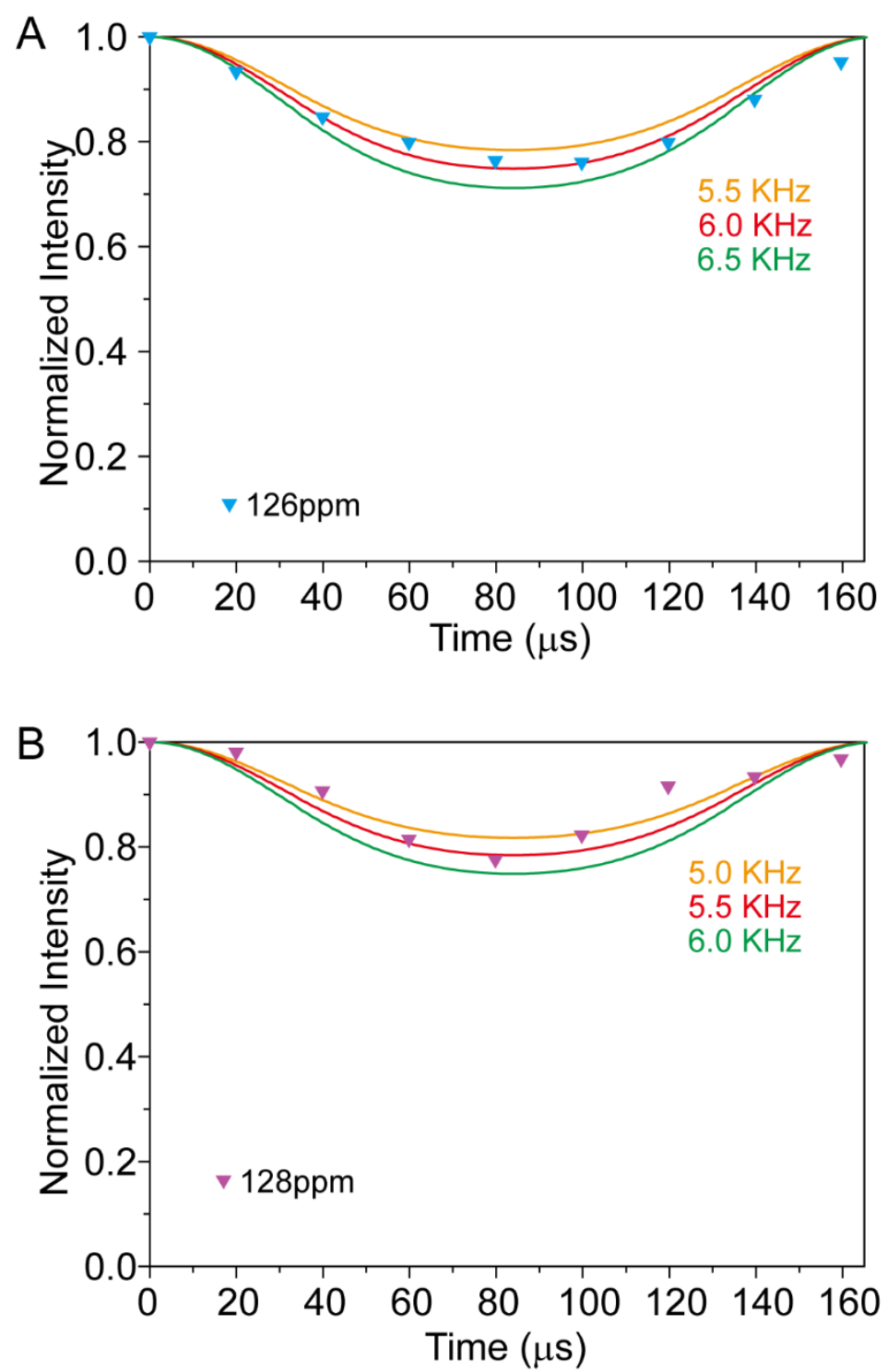

Figure S71. ${ }^{1} \mathrm{H}^{-13} \mathrm{C}$ DIPSHIFT time evolution curves of (A) unsubstituted aromatic carbon (126 ppm) in the linker and (B) PTA unsubstituted aromatic carbon (128 ppm) of P-MV-PCN-521-PTA. The simulated ${ }^{1} \mathrm{H}-{ }^{13} \mathrm{C}$ one-bond dipole coupling for unsubstituted aromatic carbon (126 ppm) in the linker is $10.4 \mathrm{kHz}$, corresponding to a $S_{\mathrm{CH}}$ order parameter of 0.44 . The simulated ${ }^{1} \mathrm{H}^{13}{ }^{13} \mathrm{C}$ one-bond dipole coupling for PTA unsubstituted aromatic carbon (128 ppm) is $9.5 \mathrm{kHz}$, corresponding to a $S_{\mathrm{CH}}$ order parameter of 0.40 . 

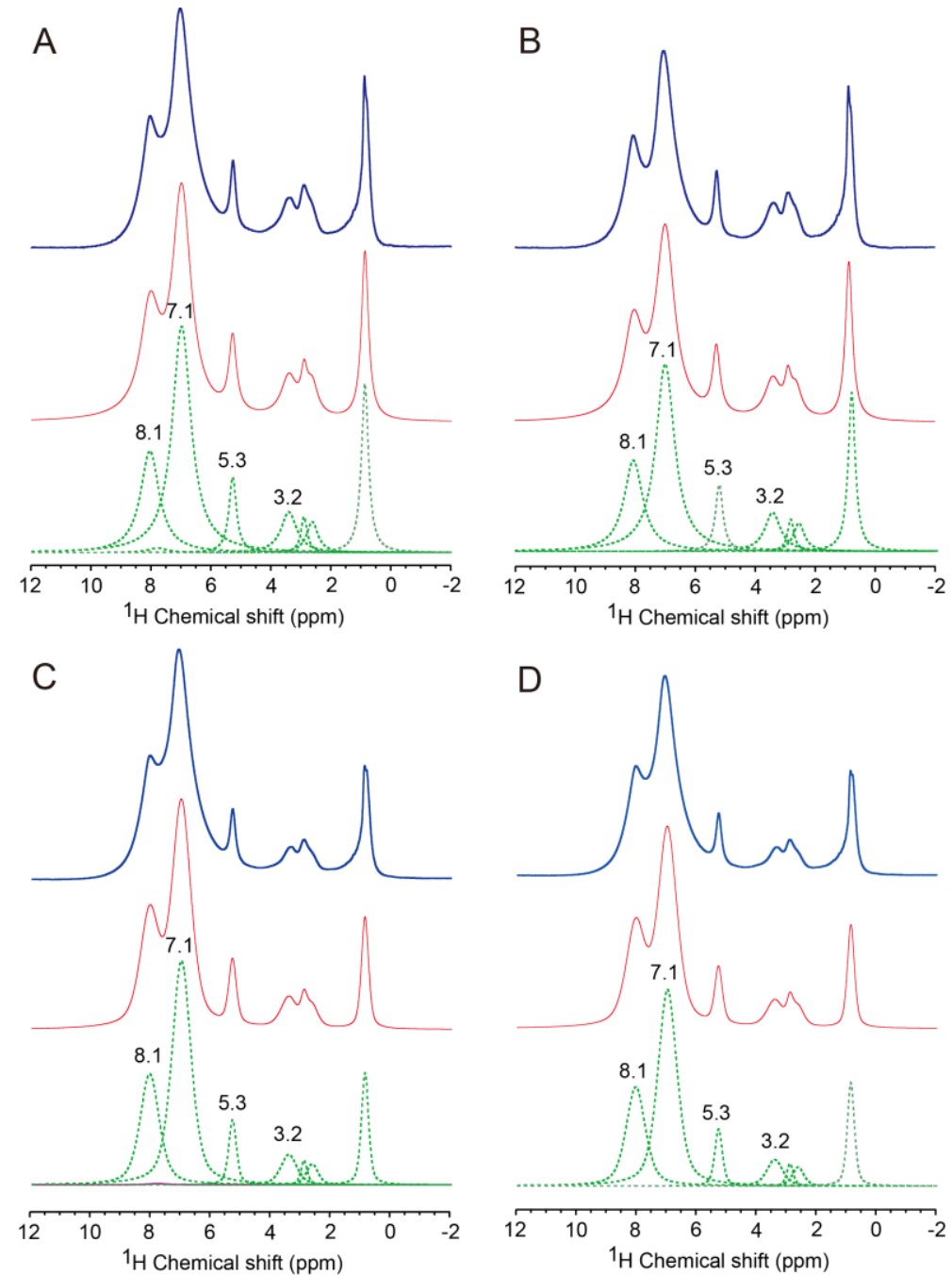

Figure S72. Deconvolution of ${ }^{1} \mathrm{H}-{ }^{31} \mathrm{P}$ REDOR NMR spectra of P-MV-PCN-521-DCA recorded without ( $\mathrm{S}_{0}$, left column) and with ( $\mathrm{S}$, right column) ${ }^{1} \mathrm{H}^{3}{ }^{31} \mathrm{P}$ dipolar recoupling time of $10 \mathrm{~ms}$ (A, B) and $6 \mathrm{~ms}(\mathrm{C}, \mathrm{D})$. 

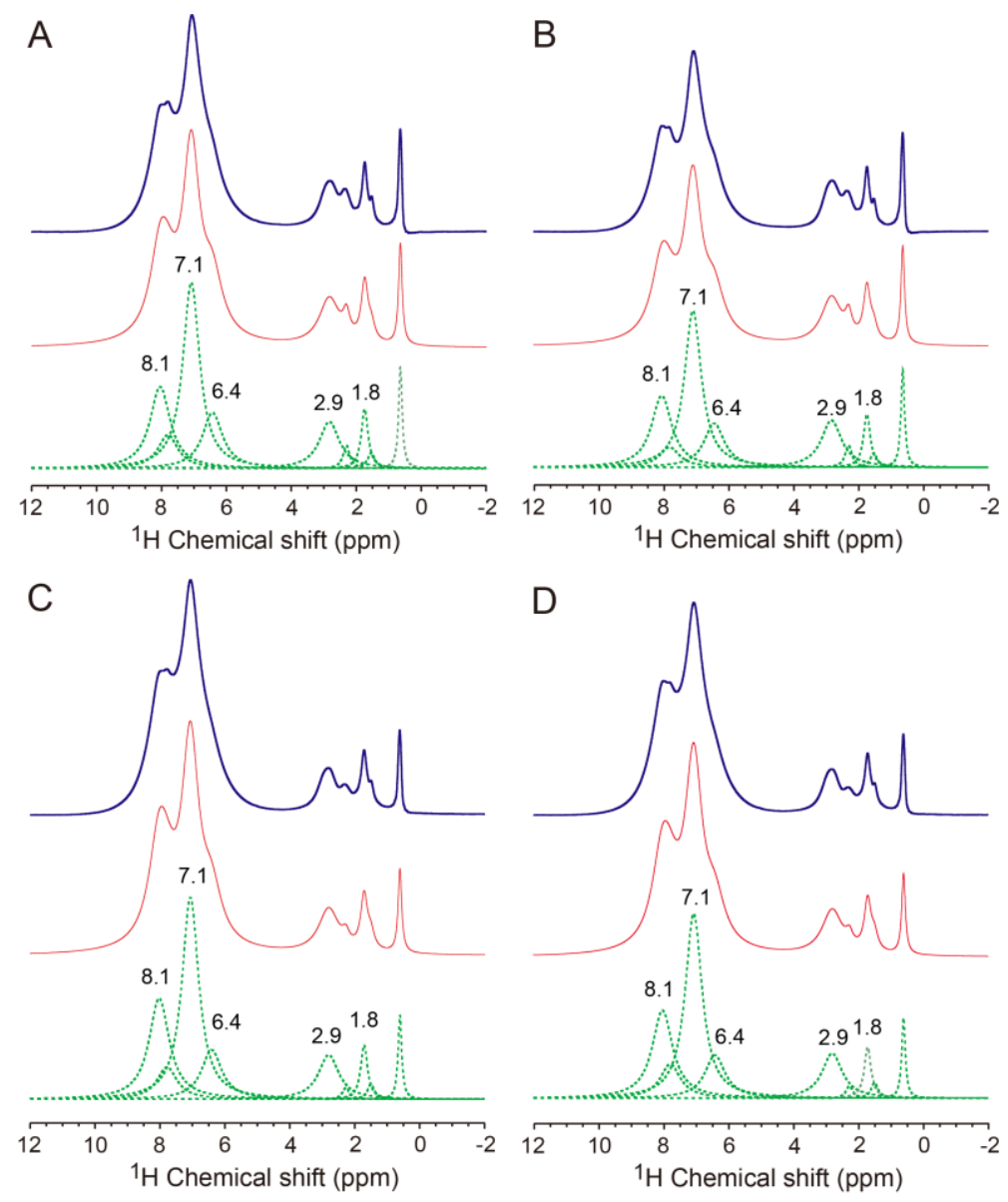

Figure S73. Deconvolution of ${ }^{1} \mathrm{H}_{-}{ }^{31} \mathrm{P}$ REDOR NMR spectra of P-MV-PCN-521-PTA recorded without $\left(\mathrm{S}_{0}\right.$, left column) and with $(\mathrm{S}$, right column $){ }^{1} \mathrm{H}_{-}{ }^{31} \mathrm{P}$ dipolar recoupling time of $10 \mathrm{~ms}(\mathrm{~A}, \mathrm{~B})$ and $6 \mathrm{~ms}(\mathrm{C}, \mathrm{D})$.

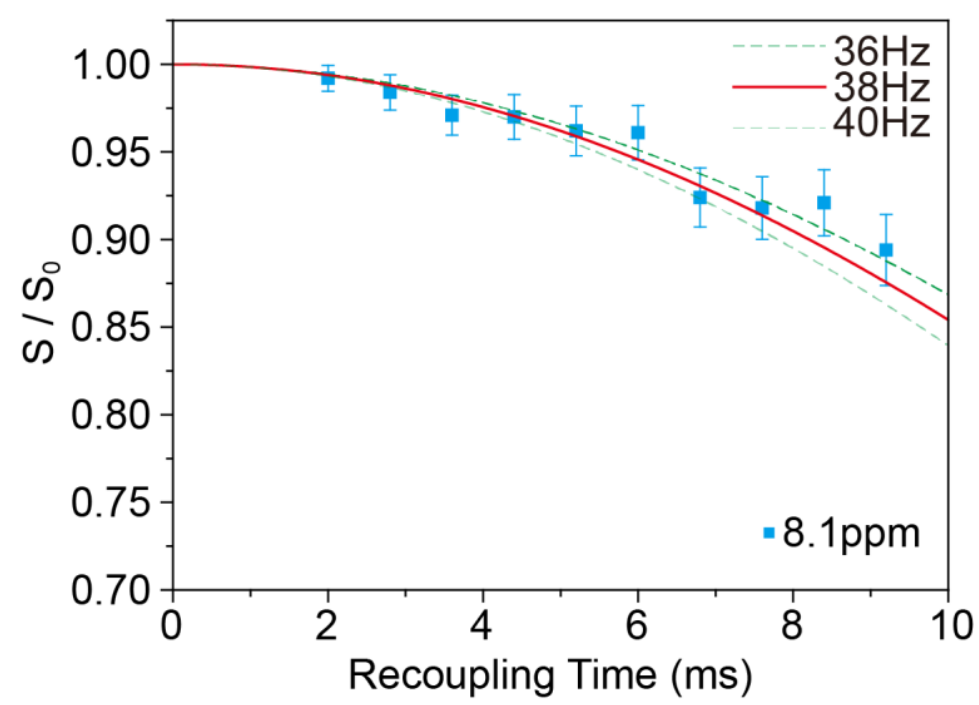

Figure S74. ${ }^{1} \mathrm{H}^{31} \mathrm{P}$ REDOR dephasing curve of aromatic protons at ca. $8.1 \mathrm{ppm}$ in P-MV-PCN-521-DCA 


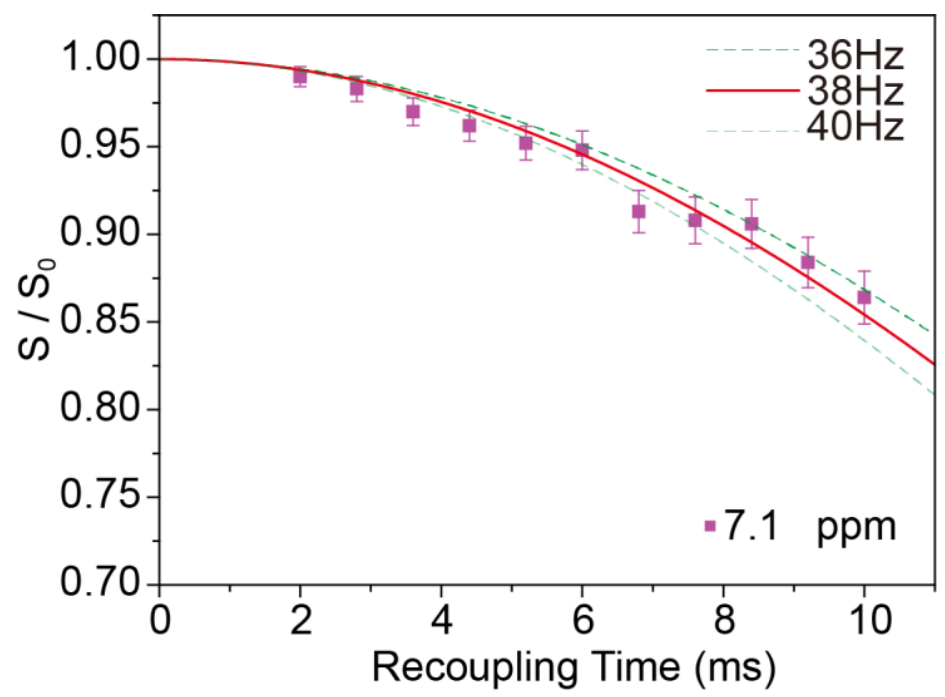

Figure S75. ${ }^{1} \mathrm{H}^{-31} \mathrm{P}$ REDOR dephasing curve of aromatic protons at $7.1 \mathrm{ppm}$ in P-MV-PCN-521-DCA.

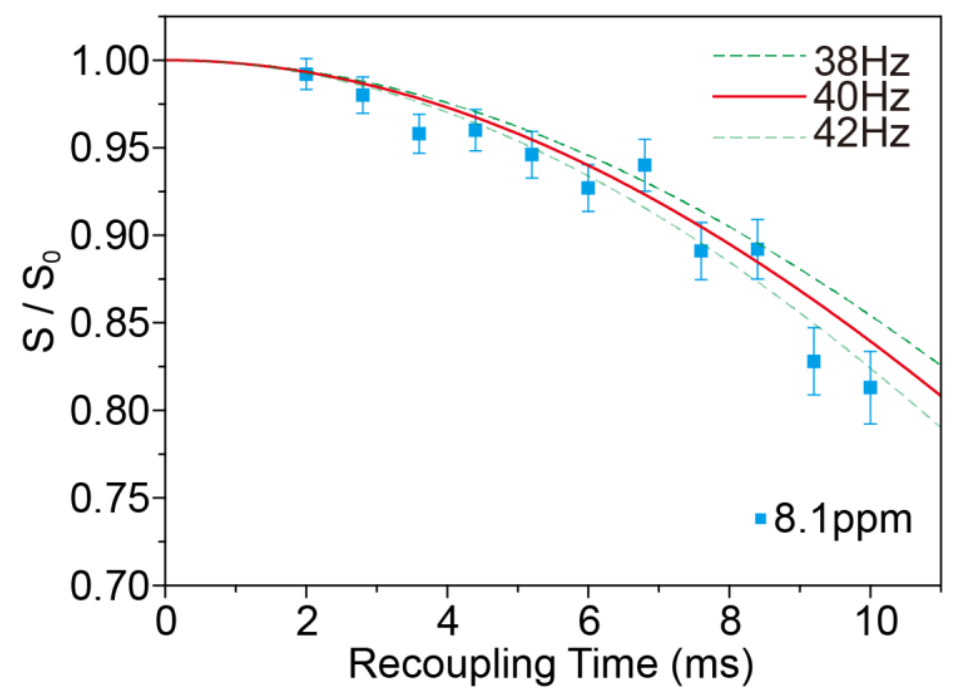

Figure S76. ${ }^{1} \mathrm{H}_{-}{ }^{31} \mathrm{P}$ REDOR dephasing curve of aromatic protons at ca. $8.1 \mathrm{ppm}$ in P-MV-PCN-521-PTA. 


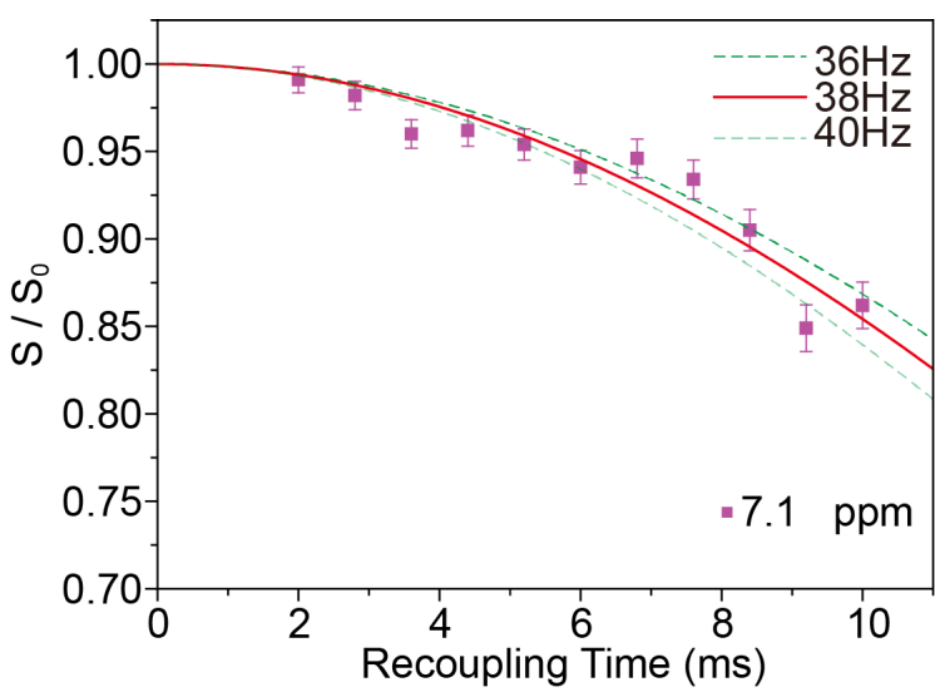

Figure S77. ${ }^{1} \mathrm{H}^{-31} \mathrm{P}$ REDOR dephasing curve of aromatic protons at $7.1 \mathrm{ppm}$ in P-MV-PCN-521-PTA.

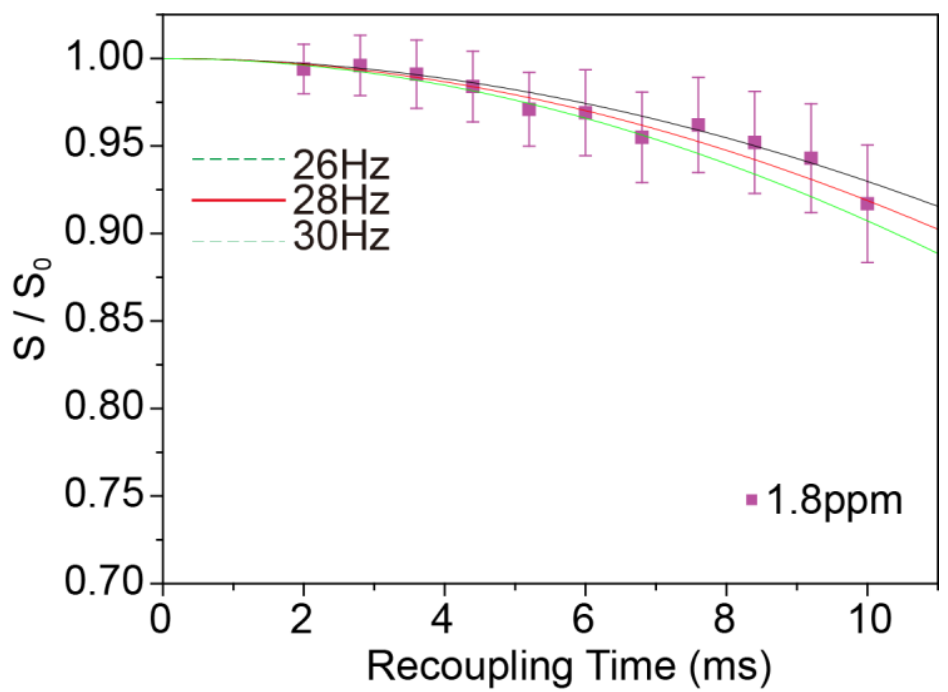

Figure S78. ${ }^{1} \mathrm{H}-{ }^{31} \mathrm{P}$ REDOR dephasing curves of the protons from PTA methyl groups at $1.8 \mathrm{ppm}$ in P-MV-PCN-521-PTA. The presence of three-site jump rotation of methyl group would further results in $S_{\mathrm{CH}}$ order parameter of PTA methyl further being scaled to around $0.33 .{ }^{1} \mathrm{H}^{-31} \mathrm{P}$ dipolar couplings constant between PTA methyl group protons and ${ }^{31} \mathrm{P}$ atom of PBCA is roughly scaled to 0.057 0.132. Thus, the average ${ }^{1} \mathrm{H}-{ }^{31} \mathrm{P}$ distance between PTA methyl group protons and PBCA phosphorus site is determined to be ranged from 4.6 to $6.0 \AA$. 


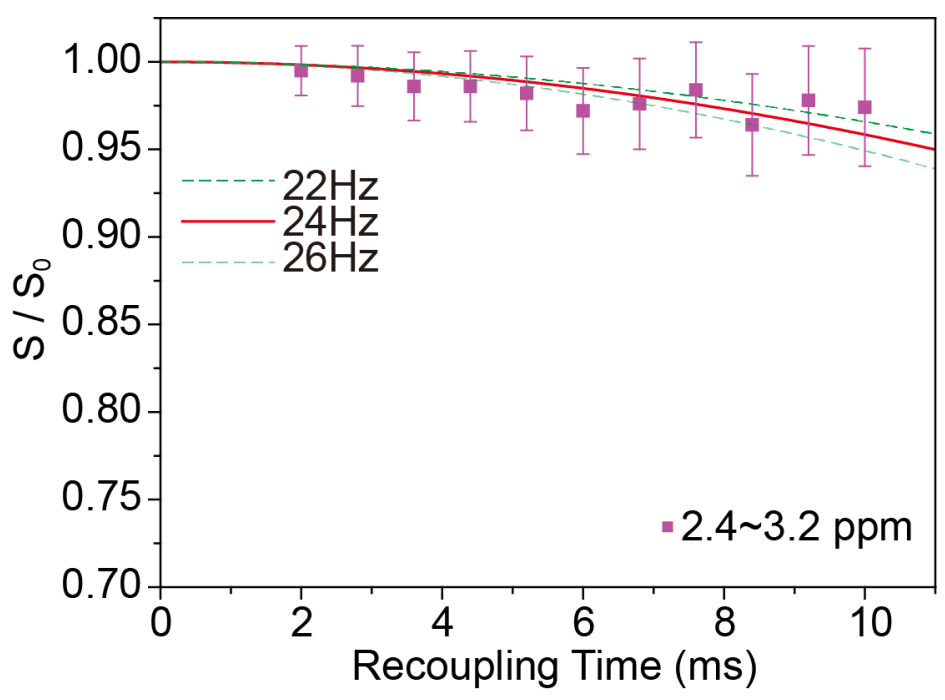

Figure S79. ${ }^{1} \mathrm{H}-{ }^{31} \mathrm{P}$ REDOR dephasing curves of the protons from zirconium hydroxyl groups at 2.4 3.2 ppm in P-MV-PCN-521-DCA. ${ }^{1} \mathrm{H}-{ }^{31} \mathrm{P}$ dipolar couplings constant between zirconium hydroxyl groups and ${ }^{31} \mathrm{P}$ atom of $\mathrm{PBCA}$ is roughly estimated to be scaled to $0.44 \sim 1.0$. The average ${ }^{1} \mathrm{H}-{ }^{31} \mathrm{P}$ distance between zirconium hydroxyl group protons and PBCA phosphorus site is determined to be ranged from 10.2 to $13.5 \AA$.

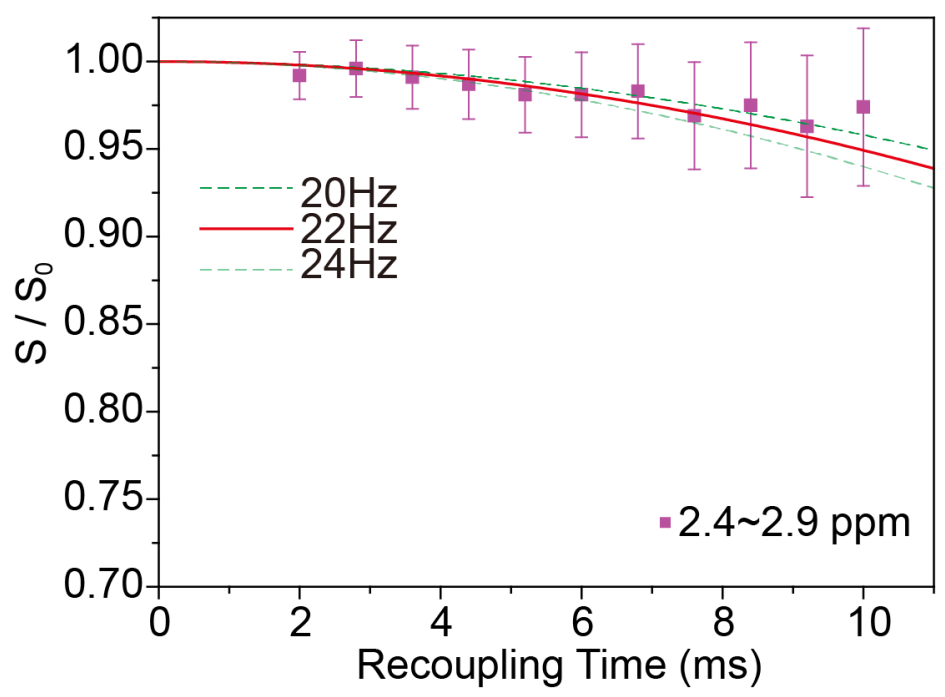

Figure S80. ${ }^{1} \mathrm{H}-{ }^{31} \mathrm{P}$ REDOR dephasing curves of the protons from zirconium hydroxyl groups at 2.4 2.9 ppm in P-MV-PCN-521-PTA. ${ }^{1} \mathrm{H}^{3}{ }^{31} \mathrm{P}$ dipolar couplings constant between zirconium hydroxyl groups and ${ }^{31} \mathrm{P}$ atom of PBCA is roughly estimated to be scaled to $0.44 \sim 0.80$. The average ${ }^{1} \mathrm{H}-{ }^{31} \mathrm{P}$ distance between zirconium hydroxyl group protons and PBCA phosphorus site is determined to be ranged from 10.0 to $13.1 \AA$. 


\section{Section S6 Stability assessment of MV-MOFs}

The chemical stability of MV-MOFs was assessed by immersion MOFs in water under acid condition. Specifically, the activated MV-PCN-521-BA was immersed in water, DCE, $1 \mathrm{M} \mathrm{HCl}$ for $24 \mathrm{~h}$, respectively. The unaltered PXRD patterns of these samples after immersion test indicated that these MV-MOF were stable in water, DCE or acidic solution.

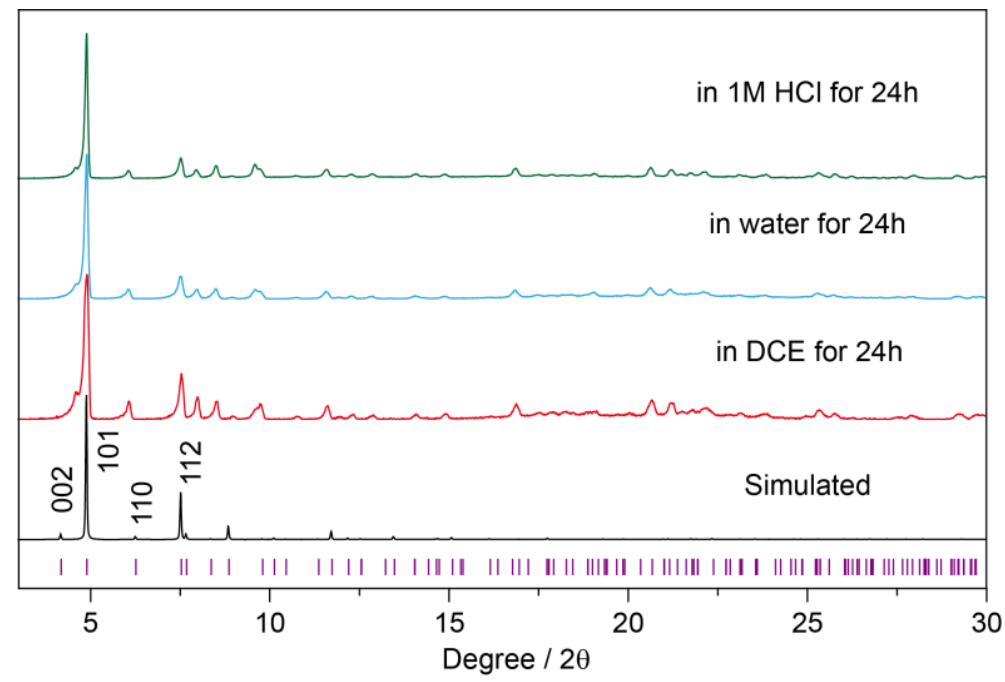

Figure S81. PXRD patterns of N-MV-PCN-521-BA crystals after immersion tests. The well-match between these patterns with the simulated diffraction patterns based on PCN-521single crystal data demonstrated the excellent chemical stability of these MV-MOFs. 


\section{Section $\mathrm{S} 7 \mathrm{~N}_{2}$ adsorptions analysis of MV-MOFs}

\section{METHODS:}

The porosity of MV-PCN-521 series was assessed by $\mathrm{N}_{2}$ adsorption analysis. $\mathrm{N}_{2}$ isotherms were measured on a Quantachrome Autosorb $\mathrm{iQ}_{2}$ automatic volumetric instrument. The temperature of $\mathrm{N}_{2}$ isotherms at $77 \mathrm{~K}$ was controlled using a liquid nitrogen bath. To estimate pore size distribution for these MV-PCN-521 samples, non-local density functional theory (NLDFT) (S12) based on a carbon model was used for the fitting of $\mathrm{N}_{2}$ isotherms at $77 \mathrm{~K}$, ranging from 2592 to $3455 \mathrm{~m}^{2} / \mathrm{g}$ (Figure S82 to S95).

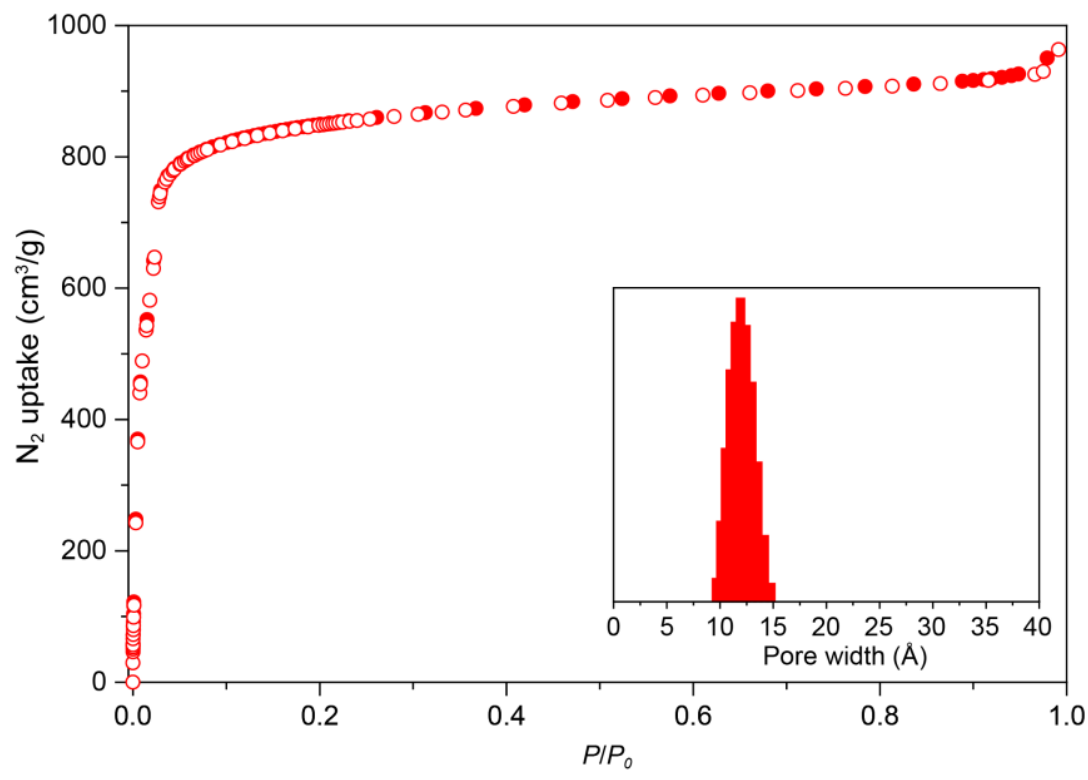

Figure S82. $\mathrm{N}_{2}$ isotherm of PCN-521 at $77 \mathrm{~K}$. Open and filled symbols represent adsorption and desorption balance, respectively. Insert, pore distribution of PCN-521.
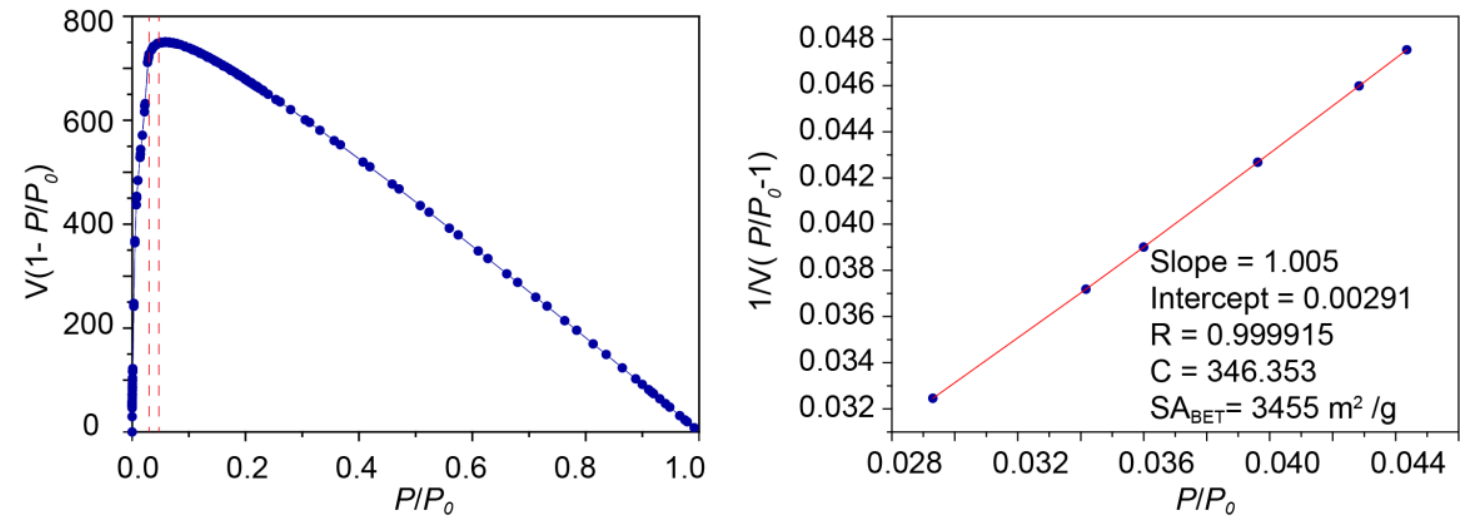

Figure S83. BET surface area calculation for PCN-521 from simulated nitrogen isotherm at

$77 \mathrm{~K}$ (A) Only points between the dashed line are selected based on the first consistency criterion, (B) Plot to select linear $P / P$ orange. 


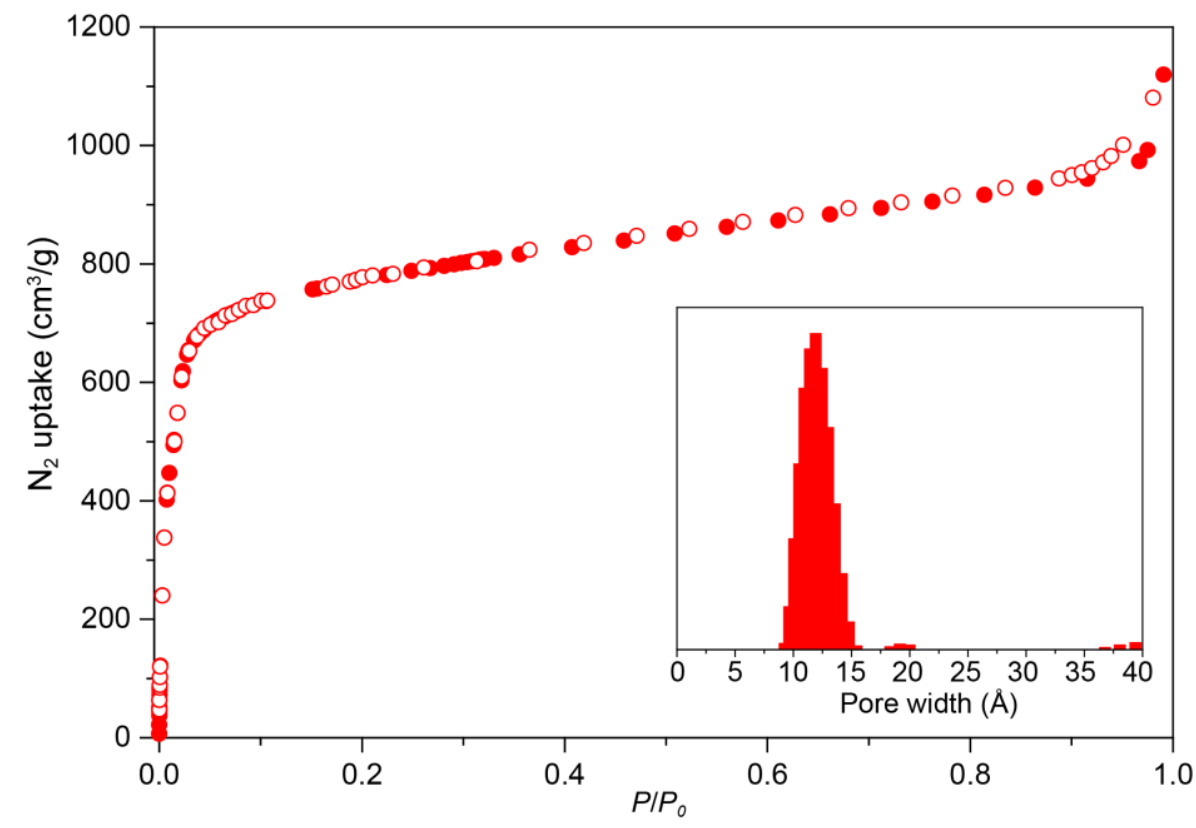

Figure S84. $\mathrm{N}_{2}$ isotherm of N-PCN-521-BA at $77 \mathrm{~K}$. Open and filled symbols represent adsorption and desorption balance, respectively. Insert, pore distribution of N-PCN-521-BA.
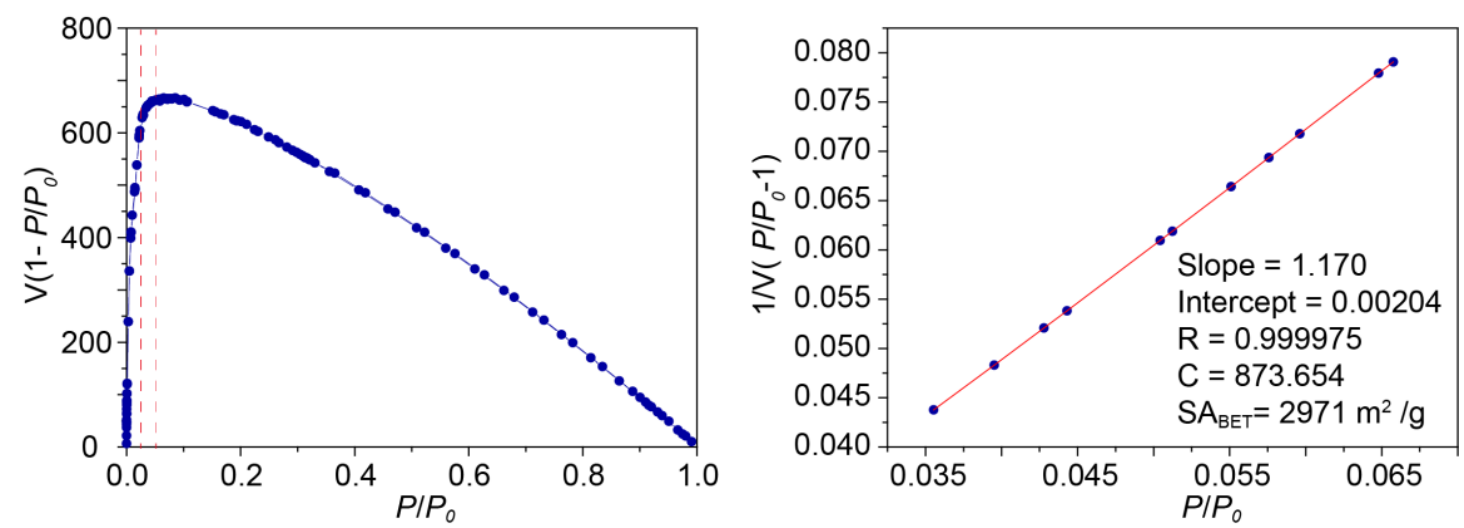

Figure S85. BET surface area calculation for N-PCN-521-BA from simulated nitrogen isotherm at $77 \mathrm{~K}$ (A) Only points between the dashed line are selected based on the first consistency criterion, (B) Plot to select linear $P / P$ o range. 


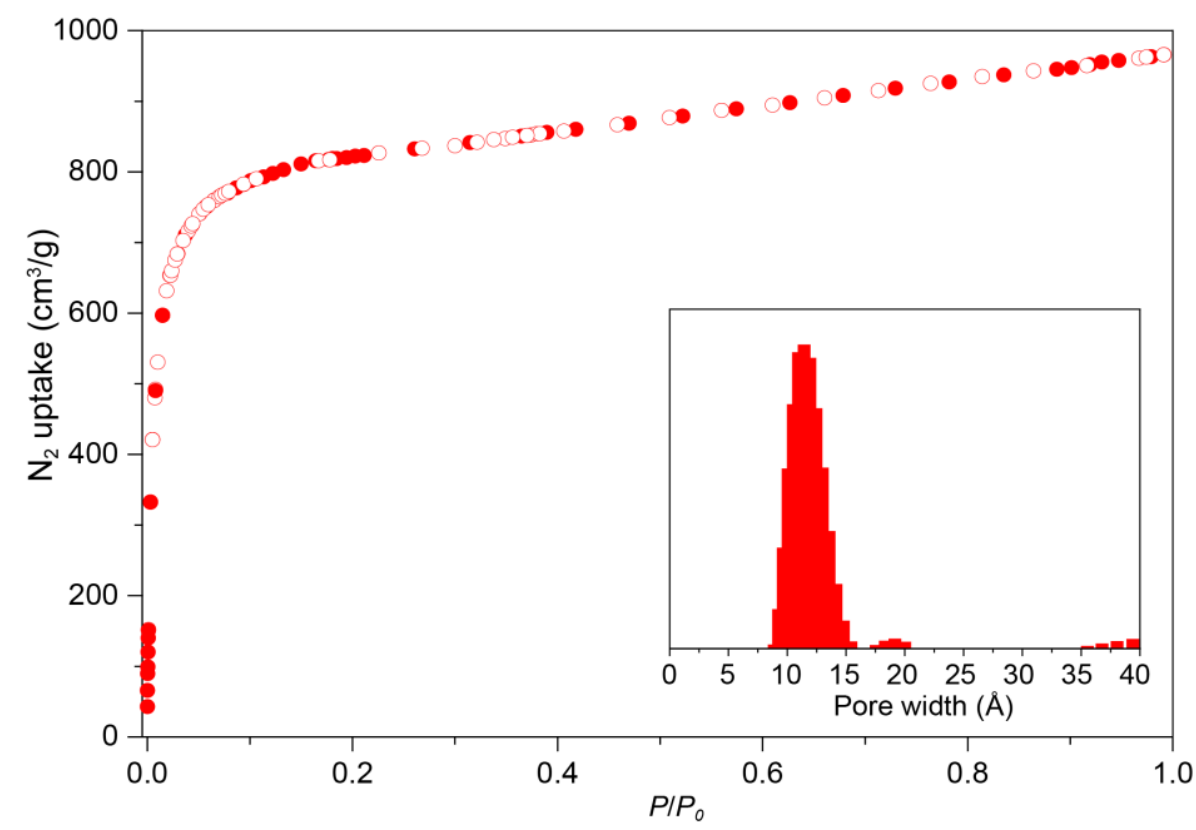

Figure S86. $\mathrm{N}_{2}$ isotherm of N-PCN-521-NBA at $77 \mathrm{~K}$. Open and filled symbols represent adsorption and desorption balance, respectively. Insert, pore distribution of N-PCN-521-NBA.
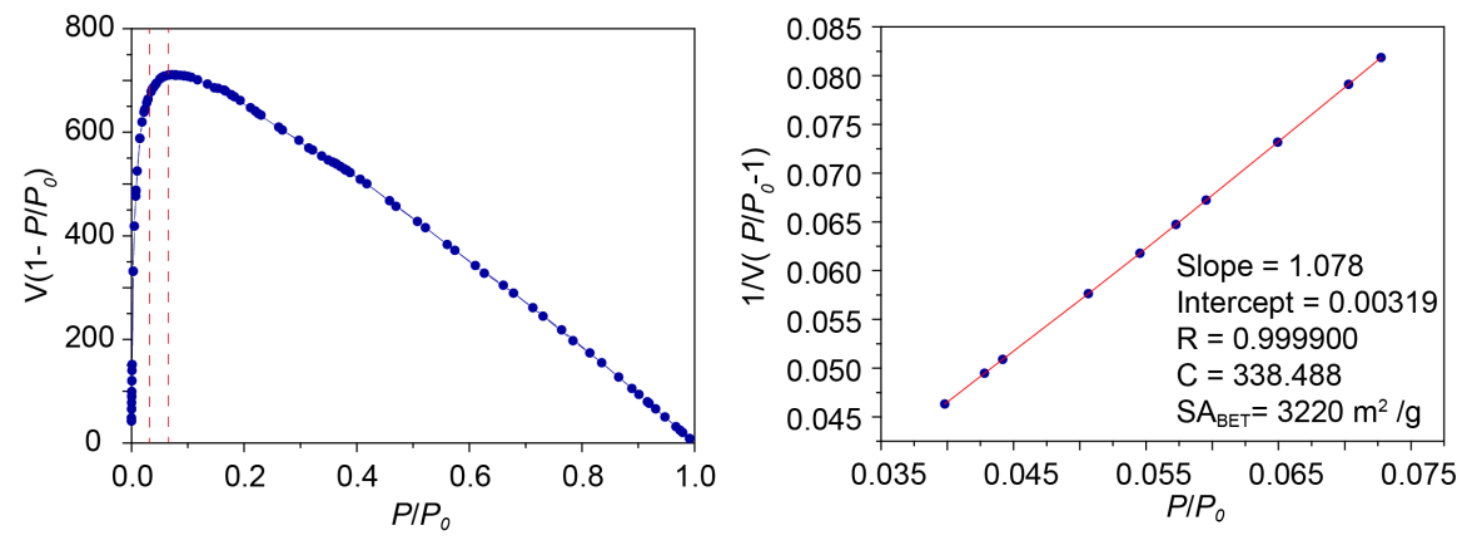

Figure S87. BET surface area calculation for N-PCN-521-NBA from simulated nitrogen isotherm at $77 \mathrm{~K}$ (A) Only points between the dashed line are selected based on the first consistency criterion, (B) Plot to select linear $P / P_{0}$ range. 


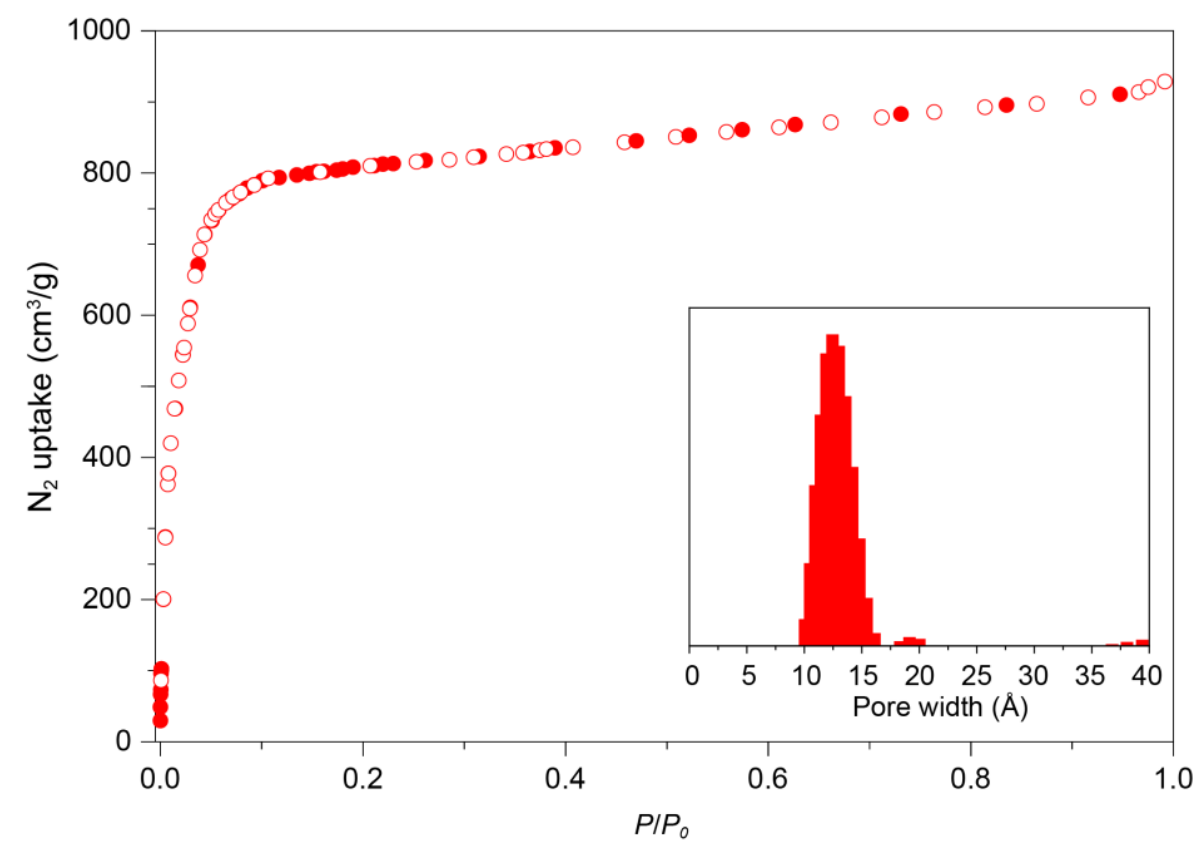

Figure S88. $\mathrm{N}_{2}$ isotherm of N-PCN-521-FA at $77 \mathrm{~K}$. Open and filled symbols represent adsorption and desorption balance, respectively. Insert, pore distribution of N-PCN-521-FA.
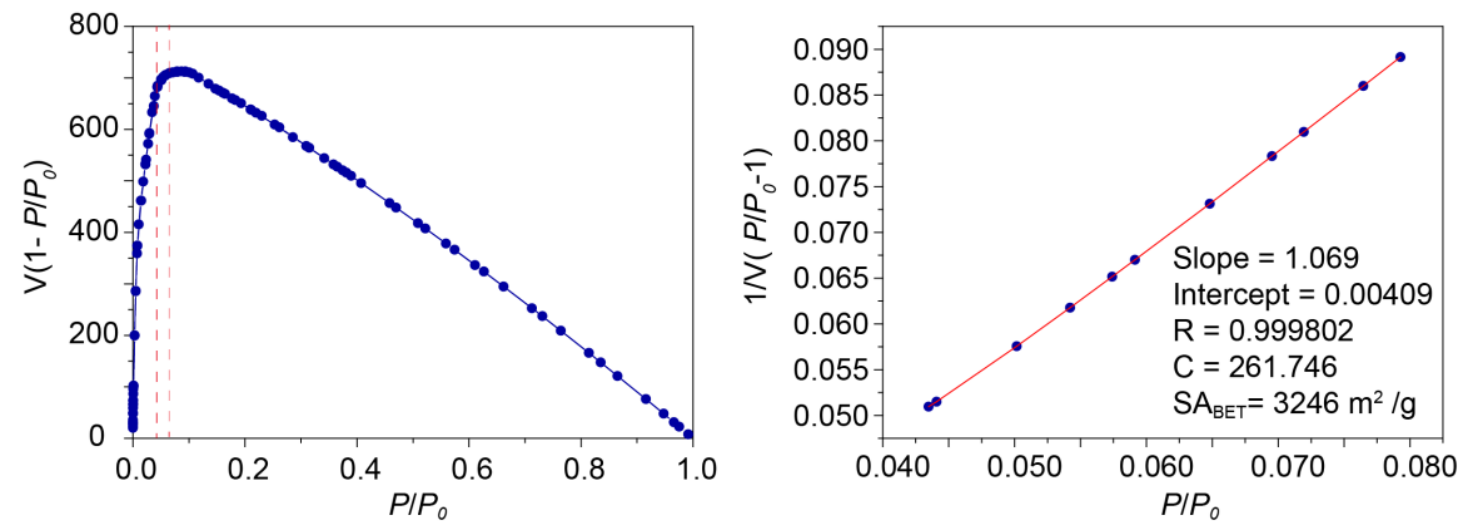

Figure S89. BET surface area calculation for N-PCN-521-FA from simulated nitrogen isotherm at $77 \mathrm{~K}$ (A) Only points between the dashed line are selected based on the first consistency criterion, (B) Plot to select linear $P / P_{0}$ range. 


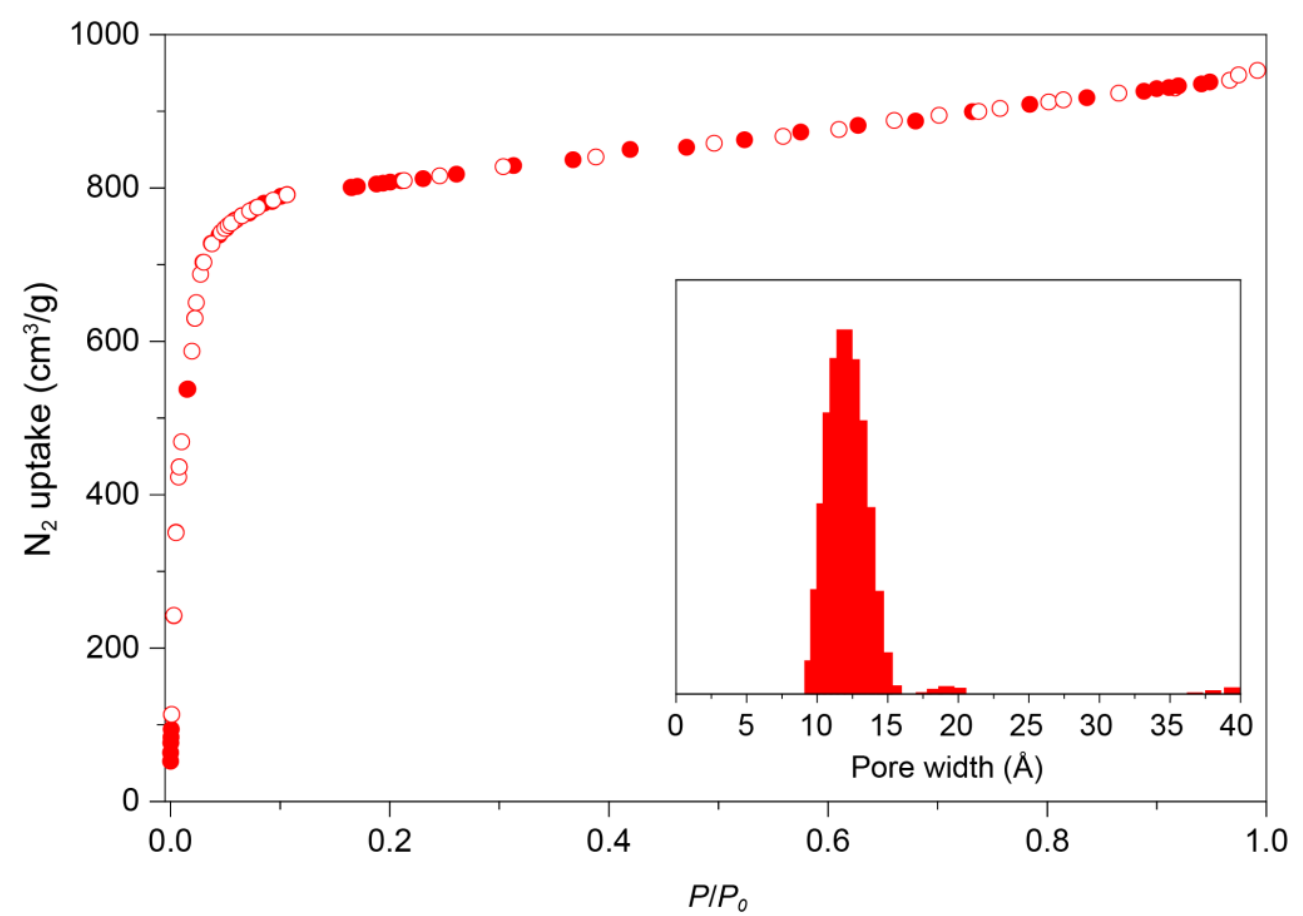

Figure S90. $\mathrm{N}_{2}$ isotherm of P-PCN-521-BA at $77 \mathrm{~K}$. Open and filled symbols represent adsorption and desorption balance, respectively. Insert, pore distribution of P-PCN-521-BA.
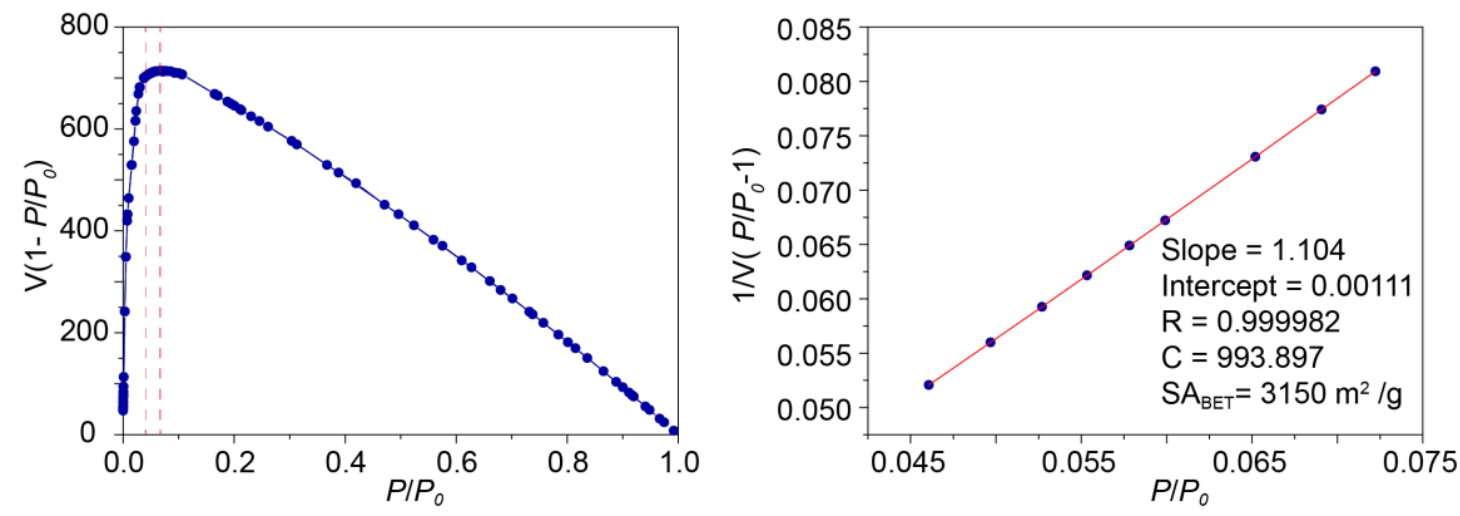

Figure S91. BET surface area calculation for P-PCN-521-BA from simulated nitrogen isotherm at $77 \mathrm{~K}$ (A) Only points between the dashed line are selected based on the first consistency criterion, (B) Plot to select linear $P / P_{0}$ range. 


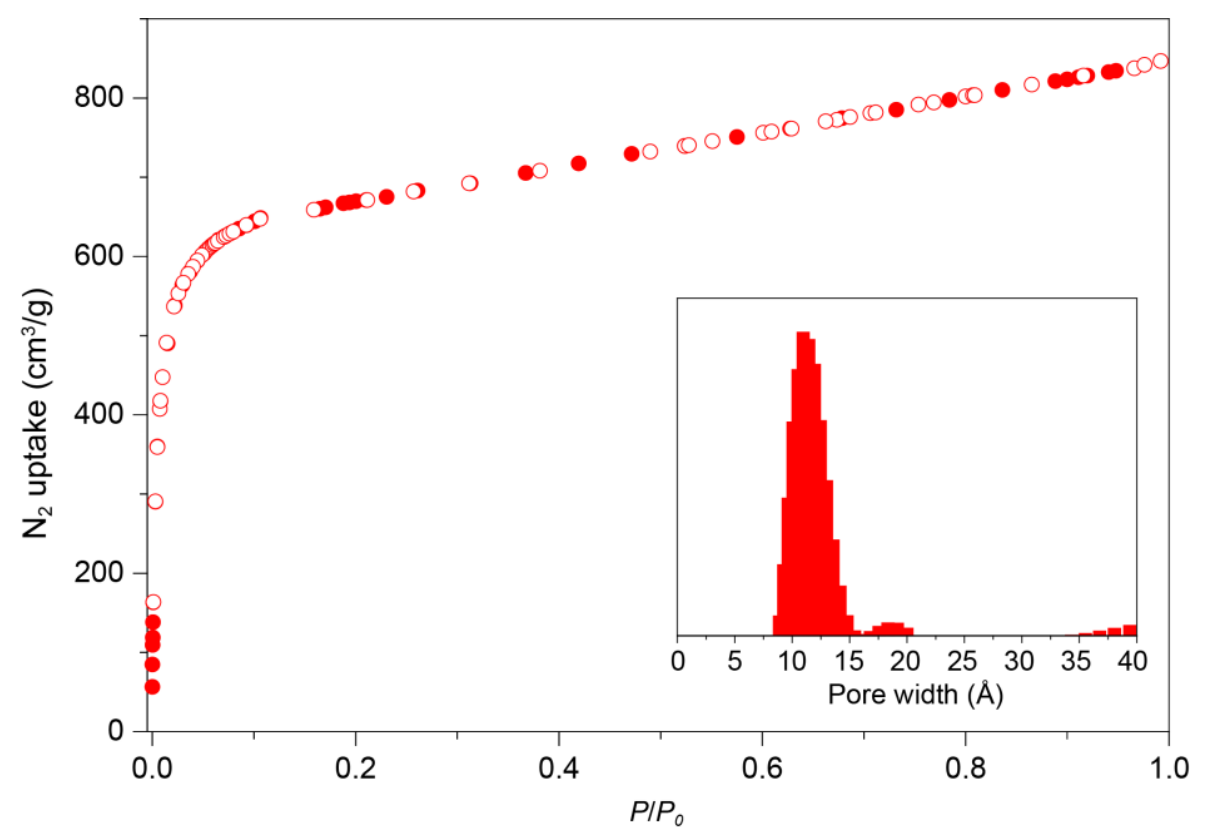

Figure S92. $\mathrm{N}_{2}$ isotherm of P-PCN-521-NBA at $77 \mathrm{~K}$. Open and filled symbols represent adsorption and desorption balance, respectively. Insert, pore distribution of P-PCN-521-NBA.
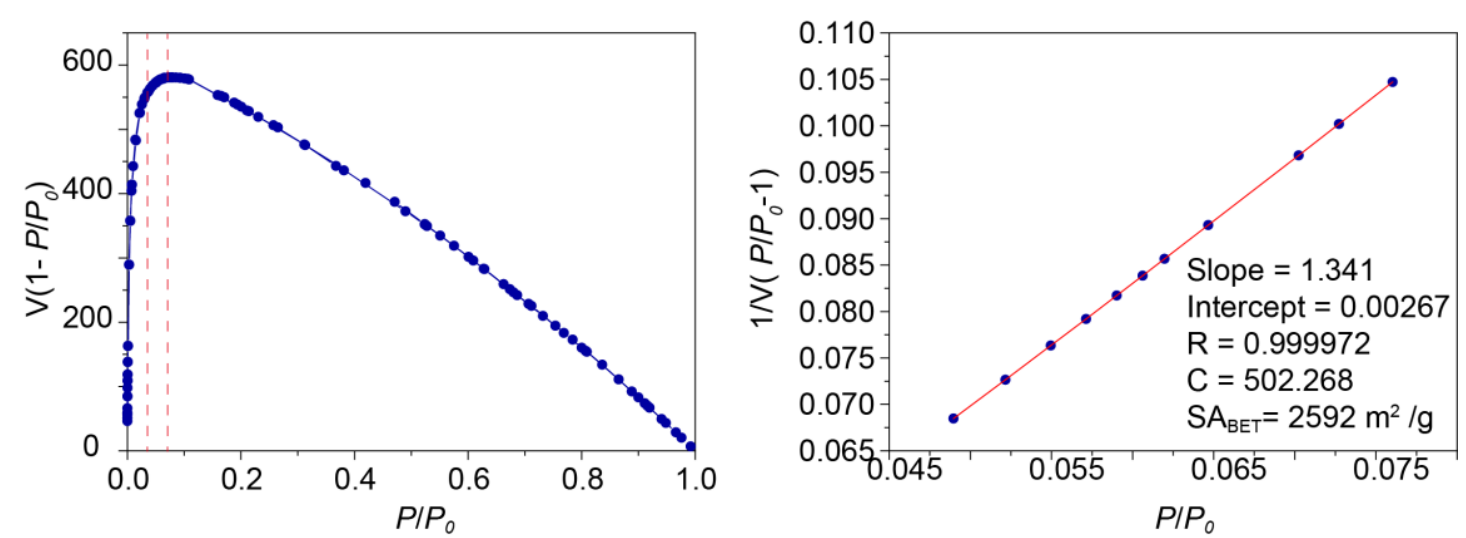

Figure S93. BET surface area calculation for P-PCN-521-NBA from simulated nitrogen isotherm at $77 \mathrm{~K}$ (A) Only points between the dashed line are selected based on the first consistency criterion, (B) Plot to select linear $P / P$ orange. 


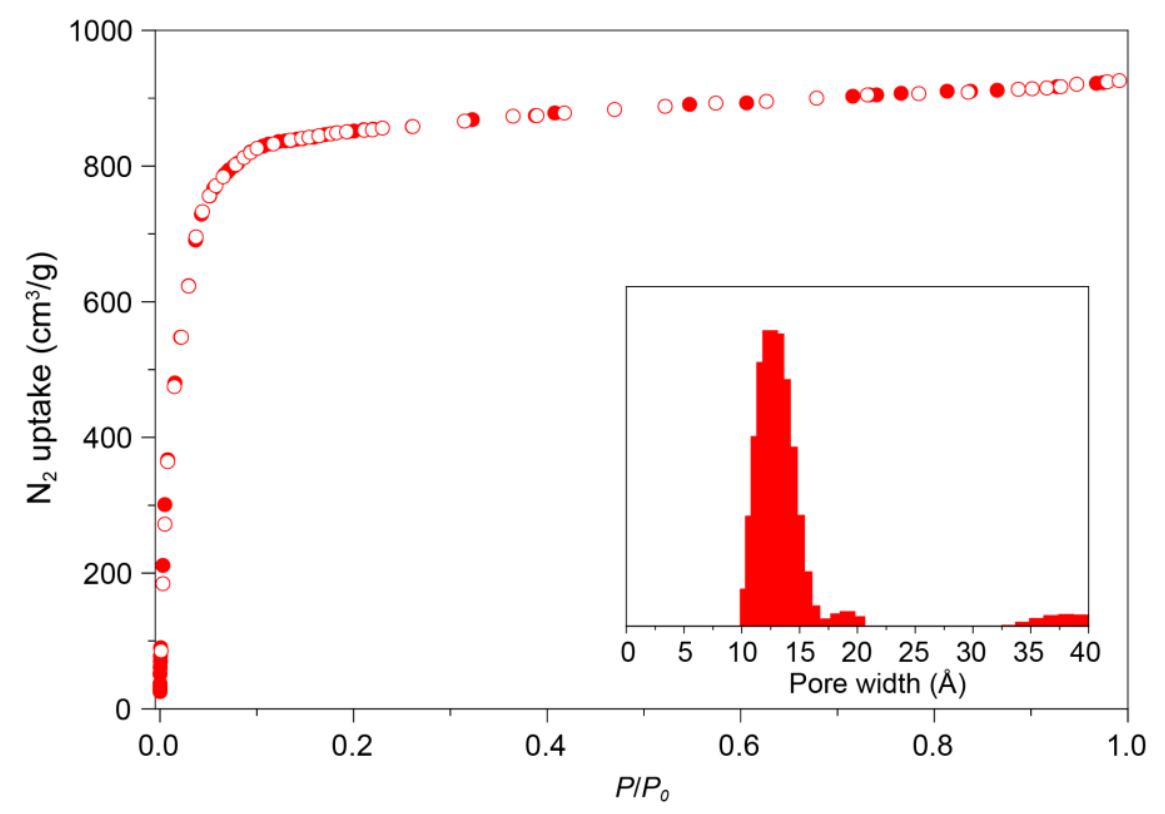

Figure S94. $\mathrm{N}_{2}$ isotherm of P-PCN-521-FA at $77 \mathrm{~K}$. Open and filled symbols represent adsorption and desorption balance, respectively. Insert, pore distribution of P-PCN-521-FA.
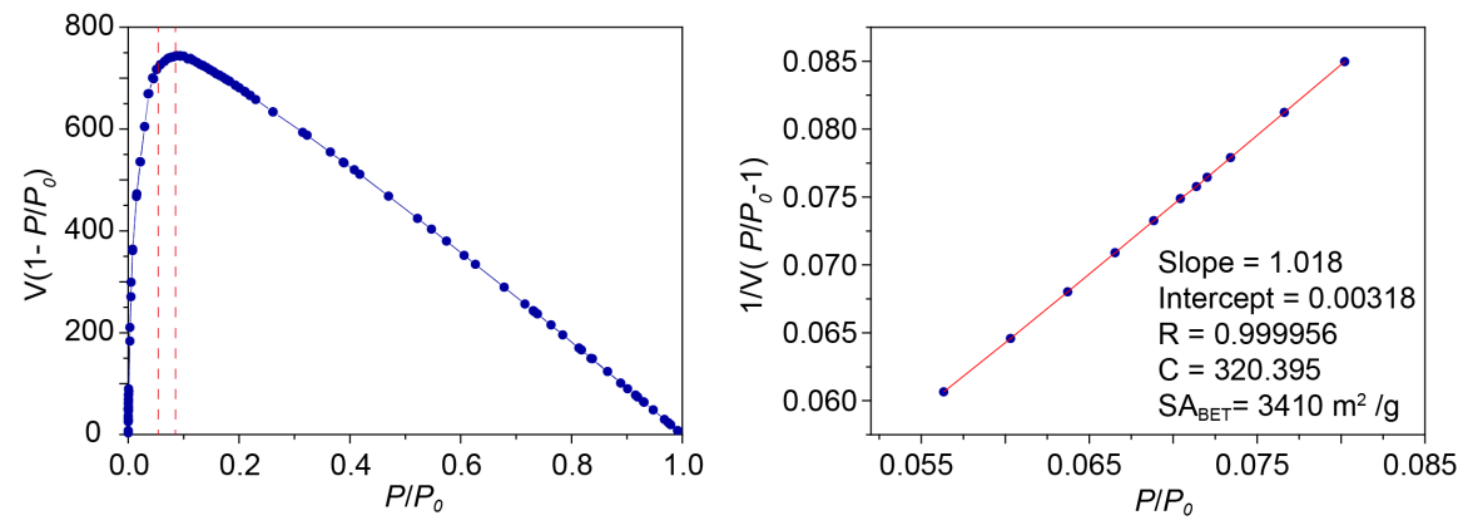

Figure S95. BET surface area calculation for P-PCN-521-FA from simulated nitrogen isotherm at $77 \mathrm{~K}$ (A) Only points between the dashed line are selected based on the first consistency criterion, (B) Plot to select linear $P / P$ orange. 


\section{Section S8 NMR studies of Digested MV-MOFs}

The ratio of all three organic linkers in MV-PCN-521 series was further confirmed by the ${ }^{1} \mathrm{H}$ NMR of the digested MOF samples (Figure S92 to S103). Integration of peak intensities leads to accurate determination of MTBC/TBPA (or PBCA) ratio in MV-MOFs. The detailed digestion procedure was described as the following. MOFs samples were digested using $1 \mathrm{M} \mathrm{NaOH}$ aqueous solution. After that, $1 \mathrm{M} \mathrm{HCl}$ was added to precipitate the linkers, then the mixture was filtered and dried in vacuum overnight. DMSO-d6 was used to dissolve the linkers. All ${ }^{1} \mathrm{H}$ NMR measurements were recorded on a Bruker AVANCE III HD (400MHz). The precise amount of each linker in each MV-MOFs was listed in Table S10 and Table S11.

Table S10. Feeding and actual linker ratios in N-MV-PCN-521-R

\begin{tabular}{|c|c|c|c|}
\hline Compound & N-MV-PCN-521-BA & N-MV-PCN-521-NBA & N-MV-PCN-521-FA \\
\hline \multicolumn{4}{|l|}{ Feed amount of TBPA } \\
\hline linker $\left(\times 10^{-6} \mathrm{~mol}\right)$ & 50 & 50 & 50 \\
\hline \multicolumn{4}{|l|}{ Feed amount of MTBC } \\
\hline linker(×10-6mol) & 25 & 25 & 25 \\
\hline \multicolumn{2}{|l|}{ Feed amount of mono-topic } & 625 & 625 \\
\hline \multicolumn{4}{|l|}{ Stoichiometric ratio of TBPA: } \\
\hline $\begin{array}{l}\text { MTBC: monotopic linker in the } \\
\text { starting materials }\end{array}$ & $2: 1: 250$ & $2: 1: 250$ & $2: 1: 250$ \\
\hline \multicolumn{4}{|l|}{$\begin{array}{c}\text { Percentage of MTBC linker } \\
\text { replaced by TBPA in MV-MOF } \\
\text { crystals* }\end{array}$} \\
\hline \multirow{3}{*}{$\begin{array}{l}\text { The ratio of the three linkers } \\
\text { (MTBC:TBPA: mono-topic } \\
\text { linker) in MV-MOFs }\end{array}$} & & & 1:1.04:(FA was \\
\hline & $1: 0.27: 0.34$ & 1:0.30:0.90 & dissolved in water in \\
\hline & & & MOF-digested process) \\
\hline
\end{tabular}

*Linker ratios in the crystal are obtained from NMR of digested MV-MOF crystals. 
Table S11. Feeding and actual linker ratios in P-MV-PCN-521-R

\begin{tabular}{|c|c|c|c|c|c|}
\hline Compound & $\begin{array}{l}\text { P-MV-PCN- } \\
521-\mathrm{BA}\end{array}$ & $\begin{array}{l}\text { P-MV-PCN- } \\
521-\mathrm{NBA}\end{array}$ & $\begin{array}{l}\text { P-MV-PCN-521- } \\
\text { FA }\end{array}$ & $\begin{array}{l}\text { P-MV-PCN-521 } \\
\text {-DCA (for } \\
\text { catalysis) }\end{array}$ & $\begin{array}{l}\text { P-MV-PCN-5 } \\
\text { 21-PTA (for } \\
\text { catalysis) }\end{array}$ \\
\hline $\begin{array}{l}\text { Feed amount of } \\
\text { PBCA } \\
\text { linker }\left(\times 10^{-6} \mathrm{~mol}\right)\end{array}$ & 50 & 50 & 50 & 50 & 50 \\
\hline $\begin{array}{l}\text { Feed amount of } \\
\text { MTBC } \\
\text { linker }(\times 10-6 \mathrm{~mol})\end{array}$ & 25 & 25 & 25 & 25 & 25 \\
\hline $\begin{array}{l}\text { Feed amount of } \\
\text { mono-topic } \\
\text { linker }(\times 10-6 \mathrm{~mol})\end{array}$ & 625 & 625 & 625 & 625 & 625 \\
\hline $\begin{array}{l}\text { Stoichiometric ratio } \\
\text { of PBCA: MTBC: } \\
\text { monotopic linker in } \\
\text { the starting materials }\end{array}$ & $2: 1: 250$ & $2: 1: 250$ & $2: 1: 250$ & $2: 1: 250$ & $2: 1: 250$ \\
\hline $\begin{array}{c}\text { Percentage of MTBC } \\
\text { linker replaced by } \\
\text { PBCA in MV-MOF } \\
\text { crystals* }\end{array}$ & $22.0 \%$ & $20.0 \%$ & $41.4 \%$ & $31.1 \%$ & $36.9 \%$ \\
\hline $\begin{array}{l}\text { The ratio of the three } \\
\text { linkers } \\
\text { (MTBC:tritopoic }\end{array}$ & $1: 0.28: 0.47$ & $1: 0.25: 0.47$ & $\begin{array}{l}\text { 1:0.71:(FA was } \\
\text { dissolved in water in } \\
\text { MOF-digested }\end{array}$ & $\begin{array}{l}\text { 1:0.45:(FA was } \\
\text { dissolved in water } \\
\text { in MOF-digested }\end{array}$ & 1:0.58:1.07 \\
\hline linker) in MV-MOFs & & & process) & process) & \\
\hline
\end{tabular}

*Linker ratios in the crystal are obtained from NMR of digested MV-MOF crystals. 


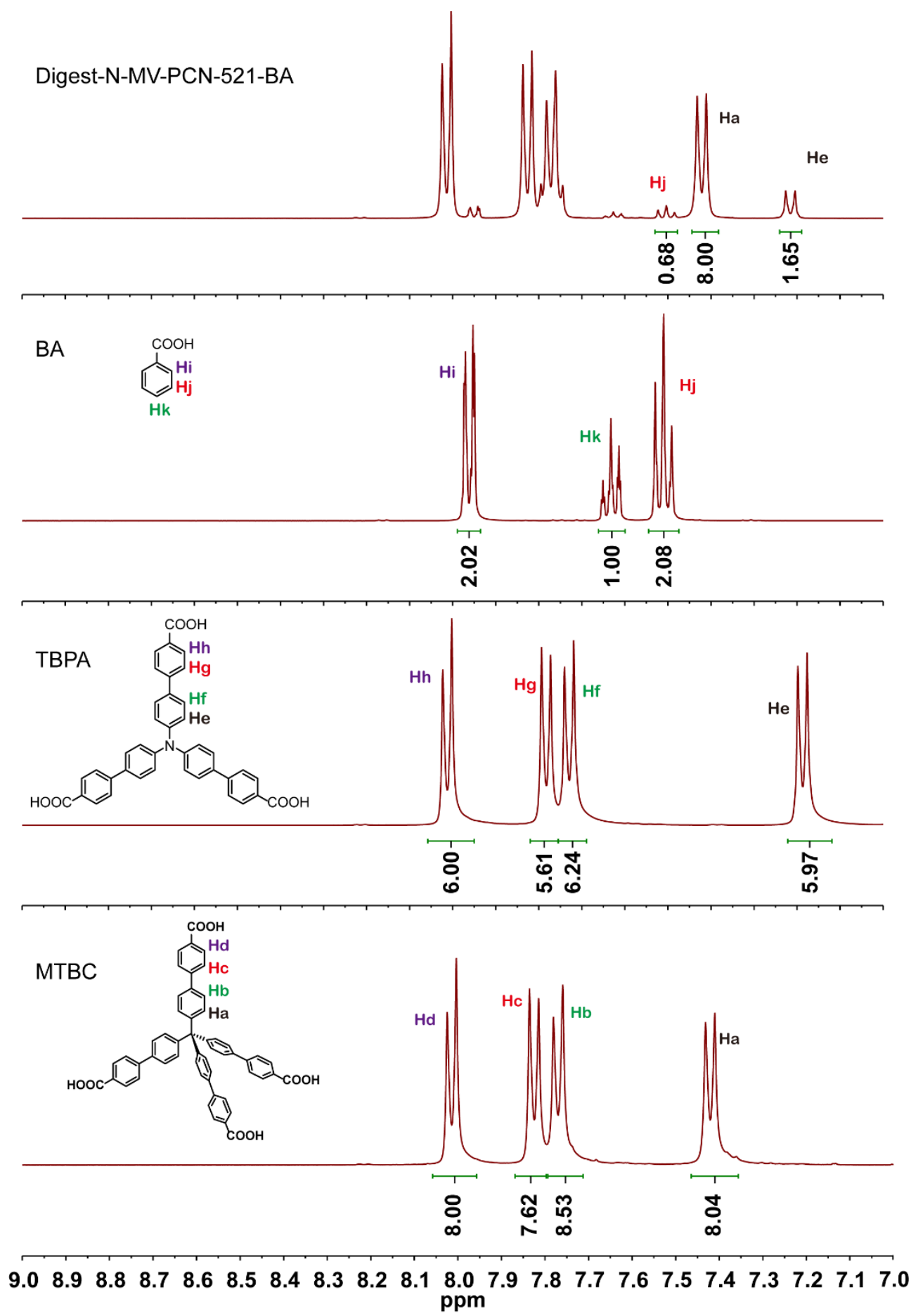

Figure S96. ${ }^{1} \mathrm{H}$ NMR spectrum of digested N-MV-PCN-521-BA. 


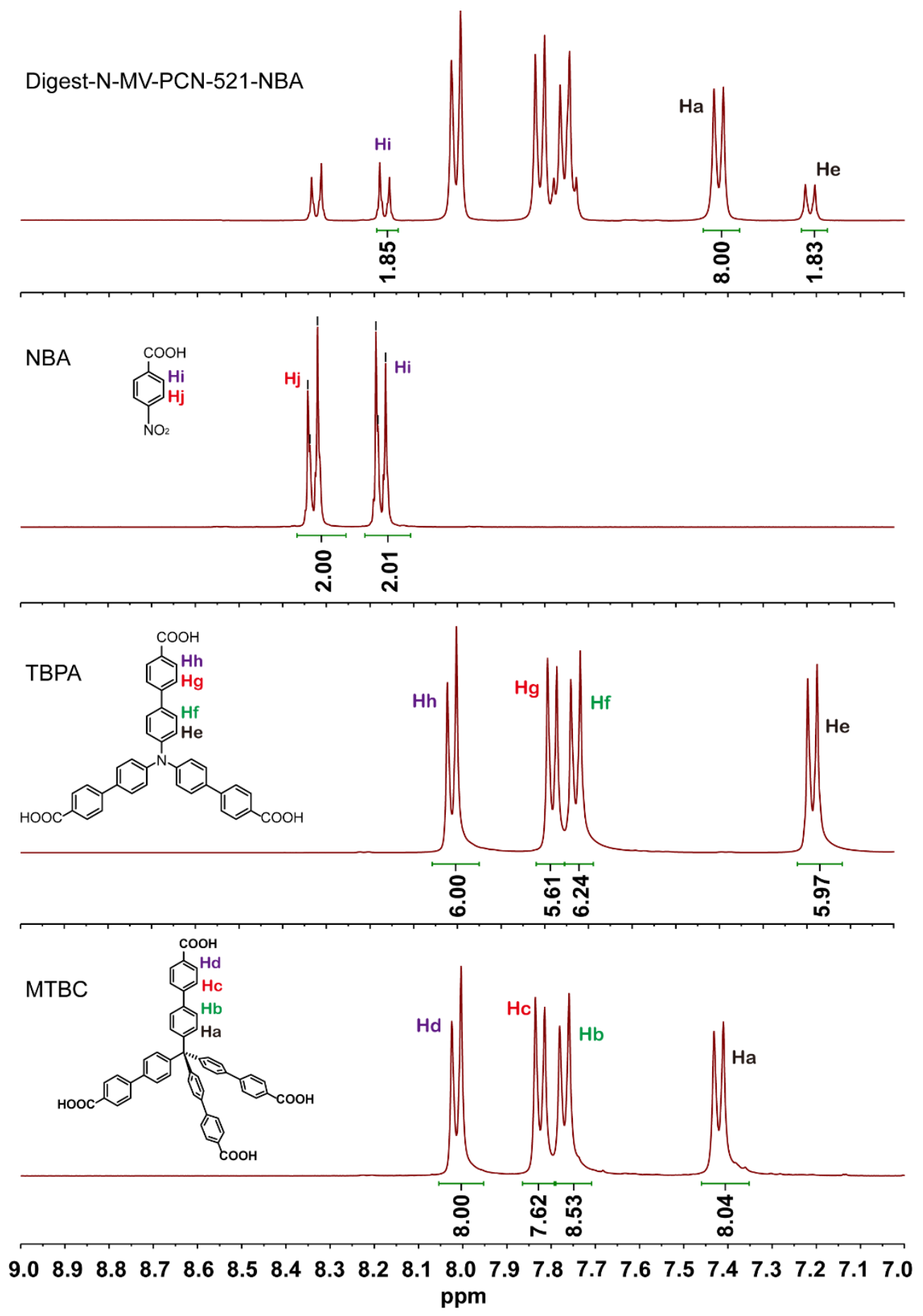

Figure S97. ${ }^{1} \mathrm{H}$ NMR spectrum of digested N-MV-PCN-521-NBA. 

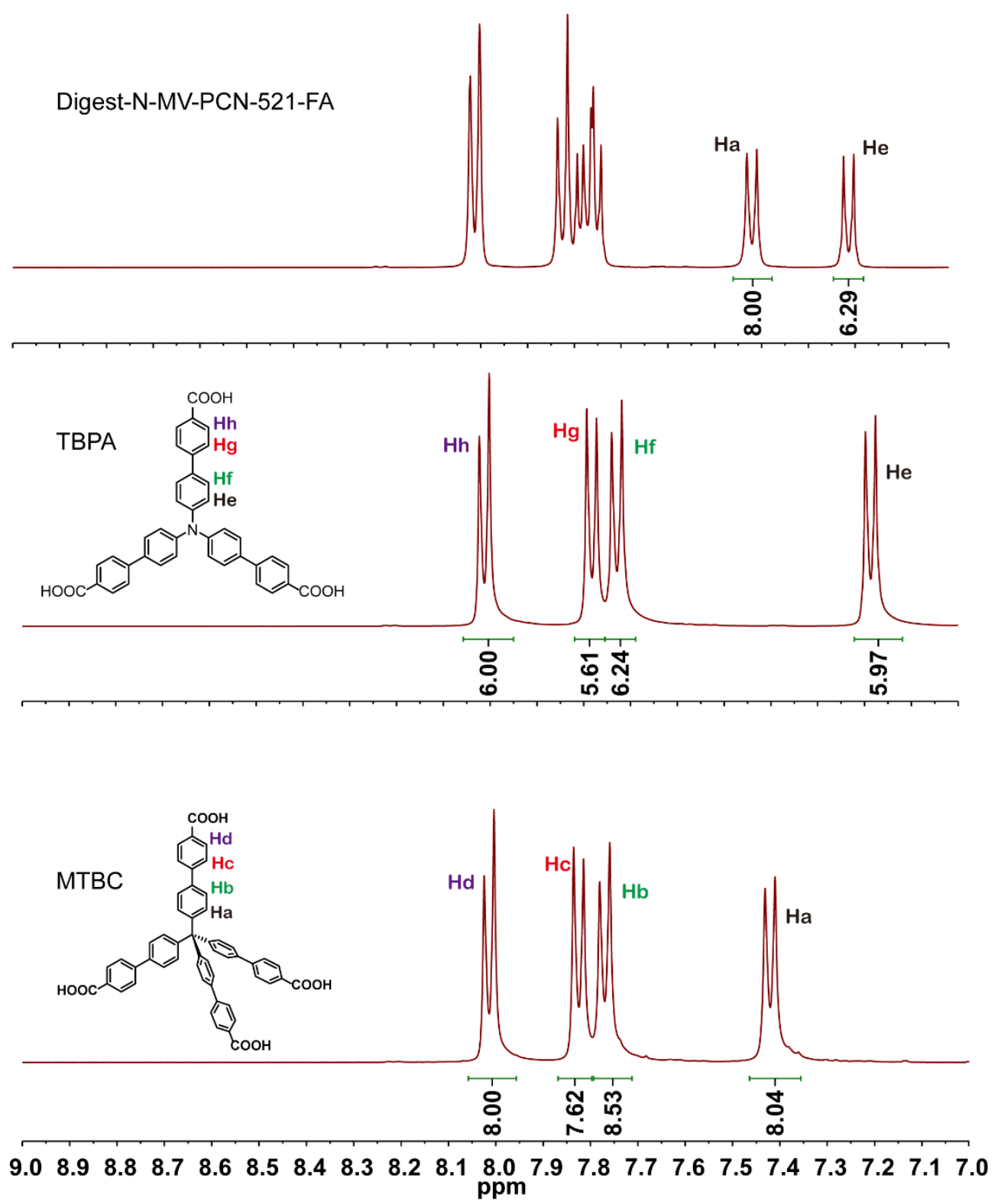

Figure S98. ${ }^{1} \mathrm{H}$ NMR spectrum of digested N-MV-PCN-521-FA. 

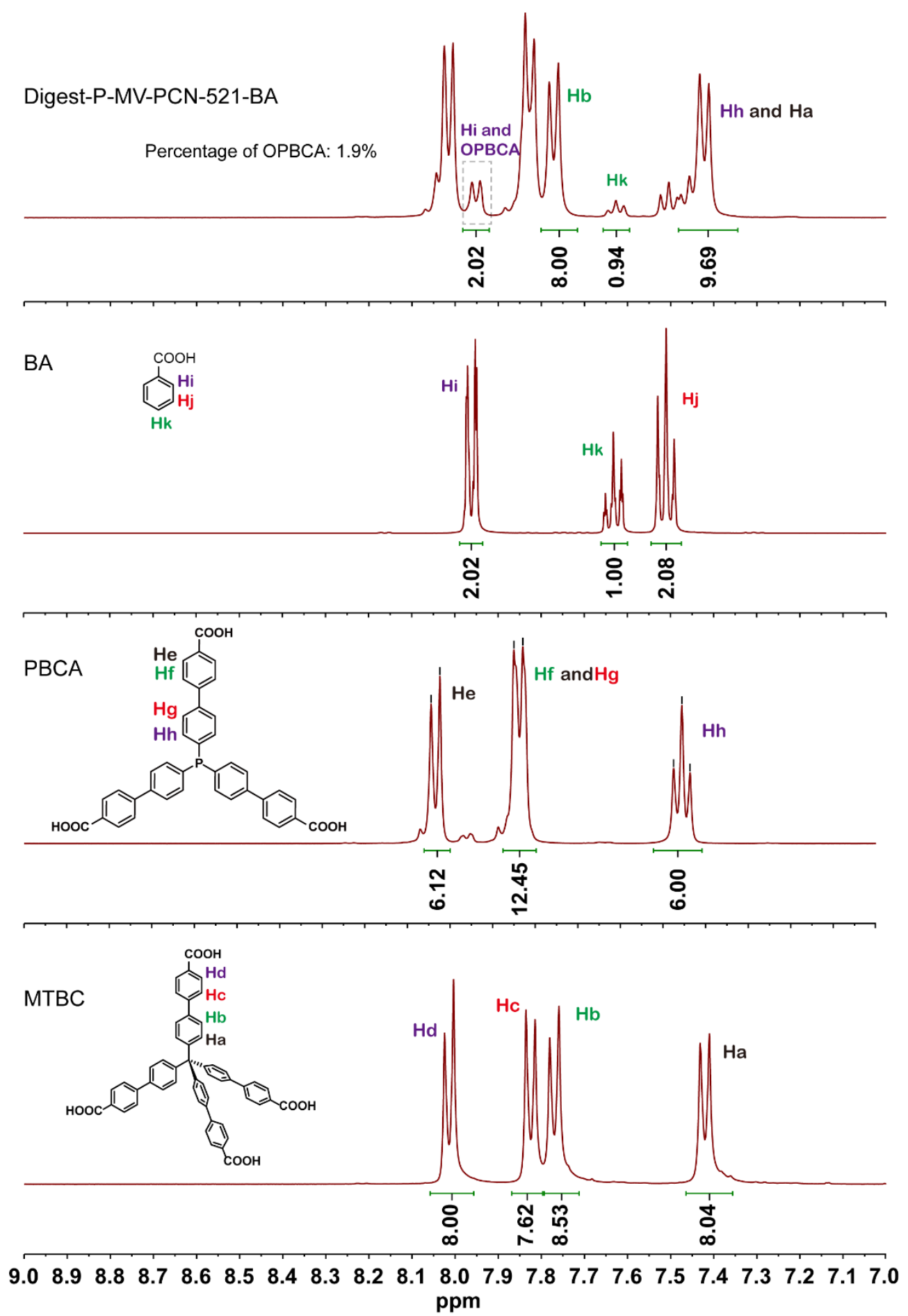

Figure S99. ${ }^{1} \mathrm{H}$ NMR spectrum of digested P-MV-PCN-521-BA. 


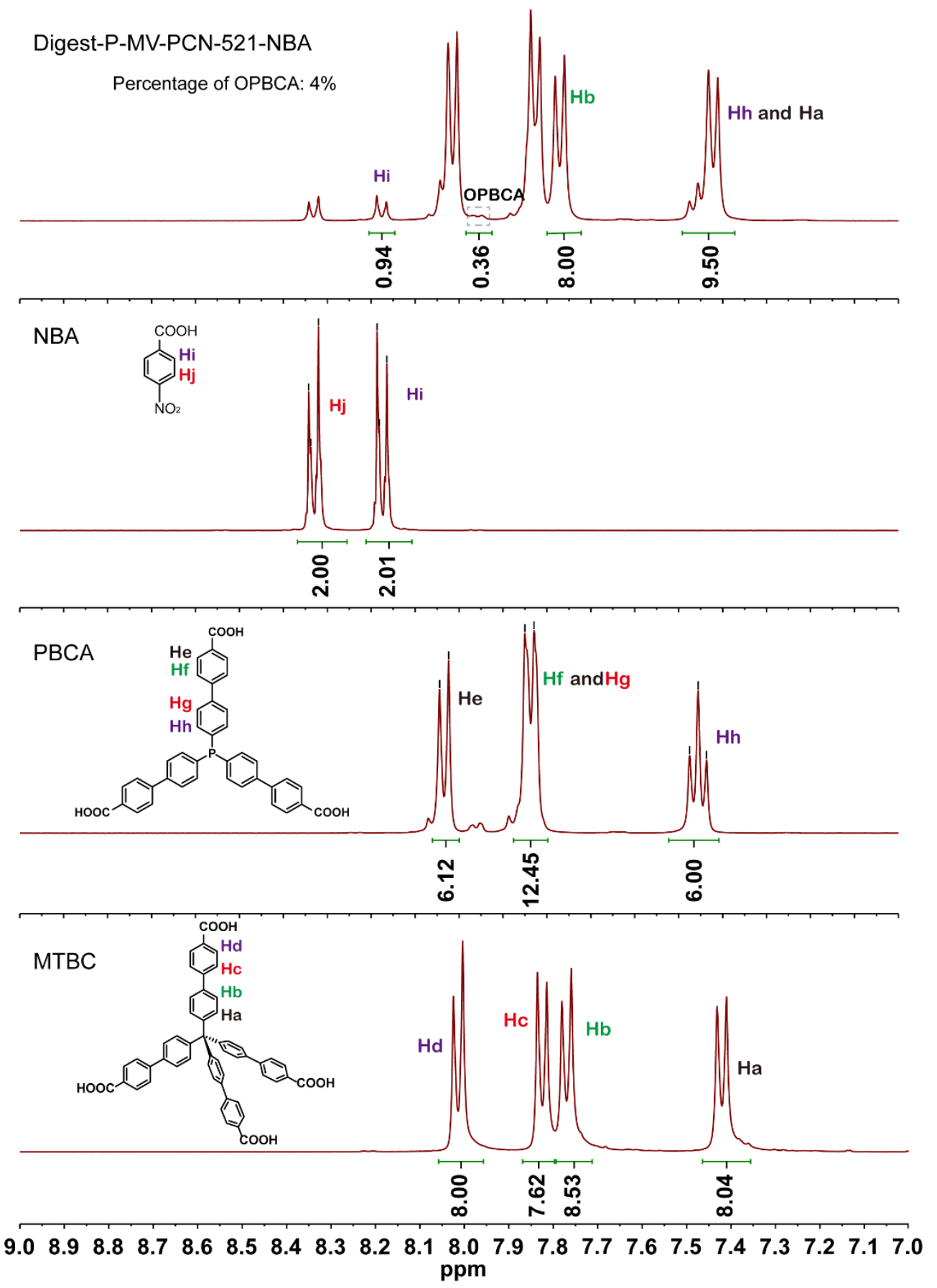

Figure S100. ${ }^{1} \mathrm{H}$ NMR spectrum of digested P-MV-PCN-521-NBA. 

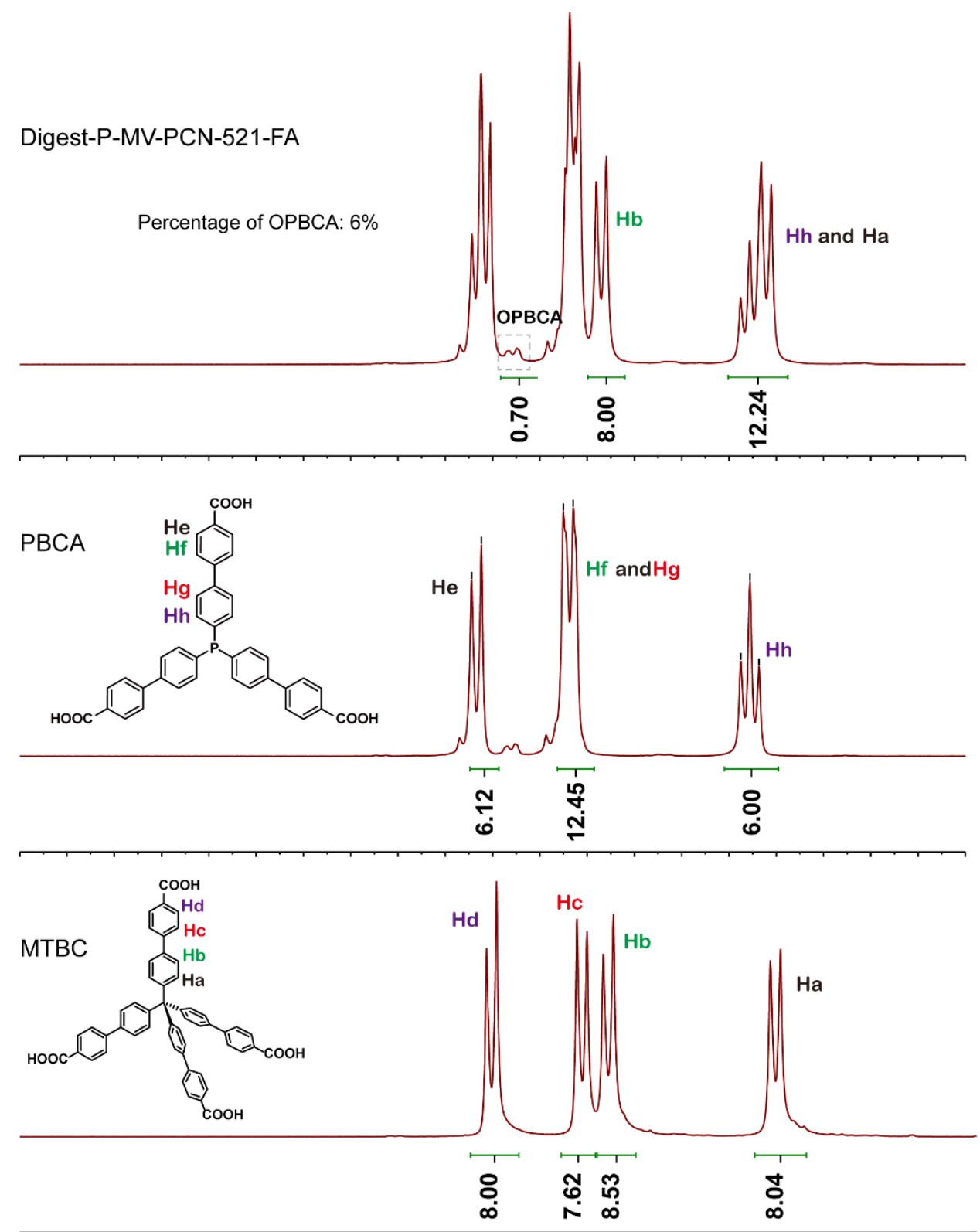

$\begin{array}{llllllllllllllllllllll}9.0 & 8.9 & 8.8 & 8.7 & 8.6 & 8.5 & 8.4 & 8.3 & 8.2 & 8.1 & 8.0 & 7.9 & 7.8 & 7.7 & 7.6 & 7.5 & 7.4 & 7.3 & 7.2 & 7.1 & 7.0\end{array}$ ppm

Figure S101. ${ }^{1} \mathrm{H}$ NMR spectrum of digested P-MV-PCN-521-FA. 


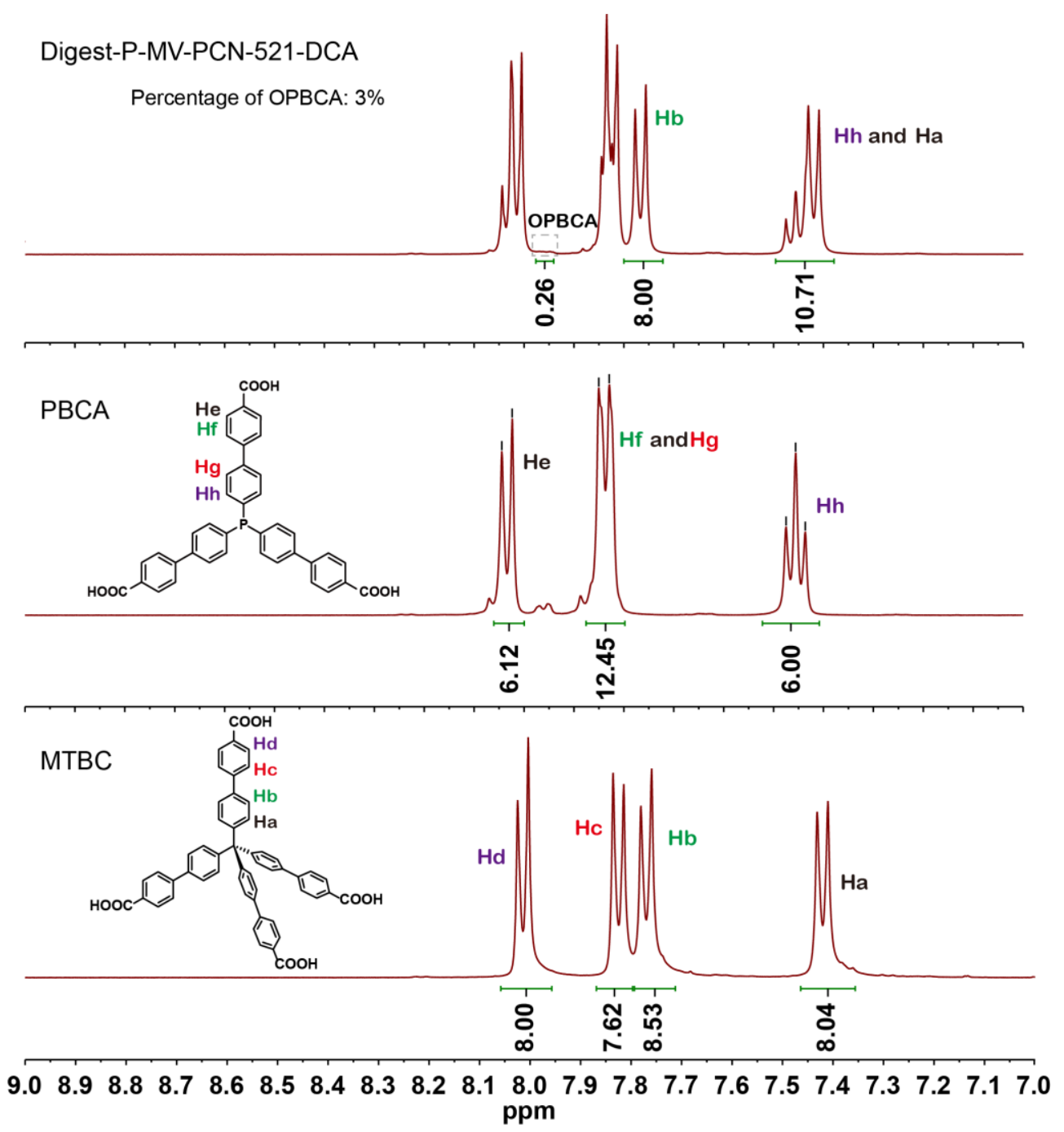

Figure S102. ${ }^{1} \mathrm{H}$ NMR spectrum of digested P-MV-PCN-521-DCA (for catalysis). 


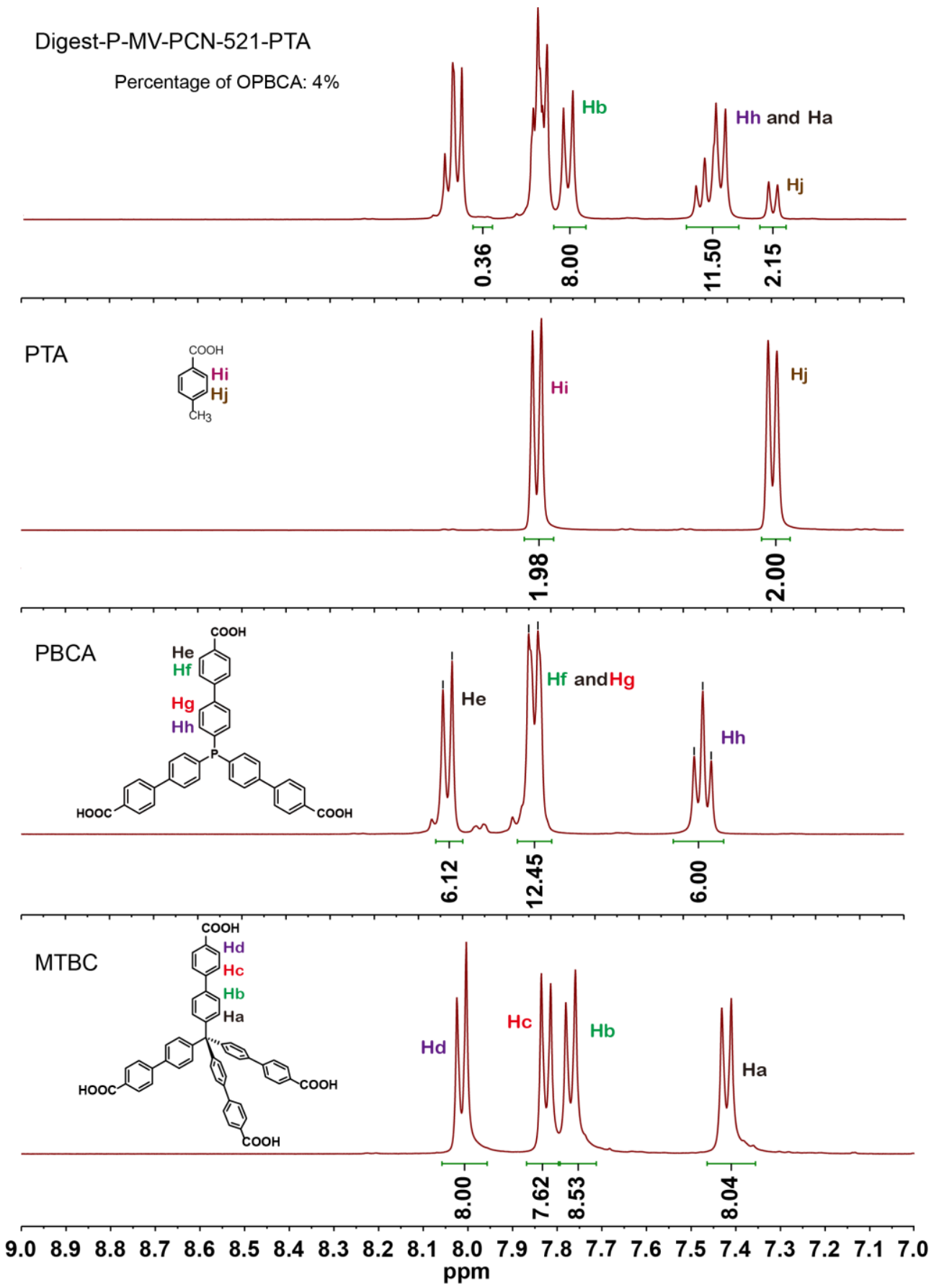

Figure S103. ${ }^{1} \mathrm{H}$ NMR spectrum of digested P-MV-PCN-521-PTA (for catalysis). 

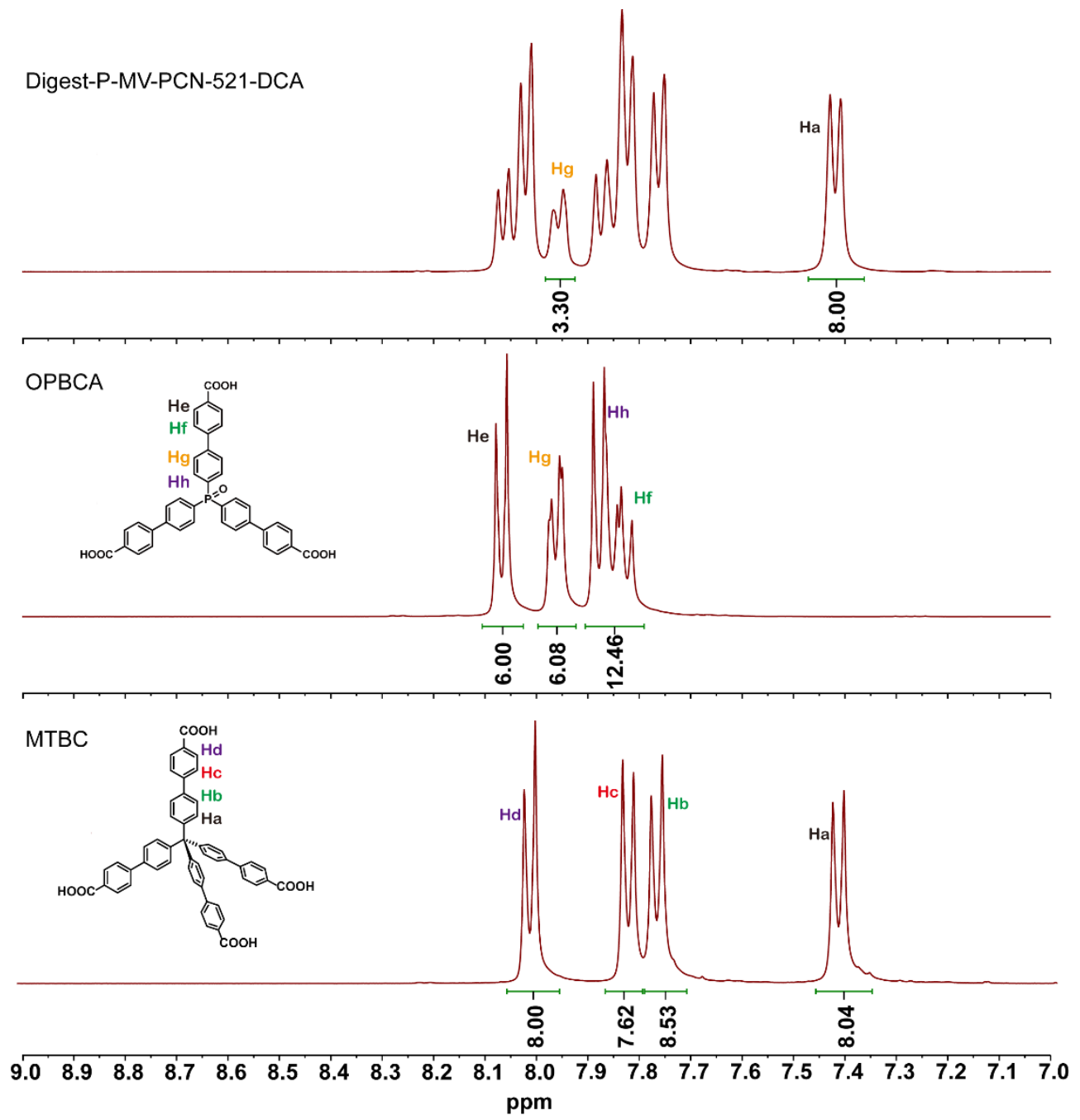

Figure S104. ${ }^{1} \mathrm{H}$ NMR spectrum of digested P-MV-PCN-521-DCA (for SSNMR). 


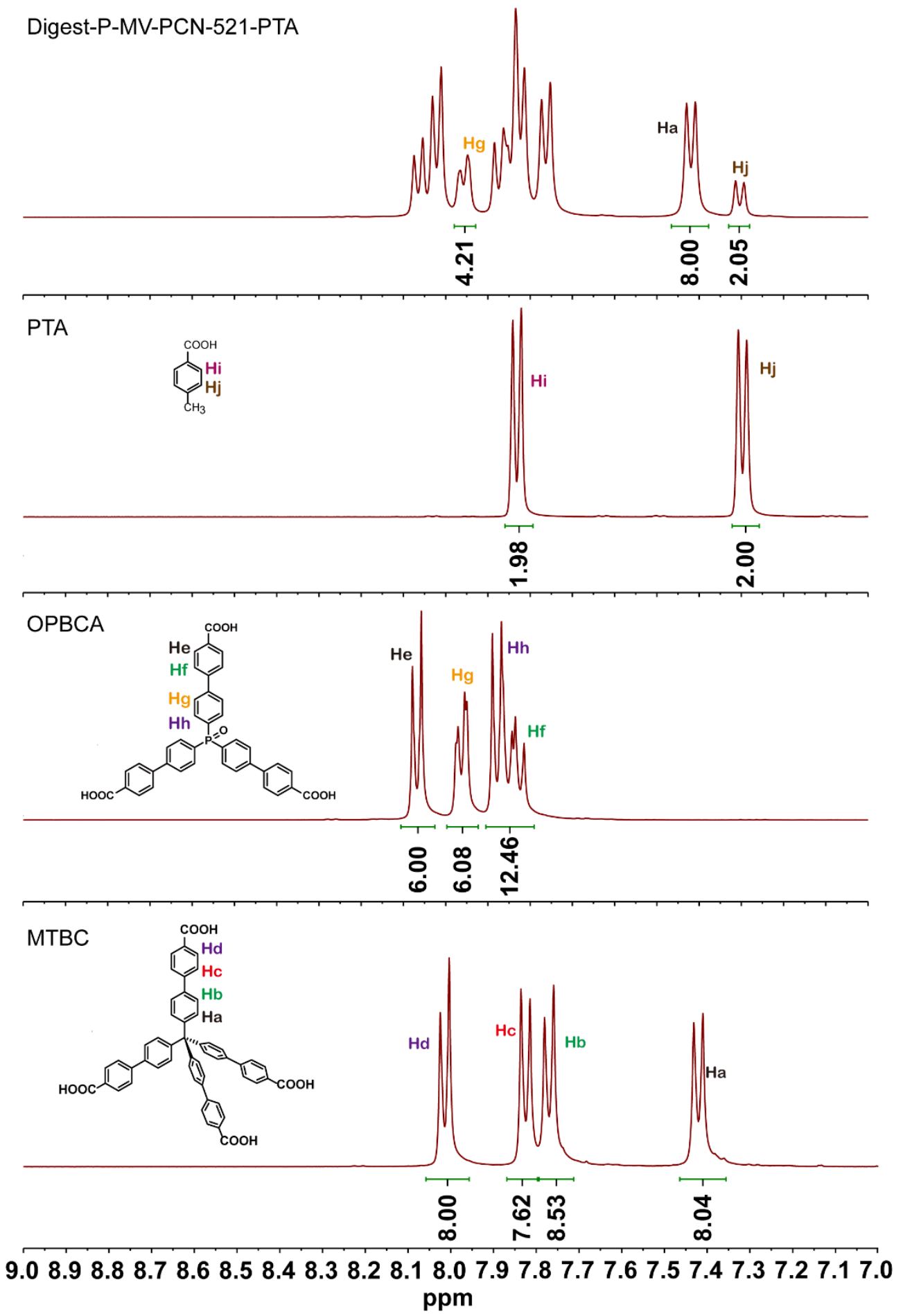

Figure S105. ${ }^{1} \mathrm{H}$ NMR spectrum of digested P-MV-PCN-521-PTA (for SSNMR). 


\section{Section S8 Laser scanning confocal microscopy (LSCM) studies of}

\section{MV-MOFs}

The homogeneous distribution of TBPA (or PBCA) linkers in the N-MV-PCN-521-BA and P-MV-PCN-521-BA structure was been determined by LSCM. Green fluorescence was clearly observed in all the MV-PCN-521 crystals examined under excitation light of $405 \mathrm{~nm}$, indicating the successful replacement of TBPA (or PBCA) with MTBC, while PCN-521 exhibits no fluorescence under the same condition. (Figures S106 to 108).

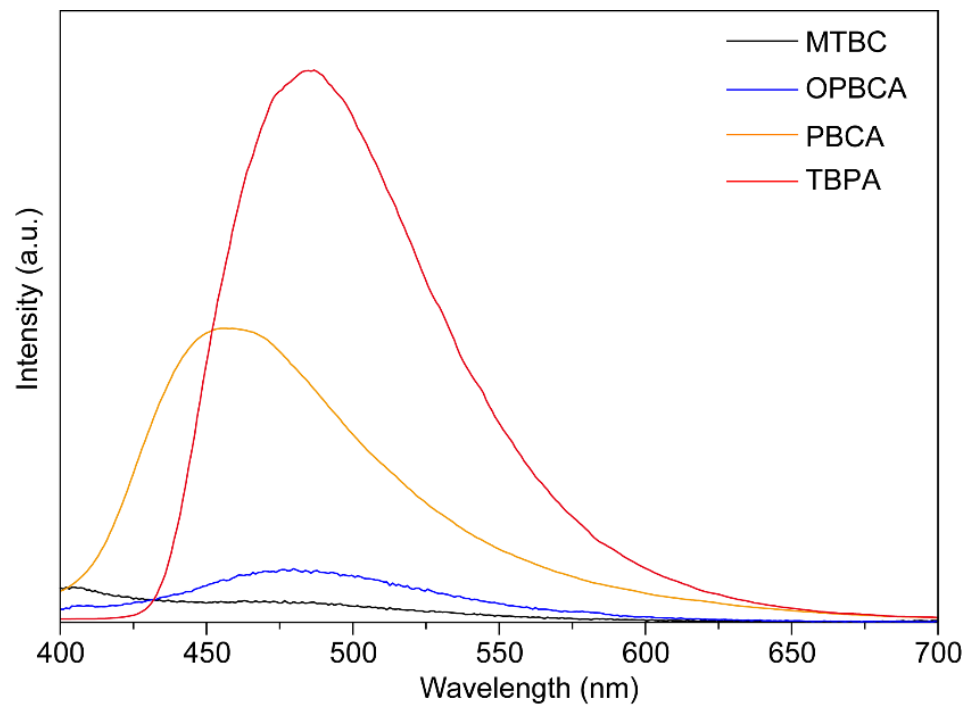

Figure S106. Fluorescence spectra of linkers TBPA (red line), PBCA (orange line), OPBCA (blue line), and MTBC (black line).

LSCM measurement was used to reveal the distribution of TBPA and PBCA linkers in MV-PCN-521 crystals. All data were recorded on a Leica SP8 microscope. The MOF crystals was immersed in DMF before they were put in between a pair of glass for measurement. Laser with $405 \mathrm{~nm}$ wavelength was used as excitation light to induce the fluorescence of TBPA and PBCA linkers in MOF crystal. The results of rhe corresponding MV-PCN-521 single crystals were displayed (Figure S107 to S108). 


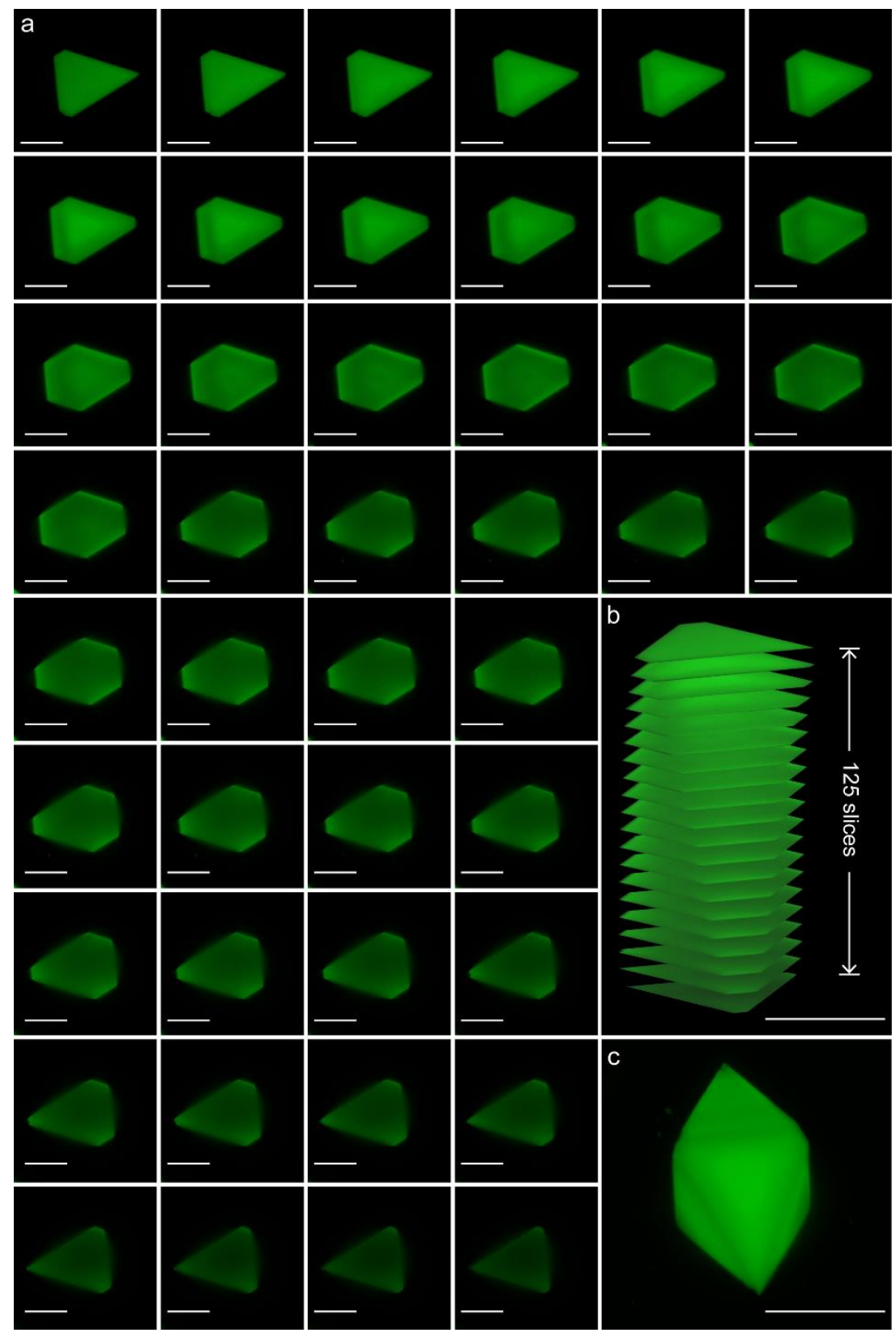

Figure S107. ( $a$ and b) Continues sections of LSCM of the second N-MV-PCN-521-BA Crystal. Scale bar: $200 \mu \mathrm{m}$. (c) 3D reconstitution of LSCM of MV-PCN-521-BA based on continuessections of total 125 slices. 


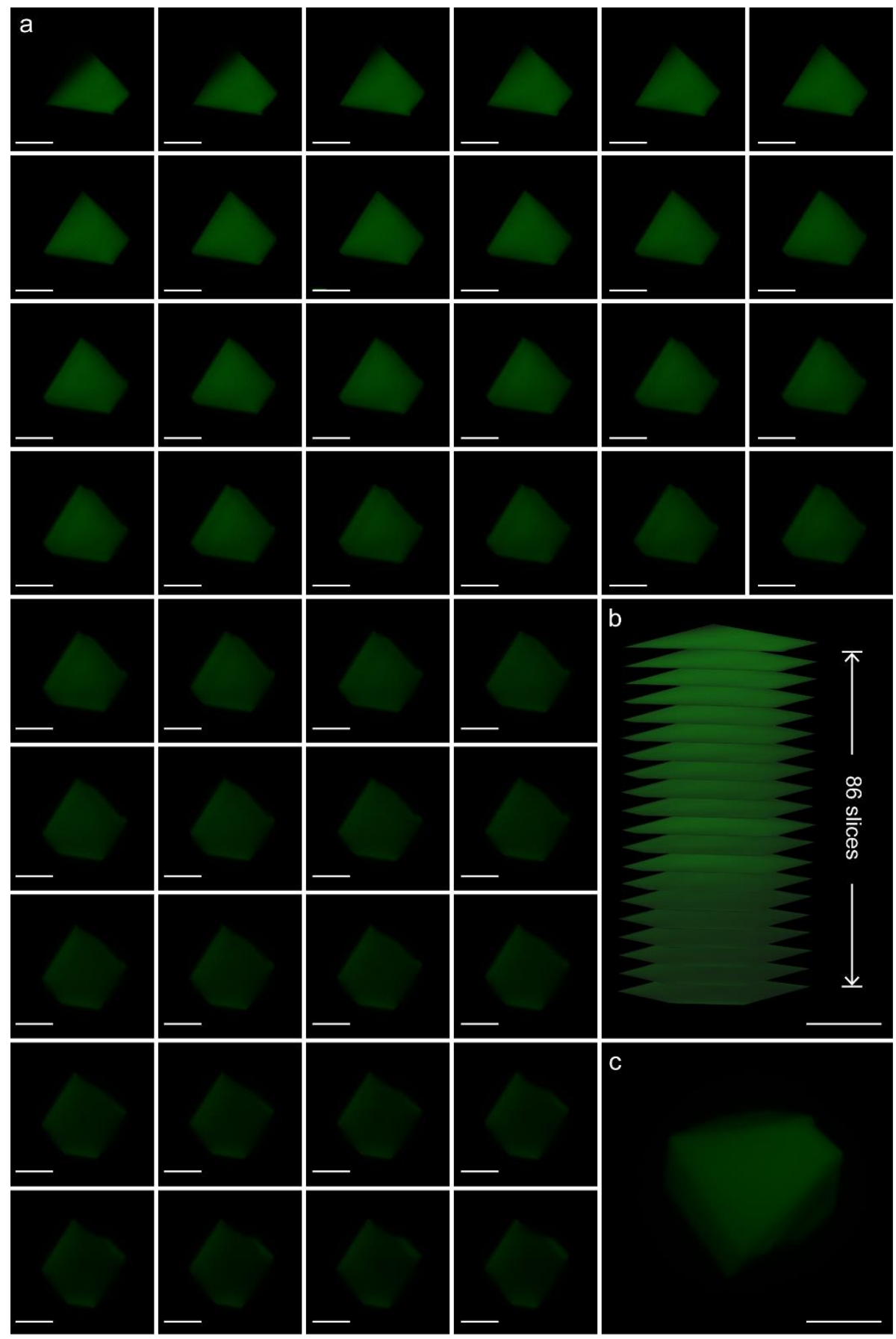

Figure S108. (a and b) Continues sections of LSCM of the second P-MV-PCN-521-BA crystal. Scale bar: $400 \mu \mathrm{m}$. (c) 3D reconstitution of LSCM of MV-PCN-521-BA based on continues sections of total 86 slices. 


\section{Section S10 Scanning electron microscopy (SEM) studies of}

\section{MV-MOFs}

SEM was used to examine the morphology of MV-MOFs series. The SEM images of these MOFs were collected on a Merlin Compact FEI Verios-460 (Figure S109 and S110). Samples were prepared by sprinkling directly onto the sample stages. The shape of these MOFs indicated the heritage of high symmetric and was consistent with results in PXRD studies. Furthermore, the homogeneous distribution of tritopic linkers inside the MOF were demonstrated by the energy dispersive spectroscopy (EDS) of MOF samples (Figure S109 and S110).

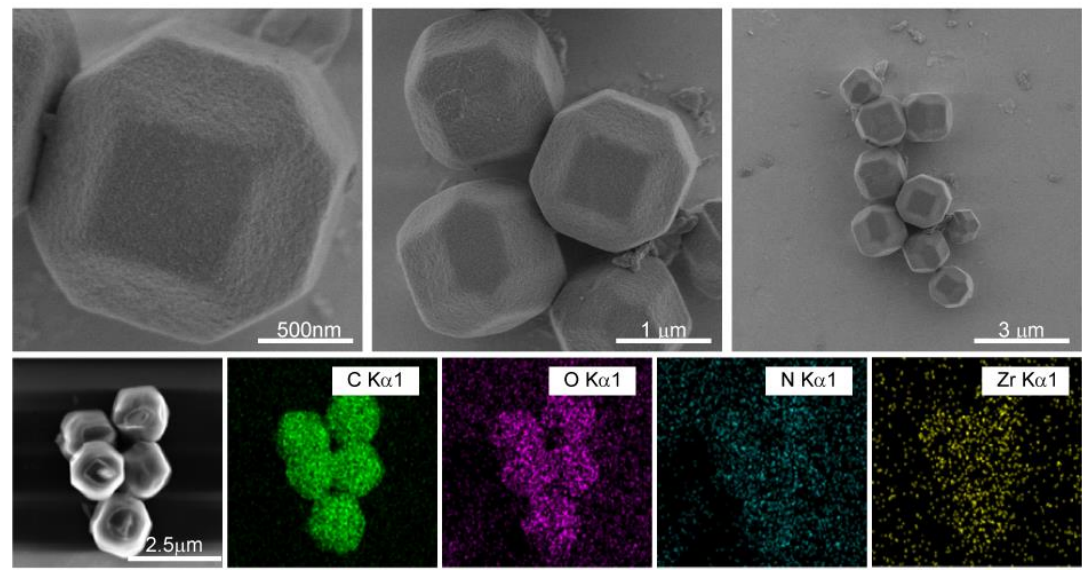

Figure S109. SEM images of N-MV-PC-521-BA and elemental mappings of C, O, N, and $\mathrm{Zr}$ in the crystal.

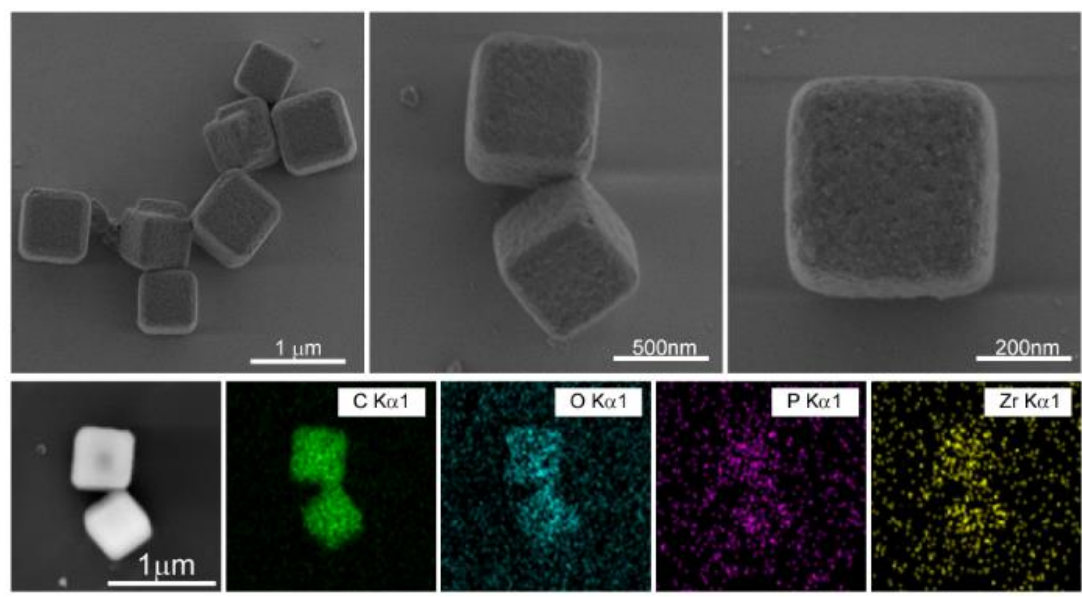

Figure S110. SEM images of P-MV-PC-521-BA and elemental mappings of C, O, P, and $\mathrm{Zr}$ in the crystal. 


\section{Section S11 ICP and EA results of metal-binded-MV-MOFs}

ICP-AES (Table S12-S13) and element analysis (EA) (Table S14) was used to determine atoms ratio in MOF samples. ICP-AES measurements were performed on an Inductively Coupled Plasma-Optical Emission Spectrum (Prodigy 7) instrument. All EA experiments were conducted on an elemental analyzer (Vario EL cube)

Table S12 ICP-AES result of Au-MV-MOFs

\begin{tabular}{cccc}
\hline Material & Au(mg/L) & $\mathbf{Z r}(\mathbf{m g} / \mathbf{L})$ & $\begin{array}{c}\text { Normalization } \\
(\mathbf{x A u} / \mathbf{Z r})(\mathbf{m g} / \mathbf{m g})\end{array}$ \\
\hline Au-N-MV-PCN-521-BA & 4.61 & 19.55 & 0.235 \\
Au-N-MV-PCN-521-NBA & 3.99 & 17.00 & 0.234 \\
Au-N-MV-PCN-521-FA & 5.11 & 17.97 & 0.278 \\
Au-P-MV-PCN-521-BA & 11.65 & 14.74 & 0.790 \\
Au-P-MV-PCN-521-NBA & 11.41 & 18.33 & 0.622 \\
Au-P-MV-PCN-521-FA & 14.95 & 17.20 & 0.869 \\
Au-N-MV-PCN-521-DCA & 0.94 & 1.31 & 0.71 \\
Au-P-MV-PCN-521-PTA & 0.43 & 0.65 & 0.66 \\
\hline
\end{tabular}

Table S13 ICP-AES result of Au-MV-MOFs after 1 cycle of bromination of aromatics

\begin{tabular}{cccc}
\hline Material & $\mathbf{A u}(\mathbf{m g} / \mathbf{L})$ & $\mathbf{Z r}(\mathbf{m g} / \mathbf{L})$ & $\begin{array}{c}\text { Normalization } \\
(\mathbf{x A u} / \mathbf{Z r})(\mathbf{m g} / \mathbf{m g})\end{array}$ \\
\hline N-MV-PCN-521-BA-Au & 0.1769 & 1.0754 & 0.161 \\
N-MV-PCN-521-NBA-Au & 0.1985 & 1.1138 & 0.178 \\
N-MV-PCN-521-FA-Au & 0.1371 & 0.7459 & 0.184 \\
P-MV-PCN-521-BA-Au & 0.6323 & 0.8608 & 0.734 \\
P-MV-PCN-521-NBA-Au & 0.2158 & 0.3517 & 0.614 \\
P-MV-PCN-521-FA-Au & 0.8216 & 0.9729 & 0.844 \\
\hline
\end{tabular}


Table S14 CHNO elemental analysis result of the materials

\begin{tabular}{cccccccccc}
\hline \multirow{2}{*}{ Materials } & Formula & $\mathrm{C}(\%)$ & $\mathrm{H}(\%)$ & $\mathrm{O}(\%)$ & $\mathrm{N}(\%)$ & $\mathrm{C}(\%)$ & $\mathrm{H}(\%)$ & $\mathrm{O}(\%)$ & $\mathrm{N}(\%)$ \\
\hline PCN-521 & $\mathrm{C}_{106} \mathrm{H}_{64} \mathrm{O}_{32} \mathrm{Zr} 6$ & 53.11 & 2.70 & 21.37 & 0 & 53.35 & 2.86 & 21.58 & 0 \\
N-MV-PCN-521-BA & $\mathrm{C}_{103.77} \mathrm{H}_{60.69} \mathrm{O}_{32} \mathrm{~N}_{0.43} \mathrm{Zr} \mathrm{r}_{6}$ & 52.52 & 2.58 & 21.58 & 0.25 & 52.27 & 2.32 & 21.83 & 0.22 \\
N-MV-PCN-521-NBA & $\mathrm{C}_{104.74} \mathrm{H}_{61.20} \mathrm{O}_{33.6} \mathrm{~N}_{0.40} \mathrm{Zr}_{6}$ & 52.20 & 2.56 & 24.02 & 0.23 & 51.97 & 2.43 & 24.24 & 0.24 \\
N-MV-PCN-521-FA & $\mathrm{C}_{92.71} \mathrm{H}_{50.71} \mathrm{O}_{32} \mathrm{~N}_{1.02} \mathrm{Zr}_{6}$ & 49.74 & 2.29 & 22.87 & 0.63 & 49.83 & 2.34 & 23.01 & 0.70 \\
P-MV-PCN-521-BA & $\mathrm{C}_{105.0} \mathrm{H}_{61.53} \mathrm{O}_{32} \mathrm{P}_{0.44} \mathrm{Zr}_{6}$ & 52.63 & 2.59 & 21.37 & 0 & 52.74 & 2.61 & 21.29 & 0 \\
P-MV-PCN-521-NBA C & $\mathrm{C}_{105.66} \mathrm{H}_{61.40} \mathrm{O}_{33.5} \mathrm{P}_{0.40} \mathrm{~N}_{0.74} \mathrm{Zr}_{6}$ & 52.29 & 2.78 & 22.09 & 0.42 & 51.96 & 2.62 & 21.89 & 0.40 \\
P-MV-PCN-521-FA & $\mathrm{C}_{95.24} \mathrm{H}_{53.24} \mathrm{O}_{32} \mathrm{P}_{0.83} \mathrm{Zr}_{6}$ & 50.11 & 2.36 & 22.43 & 0 & 49.92 & 2.29 & 22.27 & 0 \\
P-MV-PCN-521-DCA & $\mathrm{C}_{98.54} \mathrm{H}_{56.54} \mathrm{O}_{32} \mathrm{P}_{0.62} \mathrm{Cl}_{1.24} \mathrm{Zr}_{6}$ & 50.08 & 2.41 & 21.67 & 0 & 50.26 & 2.54 & 21.26 & 0 \\
P-MV-PCN-521-PTA & $\mathrm{C}_{104.84} \mathrm{H}_{61.69} \mathrm{O}_{32} \mathrm{P}_{0.74} \mathrm{Zr}_{6}$ & 52.38 & 2.59 & 21.30 & 0 & 52.14 & 2.73 & 21.48 & 0
\end{tabular}

\section{Section S12 Thermogravimetric analysis of MV-MOFs}

\section{METHODS:}

All TG analyses were performed on a TA Instruments NETZSCH STA449 C series thermal gravimetric analyzer with samples held in aluminum oxide pans in a continuous air flow atmosphere. The heating rate was set to $10{ }^{\circ} \mathrm{C} / \mathrm{min}$ from room temperature to $800^{\circ} \mathrm{C}$ for all TGA experiments (see Figure S111-S117).

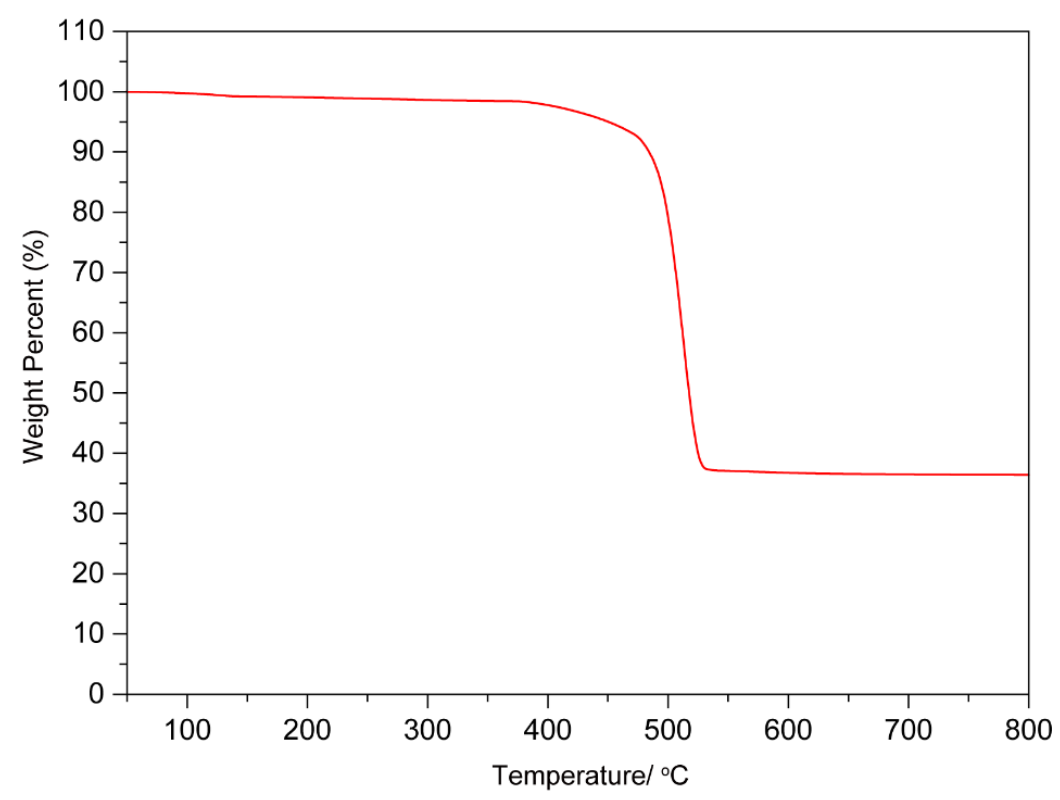

Figure S111. TGA trace of activated PCN-521. 


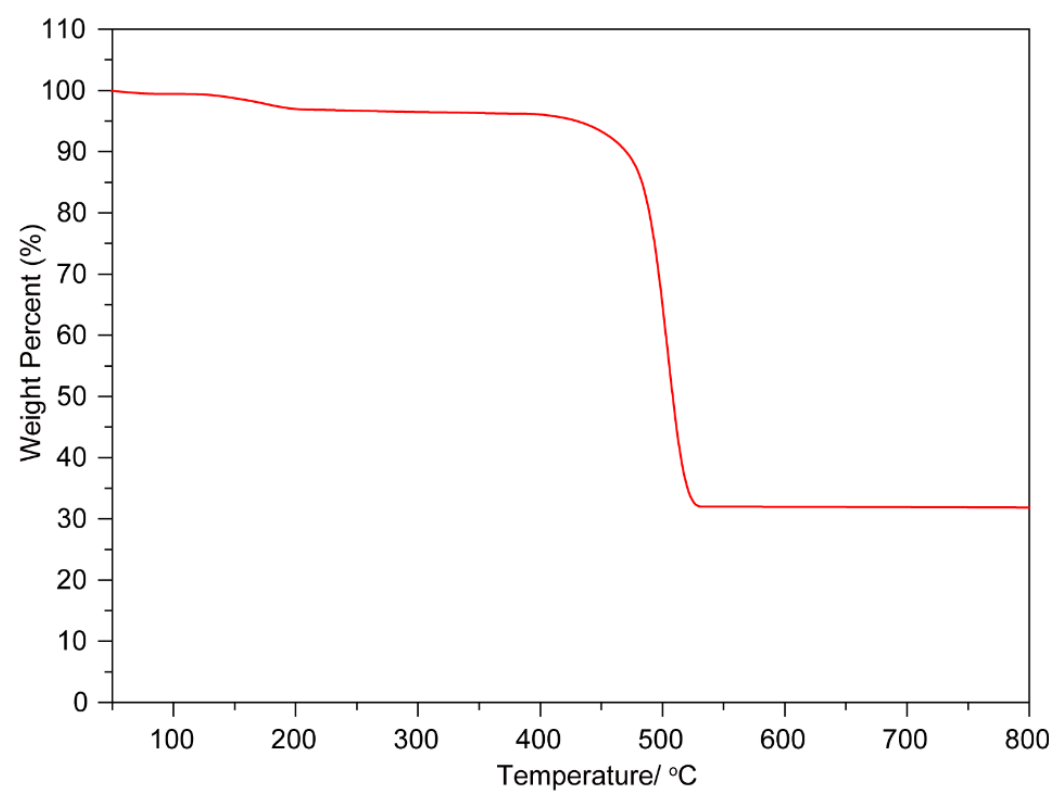

Figure S112. TGA trace of activated N-MV-PCN-521-BA.

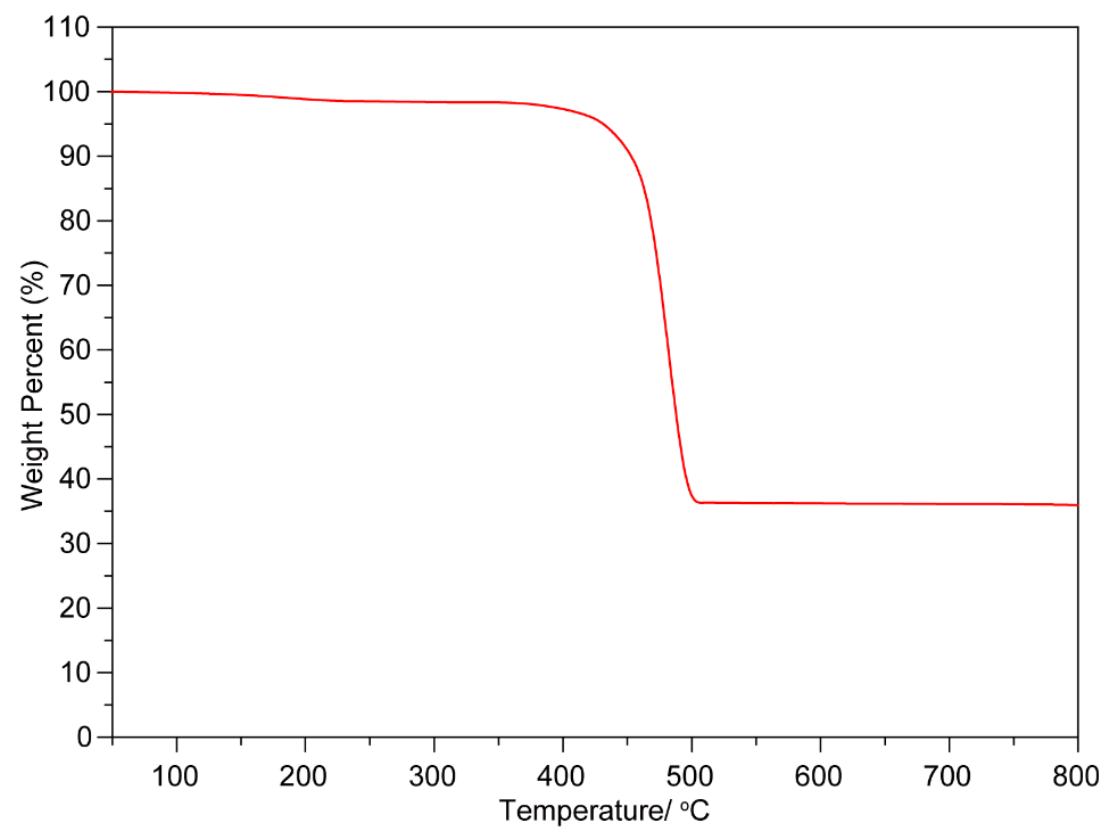

Figure S113. TGA trace of activated N-MV-PCN-521-NBA. 


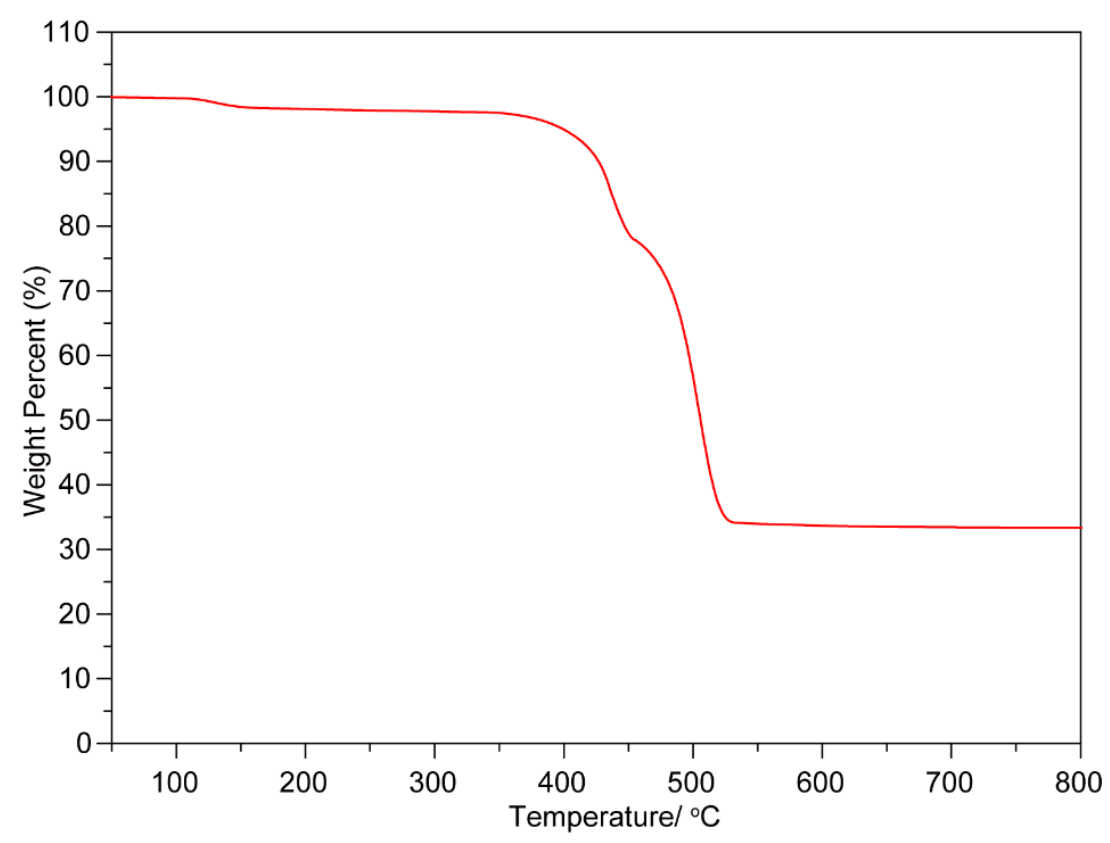

Figure S114. TGA trace of activated N-MV-PCN-521-FA.

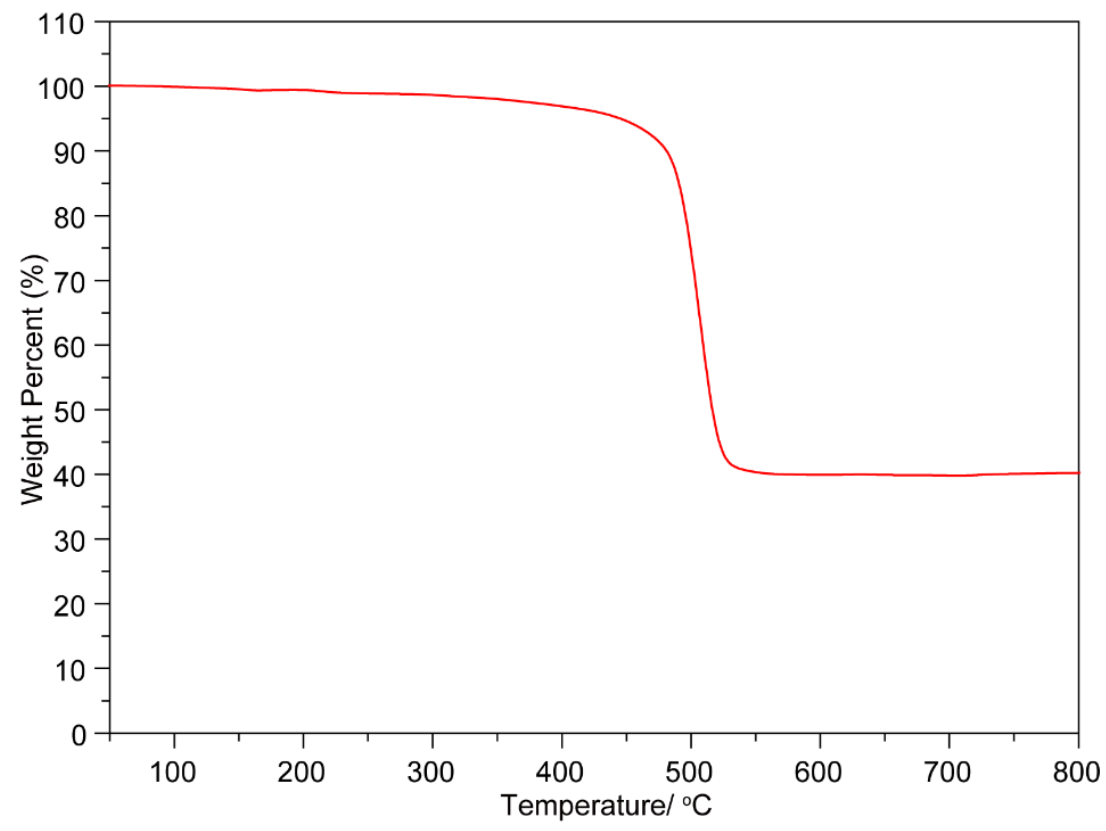

Figure S115. TGA trace of activated P-MV-PCN-521-BA. 


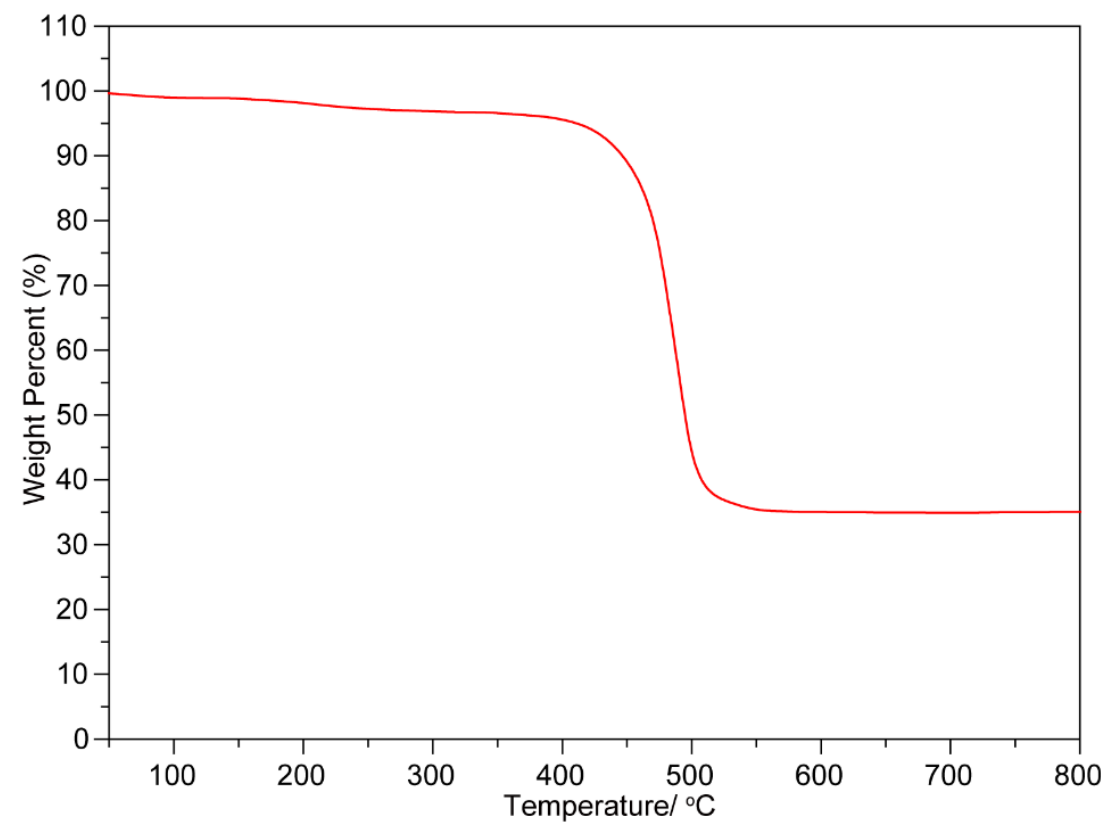

Figure S116. TGA trace of activated P-MV-PCN-521-NBA.

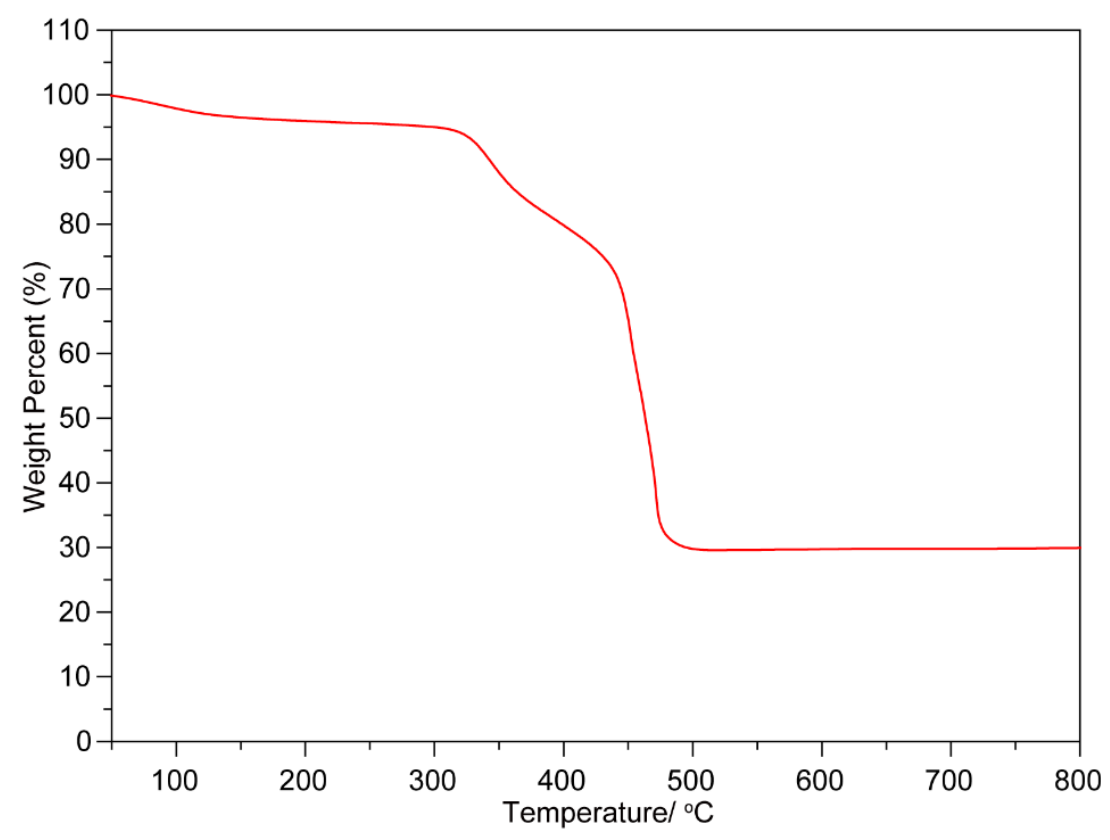

Figure S117. TGA trace of activated P-MV-PCN-521-FA.

\section{Section S13 XPS analysis of metal-binded-MV-MOFs}

X-ray photoelectron spectroscopy (XPS) of Au-MVs was performed on a Thermo Fisher Scientific ESCALAB250Xi X-ray photoelectron spectrometer. The binding energy (BE) of $\mathrm{N}$ in N-MV-PCN-521 is $399.2 \mathrm{eV}$, while a shift of $0.7 \mathrm{eV}$ was 
observed in Au-N-MV-PCN-521-FA. $\mathrm{Au}^{3+} 4 \mathrm{f}$ peak shifted by $0.5 \mathrm{eV}$ once anchored in the metal-binding site. The difference in the shift of the P 2 s peak $(1.3 \mathrm{eV})$ and $\mathrm{Au}^{3+}$ 4f peak $(1.0 \mathrm{eV})$ between $\mathrm{P}-\mathrm{MV}$ and $\mathrm{Au}-\mathrm{P}-\mathrm{MV}$ was larger, which can be attributed to better coordination of $\mathrm{Au}^{3+}$ at the metal-binding sites (Figure S118 and S119).
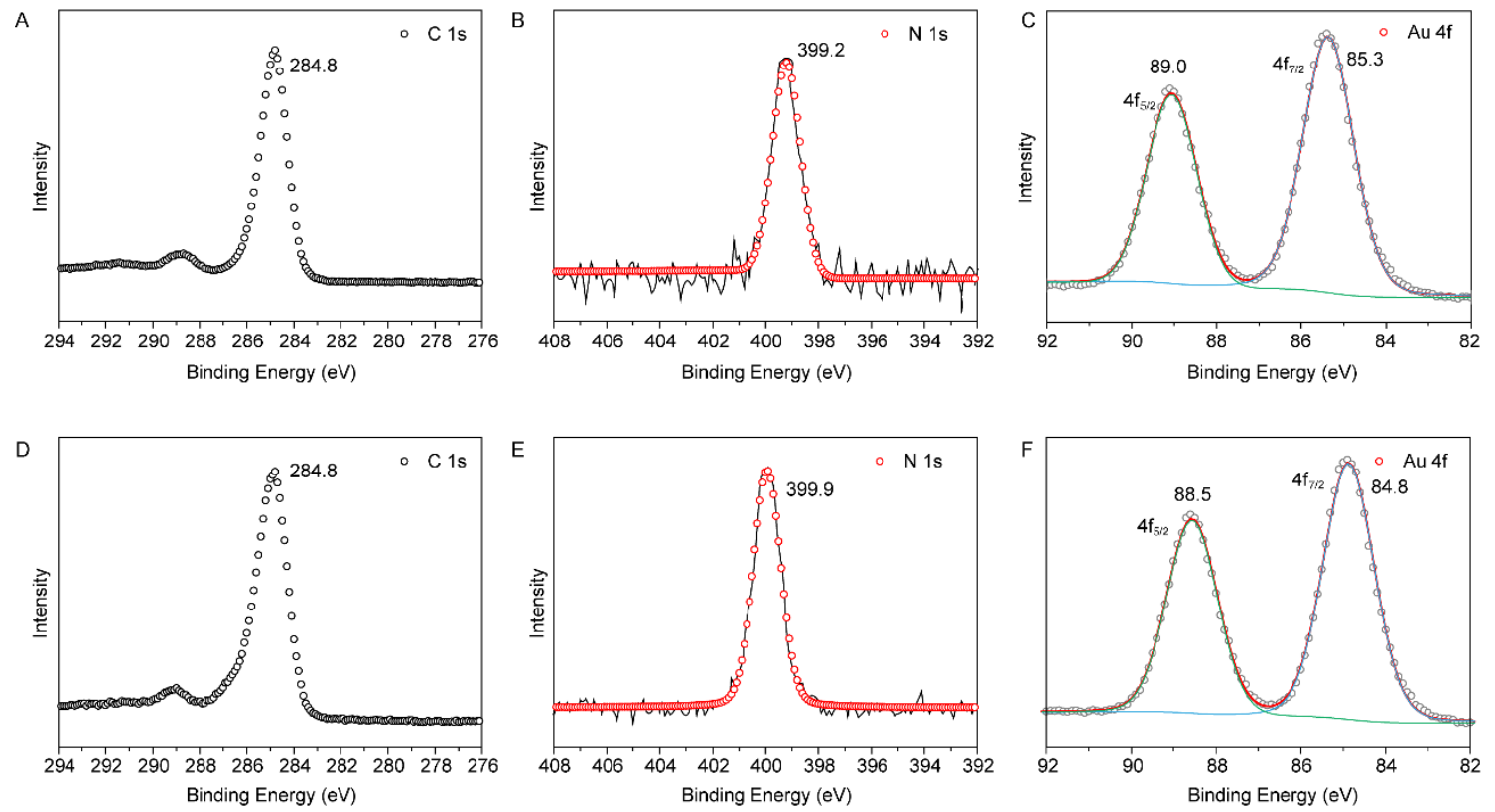

Figure S118. XPS result of P-MV-PCN-521-BA.

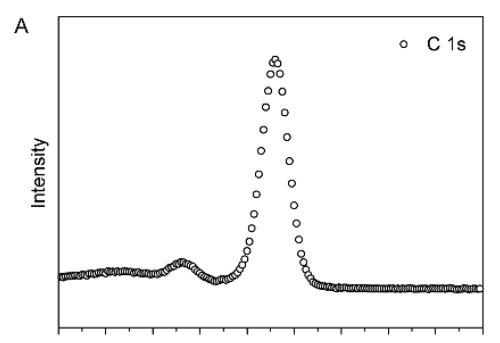

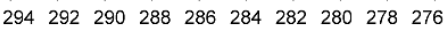
Binding Energy (eV)

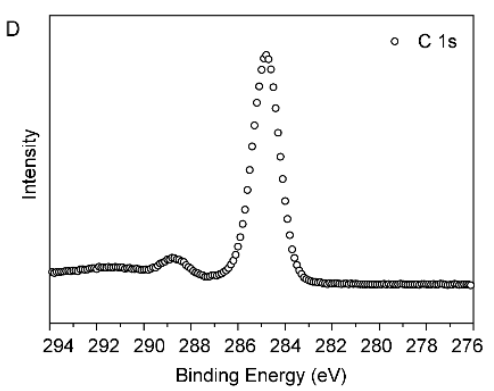

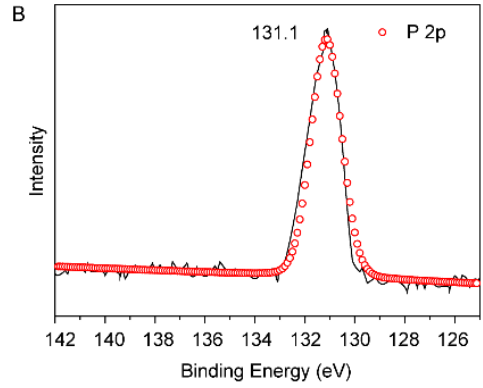
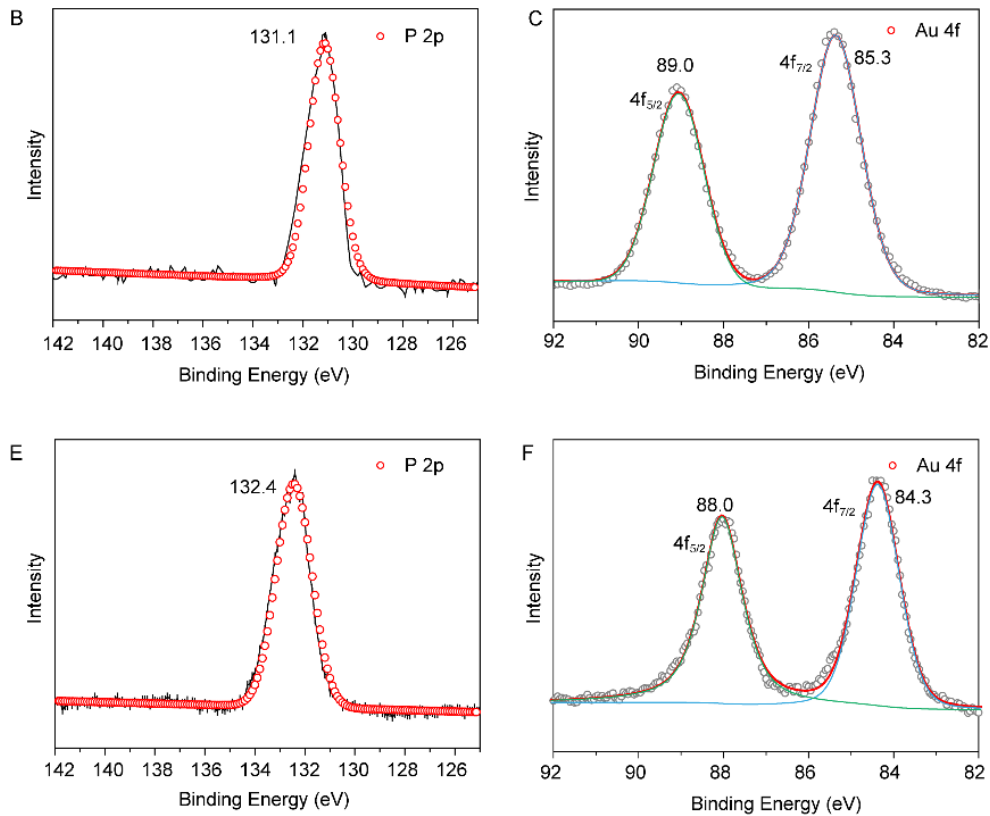

Figure S119. XPS result of Au-P-MV-PCN-521-BA. 


\section{Section S13 Catalytic performance}

General procedure for the catalytic reaction of aromatics compounds $\mathbf{1 a}, \mathbf{1 c}, \mathbf{1 d}, \mathbf{1 e}$.

To a $4 \mathrm{~mL}$ oven-dried Schlenk tube equipped with a magnetic stir bar was charged with NBS (0.6 mmol, $106 \mathrm{mg}$ ), Au-MVs (0.005 mmol, $0.1 \mathrm{~mol} \%)$, DCE (1 $\mathrm{mL})$, and arene $(0.5 \mathrm{mmol})$ under Ar condition. The reaction was stirred at room temperature until the reaction completed in $5 \mathrm{hrs}$. Then ethyl acetate $(2 \mathrm{~mL})$ and biphenyl $(30 \mathrm{mg})$ was added to the tube. The mixture was stirred at room temperature for $0.5 \mathrm{hrs}$. The samples then to be tested in a Gas chromatography (GC) instrument (Agilent 7890) to give the yield of desired product with the biphenyl as an internal standard.

General procedure for the catalytic reaction of aromatics compounds $\mathbf{1 b}, \mathbf{1 f}$.

To a $4 \mathrm{~mL}$ oven-dried Schlenk tube equipped with a magnetic stir bar was charged with NBS (0.6 mmol, $106 \mathrm{mg}$ ), Au-MVs (0.005 mmol, $0.1 \mathrm{~mol} \%)$, DCE (1 $\mathrm{mL})$, arene $(0.5 \mathrm{mmol})$ under Ar condition. The reaction was stirred at $60{ }^{\circ} \mathrm{C}$ until the reaction completed $(5 \mathrm{hrs})$. Ethyl acetate $(2 \mathrm{~mL})$ and biphenyl $(30 \mathrm{mg})$ was added to the tube after the reaction completed. Then the mixture was stirred at room temperature for $0.5 \mathrm{hrs}$. The samples then to be tested in a Gas chromatography (GC) instrument (Agilent 7890) to give the yield with the biphenyl as standard.

Table S15 Optimization of reaction conditions of solvents.

$\begin{array}{ccccccc}1 & & & & & \\ 1\end{array}$


Table S16 Comparison of bromination reactivity for $o$-xylene by using different catalysts.

\begin{tabular}{|c|c|c|c|c|c|c|}
\hline Entry & Substrate & NBS & Solvent & $\begin{array}{c}\text { Catalyst } \\
(1.0 \mathrm{~mol} \%)\end{array}$ & $\mathrm{T} /{ }^{\circ} \mathrm{C}$ & $\begin{array}{c}\text { Yield }^{G C} \\
(\%)\end{array}$ \\
\hline 1 & 1 eq. & $1.1 \mathrm{eq}$. & DCE & Au-N-PCN-521-BA & RT & 15 \\
\hline 2 & $1 \mathrm{eq}$. & $1.1 \mathrm{eq}$. & DCE & Au-N-PCN-521-NBA & RT & 13 \\
\hline 3 & $1 \mathrm{eq}$. & $1.1 \mathrm{eq}$. & DCE & Au-N-PCN-521-FA & RT & 24 \\
\hline 4 & $1 \mathrm{eq}$. & $1.1 \mathrm{eq}$. & DCE & Au-P-PCN-521-BA & RT & 56 \\
\hline 5 & 1 eq. & $1.1 \mathrm{eq}$. & DCE & Au-P-PCN-521-NBA & RT & 20 \\
\hline 6 & $1 \mathrm{eq}$. & $1.1 \mathrm{eq}$. & DCE & Au-P-PCN-521-FA & RT & 93 \\
\hline
\end{tabular}

Table S17 Comparison of bromination reactivity for $m$-xylene by using different catalysts.

\begin{tabular}{|c|c|c|c|c|c|c|}
\hline Entry & Substrate & NBS & Solvent & $\begin{array}{c}\text { Catalyst } \\
(1.0 \mathrm{~mol} \%)\end{array}$ & $\mathrm{T} /{ }^{\circ} \mathrm{C}$ & $\begin{array}{c}\text { Yield } \\
(\%)\end{array}$ \\
\hline 1 & $1 \mathrm{eq}$. & 1.1 eq. & DCE & Au-N-PCN-521-BA & 60 & 13 \\
\hline 2 & 1 eq. & $1.1 \mathrm{eq}$. & DCE & Au-N-PCN-521-NBA & 60 & 11 \\
\hline 3 & $1 \mathrm{eq}$ & 1.1 eq. & DCE & Au-N-PCN-521-FA & 60 & 21 \\
\hline 4 & 1 eq. & 1.1 eq. & DCE & Au-P-PCN-521-BA & 60 & 52 \\
\hline 5 & 1 eq. & $1.1 \mathrm{eq}$. & DCE & Au-P-PCN-521-NBA & 60 & 22 \\
\hline 6 & $1 \mathrm{eq}$. & $1.1 \mathrm{eq}$. & DCE & Au-P-PCN-521-FA & 60 & 96 \\
\hline
\end{tabular}


Table S18 Comparison of bromination reactivity for $p$-xylene by using different catalysts.

\begin{tabular}{|c|c|c|c|c|c|c|}
\hline Entry & Substrate & NBS & Solvent & $\begin{array}{c}\text { Catalyst } \\
(1.0 \mathrm{~mol} \%)\end{array}$ & $\mathrm{T} /{ }^{\circ} \mathrm{C}$ & $\begin{array}{c}\text { Yield } \\
(\%)\end{array}$ \\
\hline 1 & 1 eq. & $1.1 \mathrm{eq}$. & DCE & Au-N-PCN-521-BA & RT & 16 \\
\hline 2 & 1 eq. & $1.1 \mathrm{eq}$. & DCE & Au-N-PCN-521-NBA & RT & 11 \\
\hline 3 & 1 eq. & $1.1 \mathrm{eq}$. & DCE & Au-N-PCN-521-FA & RT & 26 \\
\hline 4 & 1 eq. & $1.1 \mathrm{eq}$ & DCE & Au-P-PCN-521-BA & RT & 47 \\
\hline 5 & 1 eq. & $1.1 \mathrm{eq}$. & DCE & Au-P-PCN-521-NBA & RT & 18 \\
\hline 6 & $1 \mathrm{eq}$. & $1.1 \mathrm{eq}$. & DCE & Au-P-PCN-521-FA & RT & 93 \\
\hline
\end{tabular}

Table S19 Comparison of bromination reactivity for anisole by using different catalysts.

\begin{tabular}{cccccccc}
\hline Entry & Substrate & NBS & Solvent & $\begin{array}{c}\text { Catalyst } \\
(1.0 \text { mol\% })\end{array}$ & T/ ${ }^{\circ} \mathrm{C}$ & $\begin{array}{c}\text { Yield }^{\mathrm{GC}} \\
(\%)\end{array}$ \\
\hline 1 & 1 eq. & 1.1 eq. & DCE & Au-N-PCN-521-BA & RT & 26 \\
2 & 1 eq. & 1.1 eq. & DCE & Au-N-PCN-521-NBA & RT & 15 \\
3 & 1 eq. & 1.1 eq. & DCE & Au-N-PCN-521-FA & RT & 49 \\
4 & 1 eq. & 1.1 eq. & DCE & Au-P-PCN-521-BA & RT & 67 \\
5 & 1 eq. & 1.1 eq. & DCE & Au-P-PCN-521-NBA & RT & 16 \\
6 & 1 eq. 1.1 eq. & DCE & Au-P-PCN-521-FA & RT & 98 \\
\hline
\end{tabular}

GC yield with biphenyl as an internal standard 
Table S20 Comparison of bromination reactivity for naphthalene by using different catalysts.

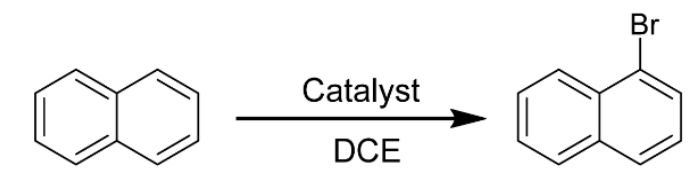

\begin{tabular}{ccccccc}
\hline Entry & Substrate & NBS & Solvent & $\begin{array}{c}\text { Catalyst } \\
(1.0 \mathrm{~mol} \%)\end{array}$ & $\mathrm{T} /{ }^{\circ} \mathrm{C}$ & $\begin{array}{c}\text { Yield } \\
(\%)\end{array}$ \\
\hline 1 & 1 eq. & 1.1 eq. & DCE & Au-N-PCN-521-BA & 60 & 10 \\
2 & 1 eq. & 1.1 eq. & DCE & Au-N-PCN-521-NBA & 60 & 10 \\
3 & 1 eq. & 1.1 eq. & DCE & Au-N-PCN-521-FA & 60 & 14 \\
4 & 1 eq. & 1.1 eq. & DCE & Au-P-PCN-521-BA & 60 & 16 \\
5 & 1 eq. & 1.1 eq. & DCE & Au-P-PCN-521-NBA & 60 & 12 \\
6 & 1 eq. & 1.1 eq. & DCE & Au-P-PCN-521-FA & 60 & 90 \\
\hline
\end{tabular}

GC yield with biphenyl as an internal standard

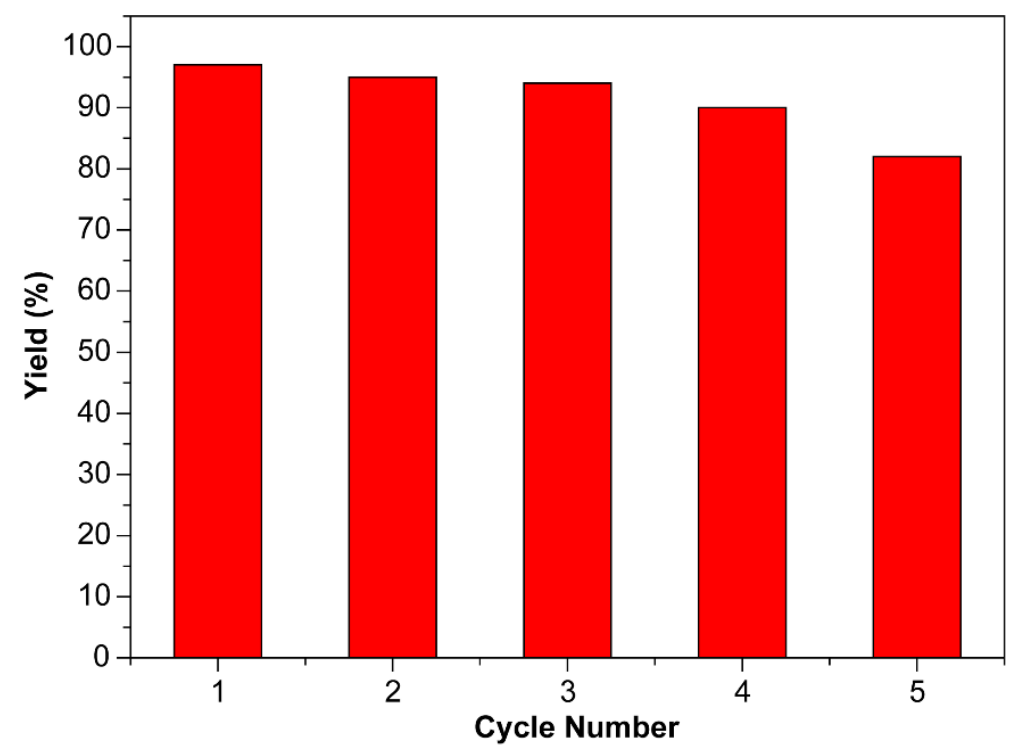

Figure S120. The catalytic cycles of bromination of mesitylene catalyzed by Au-P-MV-PCN-521-FA at room temperature. 
Table S21 Comparison of bromination reactivity for aromatics by using Au-P-MV-PCN-521-DCA and -PTA.

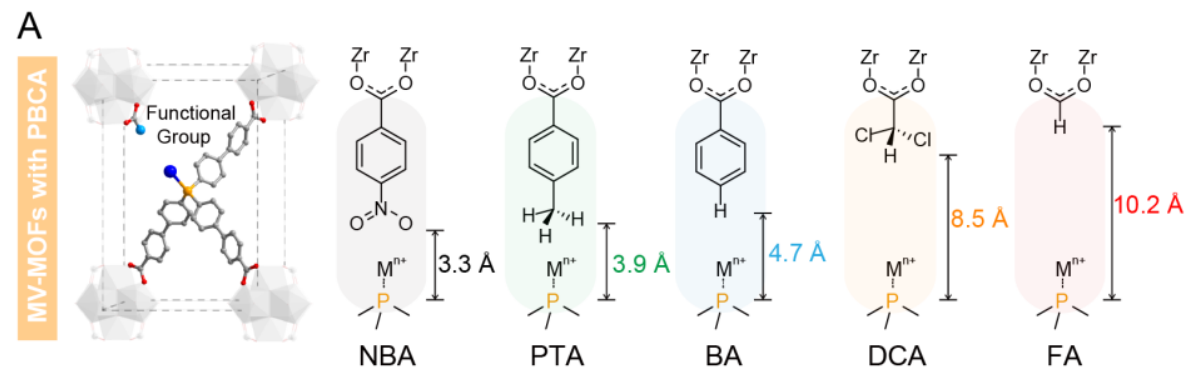

Substrate

a: GC yield with biphenyl as an internal standard.

b: The reaction was performed at $60^{\circ} \mathrm{C}$. 
Reference:

(S1) Ma, L.; Jin, A.; Xie, Z.; Lin, W. Freeze Drying Significantly Increases Permanent Porosity and Hydrogen Uptake in 4,4-Connected Metal-Organic Frameworks. Angew. Chem. Int. Ed. 2009, 48, 9905-9908

(S2) Kemper, B.; Grçning, M.; Lewe, V.; Spitzer, D.; Otremba, T.; Stergiou, N.; Schollmeyer, D.; Schmitt, E.; Ravoo, B.; Besenius, P. Reversible Covalent and Supramolecular Functionalization of Water-Soluble Gold(I) Complexes. Chem. Eur. J. 2017, 23, 6048-6055.

(S3) Lei X.; Jalla, A.; Shama, M. A. A.; Stafford, J. M.; Cao, B. Chromatography-Free and Eco-Friendly Synthesis of Aryl Tosylates and Mesylates. Synthesis 2015, 47, 2578-2585.

(S4) Xie, J.; Wang, L.; Fu, Y.; Zhu, S.; Fan, B.; Duan, H.; Zhou, Q. Synthesis of Spiro Diphosphines and Their Application in Asymmetric Hydrogenation of Ketones. $J$. Am. Chem. Soc. 2003, 125, 4404-4405.

(S5) Sawano, T.; Lin, Z.; Boures, D.; An, B.; Wang, C.; Lin, W. Metal-Organic Frameworks Stabilize Mono(phosphine)-Metal Complexes for Broad-Scope Catalytic Reactions. J. Am. Chem. Soc. 2016, 138, 9783-9786.

(S6) Sheldrick, G. M. SHELXS-97 and SHELXL-97, Program for Crystal Structure Solution and Refinement, University of Gottingen, Germany, 1997.

(S7) Dolomanov, O. V.; Gildea, L. J.; Howard, J. A. K.; Puschmann, H. J. Appl. Cryst. 2009, 42, 339.

(S8) Spek, A. L. 2005, PLATON, A Multipurpose Crystallographic Tool, Utrecht University, Utrecht, The Netherlands.

(S9) Module F. Material Studio 8.0 Accelrys Inc., San Diego, CA, 2014.

(S10) Hong, M.; Gross, J. D.; Rienstra, C. M.; Griffin, R. G.; Kumashiro, K. K.; K.Schmidt-Rohr. Coupling Amplification in 2D MAS NMR and Its Application to Torsion Angle Determination in Peptides. J. Magn. Reson. 1997, 129, 85-92.

(S11) Bak, M.; Rasmussen, J. T.; Nielsen, N. Chr. SIMPSON: A General Simulation Program for Solid-State NMR Spectroscopy. J. Magn. Reson. 2000, 147, 296-330.

(S12) Walton, K S.; Snurr, R Q. Applicability of the BET Method for Determining Surface Areas of Microporous Metal-Organic Frameworks. J. Am. Chem. Soc. 2007, $129,8552-8556$. 